

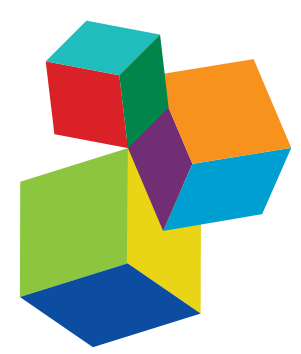

Frontiers eBook Copyright Statement

The copyright in the text of individual articles in this eBook is the property of their respective authors or their respective institutions or funders. The copyright in graphics and images within each article may be subject to copyright of other parties. In both cases this is subject to a license granted to Frontiers.

The compilation of articles constituting this eBook is the property of Frontiers.

Each article within this eBook, and the eBook itself, are published under the most recent version of the Creative Commons CC-BY licence.

The version current at the date of publication of this eBook is CC-BY 4.0. If the CC-BY licence is updated, the licence granted by Frontiers is automatically updated to the new version.

When exercising any right under the CC-BY licence, Frontiers must be attributed as the original publisher of the article or eBook, as applicable.

Authors have the responsibility of ensuring that any graphics or other materials which are the property of others may be included in the

CC-BY licence, but this should be checked before relying on the

CC-BY licence to reproduce those materials. Any copyright notices relating to those materials must be complied with.

Copyright and source acknowledgement notices may not be removed and must be displayed in any copy, derivative work or partial copy which includes the elements in question.

All copyright, and all rights therein, are protected by national and international copyright laws. The above represents a summary only.

For further information please read Frontiers' Conditions for Website

Use and Copyright Statement, and the applicable CC-BY licence.

ISSN 1664-8714

ISBN 978-2-88963-298-5

DOI 10.3389/978-2-88963-298-5

\section{About Frontiers}

Frontiers is more than just an open-access publisher of scholarly articles: it is a pioneering approach to the world of academia, radically improving the way scholarly research is managed. The grand vision of Frontiers is a world where all people have an equal opportunity to seek, share and generate knowledge. Frontiers provides immediate and permanent online open access to all its publications, but this alone is not enough to realize our grand goals.

\section{Frontiers Journal Series}

The Frontiers Journal Series is a multi-tier and interdisciplinary set of open-access, online journals, promising a paradigm shift from the current review, selection and dissemination processes in academic publishing. All Frontiers journals are driven by researchers for researchers; therefore, they constitute a service to the scholarly community. At the same time, the Frontiers Journal Series operates on a revolutionary invention, the tiered publishing system, initially addressing specific communities of scholars, and gradually climbing up to broader public understanding, thus serving the interests of the lay society, too.

\section{Dedication to Quality}

Each Frontiers article is a landmark of the highest quality, thanks to genuinely collaborative interactions between authors and review editors, who include some of the world's best academicians. Research must be certified by peers before entering a stream of knowledge that may eventually reach the public - and shape society; therefore, Frontiers only applies the most rigorous and unbiased reviews.

Frontiers revolutionizes research publishing by freely delivering the most outstanding research, evaluated with no bias from both the academic and social point of view. By applying the most advanced information technologies, Frontiers is catapulting scholarly publishing into a new generation.

\section{What are Frontiers Research Topics?}

Frontiers Research Topics are very popular trademarks of the Frontiers Journals Series: they are collections of at least ten articles, all centered on a particular subject. With their unique mix of varied contributions from Original Research to Review Articles, Frontiers Research Topics unify the most influential researchers, the latest key findings and historical advances in a hot research area! Find out more on how to host your own Frontiers Research Topic or contribute to one as an author by contacting the Frontiers Editorial Office: researchtopics@frontiersin.org 


\section{PUBLIC PARTICIPATION IN HEALTH CARE: EXPLORING THE CO-PRODUCTION OF KNOWLEDGE}

Topic Editors:

Gill Green, University of Essex, United Kingdom

Annette Louise Boaz, Kingston University, United Kingdom

Maria Clasina Stuttaford, Kingston University, United Kingdom

Citation: Green, G., Boaz, A. L., Stuttaford, M. C., eds. (2020). Public Participation in Health Care: Exploring the Co-Production of Knowledge. Lausanne: Frontiers Media SA. doi: 10.3389/978-2-88963-298-5 


\section{Table of Contents}

05 Editorial: Public Participation in Health Care: Exploring the Co-production of Knowledge

Gill Green, Annette Boaz and Maria Stuttaford

09 Public Participation in Health and Social Care: Exploring the Co-production of Knowledge

Peter Beresford

22 Beware Zombies and Unicorns: Toward Critical Patient and Public Involvement in Health Research in a Neoliberal Context Mary Madden and Ewen Speed

29 The Possibilities and Limits of "Co-producing" Research Jonathan Paylor and Christopher McKevitt

35 Power, Privilege and Knowledge: the Untenable Promise of Co-production in Mental "Health"

Diana Rose and Jayasree Kalathil

47 Public and Patient Involvement and the Right to Health: Reflections From England

Maria Clasina Stuttaford, Therese Boulle, Hanne Jensen Haricharan and Zingisa Sofayiya

59 Exploring the Relationship (and Power Dynamic) Between Researchers and Public Partners Working Together in Applied Health Research Teams Gill Green and Tracey Johns

70 A Hierarchy of Power: The Place of Patient and Public Involvement in Healthcare Service Development

Alison O'Shea, Annette L. Boaz and Mary Chambers

83 Co-producing Randomized Controlled Trials: How do we Work Together? Lucy Pollyanna Goldsmith, Rosaleen Morshead, Charlotte McWilliam, Gordon Forbes, Michael Ussher, Alan Simpson, Mike Lucock and Steve Gillard

95 Is Co-production Just a Pipe Dream for Applied Health Research Commissioning? An Exploratory Literature Review

Doreen Tembo, Elizabeth Morrow, Louise Worswick and Debby Lennard

108 Dilemmas of Ethics in Practice in Longitudinal Health Research: Identifying Opportunities for Widening Participation of Residents Rhian Twine, Gillian Lewando Hundt and Kathleen Kahn

121 Rights-Based Training Enhancing Engagement of Health Providers With Communities, Cape Metropole, South Africa

Gimenne Zwama, Maria Clasina Stuttaford, Hanne Jensen Haricharan and Leslie London 
134 Toward Co-productive Learning? The Exchange Network as Experimental Space

Rachel Matthews and Constantina (Stan) Papoulias

146 "Research Usually Sits on Shelves, Through the Play it was Shared." Co-producing Knowledge Through Post-show Discussions of Research-Based Theatre

Gillian Lewando Hundt, Maria Clasina Stuttaford, Claudette Bryanston and Christine Harrison 


\title{
Editorial: Public Participation in Health Care: Exploring the Co-production of Knowledge
}

\author{
Gill Green ${ }^{1 *}$, Annette Boaz ${ }^{2}$ and Maria Stuttaford ${ }^{2}$ \\ ${ }^{1}$ School of Health and Social Care, University of Essex, Colchester, United Kingdom, ${ }^{2}$ Centre for Applied Health and Social \\ Care Research, Kingston University, Kingston upon Thames, United Kingdom
}

Keywords: participation, public involvement, health care, knowledge co-production, user voice

Editorial on the Research Topic

Public Participation in Health Care: Exploring the Co-production of Knowledge

OPEN ACCESS

Edited by:

Beth Maina Ahlberg,

Uppsala University, Sweden

Reviewed by:

Linda Gibson,

Nottingham Trent University,

United Kingdom

*Correspondence:

Gill Green

gillgr@essex.ac.uk

Specialty section:

This article was submitted to

Medical Sociology,

a section of the journal

Frontiers in Sociology

Received: 18 September 2019

Accepted: 24 October 2019

Published: 12 November 2019

Citation:

Green G, Boaz A and Stuttaford M (2019) Editorial: Public Participation in

Health Care: Exploring the

Co-production of Knowledge.

Front. Sociol. 4:73.

doi: 10.3389/fsoc.2019.00073

\section{USER-REFERENCE GROUP: DAVID BOUSFIELD, LIZZIE LLOYD-DEHLER, SARAH RAE}

Participation and involvement of publics in the provision of health care is gaining traction as people are encouraged to become "discerning consumers" in seeking care and wellness from an increasingly diverse range of providers. In order to meet the demands of consumers, health care providers seek feedback from service users. It can be argued that the neoliberal agenda has appropriated participation and more recently there has been a discernible shift in the narrative of Patient \& Public Involvement (PPI) and a change in terminology. There is now a greater emphasis on patients and the public having a stronger voice in order to share decision-making to co-produce research, services, and policy. However, this emancipatory potential of knowledge created through co-production does not fit easily with the continued neoliberal climate whereby health care provision is increasingly dictated by market forces. This collection of papers offers a global and provocative perspective on the tension between participation as emancipatory and reformative on the one hand and participation as a servant to neoliberal capital forces on the other.

Participation in healthcare is not a new concept and reflects a long history of political and structural struggle. Nevertheless, much of the recent literature on participation has been descriptive and evaluative. We therefore deliberately sought papers for this collection that offered a fresh and challenging perspective. Written by leading figures in the field of public participation, as well as some newer voices, the papers offer penetrating critiques of participation, making this an authoritative addition to the field. Papers include conceptual radical critiques as well as insightful commentaries drawing on experiences of those trying to implement new forms of working to break down traditional hierarchies.

A further distinct feature of this collection is the contribution of service users both as authors offering powerful user-led perspectives (e.g., Beresford; Goldsmith et al.; Rose and Kalathil), and as part of the editorial process. Frontiers provided financial support for the formation of a 
user-reference group of three people with diverse backgrounds to support the Editors. Their role was to screen papers for accessibility, interest and quality to make the collection more accessible and more relevant to the public. Authors were asked to provide a Plain English Summary and these were reviewed and revised in an iterative process with authors responding to feedback from the user-reference group. The Plain English Summaries are published here, following the editorial, as part of the collection. It is worth noting, however, that despite the willingness of the journal, the Editors and the user-reference group, this process was not straightforward and was timeconsuming to implement. Academic publishing systems are not set up to include lay summaries and just as many of the articles in the collection demonstrate, it is challenging to add user input onto a pre-existing infrastructure. Based on our experience, we would suggest publishers consider making a lay summary a mandatory requirement and incorporating this into on-line submission systems.

The individual papers offer theoretical critique and empirical evidence about the potential for participation and co-production. The conceptual papers from Beresford, Madden and Speed, Paylor and McKevitt, Rose and Kalathil, and Stuttaford et al., all take a skeptical stance and provide critical perspectives about why, without significant changes, the adoption of the term co-production on its own will not lead to significant changes. Whether taking a historical (Beresford; Rose and Kalathil) or rights-based approach (Stuttaford et al.) or providing a policy (Madden and Speed) or sociological critique (Paylor and McKevitt) all authors broadly concur that while the policy narrative is supportive of participation, in reality structures and resources do not facilitate effective involvement. All caution that merely co-opting the term co-production within existing structures and processes is unlikely to lead to meaningful participation or transformational results. As a result the opportunity for public involvement to make a real difference gets lost and as Madden and Speed suggest doing good public involvement is like chasing a unicorn, a mythical creature that everyone talks about but has never actually been seen. To move forward, authors suggest that we need to re-engage with participatory traditions (Paylor and McKevitt) and focus on participation as a set of values and rights to strengthen participation (Stuttaford et al.). Writing from the field of mental health research, Beresford recommends a stronger funding base for user led organizations so they can drive innovation in involvement. Rose and Kalathil, while committed to user-led research, nevertheless caution that the user movement itself is not immune to power differentials and exclusion of marginalized, particularly "non-white" voices.

The theoretical/conceptual papers focusing on the shortcomings of PPI and skepticism about the ability to achieve co-production are complemented by a literature review and empirical contributions about the realities of co-production in practice. These provide detailed examples about why it is so challenging within the current structures to achieve spaces in which power differentials between professionals and publics can be overcome. Three papers, Green and Johns, O'Shea et al., and Goldsmith et al., focus on power between professionals and publics within decision-making processes. O'Shea et al. examine power in decision-making in clinical commissioning groups and identify a hierarchy of power, in which some professionals and public members are afforded more scope for influencing healthcare service development than others. A power differential is also evident in Green and Johns analysis of interviews with researchers and public partners, which they relate to the positivist framework which tends to dominate in health research as this privileges scientific over experiential knowledge. However, Goldsmith et al., show how knowledge from lived experience of mental health problems can be used in key decision-making even within the ultra-positivist framework of a randomized controlled trial. Co-production can be combined with randomized controlled trial methodology by incorporating service user perspectives throughout the research process. Whilst Goldsmith et al. offer a rare example of how co-production can work, the literature review by Tembo et al. show that in the early stages of research commissioning, consultation (which is frequently tokenistic) rather than co-creation of knowledge, decisions or processes, is the norm. And Twine et al. draw upon their experience of conducting longitudinal health research in an under-developed rural area of South Africa to challenge the idea of considering research participants as an experimental public separated from a notion of community and society. This serves as a timely reminder that research itself as well as public involvement per se should always be grounded in the community from whence it came to generate co-production and meaningful engagement.

The final three papers examine novel approaches to try to overcome some of the power differentials that have thus far predominated in public involvement. Zwama et al. report on an initiative in South Africa which applied a human rightsbased approach to training health professionals about how to engage with lay representatives on health committees, a key mechanism for participation. Matthews and Papoulias describe the Exchange Network, which aims to redress power imbalance by creating a space for professionals and the public to make decisions on an equal basis. Suspending the rigidity of roles generally attributed to researchers and public partners can be transformative and is a necessary step toward co-production. Hundt et al. also suggest that innovative ways to engage stakeholders, such as use of research-based theater to perform research findings, can facilitate the co-production of knowledge. Post show discussions were found to transcend boundaries between the audience, actors and panel members to co-produce new knowledge.

Taken as a whole, these articles show that while civil engagement is more important than ever before, there are huge challenges. This collection provides theoretical insight and empirical evidence about why shared decision-making and co-production is so difficult to achieve. This builds on the limited evidence to support co-production's potential for transforming relationships between researchers/policymakers/practitioners and publics. While the terminology may have changed the experiential knowledge of service users is rarely afforded equal value to that of scientific/expert knowledge. We hope that this 
collection provides a theoretical and practical steer to address these challenges in order to achieve the co-production of knowledge so that experiential and professional knowledge is afforded equal authenticity.

\section{AUTHOR CONTRIBUTIONS}

All authors listed have made a substantial, direct and intellectual contribution to the work, and approved it for publication.
Conflict of Interest: The authors declare that the research was conducted in the absence of any commercial or financial relationships that could be construed as a potential conflict of interest.

Copyright (c) 2019 Green, Boaz and Stuttaford. This is an open-access article distributed under the terms of the Creative Commons Attribution License (CC BY). The use, distribution or reproduction in other forums is permitted, provided the original author(s) and the copyright owner(s) are credited and that the original publication in this journal is cited, in accordance with accepted academic practice. No use, distribution or reproduction is permitted which does not comply with these terms. 


\section{Plain English Summary \\ Public Participation in Health And Social Care: Exploring the Co-Production of Knowledge}

\section{Peter Beresford}

This article is written by a service user researcher and looks at the progress of public and patient involvement in health and social care based on evidence from the UK and international developments. The paper offers an historical perspective on participation, which connects public and patient involvement with broader political, ideological, social and cultural developments. It identifies four major stages in this modern history and explores them in detail.

\section{These major developments are:}

- Moves towards 1) everyone having a vote (universal suffrage) in democracies where our views are meant to be represented and 2) the achievement of social rights, such as the right to decent housing, education and health care.

- Provisions for having a real say together when decisions are made in society and to be able to get together locally and with other people like us to do this.

- Having a real say in health service design and provision, and when we need some help in our lives because we are older or disabled.

- The growth of conflict and arguments as service users and our organisations work for more say and improvement in health care but the people who have had power want to keep it and fight back against losing it.

The article concludes that tensions between two conflicting approaches

to involvement have become clearer. This is an opportunity for reassessing involvement and developing people's inclusive involvement. These different approaches to involvement are on the one hand driven by the profit motive which calls for less state support and on the other from service users and their supporters calling for more say and control over their lives and policy.

\section{The article goes on to look in more detail at four key developments associated with public/user involvement. These are:}

1. The efforts of user-led organisations and their supporters to ensure there is more diverse involvement that challenges the way people are discriminated against on the basis of gender, ethnicity, sexuality, disability, distress, culture, class etc.

2. How to make occupational and professional roles more supportive of the needs and rights of service users by involving service users on equal terms.

3. The involvement of service users in research giving equal value to their lived experience and challenging traditional research approaches which gave more value to researchers' knowledge and views.

4. The development of Mad Studies, which is an area of new understanding and action relating to mental distress. This approach seeks to go beyond understandings based on a medical model, seeing something wrong within the person and involve all stakeholders in developing new user led more social ways to understand distress.

Taken together these four developments offer ways forward for an inclusive approach to participation which addresses the two key issues of ensuring sustainable health policy and supporting the equal rights and different needs of diverse populations. 
OPEN ACCESS

Edited by:

Annette Louise Boaz,

Kingston University, United Kingdom

Reviewed by:

Guido Giarelli,

Università degli studi Magna Græcia di

Catanzaro, Italy

Fátima Alves,

Universidade Aberta, Portugal

*Correspondence:

Peter Beresford

pberes@essex.ac.uk

Specialty section:

This article was submitted to

Medical Sociology,

a section of the journal

Frontiers in Sociology

Received: 03 September 2018 Accepted: 05 December 2018 Published: 04 January 2019

Citation:

Beresford P (2019) Public Participation in Health and Social Care: Exploring the Co-production of Knowledge. Front. Sociol. 3:41 doi: 10.3389/fsoc.2018.00041

\section{Public Participation in Health and Social Care: Exploring the Co-production of Knowledge}

\author{
Peter Beresford ${ }^{*}$ \\ University of Essex, Colchester, United Kingdom
}

Efforts to advance public participation in health and other policies have been associated with the production of many models and how-to-do-it guides for change. While these may have a helpful part to play in improving public and patient/user involvement in research, in this article it will be suggested that they tend to over-simplify things. Instead it is argued that an essential first step to advancing public participation in health is to put it in the context of developing modern democracy more generally. This article will seek to do this by identifying four key stages in the development of public participation in health and social care. These phases will be headlined as:

- Working for universal suffrage in representative democracy and the achievement of social rights, like the right to decent housing, education and health;

- Provisions for participatory democracy and community development;

- Specific provisions for participation in health and social care;

- State reaction and service user-led renewal as conflicts and competing agendas develop.

While the proposed article will look particularly at UK developments to do this, it will also draw upon international experience and highlight the wider relevance of these phases of development. It will make connections between the extension of representative and participatory democracy, considering the different locations in which efforts to extend participation have helpfully developed, for example, in learning and training, and research and knowledge production. It will also consider how efforts to extend participation have also been undermined by pressures to tokenise and co-opt them; the continuing barriers discriminating against some groups and, ways in which service users and allies have nonetheless sought to overcome these difficulties to take forward more inclusive and diverse participation in health and social care. It will focus on some particularly promising areas of development internationally in order to do this in which co-production and the development of user-led knowledge are key.

Keywords: public/user participation, history, user knowledge, Mad Studies, health

\section{INTRODUCTION}

There can be little doubt that there is currently significant and widespread interest in public and patient involvement in health and social care services, policy and research. This special issue of the Journal is just one more token of that. But interest should not be confused with progress or consensus. This situation is compounded by inequalities and competing interests between key 
stakeholders in the venture; between government, its research institutions, researchers and family carers, service users and our/their organizations and movements. There has been a surprising lack of progress in the development of such public and patient involvement in health and social care and a tendency to isolate the issue from its broader relations, for example, institutionalizing it as separate entity and abstracting it from its ideological connections. It has even been turned into an acronym in the UK-PPI-for public and patient involvement (Moini, 2011).

There are some noticeable features about the way the dominant discussion about such PPI or public and service user participation in health and social care has developed over the years. First, it has mainly come from people with interest and expertise primarily in health rather than in political participation. A measure of this is that publications tend to be located in health and social policy journals and other publications, rather than politics or political theory ones. For example, an international peer reviewed journal concerned specifically with participation was initiated in 2014, but while being multidisciplinary, it situates itself specifically in "health and social care" and its title, Research, Involvement and Engagement (https:// researchinvolvement.biomedcentral.com) offers a clue to its narrowly technicist and research-based focus.

Where an interest has been shown in political processes, it has tended to be limited to so-called deliberative or discursive processes, in which there has been specific and growing interest. Here bodies like citizens' juries and local committees are set up to discuss and vote on policies and budget allocations. While the pressure for deliberative democracy can be seen as expressing a will for something beyond representative democracy, it also seems to be tied to many of the limitations associated with the latter.

The sociologist and political philosopher Anthony Giddens drew an early distinction between traditional liberal (representative) democracy and deliberative democracy.

Liberal democracy is a set of representative institutions, guided by certain values; deliberative democracy is a way of getting, or trying to get, agreement about policies in the political arena... The important thing is that the participants reach a judgement on the basis of what they have heard and said (Giddens, 1994, p. 113).

Giddens didn't see such deliberative democracy as necessarily participatory- "it is not defined by whether or not everyone participates in it"-although its advocates have tended to present it in that way. For him its distinguishing mark is that wider publics are able to discuss and come to their own conclusions about policies and politics. Thus, he sees democratization "as the (actual and potential) extension of dialogic democracy... where such communication forms a dialogue by means of which policies and activities are shaped" (Giddens, op cit, pp. 114-115). This might work well on the academic page, but it is difficult to make it happen in the real world where things are less neatly compartmentalized.

Conversations and debates do not happen in isolation and people bring to such discussions all the influences they have been subject to and their own socialization.
Such deliberative structures and processes tend to reflect prevailing values and opinions, often gaining a life of their own which may not reflect wider views and frequently face difficulty in reflecting the full diversity of the communities for which they speak. They tend instead to reflect broader inequalities of status and power so that the voices of white middle class males still often predominate-as in mainstream political processes. They are also constrained by another dilemma and paradox. They tend to be initiated by the very local or central state which is the product of the ruling system and which ultimately determines what if any notice is taken of them. Such deliberative structures can be seen as the ultimate talking shop, often overlaid with a reactionary edge (Dolan et al., 1999; Fishkin and Laslett, 2003; Williams, 2004; Davies et al., 2006; Fishkin, 2011).

Second, debate on participation in health has been strongly influenced by the political agendas of politicians, policymakers and professionals, reflecting prevailing imbalances of power and ideology. Thus, PPI has been appropriated as an evaluation measure in the consumerist UK universities Research Excellence Framework (REF, formerly Research Assessment Exercise or $\mathrm{RAE}$ ) and in government research funding allocation processes. It is also judged by an economistic understanding of "impact" through which an increasing political emphasis has been placed, although of course the concept can be a much more far-reaching one (Staley, 2009; Cotterell et al., 2011). Third, it has been characterized by a particular interest in models, typologies and practical "how to do it" guides for involvement.

One of the earliest and still one of the most often cited and discussed of these, is Arnstein's "Ladder of Citizen Participation" (Arnstein, 1969) The problem with such unidimensional approaches to participation is that while in some cases recognizing power differences, they still struggle to address its essentially political nature. While they can have a helpful part to play in improving public and patient/user involvement and understanding of it, they also tend to be reductionist, over-simplifying and ill-suited to dealing with the real life complexities and ambiguities of such involvement (Beresford and Croft, 1993; Wilcox, 1994; Tritter and McCallum, 2006). All these pressures have had the effect of isolating participation from its ideological and political relations-particularly its relations with ideas, theories and practices of democracy and democratization.

In this it reflects social or public policy more generally, where the tendency has long been for them to be treated as neutral technical matters. This gave rise to the discipline of social administration and a "social administrative" model for understanding and analyzing public policy. This was typified by Fabian social policy where the political was underplayed and policymaking presented much more as a matter of neutral technical expertise, best left to academic and other "experts." It was service users' exclusion from this process, their consequent revulsion from it and the political right's populist attack on it that overlaid western social policy in the last quarter of the twentieth century and underpinned the emergence of conflicted understandings of public and service user involvement in health and social care (Beresford, 2016). 


\section{A DIFFERENT APPROACH}

My own journey to an interest in public participation and user involvement has been a different one and perhaps this helps explains why the route I have taken has been different too. My engagement with the issue has been a long one-now totaling over 40 years. It has also been multi-facetted and extended across different roles (including as a service user, and advocate and as a "local person"); different policy areas and forms of participation underpinned by different ideological motivations. I have been involved as academic, educator, researcher, activist and service user; individually and collectively, in grassroots organizations, as well as policy and practice ones, in bottomup community-based and user-led initiatives and large charitable and policy organizations, as well as local and central government and international initiatives and committees. I have been very fortunate-and unusual-to connect with participation over such a long period and from such a wide range of perspectives and settings. So in one sense. this is a very personal critique, but it is one that has engaged with and drawn on the work of very many others, locally, nationally and internationally, as researchers, activists, educators, policymakers and practitioners, but mostly as service users and other engaged citizens.

However, it is also important to highlight that there are particular barriers in the way of service users and their organizations networking and developing their own knowledge locally, nationally and particularly internationally (Branfield et al., 2006). User led organizations face particular barriers accessing funding related to the discrimination they face. Their international organizations face especial difficulties exchanging knowledge and experience because of the costs of travel and support involved (Shaping Our Lives, 2018). This author is not exempt from these problems and this imposes limits in the way of fully internationalizing accounts and studies. Mainstream non-user academics and researchers are much better placed to operate internationally. This can be seen as another expression of the epistemic inequality and injustice that has been increasingly identified as operating between conventional researchers and groups facing discrimination, marginalizing their experiential knowledge and devaluing them as "knowers" and producers of knowledge (Fricker, 2007; Liegghio, 2013, p. 124; Russo and Beresford, 2015). And yet despite the very real obstacles in their way, service users have nonetheless managed both to accumulate and share international experience and to influence major supranational bodies, like the United Nations (O'Hagan, 1993; Minkowitz, 2018).

My background has particularly encouraged me to adopt an historical perspective and highlighted its benefits in trying to understand participation. There seem to be few such discussions of public participation. Perhaps this is because it cuts across so many different disciplines, policies and professions and demands an overview and level of familiarity with these not readily gained. Furthermore, building on wider experience, a premise adopted here is that to make sense of participation in health, it is likely to be helpful to look beyond health and to take the development of participation as a starting point. Thus, here it is suggested that an essential first step to advancing public participation in health and the advancement and co-production of knowledge within it, is to put it in the context of developing modern democracy more generally. Here it is argued that when we try to do this, four key stages in the development of public participation in health and social care can be identified. These historical phases are associated with:

1. Moves toward universal suffrage in representative democracy and the achievement of social rights, like the right to decent housing, education and health;

2. Provisions for participatory democracy and community development;

3. Specific provisions for participation in health and social care;

4. State reaction and service user-led renewal as conflicts and competing agendas develop.

These phases shouldn't be seen as narrowly sequential. Overlaps and inconsistencies can be identified. They highlight the need not to isolate or reify developments in participation. These have taken place in different ways, at different times and paces in different situations and countries. They may also interact and co-exist with each other in different ways. But the broad phases identified here do nonetheless, seem to reflect wider international political, policy and ideological trends.

While this article focuses particularly on UK developments to explore this history, it also draws on international experience and highlights the wider relevance of these phases of development. It makes connections between the extension of representative and participatory democracy, considering the different locations in which efforts to extend participation have helpfully developed, for example, in learning and training, and notably in research and knowledge production. It also considers how efforts to extend participation have been undermined by pressures to tokenise and co-opt them; the continuing barriers discriminating against some groups and, ways in which service users and allies have nonetheless sought to overcome these difficulties to take forward more inclusive and diverse participation in health and social care. It will focus on some particularly promising areas of development internationally in order to do this in which co-production and the development of user-led knowledge are key.

\section{PHASE ONE: MOVES TOWARD UNIVERSAL SUFFRAGE AND SOCIAL RIGHTS}

Looking back from our vantage point in the early twenty first century, it can still be alarming to be reminded how long it took to achieve universal suffrage even in supposedly "advanced western democratic societies." Thus, it was not until 1918 in the UK that the Representation of the People Act gave women the vote provided they were aged over 30 and either they, or their husband, met a property qualification. Until 1918, when the property qualification for men was abolished, only about 60 per cent of men had the vote. The rate of change was rapid. In $1900,<7$ million people in the UK had the right to vote. This had risen to more than 21 million, more than half the population by 1918. However, not until 1928 under the Equal Franchise Act did women in the UK share equal voting rights with men (Smith, 2014). Most European countries adopted highly 
discriminatory suffrage systems for lower legislative chambers for most of the 1815-1915 period (Goldstein, 1983). In many places Black people have only obtained suffrage through national independence during the course of the twentieth century and in some countries it continues to be an issue even where it has been formally achieved (Paxton et al., 2003). Indigenous peoples also continue to face discrimination and marginalization globally (Anaya, 2004).

However, if the first half of the twentieth century was a time of increasing democratization and the extension of suffrage, it was also a time of growing suffering worldwide. The two world war and international inter-war economic depressions, caused enormous problems of want, death, disease, suffering and hunger globally. More people died in the Spanish flu epidemic after the Great War than were killed in the war itself (between 20 and 50 million). In a time of increasing political, economic and social uncertainty and inequality, rising pressure for electoral representation came to be coupled internationally with pressure for the achievement of social rights. Such rights are taken to include the right to work, to decent housing, education, adequate income and social security and proper social, health and medical services (Beresford, 2016).

This first major expression of the struggle for "social citizenship" was the setting up of post-second world war welfare states, first in the UK and then other countries. One of the central policies established as part of the UK welfare state was the National Health Service (NHS), based on principles of providing universal health care free at the point of delivery and paid for out of a progressive system of general taxation The UK welfare state's proponents saw it as having a key role to play in the protection and promotion of people's economic and social well-being. The welfare state's policy provisions and legislation were seen as compensating for inequalities arising from the market, in contrast to the Poor Law which sought to police and regulate people disadvantaged in society and through the market (Marshall, 1950). What such thinking failed to take account of, as subsequent critiques from feminist, LGBTQ, Black and disability rights perspectives have highlighted, were the inherent biases of such concepts of citizenship which were very much tied to the thinking and discriminations of their time (Williams, 1989; Oliver and Barnes, 1998).

\section{PHASE TWO: PROVISIONS FOR PARTICIPATORY DEMOCRACY AND COMMUNITY DEVELOPMENT}

The initial struggle for political and social rights can be seen as leading to the second stage of struggle for greater democratization. If the first phase was concerned with extending representative democracy, this second phase can also be seen as influenced by ideas of participatory democracy. It is concerned with ways in which people can be involved directly in the political process, rather than being represented by others and can trace its history back to the origins of democracy in ancient Athens, where all who counted as citizens could thus participate-although the lines of citizenship were drawn very narrowly (Held, 1996).
In the UK, the beginning of this second phase of interest in participation is associated with the 1960s and was linked with the return to power of left of center Labor governments after years of right of center Conservative government. There were equivalents both in other European countries, the United States and beyond. Talk in the UK was framed in terms of the "rediscovery of poverty" in the midst of what was seen as an "affluent society" This discovery was associated with major social science academics like Peter Townsend and Brian AbelSmith, who combined research with activism (Abel-Smith and Townsend, 1965). Post-war "consensus" between political left and right, that mixed economy welfare states had secured the rights and social security of citizens "from cradle to grave" was challenged. The social policy theoretician Titmuss and others pointed out that welfare services established to counter-balance inequalities in society were failing to do so and that longstanding inequalities and exclusions remained (Titmuss, 1968; Halsey, 1972). Public and social services were emerging as having their own problems and limitations as an approach to compensating for structural problems and inequalities.

As rising inequalities, exclusions and regressive redistribution were highlighted in the UK and internationally, a range of focuses and approaches for change were developed. These centered on concepts of social compensation, urban interventions and community involvement. Community based approaches range from highly structured, state and professionally-led schemes operating in localities and around issues, to much more autonomous approaches encouraging independent collective action in the community, developing ideas of "empowerment" and "conscientization." All highlight participation, but there has been a tendency in both toward increasing professionalization and state control (Craig et al., 2011; Ledwith, 2016).

Thus, the US "War On Poverty" (Sheffield and Rector, 2014) and in the UK the state-led community development project (CDP), which ran from the 1960s to late 1970s and the education priorities areas (EPA). Both sought to target help on particular individuals and groups (including women, young people, Black and minority ethnic groups and poor people) and areas (notably "inner city areas") identified as deprived and disadvantaged. All sought to "involve" the people they were working with, although they were generally professionally led. They aimed to raise people's consciousness, skills and "cultural capital." All placed an emphasis on support, out-reach and developmental work, to help make this possible. But all equally came under attack for their ambiguity. Competing strands were identified in the work, some more consensual and some conflict based (CDP, 1977; Loney, 1983). Local involvement was often limited, tokenistic and paternalistic. Poverty remained a continuing problem and was indisputably linked with persistent (and ultimately worsening) economic and social inequality in British society and institutions (Atkinson, 1983).

If involving people was part and parcel of the UK community development and anti-poverty strategies of this time, it was the central feature of new provisions for state land planning. This movement gained momentum in the late 1960s not least because of the deluge of bad planning with large scale urban redevelopment and, central government's desire to free itself of the burden of innumerable appeals. Its landmarks were a major 
government report and two town and country planning acts of 1968 and 1971 (Beresford and Beresford, 1984, p. 27). For the first time, the legislation made provision for public participation in planning-both development planning and general planning control. This became a model that attracted international interest. The notion of public participation embodied in the two acts was essentially one of public consultation and appeal. The "public" was offered the limited chance to disagree with what the local authority offered. Not only was participation limited to reacting to existing plans and proposals, rather than being able to co-create these, but the involvement engendered, tended to be very limited.

One of the abiding problems of modern public participation, as we shall explore later, has been the barriers and restrictions that seem to operate on who actually gets involved. This has been an issue that has been associated with all efforts to involve people. It was rapidly apparent in efforts to involve people in land use planning. These exercises, essentially based on expecting people to respond to invitations to get involved and relying on traditional public meetings and conventional verbal and written skills, tend to disadvantage and exclude people on the basis of class, ethnicity, gender, age, culture and disability (Beresford and Beresford, 1984). They also tend to put a premium on verbal, writing and other social skills, which inherently discriminates against less confident, less assertive, less well educated people. Thus, they may actually reinforce inequalities in relation to power and participation, rather than compensate for them.

They also exhibit another major shortcoming, which again is not confined to statutory arrangements for participation in planning. As one commentator, campaigning against redevelopment where he lived, observed early in their development:

\section{Millfield benefitted greatly from the termination of public participation in planning...In Millfield...specific issues connected with the planners' proposals were brought to a moderately successful conclusion (from the residents' point of view) only when the planners' rules were abandoned and the ordinary machinery of local councilor, MP, publicity, public discussion and so forth was utilized (Dennis, 1972).}

This is an inheritance which participatory initiatives still have to live down. While ostensibly intended to extend democracy, they can actually serve to divert people from the long fought-for provisions for representative democracy, offering no more than a tokenistic dead-end that discourages people from pursuing what may actually be more firmly established and effective structures for representative democracy. This is a much broader issue for arrangements for participation. Both community development approaches and provisions for participation in planning continue to operate internationally, but both continue to be subject to the same difficulties and shortcomings.

\section{PHASE THREE: PROVISIONS FOR PARTICIPATION IN HEALTH AND SOCIAL CARE}

The third phase of interest in participation is more much directly related to health and social care and the groups particularly associated with it. It is also related to very different pressures for change in health and social care policy and provision. It is reflected in the emergence of specific requirements for user involvement in UK health and social care reform in the 1990s, which was particularly linked with moves to market-led thinking and privatization. In England this was associated with the passing of the National Health Service and Community Care Act and its implementation in 1993. There were equivalent developments in all the UK countries and also in Europe and North America (Topol, 2015). Indeed while timings varied, this can be seen as at least an international, if not a global development. What is particularly significant about this phase of interest in participation, is that it had at least two major sources-and that these were very different in origin and aim. This should remind us of both the complexity of pressures toward participation and their ideological relations and also the potential ambiguity of interest in public and user participation.

The two developments associated with this phase of interest in citizen and user participation were first the international political shift to the right and the emergence of the New Political Right from the 1970s (culminating in the emergence of neoliberal ideology) and second, the development of new social movements, whose origins can be seen in the 1960s. These movements included the Black civil rights, women's, the gay and lesbian [later the Lesbian, gay, bisexual, transgender, queer (LGBTQ)] movements, associated with identity, as well as the green/environmental, animal rights and anti-nuclear/peace movements (Jordan and Lent, 1999; Todd and Taylor, 2004).

The participation offered in UK and other subsequent health and social care reforms offered people the right to comment, complain and to have a say in the management or running of services. There was an increasing emphasis and interest in involvement in monitoring and evaluation, audit and review, developing quality, standard setting and "outcome measures," in randomized controlled trials and systematic reviews-that is to say, in organizational issues.

This reflected the consumerist/managerialist ideology significantly underpinning such state or service system driven schemes for involvement, increasingly rooted in market sector thinking, with involvement effectively being at the level of market research or consultation. While the right to complaint for example in the English Children Act (1989), as well as the NHS and Community Care Act (1990). represented an innovation, it only applied when things had already gone wrong and tended to be experienced as an individualizing and stressful measure (Beresford and Croft, 1993).

If service system and state based pressure for participation has been concerned with eliciting and listening to people's views, the pressure from new social movements has been for political and personal change and their direct involvement and say in making it happen. A further distinction can also be drawn between these new social movements and traditional "pressure group" or "interest" group politics. This international development which has a long history, has significantly been concerned with advancing the interests of powerful rather than powerless groups. In the context of social policy and social problems, furthermore such pressure groups have tended to be 
dominated by non-service users, campaigning and speaking on behalf of service users, rather than service users speaking for themselves (Richardson, 1993; Beresford, 2016).

If traditional social movements took as their starting point economic and material concerns, new social movements highlight issues of human and civil rights and identity in postindustrial society. In the context of health and social care this has been most powerfully exemplified by the international disabled people's movement.

The pioneering UK disabled people's movement, for example, challenged traditional understandings of disability, rejected conventional interpretations of it in individualized terms of "personal tragedy" and instead developed a new social model of disability, which highlighting the discriminatory social responses to impairment which "disabled" people in society. Thus such international "user movements" have not just been concerned with resistance to oppressive policies and politics, but also the formulation of their own alternatives (Randle, 1994; Charlton, 1998). Disabled campaigners called for a new approach to understanding, policy and provision based on a philosophy of "independent living" which challenged disabling barriers and supported people with impairmentsphysical, sensory, or intellectual, to live on as equal terms as possible to non-disabled people (Oliver, 1983, 1990; Charlton, 1998). They placed an emphasis on people speaking for themselves ("self advocacy"), for collective action to support their empowerment through developing their own "user led" and disabled people's organizations' (DPULOs) and on bringing about broader social and political change. Other emerging movements, like that of older people, people with learning difficulties, people living with HIV/AIDS and mental health service users/survivors framed their demands in similar terms, pressing for a direct say in policies and services affecting them, pressing for their own participation in making change.

However, the shared language of involvement of these two often competing and conflicting pressures for participationconsumerist and democratic-disguise fundamental differences between them, which have blurred and confused the issues. While the emergence of service user movements and development of neoliberalism can be seen as having some common origins; notably a reaction against paternalistic top-down state welfare systems, in many other senses they sit at opposite ends of an ideological spectrum. Pressures for privatization and a reduced role for the state bear little relation to service users' calls for democratization and empowerment. The consumerist concerns of the neoliberal state and service system do not sit comfortably with the quest for democratization and empowerment of service users and their allies. Instead they have left many service users feeling that state-led schemes for participation are often tokenistic and ineffectual. They have instead developed their own focuses for involvement, which they see as more effective and productive than the prevailing concern with consultation and "quality control."

Key areas which have emerged from service users themselves are user involvement in professional training, learning and education; the development of user led research and knowledge production and the development of user-controlled initiatives and approaches. These have made it possible to:

- Develop the kind of learning and training for health and social care professions consistent with supporting people's rights and needs, informed by and respecting service users' understandings of their identities and worlds (SCIE, 2009);

- Challenge the exclusion and marginalization of their perspectives and experience (Faulkner, 2010);

- Advance the evidence base for the social understandings of service users and the issues they experience which they themselves have developed, rather than being tied solely to other people's interpretations and understandings of them (Beresford and Croft, 2012);

- Develop as service users their own organizations, histories, cultures, collectivities and independent action (Beresford, 2016);

- Develop as service users ideas, policy and practice consistent with their own models and philosophies (Campbell and Oliver, 1996).

While it is important not to overstate the amount of progress made in advancing user involvement in health and social care (and indeed in policies and services beyond), it would also be a mistake to under-estimate its achievements internationally. At the same time, as has already been indicated, progress has often been slow and its implementation hesitant, patchy and contested. Its history is riven with ambiguities and false trails (Ocloo and Matthews, 2016). The rhetoric about involvement has tended always to be in advance of the reality. Some service users talk about "consultation fatigue" and being "all consulted out." We have perhaps reached a new stage in the development of participation generally and user involvement in healthcare specifically. This is a time of increasing conflict and challenge over the idea and its implementation and is perhaps best framed as a new phase in its development.

\section{PHASE FOUR: REACTION AND RENEWAL}

Participatory schemes and initiatives have long tended to include ones rooted in consensus as well as conflict. This has been reflected in the different approaches of different user movements. So, for example, the UK disabled people's movement historically while engaging with existing political structures, was initially much more separatist than for example, the UK survivors movement, which tended to have much closer links with and often to be closely located within the service system (Barnes et al., 1999). The US disabled people's movement was significantly shaped by wounded and disillusioned veterans returning from the Vietnam War, whereas by contrast some mental health service user organizations accepted funding from the big pharmaceutical companies (Charlton, 1998).

There has been a tendency to overlook or fudge inherent contradictions between different approaches to participation; their different aims and underpinning ideas. Instead their various proponents have sought to advance their own agendas and highlighted the practical rather than ideological problems 
underlying resulting difficulties. But more recently we seem to be entering a new stage in participation and user involvement, where these differences and difficulties have become more evident; positions have seemed to become more polarized and entrenched and, protagonists have emerged as in greater conflict with each other. Thus, for all the talk of the rights and say of the service consumer, in both the US and the UK, for instance, the continuing dominance of neoliberal ideology in social policy has meant that the latter has become increasingly harsh and residual; service users have been increasingly marginalized and disempowered and the two positions have become more and more polarized. It has become increasingly difficult to maintain the sense that formal arrangements for participation can offer people a real say as public services and welfare provision has been increasingly cut back.

This fourth phase, perhaps best described as reaction and renewal, is thus one where the tensions between competing ideological underpinnings and objectives for user and public involvement have become more manifest, with the service system as much subverting service users' aspirations for say, empowerment and involvement as supporting them, coupling rhetoric about engagement with more regressive welfare policies and service users and their organizations increasingly recognizing this contradiction, both experiencing and recognizing the continuing discriminations, inequalities and exclusions they face and beginning to articulate more independently their own ideas, agendas and campaigns for say and involvement.

This phase has a number of expressions in health and social care, associated with developments on the part of both state/service system policies and approaches to involvement and those of citizens/service users. We can look at each of these in turn, beginning with prevailing approaches based on neoliberal ideology, considering some of the latter's broader consequences and then considering the progress of user-led approaches. The UK offers an advanced case study of this.

\section{REACTION-FROM THE SERVICE SYSTEM}

Since the economic crisis of 2007-8, public policy in the UK has been based on the idea of "austerity" with sharp cuts made in public services, including the NHS and social care particularly and with the implementation of so-called "welfare reform," based on reducing access to and expenditure on welfare benefits, notably to poor, unemployed and disabled people. The harsh and extreme effects of such policies have been evidenced and highlighted by service users themselves and their user led organizations, their allies and academic research. So far this has had little effect in changing such policy (O'Hara, 2014; Beresford, 2016; Garthwaite, 2016; Beresford and Carr, 2018), which can be seen as much more part of an underpinning neoliberal agenda, than as a response to economic difficulties. Despite the continuing governmental rhetoric extolling user choice and involvement, little if any notice has been taken of the strong and wide-ranging criticisms that there have been of such welfare reform policy, not least from service users themselves.
At the same time, disabled people's and other service users' organizations are facing increasing insecurity, having a greater struggle to continue and, many are closing down. They have long had inferior access to funding and other resources compared with traditional charities and voluntary organizations and this situation now seems to have worsened as funding has declined. Thus, the latest evidence worryingly highlights both that survivor-led organizations in the UK, are seriously declining in numbers, while the same pattern is apparent for ULOs more generally. While some new organizations are emerging, others are having to close or downsize. Over an 18 months period from 2015, more than a quarter of survivor led organizations in England had closed down (Yiannoullou, 2018). So instead of progress being made toward services becoming more democratic, access to their support is increasingly restricted and their control role highlighted.

At the same time, mainstream policy and provision have increasingly been framed in terms of ideas and values inspired by and associated with service users and their quest for more say and control over their lives. Three key expressions of this are the reframing of policy and provision in terms of:

- Self-management

- Peer support

- Recovery

Yet each can actually be seen as the incorporation and cooption of ideas originating with service users and their subversion and realignment with neoliberal values and ideas. Thus selfmanagement in mental health discourse and policy is not so much about "managing" in the sense of being able to regain personal control, but "managing" in the "new managerialist" sense that has come to permeate modern neoliberal social policy. "Peer support" has been institutionalized into the role of "peer support worker." Instead of being based on an alternative userled paradigm challenging psychiatry. Such roles seem more and more to be framed as lower paid ancillary jobs incorporated into the prevailing values, ideas and structures of psychiatry. They occupy an increasingly ambiguous role as an acceptable face of the system for patients entering it, with minimal say and control over it or their role (Penny and Prescott, 2016; Penny, 2018). The idea of "recovery" has been advanced in official policy as challenging the historic writing-off of mental health service users as permanently damaged, dependent and unreclaimable. But it is actually often tied to a bio-medical model. It does not take long to work out that if someone is seen as "recovered" then the support they have received may also be seen as no longer necessary. The reality has been that the idea of recovery has been bound up in neoliberal psychiatric thinking with "restoring" or more accurately, pressurizing service users into employment as a primary focus (Gadsby, 2015).

\section{THE NEOLIBERAL CONTEXT OF USER INVOLVEMENT AND ITS WIDER IMPLICATIONS}

The reality is that while the policy atmosphere is one that seems sensitive to and supportive of user involvement and 
developments associated with it, there is little effective support for it; policy's direction of travel is in many ways antagonistic to it and there seem to be fewer resources made available to support it. Thus, for all the talk about PPI, user involvement, public participation and the ways in which they have crept into the political and policy lexicon, there seem to be a series of continuing structural obstacles in the way of them becoming meaningful and effective, which can make up the context for their operation and potential. These apply between us as human beings, for example,

- As service workers and service users; in neoliberal contexts that are increasingly disempowering for both (Giroux, 2008; Crouch, 2011);

- As practitioners/field workers and managers in increasingly hierarchical controlling structures (Doolin and Lawrence, 1997; Kirkpatrick et al., 2005);

- As service users and family carers where too often one is put in the position of speaking for the other and the needs of the two are conflated and confused (Rogers and Pilgrim, 2014);

- As general public and service users, as if the latter aren't part of the public and should be conceived as a negative cost on the former, with insidious propaganda about the scrounging and dependence of disabled people and other groups of service users (Beresford, 2016; Garthwaite, 2016);

- Between so-called "expert" or professional knowledge, research based knowledge and the lived experience of people as service users, with the latter devalued as biased, unscientific, subjective and unreliable and user controlled research which gives value to it, similarly devalued in relation to the traditional valuing of conventional randomized controlled trials (RCTs) and systematic reviews (Beresford, 2003; Rose, 2018);

- Between us-on the basis of issues of diversity in relation to age, gender, ethnicity, sexuality, disability, class, culture and belief, so that some groups face discrimination in society and frequently schemes for participation mirror these (Williams, 1989; Beresford, 2013).

The more recent trend in public policy has been to reinforce these divisions and exclusions through the tendency under neoliberalism to increased poverty and inequality. While the post-war UK welfare state increasingly struggled to overcome such inequalities, the tendency of later and current neoliberal policy and politics has instead been to reinforce them, with its modern rhetoric dividing us into "scroungers" and "strivers"; employed and unemployed, "hard working" and "troubled families," citizens and non-citizens; "dependent" and “independent” (O’Hara, 2014; Beresford, 2016).

\section{RENEWAL-FROM SERVICE USERS}

Although the dominance of neoliberal ideology has certainly imposed limits on the development of user involvement and citizen participation, as well as on the rights and say of people as service users, it would be wrong to assume that it has killed progress. Indeed, what we can see is an increasing focus and indeed in some ways, a strengthening and redirection of activity.
Thus, welfare service users in the UK, and indeed elsewhere, while coming under particular attack from welfare reform policies, have been in the lead in challenging such developments, often providing both the evidence and the impetus for this challenge (Beresford, 2012). Thus, while experiencing much suffering in recent years, service users and their organizations have extended both their critiques and their action in relation to health and social care and other policies and services. Some key areas of activity include:

- Widening involvement and campaigning, challenging exclusions

- Involvement in professional and occupational training;

- Involvement in research and knowledge production

- The development of "Mad Studies."

It is these that are the focus of this last part of the article.

\section{WIDENING INVOLVEMENT AND CAMPAIGNING, CHALLENGING EXCLUSIONS}

As we have seen the challenging of institutionalized discrimination and exclusions in society began with the emergence of new social movements in the 1960s and 1970s. This was extended through the self-organization of service users through the creation of user led organizations (ULOs) from the 1970s. Here some of the most marginalized, disempowered and excluded groups; people with physical and sensory impairments, people with learning difficulties, mental health service users and others with long term health conditions, took the initiative and began to speak and act for themselves; struggling for self-advocacy and self-organization. As their early organizations spelled out, their goal was inclusion, integration on equal terms and participation in society, rather than segregation and marginalization. They had experienced separation and inequality. What they wanted was access to and inclusion in the mainstream and to be treated on equal terms. To achieve this, groups like disabled people emphasized their separateness; they were often separatist in their approach, but their aim was to put an end to the discrimination they understood disability to mean and to achieve inclusion, unification and reconciliation. The strategy was inclusive, aiming for unity and the equal recognition of difference; the tactics were often separatist on the basis of difference. By highlighting their difference, they sought to be treated with equality and achieve unity and inclusion.

Increasingly while recognizing their difference, as for example, disabled people or mental health service users, they highlighted their internal diversity and their overlaps with other groups. They highlighted that even within oppressed and marginalized groups, external hierarchies around gender, ethnicity, sexuality, age, impairment and so on, could operate and they increasingly evidenced and challenged the way that such exclusions operate to mean that some people within such groups face discrimination, face particular discrimination, for example disabled women and Black disabled people. They analyzed these oppressions through 
the lense of intersectionality and began to challenge them, themselves.

Beginning with the disabled people's movement, service users, have long highlighted that conventional approaches to participation tend to exclude many groups and individuals. While they have worked hard to make people's involvement more accessible and inclusive, highlighting environmental, communication and cultural barriers, these continue to operate.

Eurikha, a global project which seeks to privilege the rights and perspectives of people who experience distress, is beginning to highlight both the marginalization of the Global South in such developments and also the marginalization of black and minority ethnic communities in the Global North (https://www.eurikha. org/about/). While the United Nations convention on the rights of persons with disabilities has begun to have an impact on disability legislation, policy and practice globally, the response to it has been qualified in some countries and there have been significant limits to how participatory its implementation has been.

The history of the UK disabled people's movement is one that has increasingly highlighted and challenged exclusions and discriminations. Most recently people with long term conditions have asserted their particular difficulties and right to be involved. Service users themselves have also highlighted the ways in which social media and networking can challenge such barriers (as well as reinforcing them) (Onions et al., 2018). A study by the user led organization and network Shaping Our lives, has evidenced the way in which diverse involvement is restricted. It identified big barriers in the way of five major groups, but also strategies to overcome them. Such groups of service users are excluded according to:

- Equality issues; on the basis of gender, sexuality, ethnicity, class, culture, belief, age, disability and so on

- Where they live; if they are homeless, travelers, in prison, in welfare institutions, refugees and so on

- Communicating differently; they do not speak the prevailing language, it is not their first language, they are (D)deaf and used sign language, etc.

- The nature of their impairments; where these are seen as too complex or severe to mean they could or would want to contribute

- Where they are seen as unwanted voices; they do not necessarily say what authorities wanted to hear, are seen as a problem, disruptive etc. These includes neuro-diverse people and people affected by dementia (Beresford, 2013).

\section{INVOLVEMENT IN PROFESSIONAL AND OCCUPATIONAL TRAINING}

Involving service users (and family carers) in professional and occupational education and training has long been seen as one of the most effective ways of improving the nature and culture of social work and other helping practice and services. PowerUs, a partnership of social work educators and service users and their organizations, which already involves twelve countries, within and beyond Europe, has sought to develop methods of mutual learning in order to change social work practice to be more effective in supporting the empowerment of marginalized and discriminated groups in society (http://powerus.eu). The "gapmending" process began at Lund University in Sweden in 2005 is a method of teaching that brings service users and social work students together to learn together on as equal terms as possible. The idea is about bridging divisions between service users and social work students in their learning through new approaches to user involvement. It also represents an alternative approach to the increasing emphasis under neoliberal politics on graduate and elite/fast track approaches to social work education, giving value to "user knowledge," rather than just academic qualifications. People "meet as people" on gap-mending courses; service users get formal recognition and accreditation for the skills they offer as well as the skills they gain. Social work students who also have "lived experience" as service users are valued for it and can share it if they wish to. Perhaps most important is the building of trust and understanding between service users and wouldbe social workers which is likely to have a profound effect on future relations and practice between them. Key gaps that the approach has identified include between, needs and resources; the priority social work demands and the priority it is given; service users and providers, "expert" and experiential knowledge; social work education and practice-and researchers and research subjects (Askheim et al., 2017).

\section{INVOLVEMENT IN RESEARCH AND KNOWLEDGE PRODUCTION}

Research has been the site of one of the most complex and contentious struggles between service users and neoliberal ideology. Its origins can be seen to lie in the struggles first of feminists and then disabled people-to challenge the "epistemic violence" and exclusion we referred to earlier, from the 1970s and regain control over their "experiential" knowledgethe knowledge's that comes out of people's individual and collective lived experience. They called into question the values of distance, neutrality and objectivity of conventional positivist research and instead highlighted that these devalue their lived or subjective experience and represent a further layer of discrimination imposed upon them, invalidating their understandings of the world. They have questioned the independence of mainstream/conventional research, seeing it as frequently following from government/commercial priorities and ideology for funding and often tied to the values and assumptions of the service system.

The UK disabled people's movement condemned existing disability research in the 1970 s as biased and on the side of the service system that controlled their lives. To counter this, they developed their own "emancipatory disability research," which prioritized the equalizing of research relationships, the empowerment of disabled people and the achievement of social change to support their rights and needs (Barnes and Mercer, 1999). The survivor movement developed survivor research along the same lines. At the same time existing research structures began to show an increasing interest in 
involving research subjects in research process, framed in the UK in terms of "public, patient involvement" or PPI and elsewhere in similar terms. For some time there has seemed to be some convergence between these two developments. There are reports from the mainstream of the progress being made in patient and public involvement in health research, with for example the development of a global network (Staniszewska et al., 2018). But increasingly tensions have emerged between the consumerist/managerialist aims of such involvement in much mainstream psychiatric and other health research under neoliberalism and the emancipatory goals of mental health service users/survivors (Rose et al., 2018). Thus PPI is coming under increasing attack as "centered on a construction of the abstract, rational, compliant, and selfmanaging patient" under neoliberalism (Madden and Speed, 2017).

\section{THE DEVELOPMENT OF "MAD STUDIES"}

Finally we turn to the emergence of "Mad Studies" because it brings together many of the progressive aims and aspirations of service users in relation to health, social care and other areas of professional activity, highlighting the possibility of building alliances between different stakeholders to achieve these aims. The Mad Studies movement is committed to a praxis for radical change and is strongly rooted in Canada and also increasingly in the UK and internationally (Le Francois et al., 2013). What generally seems to define the key elements of mad studies is that:

- First, it is definitely divorcing us and itself from a simplistic biomedical model, making possible a necessary rupture from it. It allows other understandings and disciplines to come into it instead of solely medical dominance-sociology, anthropology, social work, cultural studies, feminist, Queer studies, disability studies, history-everything.

- Second is the value and emphasis it places on first person knowledge-centring on the first person knowledge of everyone, not just those psychiatrised. If you want to talk about yourself, then you have a right to, it is ok to include yourself. This is positioned/situated research-you can't just be talking from nowhere, as if you had no place in the proceedings-as it has been in psychiatry.

- And finally of course Mad Studies treats survivors' first hand knowledge with equality. But Mad Studies values and has a place for all our first hand experiential knowledge; that's why such a wide range of roles and standpoints can contribute equally to Mad Studies-if they are happy to sign up to its core principles. It isn't only us as survivors/mental health service users, but allies, professionals, researchers, loved ones, and so on, This is a venture we can all work for together in alliance. So it includes the experiential knowledge of service users, the practice knowledge/wisdom of workers and the knowledge from those offering support, of family carers as important bases for future research and development (Beresford and Russo, 2016).

\section{CONCLUSION}

The aim of this discussion has been to put public and user involvement in health and social care into broader historical, theoretical and philosophical context; to explore competing approaches to it and to chart positive progress in advancing more inclusive and diverse involvement, knowledge and coproduction through exploring both emerging barriers and helpful case studies challenging them. This approach has highlighted the tendency for such involvement to be reified and abstracted; treated in isolation, separated-particularly from its ideological and political relations. Yet its history and particularly its recent history with ideological conflict increasing in this field, points to the inadequacy of such thinking. The greatest challenge to this has come from service users and their user led organizations and first hand knowledge production. While user involvement and PPI in health and social care have been conspicuous in their development, with many positives to be seen and important initiatives developed, significant inequalities and inconsistencies continue to emerge between state and service user led approaches. These have acted as barriers to both progress and the inclusion of diversity.

Therefore, key recommendations to achieve more effective and inclusive participation are to:

- strengthen the funding basis of user led organizations, which have played a key role in user involvement innovation, to ensure that they are viable and sustainable (ULOs);

- ensure that both ULOs and service-led schemes for user involvement/PPI are adequately resourced to be more inclusive and address diversity with greater equality;

- Equalize access to funding for user controlled research, particularly within ULOs, to support the development of service user experiential knowledge and to challenge the traditional dominance of so-called "expert" or professional knowledge.

We are in the very midst of change-more advanced in some settings, some nations and with some politics than others. But nonetheless it would be very difficult to argue that health, social care and their service users have not already benefitted from the insights, learning and progress so far achieved. Directing our efforts to advance and monitor such progress, whatever the state of play in our own locality and situation, is likely to be an important and worthwhile activity and goal.

\section{AUTHOR CONTRIBUTIONS}

The author confirms being the sole contributor of this work and has approved it for publication.

\section{ACKNOWLEDGMENTS}

I would like to thank Suzy Croft, who has been my partner in the struggle for greater participation over many years. I would also like to acknowledge the many disabled people and other service users from whom I have learned so much-personally and politically. 


\section{REFERENCES}

Abel-Smith, B., and Townsend, P. (1965). The Poor and the Poorest, A New Analysis of the Ministry of Labour's Family Expenditure Surveys of 1953-54 and 1960. LSE Occasional Papers on Social Administration No. 17, London, G. Bell and Sons.

Anaya, S. J. (2004). Indigenous Peoples In International Law, 2nd Edn. Oxford, Oxford University Press.

Arnstein, S. (1969). A ladder of citizen participation. J. Am. Inst. Plann. 35, 216-24. doi: $10.1080 / 01944366908977225$

Askheim, O. P., Beresford, P., and Heule, C. (2017). 'Mend the gap' - strategies for user involvement in social work education. Soc. Work Educ. 36, 128-140. doi: 10.1080/02615479.2016.1248930

Atkinson, A. B. (1983). The Economics of Inequality. Oxford: Clarendon Press Oxford University Press.

Barnes, C., and Mercer, G. (eds.). (1999). Doing Disability Research. Leeds: The Disability Press; University of Leeds.

Barnes, M., Harrison, S., Mort, M., and Shardlow, P. (1999). Unequal Partners: User Groups and Community Care. Bristol: The Policy Press.

Beresford, P. (2003). It's Our Lives: A Short Theory of Knowledge, Distance and Experience. London: Citizen Press in association with Shaping Our Lives.

Beresford, P. (2012). From 'Vulnerable' to vanguard: challenging the coalition. Soundings 50, 46-57. doi: 10.3898/136266212800379509

Beresford, P. (2013). Beyond the Usual Suspects: Towards inclusive User Involvement-Research Report. London: Shaping Our Lives.

Beresford, P. (2016). All Our Welfare: Towards Participatory Social Policy. Bristol: Policy Press.

Beresford, P., and Beresford, S. (1984). A Say In The Future: Planning, Participation and Meeting Social Need, 2nd Edn. London: Battersea Community Action.

Beresford, P., and Carr, S. (2018). Social Policy First Hand: An International Introduction to Participatory Social Welfare. Bristol: Policy Press.

Beresford, P., and Croft, S. (1993). Citizen Involvement: A Practical Guide for Change, 1993. Basingstoke: Macmillan.

Beresford, P., and Croft, S. (2012). User Controlled Research: Scoping Review, London, NHS National Institute for Health Research (NIHR) School for Social Care Research. London: London School of Economics.

Beresford, P. and Russo, J. (2016). Supporting the sustainability of Mad Studies and preventing its co-option. Disabil. Soc. 31, 270-274. doi: 10.1080/09687599.2016.1145380

Branfield, F., Beresford, P., with Andrews, E. J., Chambers, P., Staddon, P., Wise, G., et al. (2006). Making User Involvement Work: Supporting Service User Networking and Knowledge. York: Joseph Rowntree Foundation; York Publishing Services.

Campbell, J., and Oliver, M. (1996). Disability Politics: Understanding Our Past, Changing Our Future. London: Routledge.

CDP (1977). Gilding The Ghetto: The State and the Poverty Experiments, Location Not Known. Nottingham: Community Development Inter-Project Editorial Team.

Charlton, J. I. (1998). Nothing About Us Without Us: Disability, Oppression and Empowerment. Oakland, CA: University of California Press.

Cotterell, P., Harlow, G., Morris, C., Beresford, P., Hanley, B., Sargeant, A., et al. (2011). Service user involvement in cancer care: the impact on service users. Health Expect. 14, 159-169. doi: 10.1111/j.1369-7625.2010.00627.x

Craig, G., Mayo, M., Popple, K., Shaw, M., and Taylor, M. (eds.). (2011). The Community Development Reader: History, Themes and Issues. Bristol: Policy Press.

Crouch, C. (2011). The Strange Non-Death of Neo-Liberalism. Cambridge: Polity Press.

Davies, C., Wetherell, M., and Barnett, E. (2006). Citizens At The Centre: Deliberative Participation in Healthcare Decisions. Bristol: Policy Press.

Dennis, N. (1972). People And Planning: The Sociology of Housing in Sunderland. London: Faber and Faber.

Dolan, P., Cookson, R., and Ferguson, B. (1999). Effect of discussion and deliberation on the Public's views of priority setting in healthcare: focus group study. Br. Med. J. 318, 916-919.

Doolin, B., and Lawrence, S. (1997). Managerialism, information technology and health reform in New Zealand. Int. J. Public Sect. Manag. 10, 108-122. doi: $10.1108 / 09513559710156742$
Faulkner, A. (2010). Changing Our Worlds: Examples of User Controlled Research in Action. Eastleigh: NIHR INVOLVE.

Fishkin, J. (2011). When The People Speak. Oxford: Oxford University Press.

Fishkin, J., and Laslett, P. (eds.). (2003). Debating Deliberative Democracy. Oxford: Wiley-Blackwell.

Fricker, M. (2007), Epistemic Injustice: Power and the Ethics of Knowing. Oxford: Oxford University Press.

Gadsby, J. (2015). The Recovery Star Meets The Unrecovery Star, Critical Mental Health Nurses' Network, October 19th, CMHNursing. Available online at: https://criticalmhnursing.org/2015/10/19/the-recovery-star-meetsthe- unrecovery-star/.

Garthwaite, K. (2016). Hunger Pains: Life Inside Foodbank Britain. Bristol: Policy Press.

Giddens, A. (1994). Beyond Left and Right: The Future of Radical Politics. Cambridge: Polity Press.

Giroux, H. (2008). Against the Terror of Neoliberalism: Politics Beyond the Age of Greed. Colorado: Paradigm Publishers.

Goldstein, R. J. (1983). Political Repression In 19th Century Europe. London: Routledge.

Halsey, A. H. (ed.). (1972). Trends In British Society Since 1900: A Guide to the Changing Social Structure of Britain. Basingstoke: Palgrave MacMillan.

Held, D. (1996). Models of Democracy, 2nd Edition. Cambridge: Polity Press.

Jordan, T., and Lent, A. (eds.). (1999). Storming The Millennium: The New Politics of Change. London: Lawrence and Wishart.

Kirkpatrick, I., Ackroyd, S., and Walker, R. (2005). The New Managerialism And Public Service Professions: Change in Health, Social Services and Housing. Basingstoke: Palgrave.

Le Francois, B. A., Menzies, R., and Reaume, G. (eds.). (2013). Mad Matters: A Critical Reader in Canadian Mad Studies. Toronto, ON: Canadian Scholars Press.

Ledwith, M. (2016). Community Development in Action: Putting Friere Into Practice. Bristol: Policy Press.

Liegghio, M. (2013). "A denial of being: psychiatrization as epistemic violence," in Mad matters: A Critical Reader in Canadian Mad Studies, eds B. A. Le Francois, R. Menzies, and G. Reaume (Toronto, ON: Canadian Scholars Press), $122-129$.

Loney, M. (1983). Community Against Government: British Community Development Project, 1968-78, (Studies in Social Policy and Welfare). London: Heinemann Educational Books.

Madden, M., and Speed, E. (2017). Beware zombies and unicorns: toward critical patient and public involvement in health research in a neoliberal context. Front. Sociol. 2:7. doi:10.3389/soc.2017.00007

Marshall, T. H. (1950). Citizenship and Social Class and Other Essays. Cambridge: Cambridge University Press.

Minkowitz, T. (2018). "Dreams of justice," in Social Policy First Hand: An International Introduction to Participatory Social Welfare, eds P. Beresford and S. Carr (Bristol: Policy Press), 257-261.

Moini, G. (2011). How participation has become a hegemonic discursive resource: towards an interpretivist research agenda. Crit. Policy Stud. 5, 149-168. doi: 10.1080/19460171.2011.576524

Ocloo, J., and Matthews, J. (2016). From tokenism to empowerment: progressing patient and public involvement in healthcare improvement. BMJ Qual. Saf. 25, 626-632. doi: 10.1136/bmjqs-2015-004839

O'Hagan, M. (1993). Stopovers on My Way Home From Mars: A Journey Into the Psychiatric Survivor Movement in the USA, Britain and the Netherlands. London: Survivors Speak Out.

O'Hara, M. (2014). Austerity Bites: A Journey to the Sharp end of Cuts in the UK. Bristol: Policy Press.

Oliver, M. (1983). Social Work And Disabled People. Basingstoke: Macmillan.

Oliver, M. (1990). The Politics of Disablement. Basingstoke: Macmillan and St Martin's Press.

Oliver, M., and Barnes, C. (1998). Disabled People and Social Policy: From Exclusion to Inclusion. London: Longman.

Onions, P., O'Neill, R., Kelly, F., and Machin, K. (2018). “Pat's Petition: The emerging role of social media and the internet," in Social Policy First Hand: An International Introduction to Participatory Social Welfare, eds P. Beresford and S. Carr (Bristol: Policy Press), 332-335. 
Paxton, P., Bollen, K. A., Lee, D. M., and Kim, H. J. (2003). A half-century of suffrage: new data and a comparative analysis. Stud. Comp. Int. Dev. 38, 93-122. doi: $10.1007 / \mathrm{BF} 02686324$

Penny, D. (2018). "Who gets to define 'peer support'?" in Mad In America. Available online: https://www.madinamerica.com/2018/02/who-gets- todefine-peer-support/.

Penny, D., and Prescott, L. (2016). "The co-optation of survivor knowledge: the danger of substituted values and voice," in Searching For A Rose Garden; Challenging psychiatry, fostering mad studies, eds J. Russo and A. Sweeney (Ross-on-Wye: PCCS Books), 35-45.

Randle, M. (1994). Civil Resistance. London: Fontana Press.

Richardson, J. J. (ed.). (1993). Pressure Groups,. Oxford: Oxford University Press.

Rogers, A., and Pilgrim, D. (2014). A Sociology of Mental Health and Illness, 5th Edn. Maidenhead: Open University Press; McGraw Hill Education.

Rose, D. (2018). "Renewing epistemologies: service user knowledge," in Social Policy First Hand: An International Introduction to Participatory Social Welfare, eds P. Beresford and S. Carr (Bristol: Policy Press), 132-141.

Rose, D., Carr, S., and Beresford, P. (2018). Widening cross-disciplinary research for mental health: what is missing from the Research Councils' UK mental health agenda?. Curr. Issues Dis. Soc. 33, 476-481. doi: 10.1080/09687599.2018.1423907

Russo, J., and Beresford, P. (2015). Between exclusion and colonisation: seeking a place for mad people's knowledge in academia. Dis. Soc. Curr. Issues 30, 153-157. doi: 10.1080/09687599.2014.957925

SCIE (2009). Building User And Carer Involvement In Social Work Education, At A Glance 19. London: Social Care Institute for Excellence.

Shaping Our Lives (2018). Open Letter to the Organisers of the Global Ministerial Mental Health Summit, 9-10 October 2018. London: Shaping Our Lives. Available online at: http://bit.ly/2A1xtDu accessed 31 October 2018.

Sheffield, R., and Rector, R. (2014). The War On Poverty After 50 Years. The Heritage Foundation. Available online at: https://www.heritage.org/povertyand-inequality/report/the-war-poverty-after-50-years.

Smith, H. L. (2014). The British Women's Suffrage Campaign 1866-1928. London: Routledge.
Staley, K. (2009). Exploring Impact: Public Involvement in NHS, Public Health and Social Care Research, October. Eastleigh: NIHR INVOLVE.

Staniszewska, S., Denegri, S., Bagley, H., Hickey, G., and Morley, R. (2018). Moving Forward With Global Patient and Public Involvement in Research, Cochrane Community Blog, Cochrane Community. Available online at: https:// community.cochrane.org/news/moving-forward-global-patient-and-publicinvolvement-research.

Titmuss, R. M. (1968). Commitment to Welfare. London: George Allen and Unwin.

Todd, M. J., and Taylor, G. (eds.). (2004). Democracy and Participation: Popular Protest and New Social Movements. London: Merlin Press.

Topol, E. J. (2015). The Patient Will See You Now: The Future of Medicine Is in Your Hands. New York, NY: Basic Books.

Tritter, J. Q., and McCallum, A. (2006). The snakes and ladders of user involvement: moving beyond arnstein. Health Policy 76, 156-168. doi: 10.1016/j.healthpol.2005.05.008

Wilcox, D. (1994). The Guide to Effective Participation. York: Joseph Rowntree Foundation.

Williams, F. (1989). Social Policy: A Critical Introduction, Issues of Race, Gender and Class. Cambridge: Polity Press.

Williams, M. (2004). Discursive democracy and new labour: five ways in which decision-makers manage citizen agendas in public participation initiatives. Sociol. Res. 9, 1-17. doi: 10.5153/sro.949

Yiannoullou, S. (2018). Chief Executive, National Survivor User Network, Reporting on NSUN Survey. London: Personal Communication.

Conflict of Interest Statement: The author declares that the research was conducted in the absence of any commercial or financial relationships that could be construed as a potential conflict of interest.

Copyright (C) 2019 Beresford. This is an open-access article distributed under the terms of the Creative Commons Attribution License (CC BY). The use, distribution or reproduction in other forums is permitted, provided the original author(s) and the copyright owner(s) are credited and that the original publication in this journal is cited, in accordance with accepted academic practice. No use, distribution or reproduction is permitted which does not comply with these terms. 


\section{Plain English Summary \\ Beware Zombies and Unicorns: Toward Critical Public Patient Involvement in Health Research in a Neoliberal Context}

\section{Mary Madden and Ewen Speed}

In the UK, all research funded by the National Institute of Health Research must demonstrate that it includes a level of patient and public involvement (PPI). In principle, involving patients and members of the public in health research is a great idea. However this focus on PPI has developed in a neoliberal context. This means much health policy is intended to try and get more for less in terms of how much the government spends on healthcare. This can lead to a democratic deficit, where people feel there is a gap between what they want (i.e. what they have paid for through taxes) and what they get (i.e. a reduced level of funding for the NHS). Processes of participation and involvement are often floated as solutions to this democratic deficit. However, they only work as a solution if there is the very real opportunity for the public to directly influence, change or even reverse the policies. It is our view that this is seldom the case in terms of PPI research.

In practice, finding the best way to get PPI done has proved difficult. The actual practice of involving people in research requires researchers and patients and members of the public to make all sorts of moral, ethical and political decisions. Our concern in this paper is that many mainstream approaches skip over these difficult decisions and use a version of PPI that sounds like the solution to all sorts of problems, but fails to address any of the difficulties in doing PPI properly. This can result in PPI becoming a tick box exercise. Similarly many PPI approaches can actually work to exclude people by their failure to think about how the actual processes of participation will work, for example, what would happen if a member of the public disagreed with the clinical professional researcher. All too often PPI involves getting a patient to agree that what the researchers are doing is good, sound, ethical etc. In our view, it is far too seldom that patients and publics are asked to actually contribute to the design of research projects. The consequence is that it's then left to people on the ground to make PPI work. Trying to do good PPI becomes something like chasing a unicorn, a hunt for a mythical creature that everyone talks about but has never actually been seen. Yet, despite the fact that good PPI appears almost mythical, it fails to disappear or die, rather it continues to stumble through health policy like a zombie. Given this lack of success, PPI can often feel like a lot of 'busywork' and box-ticking. This means the opportunity to make a real difference to health research, through the development of real and meaningful forms of PPI, gets lost.

We are in a time when people don't trust 'experts'. There is money to be made and vested interests in health care and health research. There are big inequalities in health. If involving people in health care research is really to make a difference to people's health, then we need to learn what works best. In this paper we consider some of the problems with the current system, paying critical attention to what is being done and why. We also consider some alternative approaches, which may allow more meaningful participation from a range of different people (members of the public, patients and healthcare practitioners).We conclude with an insistence that PPI is in principle a fantastic idea, but in practice, it needs to be re-thought so that real and meaningful processes of engagement and change can be developed. Otherwise, PPI will remain a zombie policy, unthinking and uncritical with its real potential undiscovered, almost mythical. 


\title{
Beware Zombies and Unicorns: Toward Critical Patient and Public Involvement in Health Research in a Neoliberal Context
}

\author{
Mary Madden ${ }^{1 *}$ and Ewen Speed ${ }^{2 *}$ \\ Faculty of Medicine and Health, School of Healthcare, University of Leeds, Leeds, United Kingdom, \\ ${ }^{2}$ School of Health and Human Sciences, University of Essex, Colchester, United Kingdom
}

\section{OPEN ACCESS}

Edited by:

Tiago Correia,

ISCTE - University Institute

of Lisbon, Portugal

Reviewed by:

Guido Giarelli,

Magna Græcia University, Italy Maria Berghs,

De Montfort University, United Kingdom

${ }^{*}$ Correspondence: Mary Madden m.t.madden@leeds.ac.uk; Ewen Speed

esspeed@essex.ac.uk

Specialty section: This article was submitted to Medical Sociology, a section of the journal

Frontiers in Sociology

Received: 22 February 2017 Accepted: 15 May 2017

Published: 02 June 2017

Citation: Madden M and Speed E (2017) Beware Zombies and Unicorns:

Toward Critical Patient and Public Involvement in Health Research in a Neoliberal Context. Front. Sociol. 2:7. doi: 10.3389/fsoc.2017.00007
Patient and public involvement (PPI) in UK National Health Service (NHS) research has become an imperative in policy and practice. However, lack of clarity on what PPI is (or might be) has given rise to a poorly monitored, complex field of activity, variously framed by the expectations of policy makers, funders, host organizations, researchers, health professionals, individual recruits, volunteers, activists, and third sector organizations. The normative shift toward PPI has taken place within a neoliberal policy context, the implications of which needs to be explicitly considered, particularly after the Brexit referendum which has left policy makers and researchers wondering how to better appeal to a distrustful public subjected to "post-truth" and "dog whistle" politics. This commentary examines the prospects for a more critical approach to PPI which addresses context, is evidence-informed and mindful of persistent inequalities in health outcomes, at a time when models of PPI in NHS health research tend to be conceptually vague, derived from limited clinical and managerial settings, and centered on a construction of the abstract, rational, compliant, and self-managing patient or layperson.

Keywords: patient and public involvement, public participation, evidence-informed health care, health inequalities, neoliberalism

\section{INTRODUCTION}

Patient and public involvement (PPI) in health research can be spontaneous or planned, invited or sponsored, with citizens engaging in a range of ways, from being compliant data gatherers, sources of data or legitimization, to user leaders and makers of challenging theory (Wehling et al., 2015). At its best, PPI may have the potential for increased democratic accountability, for improving health outcomes, and for addressing the social determinants of health, through for example, improved understanding of different cultures of research and engagements with evidence. At its worst, however, PPI runs the risk of being insignificant, tokenistic, and overly managerialist.

As promissory technoscientific innovations change the organization and practices of contemporary biomedicine, health research is becoming an increasingly complex field of patient expectations, financial incentives, and medical-legal concerns. More research and more medicine are not necessarily leading to more health (Godlee, 2015). If the aim of clinical research is to improve patient care, clinical trials should evaluate the outcomes that most reflect real-world settings and concerns (Heneghan et al., 2017). However, most continue to ignore patient-centered outcomes (Ioannidis, 2016). In the light of these concerns, there has been a growing concern to include patients and other 
stakeholders in the health research process (from topic selection through to the dissemination and implementation of results) on the premise that this will produce more trustworthy and useable information, which is more likely to be taken up in health-care practice.

In the US, the Patient-Centered Outcomes Research Institute has been established as an independent non-profit, nongovernmental organization to improve the quality and relevance of evidence available and so aid better-informed health decisions. ${ }^{1}$ The European Patients' Academy (EUPATI) is a pan-European project of the Innovative Medicines Initiative, which works to involve patients in medicines research and development. ${ }^{2}$ EUPATI is led by The European Patients' Forum with partners from patient organizations, universities, not-forprofit organizations, and pharmaceutical companies. In the UK, the non-profit making organization, the James Lind Alliance (JLA), which supports priority setting partnerships of patients, carers, and health-care professionals affected by a health-care condition, has become a partner organization of the National Institute for Health Research (NIHR). ${ }^{3}$ The JLA has its origins in the evidence-informed health-care movement rather than formal National Health Service (NHS) and NIHR PPI policy or patient/service user movements and has had limited engagement with industry in its processes because commercial interests may not align with scientific or public interests. The NIHR itself was created in 2006 and is funded by the Department of Health "to improve the health and wealth of the nation through research" (Department of Health Research and Development Directorate, 2006). INVOLVE, established as "Consumers in Research" in 1996, is funded by the NIHR to support, "active public involvement in NHS, public health and social care research"; in 2015, they headed a strategic review of public involvement in the NIHR (INVOLVE, 2015a).

In the last decade, PPI in UK NHS research has become a requisite condition for securing funding. The involvement imperative has led to an increase in the levels of PPI activity, but it is not yet the case that, "involvement is a mainstream activity that sits alongside other policy and performance requirements in the NHS" (Ocloo and Fulop, 2011; Crowe and Ceinwen, 2016). Furthermore, the empirical evidence-base demonstrating the worth and impact of PPI remains poor, with supporting evidence tending to be descriptive rather than evaluative (Brett et al., 2010; Wilson et al., 2015). Consequently, there is a lack of consensus about what effective PPI in research processes might look like and how to develop and maintain such processes over time. There are many localized case studies examining PPI in research and service delivery but little conclusive evidence about the best (or worst) ways to invoke PPI in research design, research practice, or research commissioning. The extent to which policy support for PPI in health research results in any actual influence on health research agendas also remains unclear (Madden and Morley, 2016).

\footnotetext{
${ }^{1}$ http://www.pcori.org.

${ }^{2}$ https://www.eupati.eu.

${ }^{3}$ http://www.jla.nihr.ac.uk.
}

This commentary is a provocation stemming from a concern that the investment of time and resources in much mainstream UK PPI in applied health research is taking a form of "busywork," i.e., a time-consuming technocratic distraction. Ironically, the notion of the usefully participating, evidence-engaged patient or citizen has become ubiquitous at the same time as ignorance (McGoey, 2012) and "bullshit" (Frankfurt, 2005) have been successfully harnessed as resources in "post-truth" politics. Simultaneously, UK health policy is being subordinated to the demands of the market while socialized health care is subjected to forces of marketization and privatization (Whitfield, 2012). The NHS has been radically reorganized and spending on key determinants of health has fallen as a result of postcrash austerity policies.

\section{THE UK IMPERATIVE FOR PPI}

A recent statement from NHS England on the benefits of patient and public participation in NHS services makes grand claims for the participatory potential of PPI.

We encourage patient and public participation in the NHS, treat them respectfully and put their interests first. This allows us to develop the insight to help us improve outcomes and guarantee no community is left behind or disadvantaged (NHS England, 2015).

These aspirations draw impetus from the need to respond to scandals reported in the Francis (2013) review and Berwick (2013) report. They are laudable, but declarations such as this acknowledge none of the messy history and complexity of PPI and democratic politics or the power imbalances therein. There is no guarantee that participation "per se" improves outcomes or addresses the causes or effects of disadvantage. This statement conflates aims with achievements via the assertion that everyone is treated with respect and that this somehow puts the apparently complementary interests of patients and publics first, without any competing interests from the professions, third sector or even private sector actors, never mind the state.

In terms of the PPI expectations of key UK research bodies, the NHS Health Research Authority (2013) stipulates that by public involvement it means:

... a range of activities that enable patients and the public to have a say in decisions about the way health research is planned, designed, delivered, developed, evaluated, managed and regulated. It also means where patients and the public are actively involved in the conduct of research studies (p. 12).

Similarly, the NIHR (currently seen as a PPI leader in an international context-INVOLVE, 2014), states that PPI in research is, "an important part of the research that we fund as well as being part of our research commissioning and management processes. We expect researchers to actively involve the public in their research" (National Institute for Health Research, 2015). The 
NIHR clarify that, in talking about the "public," they draw from the definition offered by INVOLVE (2015b) to include, "patients, potential patients, carers, and people who use health and social care services as well as people from organizations that represent people who use services." INVOLVE defines public involvement as research being carried out "with" or "by" members of the public rather than "to," "about," or "for" them.

Researchers applying for NIHR research funding must therefore design PPI strategies into their research proposals, which may variously facilitate the involvement and engagement of the public, patients, potential patients, carers, service users, and representative bodies, in ways that will positively influence some or all of the planning, design, delivery, development, evaluation, management, and regulation of research. Consider the complexity involved in the social relations across this range of actors and the potential range of different vested interests. Consider also the relative degrees of power and influence that different actors might have within and across these groups. As part of review panels for these research bids, the strength of PPI in submitted research proposals is commented on by individuals appointed as lay PPI experts. If the approaches described by researchers are considered weak, there is little room for feedback to applicants about how to improve (Crowe and Ceinwen, 2016). The outcome of this field of self-definition and complexity is a wide range of PPI activity with various models of patients and public as citizens, consumers, partners in their own care and co-researchers, involving a plethora of potentially conflicting values (Gradinger et al., 2015). The problematic conflation and elision of distinctions between patients and the public identified in health-care service decision-making (Fredriksson and Tritter, 2017) requires further investigation in the field of PPI in health research.

All of which raises a question of why, despite this ongoing lack of clarity about its practices, processes, and means of evaluation, has this drive for PPI in UK health research become ubiquitous? The PPI imperative can be seen as part of a wider "participatory shift" in policy which encourages citizens to participate in democratic decision-making by actively contributing as partners, collaborators, and consultees in political processes (Petersen and Lupton, 1996). This mirrors broader international shifts away from models of "government" toward models of "new public governance," informed by a perceived need to address a purported "democratic deficit," as established representative democracies were criticized for failing to match citizens' aspirations for democracy (Norris, 2011). This shift signaled a move from a position that saw involvement, "in relation to people as citizens with rights to receive public services and responsibilities to be involved in their development and accountability," toward a more consumerist model, "in which the relationship is between the layperson and a particular service or organisation" (Taylor, 2007). Moves toward PPI may speak to the perceived democratic deficit, but PPI continues to be so conceptually and theoretically vague that it can mean anything (and nothing) and serve a variety of purposes. In a competitive health research market, prioritizing the perspectives of consumers directly affected by certain conditions has wider implications for public health and public resource distribution. Certain conditions affecting some consumer/citizens currently get lots of research attention and resources while other (more common conditions) get little (Ioannidis, 2016).

\section{TYPOLOGIES OF PPI}

Different models of PPI carry distinctive and sometimes contradictory assumptions about the types of public to be involved, the knowledge those publics might bring to bear, and their degree of involvement in decision-making processes. Ives et al. (2013) in questioning, "whether the concept/practice of PPI is internally coherent" (p. 181), identify two broad sets of motivations for PPI. The first is a pragmatic and outcome orientated type of PPI which positively impacts on the "quality of research processes and outputs, and promotes more reliable, relevant research" (p. 181). The second is a more ideological, rights-based type of PPI which, "draws on broader social and ethical narratives around democratic representation, transparency, accountability, responsibility and the redressing of power imbalances," (p. 181). Ives et al. set up a dichotomy between a pragmatic, transactionbased model, and a more ideological, process-orientated model, arguing that if lay people become too expert at carrying out research they will jeopardize their "genuine" lay status. The implication is that public involvement should be confined to funding decisions, prioritization of research agendas, research governance, and ethical review, where "layness" is the required asset.

Knaapen and Lehoux (2016) similarly find confusion and contradiction in the underlying principles guiding PPI in clinical standard setting. They categorize arguments in favor of PPI into three main types. These are first, a theoretical case for citizen participation premised on notions of individual rights, civic responsibility, social justice, and political accountability (a democratic voice model of PPI); second, a consumerist argument for involving autonomous consumers in personalizing clinical care (a consumer choice model); and third, an argument which claims that experiential knowledge from those affected improves health research (a lay expertise model). There is a clear overlap across these three types, but also, each has a somewhat different conception of the use and utility of PPI, which at times, pull the constituent PPI actors in opposite directions. For example, consider the impossibility of trying to reconcile a consumer choice model of PPI with the altruism and surrendering of choice required of those being asked to take part in randomized controlled trials as research subjects. Ethical standards dictate that patients and clinicians should not consent to randomization unless there is uncertainty about whether any of the treatment options in a trial offers greater harm or benefit than any other. However, explaining the uncertainty principle is challenging (Madden and Morley, 2016) and there is some evidence of "therapeutic misconception," where, despite explanation, participants maintain the view that taking part in research is to benefit them directly rather than to test or compare treatment methods and resolve uncertainty (Appelbaum et al., 1987). As Dean (2017) points out, the empowered self-interest of the neoliberal consumer-citizen is somewhat at odds with the, "other-oriented, reasoning-citizen of deliberative democracy," (p. 2). 
This tension is something that Dean (2017) attempts to address by proposing a new typology of public participation (involvement) in policy decisions. In this model, Dean identifies two intersecting dimensions that underpin all PPI activity, a dimension of sociality and a dimension of negotiability. The sociality dimension is the extent to which PPI activities are agonistic or solidaristic. Agonistic participation is “...conflictual with individuals and groups predominantly concerned with promoting and defending their own interests and values against other participants," (p. 4). Solidaristic participation is where, "participants view themselves as interdependent members of a social collective and participation is oriented towards collective ends and the common good," (p. 5). In negotiated participatory spaces, the conditions of participation are determined by the participants themselves, as part of the process. In prescribed participatory spaces, issues of who participates and how they do so, "are determined outside of the space (perhaps by the commissioning organisation, perhaps by circumstance) and imposed upon the participants, who thus have little scope to determine the conditions of their participation," (p. 5).

For Dean, different modes of participation are reflective of changing notions of the form and function of the state, combined with, "characteristic participatory practices and conceptions of the citizen" (p. 14). Dean does not propose this model as a schema for characterizing all forms of participation, but the notion of dimensionality is useful as a means for identifying specific tropes, processes, and practices that might play out across PPI activity. Dean's dimensional approach enables us to make sense of the inherent tensions between consumer choice models of PPI versus lay expertise and democratic models, allowing us to begin to understand how these contradictory and indeed conflictual models can exist and persist in the same field at the same time. For example, the JLA approach moves beyond the aggregation of individual/patient concerns to include the prioritization of research through deliberation but within a narrow topic focus and only from the perspective of those directly affected (and relevant health professionals). Wider societal perspectives, including inequities in what attracts most research attention and how public resources are allocated among competing interests are outside its scope (Cullum et al., 2016).

\section{APPLYING TYPES OF PPI}

Limited engagement with its own history and the skills, experience and evidence-base outside the narrow disciplinary boundaries of health sciences fuels a sense that mainstream NHS and NIHR PPI initiatives constantly reinvent the wheel (INVOLVE, 2015a). For example, social movements, charities, and non-governmental organizations have invented and experimented with a range of participatory mechanisms (including user-controlled research and service provision) to bring together citizens and experts in new forms of cooperative inquiry. These have often been critical of established policy and political contexts and have employed a range of participatory techniques intended to strengthen civil society while also problematizing how participation works (e.g., Cooke and Kothari, 2001). In this context, PPI can be seen as a field of solidaristic, non-governmental public-spirited experimentation, much of it located in the memories and documentary traces of citizens and activists whose attempts at an informal type of PPI often get overlooked and "forgotten" within formal, more individualistic PPI processes.

Formal PPI policy initiatives proliferate alongside a huge growth in the amount of health research funded and published, although, "there is little to suggest increased outputs have led to real improvements in patient care" (Heneghan et al., 2016). Despite the rise of the evidence-based medicine movement, Maynard (2012) argues that UK health care is still (and perhaps more than ever) an arena of faith-based policy making. For Bambra (2013), "politics has primacy" in policy making regardless of the rhetorical emphasis on evidence. Yet, thorny issues of politics and power are backgrounded in the resulting dominant individualistic, politely agonistic forms of participation, meaning that insufficient attention is paid to connections between clinical (bio-medical) and public (social) health contexts.

\section{ARNSTEIN REDUX?}

Arnstein's (Arnstein, 1969) much-cited ladder of participation clearly equates participation (involvement) with the power of citizens to make decisions. It has been both influential and controversial (see Tritter and McCallum, 2006). Dean (2017) characterizes Arnstein as having an activist's view of participation, as, "insurgency against government power" and indeed as a redistribution of power (p. 2). Certainly, Arnstein is clear that there is a critical difference between going through the empty ritual of participation/involvement and having the real power needed to affect the outcome of the process. Participation without redistribution of power is an empty and frustrating process, "it allows the powerholders to claim that all sides were considered, but makes it possible for only some of those sides to benefit. It maintains the status quo..." (p. 217). The political implications of contemporary PPI, when and if they are discussed, tend to be couched in "moral" rather than redistributive terms (Wilson et al., 2015). Arnstein's view resonates with the hubristic statement from NHS England above and with Wilson et al's (Wilson et al., 2015) findings that patients involved in health research are most often involved in steering committees with uncertain powers to steer or in reviewing participant information leaflets.

This is not to say Arnstein's work is without criticism. She was the first to point out why her ladder, "obviously... a simplification" (p. 217), should be used to generate discussion rather than as an off the peg "tool” or model. However, Arnstein's depiction does offer a contra view to current contexts, where public policy issues are increasingly presented as arising from aggregated individual choices made in a marketplace rather than the outcome of structural or political arrangements. Formal NHS PPI processes draw from an under-socialized view of a consumerist subject constituted within a transactional and individualistic participatory paradigm, which leaves matters of public value as free floating arbitrary ideas to be determined by individual choice. The potential for the conflictual nature of democratic politics is underplayed, as the nature of the public good is reduced to a matter of personal preference and individual experience. In 
this context, PPI "experts by experience" are in danger of being reduced to another commodity, as an opportunity for professionals to consume affective individual testimony without the need to engage with wider publics or more contextualized forms of research. Narratives of experience are structured, performative, means of understanding, and persuasion, not an unproblematic means of transparent access to truth. Those asked to narrate their experience are subject to the quest for particular forms of expert, but not too expert, experience (Martin, 2008; Thompson et al., 2012; Snow, 2016).

\section{CONCLUSION}

It is in this context that we assert that PPI operates as an empty signifier, intermittently populated with whatever policy ideas of citizen engagement are a la mode (Stewart, 2012). Maynard (2012) depicts contemporary health policy making as Nirvania, a land of faith inhabited by zombies and unicorns. This draws on Evans et al.s (Evans et al., 1994) characterization of zombie ideas as, "intellectually dead but...never buried," because they, "offer a simple and intuitively appealing 'solution' to a complex and urgent policy problem," (p. 1). Applying Maynard's (Maynard, 2012) Nirvanian terminology, formal PPI can be seen as a ghastly composite of a zombie policy that continually pops up, offering (but never providing) a solution to purported deficits in democratic engagement, despite being useless in the last policy round, and a unicorn policy, a mythical beast, prevalent, and much discussed but never discovered in replicable form in any health-care system. This zombie/unicorn hybrid creates PPI as a form of busywork in which the politics of social movements are entirely displaced by technocratic discourses of managerialism.

Meanwhile, patients are becoming competitive consumers for public and private funds as neoliberal policy delegates ever more of the state's functions to capital, transforming the value of the public good to the benefit of private individuals. PPI is part of a

\section{REFERENCES}

Appelbaum, P., Roth, L., Lidz, C., Benson, P., and Winslade, W. (1987). False hopes and best data: consent to research and the therapeutic misconception. Hastings Cent. Rep. 17, 20-24. doi:10.2307/3562038

Arnstein, S. R. (1969). A ladder of citizen participation. J. Am. Inst. Plann. 35, 216-224. doi:10.1080/01944366908977225

Bambra, C. (2013). The primacy of politics: the rise and fall of evidence-based public health policy? J. Public Health 35, 486-487. doi:10.1093/pubmed/fdt113

Berwick, D. (2013). A Promise to Learn - A Commitment to Act: Improving the Safety of Patients in England. London: Department of Health.

Brett, J., Staniszewska, S., Mockford, C., Seers, K., Herron-Marx, S., and Bayliss, H. (2010). The PIRICOM Study: A Systematic Review of the Conceptualisation, Measurement, Impact and Outcomes of Patients and Public Involvement in Health and Social Care Research. Warwick: University of Warwick.

Cooke, B., and Kothari, U. (2001). Participation: The New Tyranny? London: Zed Books.

Crowe, S., and Ceinwen, G. (2016). Making patient relevant clinical research a reality. BMJ 355, i6627. doi:10.1136/bmj.i6627

Cullum, N., Buckley, H., Dumville, J., Hall, J., Lamb, K., Madden, M., et al. (2016). Wounds research for patient benefit: a 5-year programme of research. Programme Grants Appl. Res. 4, 303. doi:10.3310/pgfar04130

Dean, R. (2017). Beyond radicalism and resignation: the competing logics for public participation in policy decisions. Policy Polit. 45, 213-230. doi:10.1332/ 030557316X14531466517034 wider politics of knowledge in which patient groups, clinicians and universities are co-opted into a corporatized health research agenda (Gabe et al., 2012). Involvement should be about populations engaging in the decisions that impact their lives, identifying opportunities and strategies for action. Being "critically involved" requires acknowledging processes of situated contestation rather than epistemic authority, identifying varieties of publics and the contingency and complexity of the construction of evidence. The ongoing narrow technocratic co-option of PPI is not grounds for yet more cynicism but for a renewed skepticism that actively seeks evidence and understanding of the fields of power within which health equity and meaningful participation for transformative health and social change lie. For example, it might be useful for patients and the public interested in health research to know more about the difficulty of producing health research which addresses meaningful clinical and public health outcomes. Despite the technocratic ratcheting up of expectations and claims for impact, many experts by experience of research acknowledge that most clinical research is not useful and is in need of reform (Ioannidis, 2016), that the EBM "quality mark" has been misappropriated by vested interests (Greenhalgh et al., 2014) and that while the UK has been recognized as a global leader in research and policy on health inequalities, these inequalities continue to widen leaving some researchers feeling that all they are doing is counting the bodies (Garthwaite et al., 2016). PPI offers the opportunity to help address some or all of these failings, but not if context and history continue to be ignored and there is failure to properly evaluate because we are off chasing the Nirvanian zombie/unicorns that spring from the landscape of NHS redisorganization (c.f., Oxman et al., 2005).

\section{AUTHOR CONTRIBUTIONS}

Both authors have contributed equally to the production of this manuscript.

Department of Health Research and Development Directorate (2006). Best Research for Best Health. A New National Health Research Strategy. Available at: https://www.gov.uk/government/uploads/system/uploads/attachment_data/ file/568772/dh_4127152_v2.pdf

Evans, R., Barer, M., Stoddart, G., and Bhatia, V. (1994). Who Are the Zombie Masters and What Do They Want? BC, Canada: University of British Columbia.

Francis, R. (2013). Report of the Mid Staffordshire NHS Foundation Trust Public Inquiry. London: Crown Copyright.

Frankfurt, H. (2005). On Bullshit. Oxfordshire: Princeton University Press.

Fredrikkson, M., and Tritter, J. (2017). Disentangling patient and public involvement in healthcare decisions: why the difference matters. Sociology of Health and Illness. 39, 95-111. doi:10.1111/1467-9566.12483

Gabe, J., Chamberlain, K., Norris, P., Dew, K., Madden, H., and Hodgetts, D. (2012). The debate about the funding of Herceptin: a case study of 'countervailing powers'. Soc. Sci. Med. 75, 2353-2361. doi:10.1016/j.socscimed.2012.09.009

Garthwaite, K., Smith, K. E., Bambra, C., and Pearce, J. (2016). Desperately seeking reductions in health inequalities: perspectives of UK researchers on past, present and future directions in health inequalities research. Sociol. Health Illn. 38 , 459-478. doi:10.1111/1467-9566.12374

Godlee, F. (2015). Too much medicine. BMJ 350, h1217. doi:10.1136/bmj.h1217

Gradinger, F., Britten, N., Wyatt, K., Froggatt, K., Gibson, A., Jacoby, A., et al. (2015). Values associated with public involvement in health and social care research: a narrative review. Health Expect. 18, 661-675. doi:10.1111/hex.12158

Greenhalgh, T., Howick, J., and Maskrey, N. (2014). Evidence based medicine: a movement in crisis? BMJ 348, g3725. doi:10.1136/bmj.g3725 
Heneghan, C., Goldacre, B., and Mahtani, K. (2017). Why clinical trial outcomes fail to translate into benefits for patients. Trials 18, 122. doi:10.1186/ s13063-017-1870-2

Heneghan, C., Mahtani, K., Goldacre, B., Godlee, F., Macdonald, H., and Snow, R. (2016). EBM Manifesto. Available at: http://evidencelive.org/manifesto/V1.5

INVOLVE. (2014). NIHR Senior Investigators: Leaders for Patient and Public Involvement in Research. Eastleigh: INVOLVE.

INVOLVE. (2015a). What Is Public Involvement in Research? Available at: http:// www.invo.org.uk/find-out-more/what-is-public-involvement-in-research-2

INVOLVE. (2015b). Going the Extra Mile: Improving the Nation's Health and Wellbeing through Public Involvement in Research. Eastleigh: INVOLVE.

Ioannidis, J. (2016). Why most clinical research is not useful. PLoS Med 13, e1002049.

Ives, J., Damery, S., and Redwod, S. (2013). PPI, paradoxes and Plato: who's sailing the ship? J. Med. Ethics 39, 181-185. doi:10.1136/medethics-2011100150

Knaapen, L., and Lehoux, P. (2016). Three conceptual models of patient and public involvement in standard-setting: from abstract principles to complex practice. Sci. Cult. 25, 239-263. doi:10.1080/09505431.2015.1125875

Madden, M., and Morley, R. (2016). Exploring the challenge of health research priority setting in partnership: reflections on the methodology used by the James Lind Alliance Pressure Ulcer Priority Setting Partnership. Res. Involvement Engagement 2, 12. doi:10.1186/s40900-016-0026-y

Martin, G. (2008). 'Ordinary people only': knowledge, representativeness, and the publics of public participation in healthcare. Sociol. Health Illn. 30, 35-54. doi:10.1111/j.1467-9566.2007.01027.x

Maynard, A. (2012). The Maynard doctrine: the chronicles of Nirvania, home of unicorns and zombies. Health Policy Insight. Available at: http://www.healthpolicyinsight.com/?q=node/1433

McGoey, L. (2012). Strategic unknowns: towards a sociology of ignorance. Econ. Soc. 41, 1-16. doi:10.1080/03085147.2011.637330

National Institute for Health Research. (2015). Patient and Public Involvement. Available at: https://www.nihr.ac.uk/patients-and-public/

NHS England. (2015). About NHS England. Available at: https://data.england.nhs. uk/organization/about/nhs-england

NHS Health Research Authority. (2013). Strategy for Public Involvement. Available at: http://www.hra.nhs.uk/documents/2013/10/hra-public-involvement-strategycirculation-september-2013.pdf

Norris, P. (2011). Democratic Deficit: Critical Citizens Revisited. Cambridge: Cambridge University Press.

Ocloo, J., and Fulop, N. (2011). Developing a 'critical' approach to patient and public involvement in patient safety in the NHS: learning lessons from other parts of the public sector? Health Expect. 15, 424-432. doi:10.1111/j.1369-7625.2011.00695.x

Oxman, A., Sackett, D., Chalmers, I., and Prescott, T. (2005). A surrealistic mega-analysis of redisorganization theories Journal of the Royal. Soc. Med. 98, 563-568. doi:10.1258/jrsm.98.12.563

Petersen, A., and Lupton, D. (1996). The New Public Health: Health and Self in the Age of Risk. London: SAGE.

Snow, R. (2016). What makes a real patient? BMJ Blogs. Available at: http://blogs. bmj.com/bmj/2016/07/19/rosamund-snow-what-makes-a-real-patient

Stewart, E. (2012). Governance, Participation and Avoidance: Everyday Public Involvement in the Scottish NHS. Edinburgh: University of Edinburgh.

Taylor, P. (2007). "The lay contribution to public health," in Public Health for the 21st Century: Policy, Participation and Practice, 2nd edn, eds J. Orme, M. Grey, T. Harrison, J. Powell, and P. Taylor (Berkshire: Open University Press/ McGraw Hill Education), 100-101.

Thompson, J., Bissell, P., Cooper, C., Armitage, C., and Barber, R. (2012). Credibility and the 'professionalized' lay expert: reflections on the dilemmas and opportunities of public involvement in health research. Health 16, 602-618. doi:10.1177/1363459312441008

Tritter, J., and McCallum, A. (2006). The snakes and ladders of user involvement: moving beyond Arnstein. Health Policy 76, 156-168. doi:10.1016/j. healthpol.2005.05.008

Wehling, P., Viehöver, W., and Koenen, S. (2015). The Public Shaping of Medical Research: Patient Associations, Health Movements and Biomedicine. Abingdon Oxon: Routledge.

Whitfield, D. (2012). In Place of Austerity: Reconstructing the Economy, State and Public Services. Nottingham: Spokesman.

Wilson, P., Mathie, E., Keenan, J., McNeilly, E., Goodman, C., Howe, A., et al. (2015). ReseArch with patient and public invOlvement: a realisT evaluation the RAPPORT study. Health Serv. Deliv. Res. 3, 38. doi:10.3310/hsdr03380

Conflict of Interest Statement: The authors declare that the research was conducted in the absence of any commercial or financial relationships that could be construed as a potential conflict of interest.

Copyright (C) 2017 Madden and Speed. This is an open-access article distributed under the terms of the Creative Commons Attribution License (CC BY). The use, distribution or reproduction in other forums is permitted, provided the original author(s) or licensor are credited and that the original publication in this journal is cited, in accordance with accepted academic practice. No use, distribution or reproduction is permitted which does not comply with these terms. 


\section{Plain English Summary}

\section{The possibilities and limits of co-producing research}

\section{Jonathan Paylor \& Christopher McKevitt}

There is increasing enthusiasm for the idea of co-produced research. The National Institute of Health Research - a major funder of research - has recently adopted the term co-production to refer to the involvement of patients and the public in research. In this paper, we explore some of the reasons for this change, as well as some potential consequences.

We argue that this interest in co-production is driven by concerns that existing methods of involving patients and the public in research are limited and have not resulted in greater involvement. For example, many have suggested that involvement in research is often 'tokenistic'; and that it has not changed the power imbalances between researchers and the public. We then go on to argue that shortcomings in public involvement in research need to be understood in relation to a range of social, economic and political factors. These factors are deep-seated and just as they have shaped 'involvement' in research, they will also shape how co-production is interpreted and put into practice.

To conclude, we suggest that the adoption of the term 'co-production' will not necessarily lead to the collaborative forms of public involvement that funders and patients and members public wish to see. 


\section{OPEN ACCESS}

Edited by:

Annette Louise Boaz,

Kingston University, United Kingdom

Reviewed by:

Rachel Matthews,

National Institute for Health Research

(NIHR), United Kingdom

Doreen Tembo

University of Southampton,

United Kingdom

${ }^{*}$ Correspondence:

Christopher McKevitt

christopher.mckevitt@kcl.ac.uk

Specialty section:

This article was submitted to

Medical Sociology,

a section of the journal

Frontiers in Sociology

Received: 31 October 2018 Accepted: 14 March 2019

Published: 05 April 2019

Citation:

Paylor J and McKevitt C (2019) The

Possibilities and Limits of

"Co-producing" Research.

Front. Sociol. 4:23

doi: 10.3389/fsoc.2019.00023

\section{The Possibilities and Limits of "Co-producing" Research}

\author{
Jonathan Paylor and Christopher McKevitt* \\ School of Population Health and Environmental Sciences, King's College London, London, United Kingdom
}

In this perspective paper, we explore the growing enthusiasm for "co-produced" research, focusing in particular on the United Kingdom's National Institute for Health Research's (NIHR) recent adoption of the term co-production. We consider how this interest in co-production is driven by concerns that patient and public involvement (PPI) in health research tends to be "tokenistic" and to reproduce power imbalances between researchers and lay contributors. We argue that these apparent implementation "barriers" or "inconsistencies" need to be understood in relation to the various elements that the institutionalisation of PPI brings together. We show how these elements are articulated in such a way that consumer, managerial, and performative logics and practices are dominant, resulting in limits being placed on the scope and forms of PPI, and the emergence of acts of recalcitrance and impression management. By considering the alternative discursive repertoires made available through co-production, we point to the possibilities co-production presents for moving beyond these dominant tendencies. We argue, however, that such possibilities need to be understood in relation to the constraints of the present. In doing so, we draw attention to the tenacity of the articulations that have historically constituted the institutionalisation of PPI.

Keywords: co-production, public participation, knowledge production, articulation, impact, knowledge economy, performativity, consumerism

\section{INTRODUCTION}

Indicative of a heightened interest in promoting participatory approaches to knowledge production, the term "co-production" has recently entered the lexicon of research funders in the United Kingdom (Bell and Pahl, 2017). The UK's National Institute for Health Research (NIHR) is one funder that appears to be particularly enthused by co-production. In Going the Extra Mile (NIHR, 2015a), co-production is placed at the heart of the NIHR's plans to "improve" public participation in health research [what the NIHR have traditionally referred to as "patient and public involvement" (PPI)]. As the emphasis on "sharing of power" (Hickey et al., 2018, p. 7) indicates, the NIHR frames co-production as offering a more collaborative and egalitarian mode of involvement than that of conventional PPI approaches. In this perspective paper we ask whether the embracement of co-production will translate into the enhanced forms of involvement the NIHR speaks of. To do so, we draw on insights from an analysis of relevant policy and practice guidance documents as well-previous ethnographic work (Fudge et al., 2008; McKevitt et al., 2010; Komporozos-Athanasiou et al., 2016).

Our starting point is to examine the potential reasons for the NIHR's enthusiastic adoption of co-production. We suggest that in part this stems from concerns about PPI being "tokenistic" and power remaining firmly in the hands of researchers. In seeking to counter previous literature 
which suggests that these implementation "barriers" or "inconsistencies" are simply down to the negative attitudes or inabilities of researchers, we bring to the fore the contextual conditions of their existence. We do so by exploring how the institutionalisation of PPI is articulated (Slack, 1996) in such a way that consumer, managerial and performative logics and practices are dominant. We show how this entails limits being placed on the scope and form of PPI and the emergence of acts of recalcitrance and impression management. By considering the alternative discursive repertoires made available through co-production, we point to the possibilities co-production presents for moving beyond these dominant tendencies. We argue, however, that such possibilities need to be understood in relation to the constraints of the present. Here we draw attention to the tenacity of the articulations that have constituted the institutionalisation of PPI, arguing that the alternative discursive repertoires offered through co-production are likely to be articulated with and subordinate to the consumer, managerial and performative ways of thinking and acting that have historically imbued PPI.

\section{THE SHORTCOMINGS OF PPI?}

The NIHR's interest in co-production appears to be driven by concerns that existing PPI practice falls short of generating the collaborative forms of involvement that the NIHR and other proponents of PPI seek. While it is reported that there is "much to celebrate" (NIHR, 2015a, p. 15) concerns are expressed about "[i]nconsistencies in practice and implementation and [b]arriers to public contributing to research including negative attitudes and lack of support" (NIHR, 2015a, p. 21). The references to scepticism and paternalism (NIHR, 2015a, p. 37) implies that much of this has to do with the recalcitrance or lack of commitment on the part of researchers. Recommendations to improve infrastructure and support reveal a strategy for overcoming these issues that is broader than co-production alone. Nevertheless, co-production-with its proclaimed ability to "encourage collaboration and underline the value of people's expertise through experience" (NIHR, 2015a, p. 12)-is framed as the potent force that could bring about the necessary change in attitudes and practices and ultimately help to deliver research that improves the "health and wealth of the nation" (NIHR, 2015a, p. 12).

The "authoritative instrumentalism" (Shore and Wright, 2011, p. 4) that underpins the NIHR's approach to PPI is clear to see in Going the Extra Mile. Both PPI and co-production are presented as means to solve a problem and produce a desired outcome. They are also portrayed as "things" to be implemented and managed. This "orthodox" approach to policy also frames much of the literature on PPI, not least in the numerous studies on barriers and enablers, impact and good practice (see, for example, Brett et al., 2014). These texts often place tokenism and other implementation "failures" at the hands of researchers who are reluctant to share power and/or recognise the value of "lay" knowledge. One problem with such accounts is that they tend to instil a narrow view of implementation that filters out the diverse ways in which actors interpret and reconstitute policy and ignores how such processes of "translation" (Clarke et al., 2015) involve struggles over subjectivity and power. Moreover, the contextual conditions of these apparent implementation inconsistencies and failures are seldom reckoned with. As we now move to show, the tensions and antagonisms that surface in PPI practices are not simply the product of negative attitudes nor discordant actors but rather the combination of multiple social forces.

\section{ARTICULATING PPI}

We want to draw attention to three trends and trajectories that are important to understanding how the policy of PPI has been institutionalised and enacted. The first is the rise of consumerism. The figure of the consumer came to prominence following Thatcher's neoliberal public-sector reforms. Key to the mobilisation of these reforms was the notion that the public had to be saved from an overbearing and unresponsive statea motif which saw the government create "synapses" (Clarke et al., 2007, p. 29) between the disaffections and demands of social movements and user groups, and the neoliberal logics of choice and market competition (Cowden and Singh, 2007). New Labour brought a renewed emphasis on public service values and deliberative democracy, heralding a move to animate conceptions of the citizen. It is within this context that a system of "Patient and Public Involvement" was introduced in the NHS and the "Standing Advisory Group on Consumer Involvement in the NHS Research \& Development Programme" was renamed INVOLVE. While such developments have been described as an attempt to "put right the failings of the overtly consumerist approach to involvement" (Martin, 2007, p. 42), the image of the consumer remained a fundamental feature of New Labour's discourse and provided "the central element around which the other, subordinate, elements were articulated" (Clarke et al., 2007. p. 44). More recent reforms relating to PPI came with the Coalition government's Health and Social Care Act (Department of Health, 2012). Patient choice and market competition were at the centre of these reforms, signalling the continual prominence of the consumer figure.

The second is the advancement of "performativity." Predicated on the drive for efficiency and greater productivity, the neoliberal public sector reforms also gave rise to management practices based on individualised incentives and the measurement of performance. Exemplified by the onset of quasi-market mechanisms and quality audits such as the Research Assessment Exercise (RAE) (Elton, 2000), this move toward systems of performativity had a notable bearing on the organisation and governance of universities. Along with the "publish or perish" imperative, one of the consequences of this shift is the increased pressure on academics to secure external research funds. As some have suggested (Chubb and Watermeyer, 2016), a "grants culture" now dominates UK universities as academics strive to remain economically viable and prove their worth through the procurement of funds. The establishment of the NIHR played a notable role in fostering such a grants culture in the health domain. Prior to the NIHR's 
conception, funding was locked into historical allocations to NHS trusts (Shergold and Grant, 2008). Premised on the goals of funding the "best research" and "acting as sound custodians of public money for public good" (Department of Health, 2006), the NIHR centralised this funding and made it available through various competitive funding streams. Crucially, this reorganisation of research funding put PPI further into the limelight as it became a condition of funding and an assessment criterion.

The third is the shift to a global knowledge economy. This transition has seen the UK health research system and the NHS become a central feature in the government's plans to build the nation's knowledge economy, as exemplified by the creation of the NIHR and its vision to improve the "health and wealth of the nation" (Department of Health, 2006). This health and wealth agenda brings together a wide range of elements (including different logics, values, technologies and actors) which are articulated around the aim of speeding up knowledge translation (Adams and McKevitt, 2015; Caffrey et al., 2018). Alongside the push for "stakeholder" involvement (including patients and industry) this move to align health research with the imperatives of a global knowledge economy has resulted in a greater emphasis on biotechnology and microbiological sciences as well as a drive for clinical trials (Shaw and Greenhalgh, 2008).

\section{TENDENCIES IN PPI PRACTICES}

A consideration of these three trends and trajectories starts to uncover the multiple and diverse elements that the policy of PPI and its institutionalisation articulates. The coming together of these different elements complicates readings that simply frame PPI as the product and manifestation of neoliberalism or any other dominant force. Such multiplicity, however, does not mean dominant tendencies do not exist. The various elements that are brought together are "structured in dominance" (Newman and Clarke, 2009, p. 26) and articulated in ways that shape the possibilities for thinking and acting. What we are particularly interested in here is how this offers an insight in to the formation of power differentials and the surfacing of "tokenistic" PPI.

One tendency is the dominance of consumerist or managerialist models of PPI. While the spaces that institutionalisation of PPI generates are diverse and contain possibilities for multiple forms of action, PPI practices tend to reproduce processes of consultation that position the public as individual consumers rather than democratic publics. In such settings, the rationalities of funders and research teams delineate the scope of involvement. This often means that PPI is merely a tool to gather feedback on the relevance and appropriateness of predefined research aims and procedures. Thus, decision-making tends to remain in the hands of researchers, and issues deemed out of scope are side-lined. Moreover, viewed in light of the linkages with systems of performativity and the goal of speeding up knowledge translation, such contained involvement can be seen to embody and instil a mode of public accountability that is narrowly defined in terms of efficiency and cost-effectiveness.
The dominance of consumerist and managerialist models of PPI goes some way to understanding why concerns are expressed about the restricted nature of PPI and the reproduction of power imbalances. It's also important to consider the type of research that the NIHR funds. As exemplified by the "gold standard" of the randomised controlled trial, NIHR-funded research tends to adhere to the tenets of positivism and thereby embed a knowledge hierarchy that privileges scientific expertise over lay understandings. It's no surprise then that the remit of PPI often centres on the appropriateness of trial procedures and materials such as patient information sheets. As valuable as this may be, especially if trial recruitment is a priority (Adams and McKevitt, 2015), it does point to a situation where the various components and phases of a study are controlled and undertaken by researchers. It's also important to consider how the NIHR funds research. Much of the NIHR's funding is allocated on a study-by-study basis and thus feeds into processes of "projectisation" (Newman and Clarke, 2009, p. 150). In this way, PPI often becomes a bounded event which operates in line with the managerial logics of the health research system. Coupled with the temporal pressures of the "accelerated academy" (Carrigan, 2015), we suggest that such time-limited involvement hinders collaboration and sustained dialogue.

The allocation of grants brings us onto how PPI becomes enmeshed in a "grants culture." We want to suggest that making PPI a condition of funding and an assessment criterion has three consequences $^{1}$. Firstly, PPI adds to the multitude of activities that researchers need to perform to maintain and advance their career, generating tensions and acts of recalcitrance or resistance as researchers find themselves having to negotiate different demands and logics. Secondly, PPI is performed to meet the requirements and expectations of funders. This may manifest itself in surface level spectacles or acts of impression management, which are deemed an inevitable part of "playing the game" and securing research funds. Thirdly, PPI destabilises researchers' professional identity, as their enactment of PPI is imposed rather than based on their own judgment. This destabilisation may also be brought on by the undermining of integrity and collegiality that results from needing to succeed in the competitive game of grant-seeking and perform acts of dramaturgy.

These three points bring into further focus the reasons why PPI may be described as "tokenistic." They also cast concerns about sceptical or recalcitrant researchers in a new light. Rather than simply reflecting ingrained paternalist or elitist views, researchers' identifications with traditional conceptions of professionalism may signify an attempt to deal with the destabilisations and costs that are induced through the regimes of performativity that PPI embodies and augments. Such processes of identity formation perhaps reveal a "struggle over subjectivity" and a "politics of refusal" (Ball, 2016); that is to say, the refusal to take up the subject positions made available through discourses of performativity. To be clear, we do not wish to downplay

\footnotetext{
${ }^{1}$ The argument we make here draws particularly on a study conducted by ourselves and colleagues which used in-depth interviews to explore researchers' views and experiences of PPI.
} 
the existence and regressiveness of paternalism or elitism, nor to suggest that the redrawing of traditional professionallay boundaries amounts to effective forms of resistance and mobilisation. Rather, our contention is that the reasons that sit behind "negative attitudes" are far more multifaceted than the NIHR and much of the literature on PPI suggests.

\section{ARTICULATING PPI WITH CO-PRODUCTION}

What possibilities does "co-production" present for moving beyond the tendencies outlined above? The first thing to note is that while the NIHR frames co-production as distinct from existing understandings and practices of PPI, both PPI and coproduction are concepts that have historically been interpreted in various-and indeed analogous-ways. It's understandable if some think co-production is "old wine in new bottles" (Hickey et al., 2018). Nevertheless, we want to suggest that the uptake of term co-production could expand the discursive repertoires available to actors, generating possibilities for forms of involvement that transcend dominant understandings and practices.

What is perhaps most significant is how co-production could encourage (re)engagement with participatory research traditions and "bottom up" social movements that bring questions of empowerment, ethics and social justice to the fore. This may help to dislodge the consumerist and managerialist tendencies of PPI, aligning it more with democratic currents that centre on deliberative and collective forms of involvement. Such a realignment could "offer connections between publics rather than further processes of individuation" (Newman and Clarke, 2009, p. 151). It could also open up a space where broader questions of public legitimacy and social transformation are addressed, providing the grounds for a mode of accountability that isn't simply narrowly defined in terms of using public resources efficiently and effectively.

Such possibilities, however, exist within the constraints of the present. What we are particularly concerned with here is how the articulations that provide the conditions for the tendencies in PPI practice discussed earlier exhibit what Stuart Hall (Grossberg, 1996) called "lines of tendential force." That is to say, "they are rather firmly forged and difficult to disarticulate" (Slack and Wise, 2005, p. 128). The tenacity of consumerism can be seen in recent attempts to introduce co-production models of public service design and delivery. For instance, Glynos and Speed (2012) show that a mode of co-production based on the logics of cooperation, generalised reciprocity and collective deliberation sits uncomfortably with and is subordinate to a health care regime centred around choice. The tenacious force of the knowledge economy is evident in the continuation of the NIHR's health and wealth agenda (NIHR, 2015b). And, as Going the Extra Mile indicates (2015a, p. 12), it is these rationalities that underpin their interest in co-production.
A culture of performativity also shows no sign of abating. A significant development is the recent policy drive to assess the impact of research beyond academia. This is exemplified by the Research Excellence Framework (REF) succeeding the RAE - a move which signifies a more pronounced connection between the imperatives of a global knowledge economy and systems of performativity (Holmwood, 2014). Importantly, it is within this context that co-production has gained currency and has been framed as a way to help "shorten the 'time from idea to income' or the research-development cycle" (Holmwood and Balon, 2018, p. 309). Another notable development relating to performativity is the NIHR's desire to develop a set of standards to assess and improve PPI (NIHR, 2015a, p. 17). This coincides with the recommendation to measure the success of PPI and to develop its "evidence base for REF2020" (NIHR, 2015a, p. 18).

These tendential lines of force shift attention to the likelihood of alternative discursive repertoires offered by co-production being articulated with and subordinate to the consumer, managerial and performative logics that have historically imbued PPI. We thus want to offer a note of caution and suggest that it cannot be assumed that the change in signifier ("coproduction") will lead to greater collaboration and "sharing of power." As we have shown, these dominant logics tend to give rise to narrowly defined and "thin" forms of involvement that curb how the public can be involved and what they can say. Moreover, there is a risk that the shift towards coproduction could exacerbate the tensions that surface in PPI practices. The public may become more dissatisfied as they are promised greater power that fails to materialise in practice, while researchers may feel pressurised to perform "co-production" to meet expectations and "standards," furthering acts of dramaturgy and resistance.

We want to close by underscoring the need to remain open to the ambivalent potentialities of the turn to co-production. As previous ethnographies have shown (Komporozos-Athanasiou et al., 2016), the institutionalisation of PPI generates ambiguous spaces where enactments of PPI exceed binary distinctions (such as empowerment vs. consumerism) and where the form and outcomes of such enactments cannot be predicted in advance. It's likely that the arrival of co-production will augment such ambiguities, and researchers need to be attentive to how they unfold in everyday practices.

\section{AUTHOR CONTRIBUTIONS}

JP drafted the manuscript. CM provided feedback on drafts.

\section{ACKNOWLEDGMENTS}

The authors acknowledge the support of the National Institute for Health Research's Biomedical Research Centre at Guy's and St Thomas' NHS Foundation Trust and King's College London. 


\section{REFERENCES}

Adams, M., and McKevitt, C. (2015). Configuring the patient as clinical research subject in the UK National Health Service. Anthropol. Med. 22, 138-148. doi: 10.1080/13648470.2014.997192

Ball, S. J. (2016). Subjectivity as A site of struggle: refusing neoliberalism? Br. J. Sociol. Educ. 37, 1129-1146. doi: 10.1080/01425692.2015.1044072

Bell, D., and Pahl, K. (2017). Co-production: towards a utopian approach. Int. J. Soc. Res. Methodol. 21, 105-117. doi: 10.1080/13645579.2017. 1348581

Brett, J., Staniszewska, S., Mockford, C., Herron-Marx, S., Hughes, J., Tysall, C., et al. (2014). Mapping the impact of patient and public involvement on health and social care research: a systematic review. Health Expect. 17, 637-650. doi: 10.1111/j.1369-7625.2012.00795.x

Caffrey, L., Ewan, F., and McKevitt, C. (2018). The strange resilience of New public management: the case of medical research in the UK's national health service. Public Manage. Rev. 21, 537-558. doi: 10.1080/14719037.2018.1503702

Carrigan, M. (2015). Life in the Accelerated Academy: Anxiety Thrives, Demands Intensify and Metrics Hold the Tangled Web Together. Impact of Social Sciences April 7, 2015. Available online at: http://blogs.lse.ac.uk/impactofsocialsciences/ 2015/04/07/life-in-the-accelerated-academy-carrigan/ (accessed March 22, 2019).

Chubb, J., and Watermeyer, R. (2016). Artifice or integrity in the marketization of research impact? Investigating the moral economy of (pathways to) impact statements within research funding proposals in the UK and Australia. Stud. Higher Educ. 42, 1-13. doi: 10.1080/03075079.2016.1144182

Clarke, J., Bainton, D., Lendvai, N., and Stubbs, P. (2015). Making Policy Move: Towards a Politics of Translation and Assemblage. Bristol: Policy Press.

Clarke, J., Newman, J., Smith, N., Vidler, E., and Westmarland, L. (2007). Creating Citizen-Consumers: Changing Publics and Changing Public Services. London: SAGE.

Cowden, S., and Singh, G. (2007). The "User": friend, foe or fetish? A critical exploration of user involvement in health and social care. Crit. Soc. Policy 27, 5-23. doi: 10.1177/0261018307072205

Department of Health (2006). Best Research for Best Health: A New National Health Research Strategy. The NHS contribution to health research in England. London: Department of Health.

Department of Health (2012). Health and Social Care Act 2012. London: Department of Health.

Elton, L. (2000). The UK research assessment exercise: unintended consequences. Higher Educ. Quart. 54, 274-283. doi: 10.1111/1468-2273.00160

Fudge, N., Wolfe, C., and McKevitt, C. (2008). Assessing the promise of user involvement in health service development: ethnographic study. Br. Med. J. 336, 313-317. doi: 10.1136/bmj.39456.552257.BE

Glynos, J., and Speed, E. (2012). Varieties of co-production in public services: time banks in a UK health policy context. Crit. Policy Stud. 6, 402-433. doi: 10.1080/19460171.2012.730760

Grossberg, L. (1996). "On postmodernism and articulation: an interview with Stuart Hall" in Stuart Hall: Critical Dialogues in Cultural Studies, eds D. Morley and K. H. Chen (London: Routledge), 131-150.

Hickey, G., Brearley, S., Coldham, T., Denegri, S., Green, G., Staniszewska, S., et al. (2018). Guidance on Co-Producing a Research Project. Southampton: INVOLVE.
Holmwood, J. (2014). From social rights to the market: neoliberalism and the knowledge economy. Int. J. Lifelong Educ. 33, 62-76. doi: $10.1080 / 02601370.2013 .873213$

Holmwood, J., and Balon, J. (2018). "Afterword: monstrous markets - neoliberalism, populism and the demise of the public university" in Science and the Politics of Openness: Here be Monsters, eds B. Nerlich, S. Hartley, S. Raman, and A. Smith (Manchester: Manchester University Press), 302-321.

Komporozos-Athanasiou, A., Fudge, N., Adams, M., and McKevitt, C. (2016) Citizen participation as political ritual: towards a sociological theorizing of 'health citizenship'. Sociology 52, 744-761. doi: 10.1177/0038038516664683

Martin, G. (2007). "Ordinary people only": knowledge, representativeness and the publics of public participation in healthcare. Sociol. Health Illness 30, 35-54. doi: $10.1111 /$ j.1467-9566.2007.01027.x

McKevitt, C., Fudge, N., and Wolfe, C. (2010) What is involvement in research and what does it achieve? Reflections on a pilot study of the personal costs of stroke. Health Expect. 14, 349-256. doi: 10.1111/j.1369-7625. 2009.00573.x

Newman, J., and Clarke, J. (2009). Publics, Politics and Power: Remaking the Public in Public Services. London: SAGE.

NIHR (2015a). Going the Extra Mile: Improving the Nation's Health and Wellbeing Through Public Involvement in Research. Available online at: www.nihr.ac.uk/ patients-and-public/documents/Going-the-Extra-Mile.pdf (accessed March 22, 2019).

NIHR (2015b) Research Growth Through Health Research: the NIHR as an Engine for Growth. Available online at: https://www.nihr.ac.uk/life-sciencesindustry/documents/Brochures\%20and\%20flyers/The_NIHR_as_an_engine_ for_growth.pdf (accessed March 22, 2019).

Shaw, S. E., and Greenhalgh, T. (2008). Best research - for what? Best health - for whom? A critical exploration of primary care research using discourse analysis. Soc. Sci. Med. 66, 2506-2519. doi: 10.1016/j.socscimed.2008.02.014

Shergold, M., and Grant, J. (2008). Freedom and need: the evolution of public strategy for biomedical and health research in England. Health Res. Policy Syst. 6:2. doi: $10.1186 / 1478-4505-6-2$

Shore, C., and Wright, S. (2011). "Conceptualising policy: technologies of governance and the Politics of Visibility," in Policy Worlds: Anthropology and the Analysis of Contemporary Power, eds C. Shore, S. Wright, and D. Pero (New Yok, NY: Berghahn Books), 1-21.

Slack, J. (1996). "The theory and method of articulation in cultural studies," in Stuart Hall: Critical Dialogues in Cultural Studies, eds D. Morley and K. H. Chen (London: Routledge), 112-127.

Slack, J., and Wise, J. (2005). Culture + Technology: A primer. New York, NY: Peter Lang.

Conflict of Interest Statement: The authors declare that the research was conducted in the absence of any commercial or financial relationships that could be construed as a potential conflict of interest.

Copyright $\odot 2019$ Paylor and McKevitt. This is an open-access article distributed under the terms of the Creative Commons Attribution License (CC BY). The use, distribution or reproduction in other forums is permitted, provided the original author(s) and the copyright owner(s) are credited and that the original publication in this journal is cited, in accordance with accepted academic practice. No use, distribution or reproduction is permitted which does not comply with these terms. 


\section{Plain English Summary}

\section{Power, Privilege and Knowledge: the Untenable Promise of Co-production in Mental 'Health'}

\section{Diana Rose, Jayasree Kalathil}

This paper argues that 'coproduction' in mental health is not possible because of how power shapes knowledge and what is considered knowledge. We give three examples of partnership working in mental health to show why it is so difficult to share power.

We trace the history and vocabulary around partnership working and the widespread use of the term coproduction. We look at how, during the historical period known as the Enlightenment, knowledge produced by white Europeans came to be considered dominant and universal. In contrast, knowledge produced by groups such as mad people or anyone who was not white European was considered inferior. We argue that the way science is currently organised continue to use these ideas and keep in place these power differences.

What does this mean for coproduction in research and services, and user-led research in particular? If we continue to use traditional scientific frameworks and methods in mental health research, then mental health research will be based on the assumption that white knowledge is universal and objective. If this is the case, then user involvement in research and user-led research may create a paradox of one marginalised group (the mad) being part of marginalising another one (the racialized mad, that is people and communities made inferior and discriminated against by ideas and practices that use 'race' as a category to keep some groups on top as universally superior). We argue that the user movement itself needs to examine existing practices that marginalise or make invisible the work of mad people from racialized groups.

To illustrate these points, we examine a project we are involved with which aims to map user/survivor knowledge production globally. We trace the challenges involved in doing this project from within an elite university in the West. We describe how our initial definition of knowledge as 'research' changed as we started working with communities and movements that are not part of the mainstream white western user movement. We describe the methodological, practical and political dilemmas we continually have to address in this project to avoid assuming that white western knowledge, thinking and practices are privileged and dominant. We conclude that as long as these deeply engrained power dynamics remain at the level of knowledge, institutions and practices, coproduction is impossible. We would rather have meaningful change. Making that happen, even in a small way, will be challenging yet necessary. 
OPEN ACCESS

Edited by:

Annette Louise Boaz,

Kingston University, United Kingdom

Reviewed by:

Fátima Alves,

Universidade Aberta, Portugal

Hannah Bradby,

Uppsala University, Sweden

*Correspondence:

Diana Rose

diana.rose@kcl.ac.uk

Specialty section:

This article was submitted to

Medical Sociology,

a section of the journal

Frontiers in Sociology

Received: 09 November 2018

Accepted: 26 June 2019

Published: 16 July 2019

Citation:

Rose D and Kalathil J (2019) Power,

Privilege and Knowledge: the

Untenable Promise of Co-production

in Mental "Health". Front. Sociol. 4:57.

doi: 10.3389/fsoc.2019.00057

\section{Power, Privilege and Knowledge: the Untenable Promise of Co-production in Mental "Health"}

\author{
Diana Rose ${ }^{1,2 *}$ and Jayasree Kalathil ${ }^{3}$ \\ ${ }^{1}$ Service User Research Enterprise, London, United Kingdom, ${ }^{2}$ Health Services and Population Research (HSPR), King's \\ College London, London, United Kingdom, ${ }^{3}$ Independent Researcher, London, United Kingdom
}

This paper examines the concept and practice of coproduction in mental health. By analyzing personal experience as well as the historical antecedents of coproduction, we argue that the site of coproduction is defined by the legacy of the Enlightenment and its notions of "reason" and "the cognitive subject." We show the enduring impact of these notions in producing and perpetuating the power dynamics between professionals, researchers, policy makers and service users within privileged sites of knowledge production, whereby those deemed to lack reason - the mad and the racialized mad in particular-and their knowledge are radically inferiorised. Articulating problems in what is considered knowledge and methods of knowing, we argue that modern "psy" sciences instantiates the privilege of reason as well as of whiteness. We then examine how the survivor movement, and the emergent survivor/mad knowledge base, duplicates white privilege even as it interrogates privileges of reason and cognition. Describing how we grapple with these issues in an ongoing project-EURIKHA-which aims to map the knowledge produced by service users, survivors and persons with psychosocial disabilities globally, we offer some suggestions. Coproduction between researchers, policy makers and those of us positioned as mad, particularly as mad people of color, we argue, cannot happen in knowledge production environments continuing to operate within assumptions and philosophies that privilege reason as well as white, Eurocentric thinking. We seek not to coproduce but to challenge and change thinking and support for psychosocial suffering in contexts local to people's lives.

Keywords: power, madness, racialized groups, privilege, knowledge

\section{PUBLIC PARTICIPATION IN HEALTH CARE: EXPLORING THE CO-PRODUCTION OF KNOWLEDGE}

This paper argues that co-production in mental health is likely impossible in privileged sites of knowledge production: the academy and the government considered not as a unified "state" but as an assemblage. This is particularly the case for people from racialized groups. The reasons for this are multiple but many bear on questions of power and privilege arising from Enlightenment ideas about science and knowledge as universal, rational and individual. Starting by looking at the antecedents of co-production, we argue that while these ideas are presented and preserved as "objective" and "unbiased," they are steeped in Eurocentric notions about mad people and racialized people. Mental health is a special and exemplary case as it is the only "medical" specialty where 
people can be detained and treated against their will. This power relation is less interpersonal than institutional and it is intensified in the case of racialized groups (Fernando and Keating, 2009). For some 40 years now, there have been user groups that contest psychiatry and much of the knowledge produced by survivors has its roots in these politics (Campbell, 2005/1985). It does not necessarily take place in privileged sites of knowledge production or use. Academic and governmental spaces constrain what can and cannot be said and the question of what counts as knowledge and whose knowledge counts are fundamentally crossed by questions of power and privilege. We examine how this functions and how, despite the promise of co-production, the mad and racialized people are rendered speechless. We argue that without critical examinations of entrenched positions of privilege and how the established history of ideas perpetuate that privilege, co-production will fail in its stated aim of democratizing knowledge production. The knowledge produced by users, survivors and people with psychosocial disabilities may count as the "discontents" of mainstream knowledge in the sense that it has to be held back for that mainstream to exist at all.

\section{CO-PRODUCTION-THE PROMISED "THIRD SPACE"}

The term co-production is everywhere it seems, sometimes used almost unthinkingly but recently questioned at a theoretical level (Filipe et al., 2017; Madden and Speed, 2017). INVOLVE, the public involvement programme within the main research funder of health care in England, started by distinguishing three "levels" of public involvement in research: consultation, collaboration, and user-controlled. The first was generally considered superficial and the last conceived as the domain of the voluntary sector, and this latter is important because it promises to privilege non-elite spaces (Faulkner and Kalathil, 2012). "Collaboration," meanwhile, indexed a promise of equality between researchers and the public or service users (Rose, 2003). However, it quickly became evident that this promise was hollow as power asymmetries were hidden, not abolished. Gradually the term "collaboration" was replaced with "partnership" in both public health endeavors and mental health (Balloch and Taylor, 2001; Constand et al., 2014).

When co-production entered this constantly changing vocabulary for partnership working, it promised to herald a paradigm shift in the collaboration between different actors, proposing "a relationship where professionals and citizens share power" and recognize the contributions that each actor makes to this process (Slay and Stephens, 2013, p. 3).

Theoretically, then, co-production in mental health proposes to open up what Homi Bhabha has called "a Third Space"in this case between the expert knowledge of the professional and the expert experience of the service user and carer. According to Bhabha, a Third Space is a position of hybridity with the potential to enable "a new area of negotiation of meaning and representation," for other positions to emerge (Rutherford, 1990, p. 211). That is, it is not an addition to an existing binary but a new and generative terrain. For mental health, where binaries supervene, this is promising. However, it is also an ambivalent space which continues to bear the traces of feelings and practices borne out of the existence of a hierarchy of cultural and power differences. The potential of a Third Space to create new meanings can only be realized when these "residual" powers and hierarchies that have thus far allocated different values for the expertise of the various actors coming together to occupy this space can be examined.

Herein lies the problem. What appeared on the surface in one project as a successful partnership hid the persistent power relations based on both status and knowledge possession (Mason and Boutilier, 2009). Knowledges that are prized and accorded the status of "science" and "truth" are an intrinsic part of the difficulty in shifting power relations and this is in part because they are situated in a taken-for-granted or implicit hierarchy of ideas and methodologies (Johnson and Martínez Guzmán, 2013). The power dynamics between parties themselves are often deeply unequal when some hold a "veto" on what can be said or enacted. Important, and often remaining unacknowledged, is the fact that the value and status accorded to knowledge and knowledge makers in the Industrialized West takes place within what Robin DiAngelo has called the two master discourses of whiteness in practice-individualism and universalism-which obscures white power and privilege within knowledge production spaces (DiAngelo, 2010).

\section{CO-PRODUCTION-A PERSONAL REFLECTION}

Before going further, we want to present some personal reflections on engaging in the potential Third Space of coproduction from our own position as user/survivor researchers, one white and working within an academic institution and the other a person of color working in the community, both with a history of being "involved" in participatory, collaborative and co-produced knowledge making spaces. Both of us have been given several psychiatric diagnoses, including the diagnosis of "personality disorder". While there are many similarities in our experiences of engaging in these spaces, there are also major differences in how our madness and our "race" intersect in these spaces. The following example comes from JK specifically, and is written in the first person.

In 2013, I (JK) was invited to be part of a series of workshops that led to a project then titled "Co-production and mental health: Beyond therapeutic conflicts," organized by the Mental Health Foundation and the Faculty of Philosophy at the University of Oxford. In the preparatory phase, I was invited to speak at a seminar on "personality disorder" from the perspective of having been diagnosed with it, alongside two experts who treated "personality disorder". As part of the preparation for the seminar, I learned that:

- My fellow speakers were psychiatrists and philosophers who believed that people with "personality disorders" could be divided into three groups: the mad, the sad, and the bad (Edmonds and Warburton, 2012). According to them, I, with 
a diagnosis of "borderline personality disorder," fell into the category of "the bad" and was characterized by a "markedly unstable sense of self" and extreme behaviors including aggression and violence.

- While, as psychiatrists, they posited several reasons for a personality-a central core of what it means to be humanthat was "disordered" (ranging from genetic predisposition to childhood experience of abuse and broader socio-political backgrounds such as poverty), as philosophers, they deemed that essentially we were "morally corrupt."

- As philosophers and therapists, my fellow speakers believed that psychiatric treatment can "enhance human morality" through medication by increasing "the likelihood that moral states of mind remain stable and lead to action" and through psychological interventions leading to "acquisition and development of moral motives, skills and understanding" (Pearce and Pickard, 2009). In effect, they possessed not just the knowledge, but the virtue and the correct moral values to "fix" people like me.

There is much here to discuss around the validity of "personality disorders" as diagnoses, the efficacy of medication as well as Eurocentric philosophical debates around morality, virtue etc. which are beyond the scope of this paper. For now, the focus is on what this episode tells us about the contexts and nature of co-production and the positionality of individuals who come together to co-produce. I was one of the only two people who had the lived experience of being diagnosed with mental disorders and subjected to psychiatric interventions in the whole group. This immediately raises issues of power and the possibility of speech. I was being asked to speak about my personal experience alongside others who wrote about people like me as damaged human beings, with a corrupt morality and a disordered personality. These others contributed routinely to the very knowledge base that makes it possible for one group of people not only to pass medical and moral judgements on another group of people, but also to claim the possession of a "correct morality" to fix them. What possible effect would my little story of being diagnosed with personality disorder have, faced with centuries of collective professional wisdom on the subject? So, while the invitation to speak at this event endowed my experiential knowledge with a certain authority and legitimacy, momentarily elevating me from the position of the subaltern, the context of this interaction rendered my speech unspeakable (Spivak, 1988).

The experience of being rendered speechless became even more pronounced given that I was the only person of color in this space for co-production. Thus, this space was pre- defined not only by the authority of psychiatric knowledge but also by the authority of white Eurocentric knowledge and philosophy within which the identity, experience and knowledge of non-white people have been historically racialized as inferior. As Dabashi argues, epistemic racism "consists in devaluing the humanity of certain people by dismissing it or playing it down (even when not intentional) at the same time as highlighting and playing up European philosophy, assuming it to be universal" (Dabashi, 2015, xi). The most immediate marker of how this works in knowledge making spaces is to see who is in that space. Paying attention to this illustrates the fact that, despite all the research evidence on racial and ethnic inequalities within our services, our institutions of higher education and our policy making contexts, and despite repeated calls for the need to be diverse and inclusive, partnership working tables are homogenous places reflecting little of the vast array of experiences, identities, skills, and backgrounds that constitute the wider user/survivor community (Begum, 2006; Kalathil, 2009; Trivedi, 2009).

In the end, after discussing the issue with the organizers, it was clear that I had two realistic options: one, accept the context and its inherent hierarchies and continue to collaborate within the apparently immovable constrains of its parameters, or two, refuse to engage, both options essentially making my knowledge "unspeakable." I chose the latter.

\section{HISTORICISING CO-PRODUCTION}

The experience narrated above by JK was in the context of an event specifically named "co-production." However, coproduction is not the first time we have seen the possible emergence of a Third Space that allows for shared understandings of mental health and distress. We shall briefly present three examples that can be seen as historical antecedents to coproduction, and to discussions about power and privilege in collaborative settings.

First, an example in the service delivery context: no other context is more important for working in partnership in a relationship of shared power than one's own care. The Care Programme Approach (CPA) in the UK can be seen as an example of such a space.

Introduced in 1990 and in implementation from 1991, twice reviewed in 1998 and in 2008, CPA is essentially a framework by which professionals from health and social care services work alongside service users and, where relevant, with their family and friends, to produce a plan for treatment and support (Department of Health, 1990b, 2008). If collaboration between professionals and service users and their significant others in care and treatment is the issue, we have had a system that is supposed to work for almost 30 years. Yet, the Care Quality Commission's latest community mental health survey showed that only 27 per cent of the participants had a care plan under CPA (Care Quality Commission, 2017). Even where CPAs exist, significant dissatisfactions among service users have been noted in how these capture their opinions and the efficacy of care plans in meeting their needs (Rose, 2001; Gould, 2012). Service users from racialized communities have expressed particular dissatisfaction with CPAs and how care plans are developed and used (Gould, 2012).

So why hasn't it worked? Put simply, the sharing of power in theory did not translate into practice. If CPA was a Third Space within which to reorganize and share power, it could not be done unless and until this space also made possible the examination of the hierarchical dualisms remaining within this space: the continuing primacy of the medical model over the social and personal meanings and understandings of distress in how care is 
organized; practices that focus on risk and dangerousness rather than on agency and empowerment; legally sanctioned use of coercion and control that inevitably undermine the call for choice and agency. In effect, what we have is a theory or a framework, despite its lofty ideals, that will not work until there is also a parallel rethinking of how mental health services work.

Our second example is in the context of knowledge production and the idea of democratic research. The idea that research and ensuing action should be done "with" people and not "on" them and its reflection in a specific methodology goes at least as far back as the 1970s to the rapid growth of Participatory Action Research (PAR). PAR was influenced by a range of political philosophies and knowledge production processes, for example, by the work of Paulo Friere and Orlando Fals Borda, the civil rights movement and social movements such as the Bhoomi Sena in Maharashtra, India (Hall, 2005; Rahman, 2008). It offered the possibility of creating knowledge and action that is based on the experience of the community as opposed to the grand theory making based in traditional academia. In terms of its influence on democratizing psychiatric knowledge, however, there have been several issues. The principles and origins of PAR are political in nature and are often held to be at the margins of "the mainstream of academic research with its conventional if unsupportable notions of objectivity in either North America or Europe" where "objectivist, hypothetico- deductive research retains a dominance" (Reason and Bradbury, 2008, p. 3). Consequently, within applied mental health research, it has the reputation of being biased research and is lowly placed in the hierarchy of evidence. PAR focuses on action and learning-indeed some schools have done away with the word "research" completely and talk about participatory action learning. Hence, it has also easily been dismissed as "soft" knowledge against the "hard" "scientific" knowledge of RCTs and other quantitative methodologies.

However, we argue, there is also a much more crucial issue: "community" itself is not homogenous and various hierarchies exist within any given community. While PAR has been able to challenge the influence of power over knowledge, it is successful only in as much as it can question existing hierarchies of power within community itself and how that reflects on the modes and nature of participation in unequal societies.

Our third example is perhaps the closest antecedent to coproduction in mental health: the concept of "user involvement." In the UK, the 1990 NHS and Community Care Act (Department of Health, 1990a) was the first piece of legislation that established a formal requirement for user and carer involvement in service planning. Since then, several legal and policy measures have been put in place to ensure that those who use services have an equal say in how services are planned, developed and delivered. In research too, what is known as PPI-patient and public involvement-is a key requirement of many funding bodies and ethics committees. Yet, the extent to which this involvement has been able to influence the thinking and theorizing of mental wellbeing and distress-in other words, bringing about a paradigm shift-has been limited.

Several issues have been identified as the reasons for the gulf between the stated lofty aim of democratizing research and practice through user involvement and what has actually been achieved (Blakey, 2005; Kalathil, 2009; Faulkner, 2015). Experientially, user involvement has remained tokenistic, with users having little role in setting the agenda or making crucial decisions. Ideologically and methodologically there are several tensions that are not addressed. For example, Blakey comments on how the Department of Health in its statement about patient and public involvement posits an ideal situation where participants in involvement forums would rarely need to be adversarial and would work in a positive and collaborative manner. She suggests that "service providers need to think through the boundaries to participation, and the ways in which difference and conflicting views would be handled, if participation is to be meaningful" (Blakey, 2005 p. 23). If your experience of service has been consistently negative-because of compulsion, coercion, racism or other such factors-you are not going to be able to work collaboratively unless involvement forums allow safe spaces for discussing difficult emotional journeys through services.

Here too, we are invited to collaborate within spaces that retain residues of hierarchical dualisms. Our services continue to be risk averse; our lives governed by laws that allow for compulsion and coercion; our distress medicalised. The possible shifts in our positionality-as an "expert by experience" and as a service user who might be sectioned for example-render our legitimacy unstable. We have fought long and hard for the legitimacy of our knowledge or, more fundamentally, the possibility of a self that is capable of holding legitimate knowledge. But this is a precarious victory. Unlike our collaborators, whose legitimate knowledge is considered inviolable and consistent, the perceived legitimacy of our knowledge shifts with the perceived content of madness in our positionality.

\section{ALL KNOWLEDGE IS SOCIALLY PRODUCED}

We have seen that the casual and formal use of the term "coproduction" can function to render invisible power relations that remain stark. We can therefore ask the question whether the concept can be articulated in such a way that power relations are rendered visible as a first step to dismantling them. Judi Chamberlin, one of the first activists in the US Patients' Liberation Movement, dedicated her life to arguing for and enacting patient-run alternatives to mainstream psychiatry (Chamberlin, 1978). However, in one of her last papers she broached the question of the conditions for true partnership and argued that this entails all parties explicitly putting their power position on the table before any endeavor begins (Chamberlin, 2005). And she meant not only personal power but that accorded by institutional positions and discourses. This would be needed for proper co-production in mental health but it is unlikely as a central aspect of power in the Industrialized West is hidden by the apparent superiority of science-and science of particular forms-which is steeped in the European Age of Enlightenment. Enlightenment thought, and its central concepts of rationality and the reasoning subject, permeates all academic disciplines in 
the West. Importantly, these are concepts defined within ideas about the racial and cultural superiority of the white European. Indeed, as Eze has argued, "the Enlightenment's declaration of itself as "the Age of Reason" was predicated upon precisely the assumption that reason could historically only come to maturity in modern Europe, while the inhabitants of areas outside Europe, who were considered to be of non-European racial and cultural origins, were consistently described and theorized as rationally inferior and savage" (Eze, 1997, p. 4). In medicine and in psychiatry, rationality undergirds empirical science which is the main way knowledge is produced in health research, and this knowledge is also inherently racialized (Fernando, 2017).

We contend that this idea of rational, racialized science itself poses obstacles to co- production in terms of the methodologies it allows and the resultant knowledge produced. These methodologies constitute one of the main ways in which power inheres in knowledge itself. Service users cannot overturn the hierarchy of methods in general or question particular ones and, as a result, can change little in research or policy. This is partly because method rules in research, and policy fluctuates radically in what it selects as "evidence" according to the exigencies of the moment, although this is not how it is represented. Government is part of this dynamic as it may give service users a place at the table but decisions are made elsewhere than in formal fora, an "elsewhere" that is elusive.

We must, then, radically broaden what counts as knowledge and whose knowledge counts. Advocacy and campaigning have long generated knowledges important to the emancipation of mental health service users (Pembroke, 1994; Reynolds, 2010; The Survivors History Group, 2012; Jackson, 2018). But this knowledge is fragile, under-resourced and undervalued because it is not generated in mainstream institutions and because it is generated by people who are positioned as "lacking rationality" and so deemed inferior. Unsurprisingly, knowledges generated outside academic spaces have even greater difficulty in being disseminated and enacted. Most simply, there is a lack of funds and resources. Additionally, the distinction between peer-reviewed and "gray" literature and the hierarchies involved function to prevent the foregrounding and spreading of these alternative ways of producing knowledge. It remains as what critical sociologists have termed "undone science," "areas of research identified by social movements and other civil society organizations as having potentially broad social benefit that are left unfunded, incomplete, or generally ignored" (Frickel et al., 2010).

In a word, what counts as knowledge is policed. Coproduction becomes impossible between academia and those who produce knowledge differently and in different environments as the latter is systematically devalued. It ignores the residual dualisms and counts as the "discontents" of mainstream science, a threat that must always be suppressed.

Despite this, and especially in the era of social media, there is a vibrant community of independent survivor scholars who maintain their roots in user organizations both for political reasons and as a way of staying grounded in the experiences of people who use or refuse services (Francis, 1993; Beresford, 2002; Allison et al., 2003; Faulkner and Kalathil, 2012; Rose et al., 2017). This knowledge was always political, stemming from a user movement that contested psychiatry (Chamberlin, 1990; Campbell and Rose, 2011). But what is refused or sometimes rendered invisible is that mainstream knowledge is fundamentally political too. Governments need "experts" and in their post-colonial incarnation they need expertise formed in a Eurocentric tradition, the academic embodiment of whiteness. And the knowledge of mad people existing at the intersections of "race", gender and sexuality are further rendered inferior and particular forms of subjugations generated in relation to white privilege. If this is articulated it threatens basic assumptions of objectivity and neutrality.

Contrary to what is often thought, individuals do not become leading scientists because they are the cleverest or the best of their cohort. As Thomas Kuhn argued, most of the time academics operate within a field of "normal science" (Kuhn, 2012). So, those who succeed are those who play by the rules of normal science and know how to accord some findings the status of "fact" (Shapin, 2010; Latour and Woolgar, 2013). Even for the physical sciences this is a social endeavor although it is necessary for its reputation to hide this.

Practices such as peer review of grants and of journal articles are prime ways in which normal science perpetuates itself. Only rarely does the framework crack and a new one take its place-a scientific revolution or paradigm shift.

\section{THE DOMINANCE AND DRAWBACKS OF METHOD}

Today, in the psy sciences as well as others that depend on empirical method, truth is supposedly guaranteed by method. There is an accepted hierarchy of "evidence" but this hierarchy consists of methods for generating knowledge, usually taking off from Cochrane (Sackett, 1997). At the apex of the hierarchy is meta-analysis, followed by Randomized Controlled Trials (RCTs), quasi-experiments, cohort studies and, finally, expert witnesses. It can be noted that, bar the last, all these methods are quantitative and although this has been questioned empirically (Greenhalgh and Hurwitz, 1999) and conceptually (Plsek and Greenhalgh, 2001), we would argue that this still heavily constrains any attempt at collaboration or co-production in research. Service users or the public are never invited to pose basic questions to a chosen methodology because that is taken for granted, and "lay" individuals must content themselves with turning documents into plain English or meeting four times a year to comment on the progress of a study (Slade et al., 2010). Thus knowledge, or the means of generating knowledge, is a form of power because it dictates the role of both professional and "lay" researchers in any study, and in such a way that very little can change and still less can have an impact, although attempts have been made to claim this (Staley, 2009). In sum, scientists make a reputation for themselves because they play by the rules of normal science, assume that method is the royal road to truth, that the activity is objective and value-free, and that the findings and the position of the scientist are universal. Such underlying assumptions make it virtually impossible for 
other forms of expertise, such as collective first-hand knowledge of distress or services, to play a full role in or to contest the bases of any study in mainstream psy research (Faulkner, 2017).

As long as current normal science with its underpinning assumptions is in the ascendant, co-production-where the skills and experiences of all those who come together to co-produce, including service users/survivors, is explicitly acknowledged as valuable-cannot happen. So what can be done? We may propose several activities of varying degrees of departure from what counts as normal science and the resultant valid knowledge. First, mainstream methods may be adapted or overturned: metaanalysis (Rose et al., 2003), measure generation (Rose et al., 2011), critical reflexivity (Kalathil et al., 2011), or oral history (Jackson, 2002). Second, although these may be represented as methodological changes, they are much more as they shift the values and assumptions of knowledge making and so give voice to otherwise silenced groups-in this case the mad and the racialized mad.

\section{INTERROGATING METHODS, DISCIPLINES, CONCEPTS AND PRACTICES}

Two things follow from this, one inside the academy, and the other paying attention to and privileging knowledge generation in other, less valued spaces. Inside the academy we need to break free from capture by psychiatric discourse and practice. Other "disciplines" such as history, social science, cultural studies and critical theory can be drawn upon to contest the underlying assumptions of the psy sciences. But the difficulties of interdisciplinary work cannot be overstated-the pull and comfort of one's own framing perpetually undermines attempts to pay proper attention to other ways of understanding (Frodeman and Mitcham, 2007; Jacobs and Frickel, 2009). And there is rarely an attempt to pay attention to and critique the white Eurocentric Enlightenment grounding of all western disciplines, its pedagogic practices, curricula, and methods (Zuberi and Bonilla-Silva, 2008; Bhambra, 2011).

But what of environments that are not usually seen as sites of knowledge generation or, to the extent that they are, the knowledge is intrinsically seen as inferior and devalued? Many users and survivors of the mental health system in the Industrialized West have produced new and different understandings of distress and helpful supports in the course of advocacy work, campaigning, collective peer support and educational endeavors (Molyneux and Irvine, 2004; Basset et al., 2006; Lopez- Baez and Paylo, 2009; Mead, 2014; Voronka, 2017). However, these spaces also reflect existing power relations within society when they exclude, exoticize or marginalize racialized people and their knowledge (Gorman et al., 2013; Tam, 2013). Through these processes that reflect racial hierarchies within societies, the new knowledge generated specific to people marked by psychiatry is also marked by white privilege-the white privilege of the academy as well as the emergent user-researcher community (Wilson, 2006; Kalathil, 2013; King, 2016). Bell (2006) has made this very clear in his argument that Disability
Studies, borne out of advocacy, activism and interdisciplinarity, is in fact, and should be called, White Disability Studies.

Normal science today contends that it produces knowledge that is universally true, at most that such universality might need to be "adapted" to local contexts without altering the core. This entails, too, the idea that the scientist is the embodiment of a universal knower-that sticking to privileged methods will produce the same knowledge whoever the scientist might be. Donna Haraway (1988) calls this "the God trick" and mounts a sustained attack on the ideas of universal knowledge and a valuefree universal knower. In this she pushes feminist standpoint epistemology as far as it will go and, unlike Marxist feminists such as Nancy Hartsock (1983), emphasizes the power of discourse and associated practices. Still, it would do us good to pay heed to the critiques of the potential for "new universalisms" in knowledge produced from within political movements. Black feminists early on voiced concern that feminist epistemology itself could become a new universalism (Hooks, 1982) and this was followed by close attention to intersectionality (Crenshaw, 1991; McCall, 2005; Nash, 2008). Subaltern Studies started a critique of both internal power structures but also the specificity of ex-colonial countries and their capture by Eurocentric knowledge which itself embodies universalism (Spivak, 1988; Ludden, 2002). A similar argument was made in Britain from the perspective of racialized groups and cultural studies (Hall, 1997; Gilroy, 2013). So it is necessary to pose a question about the embryonic emergence of mad knowledge in the Global North. If this knowledge draws on elements of Enlightenment thinking, if it uses the methods of mainstream "psy" science and its hidden epistemology, if it does not reflect on white privilege, is it then a White Mad Knowledge which excludes racialized groups in a way that aligns with both the academy and society generally in the Industrialized West? Our answer would be in the affirmative and, as such, it risks becoming a new universalism in the same way as white feminism, even as it occupies a marginalized position itself. In this case, co-production between white mad knowledge and the knowledge and praxis of racialized groups is again crossed by privilege and power, and so has not addressed the concomitant residual dualisms. Racialised peoples are not just treated oppressively by psychiatry; they are epistemically ignored or suppressed by their white peers. As Kalathil and Jones have argued, within user/survivor research originating in western multicultural and multiethnic countries, "institutional whiteness, heteronormativity, and Eurocentrism-in configurations of mad/survivor collectives; in references to conceptual work from philosophy, feminism, critical theory, and so on; in opportunities to collaborate; in enduring colonial mentalities within academic spaces and in curricula; in collective theorization-are rarely addressed" (Kalathil and Jones, 2016, p. 186).

It may be noted that we have drawn mainly on critical theory, disability studies, subaltern studies and feminisms as well as our own reflected experience. And while we have drawn on the works of critical sociologists, we have made little direct reference to medical sociology, which may appear an absence in a journal such as this. Analyses and critiques of biomedicine and, especially, psychiatry from medical sociology perspectives have been hugely 
relevant in disrupting the power hierarchies of knowledge around mental health. However, the interest in exploring the intersections between mental health and "race"/racialization in western medical sociology tends to be confined to issues such as racial disparities and inequalities. Whiteness as a concept, discourse or praxis is rarely examined. This is, we feel, because the critique partakes of those very same structures, knowers and policies, thereby providing little that is generative, little that gives us purchase on the structural, political and epistemic conditions that sustain deeply entrenched White Eurocentric knowledges and practices.

\section{WHITE PRIVILEGE AND THE PARADOXES OF WORKING IN MAINSTREAM SPACES}

There is a reason in working in academic, governmental and policy environments, and there are paradoxes in doing so within these assemblages. The reason is simply that these spaces are currently the privileged sites of knowledge generation and practice and so deserve sustained contention. The paradox is the difficulty exactly of sustaining that contention whilst working inside the hierarchies, discourses and practices of these contexts. At least it has to be transparent and reflected upon constantly. To expand on this, we describe the paradoxes we are currently addressing as part of a team working on a project titled EURIKHA which aims to map the knowledge produced by service users, survivors, and persons with psychosocial disabilities across the globe (www.eurikha.org). The project is the result of a personal award of funds to DR who is the Principal Investigator.

In the course of this work, our questioning of privileged knowledge and sites of knowledge production and use has led us to radically change our conception of knowledge and how some knowledges are permitted to govern whilst others are subjugated. However, there are some obstinate hurdles. We are carrying out this work in a prestigious university, a privileged site of knowledge production. The faculty in which we are situated is a bulwark of mainstream psy research. However, hard we try to step outside this space, it is riven with hierarchies both of status and of what is speakable. So how can we be sure, even partially, that we understand the global and diverse pictures or will come to do so?

There are indeed methodological issues here. The communities and movements we want to reach are by definition marginalized and minoritised. For some, they are "hard to reach" or "seldom heard" and by those words does their marginalization fall back on them as responsible for their own hardships. This is especially true of racialized communities and their movements which, through being defined as "hard to reach" are characterized as "difficult and separatist" (Kalathil, 2013). By contrast, we take it as axiomatic that it is our responsibility in doing this work to surface the most marginalized discourses and forms of support. This can entail spending months on social media as well as finding visible and prominent persons with psychosocial disabilities and asking them for contacts to others we would not otherwise identify. We have launched interactive pages on our website that will be accessible on smart phones and low internet speed connections in the hope that these pages will be accessed by individuals and communities we would otherwise find difficult to identify and by making this worthwhile for people to interact with. Western user/survivor researchers have a responsibility to surface this knowledge, although this is not without its own power dynamics as will be shown. This devalued knowledge is often knowledge-in-practice, working with communities for inclusion of those with psychosocial disabilities.

But of course these issues are not just methodological-they are conceptual and political. In the project team, we start from a social justice stance. We are ourselves people who embody the conceptual and political issues relating to knowledge production: We are all "mad" people; we have used psychiatric and/or indigenous services, some of us both in the Global North and Global South; some of us are white and others persons of color; some of us work predominantly within academia and others in the community. All of this has had implications in our roles as knowledge producers. We thus have a responsibility and an ethical imperative to surface these grass roots knowledges and acknowledge our own developments.

We began our work with a focus on user/survivor research and then discovered that this term and concept did not align with activities carried out by persons with psychosocial disabilities who declined to be part of the project on grounds that "I am not a researcher." The western focus on "knowledge as research" could be argued to originate from Cartesian dualism and its resultant idea of a subject of cognition separate from social, cultural, racial and sexual realities, the universal and individual subject of the Enlightenment. This notion alienated the very people we wished to talk with, often from racialized and other marginalized groups, and this led us to a broader and more inclusive concept of knowledge or knowledges. We slowly recognized that this knowledge was generated by people working in local situations in order to bring power to the collective and to individual subjectivities. The contestation of the psy sciences has been facilitated not only by local interpretations of the UN CRPD, but by recent documents from the Office of The Special Rapporteur for Health from UN Human Rights Council. This latter roundly rejects medical interpretations of human distress and commends local practices aimed at inclusion and emancipation and the knowledge that is both embedded in and facilitates this (UN HRC, 2017).

However, there is a related power dynamic to which we must attend. There is a power differential between white, western service user activists and, especially, researchers, and groups working for community inclusion and collective and human rights in the Global South and diasporic communities in the Industrialized West. Whatever the battles (and compromises) involved, some service user researchers and activists in the UK and elsewhere have reached the heady heights of academic and governmental (apparent) acceptability, have reached the peer reviewed literature, and established an embryonic knowledge base. For reasons articulated at the beginning of this paper, we do not believe this can in any way be called "co-production." It is either collaboration in the negative sense or it is autonomous work forged against the mainstream as identified earlier. It is 
also predominantly unacceptable to the mainstream (Rose et al., 2018). But, to the degree that it works within the structures of elite spaces as well as whiteness, we have to own these privileges (Van Dijk, 1992; McIntosh, 2007; Meerai et al., 2016), and question the extent to which our work partakes of those hierarchies of knowledge and status. For privilege is not just a property of persons; it is a property of the dominant knowledge we have been trying to unpick. The simplest answer is of course that it is locally situated itself, which does not make it "wrong," but we need to be clear that it is both partial and not necessarily of use to those working for their own power in practice and knowledge, and those positioned as inferior by the legacy of the Enlightenment. Whilst trying to own western, academic and/or white privilege at individual and epistemic levels and the ramifications of this in our work, it is necessary that we do this collectively and in dialogue with those whose roots are in other traditions. The power/knowledge axis of mainstream psy research and practice may be in the ascendant now but it cannot ignore forever how the "same" concepts and practices have very different meanings and implications in different parts of the globe and for different movements of users/survivors and persons with psychosocial disabilities (Davar, 2012; Freeman et al., 2015).

Those of us who are situated as white western researchers and knowledge makers cannot walk in other people's shoes but, free of conceptual and methodological universalism, we can pay attention from a political as well as epistemological perspective to the real-life meaning making and practices that constitute the world of survivor knowledge. Diverse and contentious it may be but as a commonality it is pushing the boundaries of what counts as knowledge and whose knowledge counts. The diverse "discontents" of mainstream knowledge and associated practices about us will not last forever, indeed is already critiqued and cracking as a result of mobilization of both alternative disciplinary and political attention (Rose, 2017). So we cannot countenance the notion of "co-production" as at all possible in relation to this mainstream. There are times when knowledges simply collide. Indeed, within our own work we have a specific project on the history of Black activism and knowledge- making in the UK. This project is part of the main one but is also autonomous. The links are yet to be fully established as we struggle to consciously work against the marginalization and mythologisation of minority histories according to the terms of a mainstream hegemonic worldview, and to surface and challenge conventions in knowledge making embedded in white privilege and practice. Similarly, we know now that the Global South component of this project is under-resourced because, situated in a UK university and privileging research over other forms of knowledge-making, the Principal Investigator (DR), to whom the funds were personally awarded, was unaware of the degree of activity and activism in those regions. That lack of awareness is not an accident but an instance of white privilege. So even as we strive to work in a democratic way, there are residual dualisms to contend with that are institutional, epistemic and practical. In the making of mad knowledge, whiteness still prevails. We can do little about our institutional location but we hope that constant reflexivity, which can include very uncomfortable, sometimes stark, tensions, will move us to new ways of working conceptually, methodologically as well as practically.

\section{CONCLUSION}

We have argued that co-production between professionals and service users is fundamentally an unequal relationship despite the promise of a Third Space for collaboration. The experiential knowledge that we bring into the relationship is defined by the expert knowledge of the professional, and the legitimacy of that expertise will be confined to one of experience alone unless there is a context that allows us to interrogate the nature of expert knowledge. As of now, the context of co-production in mental health does not provide the possibility of engaging in an epistemological paradigm shift that disrupts the dominant discourse of psychiatry without assimilating user perspectives into the engine of legitimized science.

Secondly, the "expert" discourse of co-production calls for the legitimization of a certain kind of positionality, one that easily overlooks what Jones and Kelly (2015) have called "inconvenient complications," complications based in the vast heterogeneity within the experience of madness and of socio-political identities. Co-production could be seen as a way of acknowledging and honoring previously subjugated knowledges. However, the conspicuous absence of marginalized and minoritised communities, especially through the processes of racialisation and white privilege, and the continuing assumptions of universality in Eurocentric epistemologies and philosophies of science, evidence and knowledge seem to indicate otherwise. Until we are able to actively reflect on our own entrenched positions of privilege, and how the established history of ideas perpetuate that privilege, co-production will fail in its stated aim of democratizing knowledge production.

Thirdly, the routine "solution" to these questions is a proclamation of allegiance to the virtues of equality and diversity. The user/survivor identity is one that is culturally and politically constructed. For it to be articulated fully, we will need to be mindful not only of the vast diversity and difference within that identity but also of how privileges borne out of race, class and geographical location demarcate our collective spaces. The call to diversity is often addressed to the person embodying difference. It creates a situation where addressing issues of marginalization becomes the task of those people who are marginalized. So, for instance, "race" and racism become issues that black folks need to talk about, as if whiteness embodies no part of racialisation, a task that calls on people of color to "embody diversity by providing an institution of whiteness with color" (Ahmed, 2012, p. 4).

In summary, co-production' implies equality not just in the sense of persons or statuses but at the level of how knowledge itself is valued. We have argued that this is not possible in current configurations which demarcate elite sites of privilege in knowledge generation and accord value to what results. We seek to change these, not "co-produce" them, and so align ourselves with grassroots and local discourses and practices as producing more coherent explanations and better supports for socio-psychic suffering. 


\section{AUTHOR CONTRIBUTIONS}

All authors listed have made a substantial, direct and intellectual contribution to the work, and approved it for publication.

\section{REFERENCES}

Ahmed, S. (2012). On Being Included: Racism and Diversity in Institutional Life. Durham and London: Duke University Press.

Allison, L., Beckett, J., Faulkner, A., Smith, C., and Thorpe, J. (2003). Evaluation of the Leeds Survivor Led Crisis Service. Leeds: Leeds Crisis House.

Balloch, S., and Taylor, M. (2001). Partnership Working: Policy and Practice, Bristol: Policy Press.

Basset, T., Campbell, P., and Anderson, J. (2006). Service user/survivor involvement in mental health training and education: Overcoming the barriers. Soc. Work Educ. 25, 393-402. doi: 10.1080/02615470600593675

Begum, N. (2006). Doing it for Themselves: Participation and Black and Minority Ethnic Service Users. London: SCIE/REU.

Bell, C. (2006). "Introducing white disability studies: a modest proposal," in The Disability Studies Reader, $2^{\text {nd }}$ Edition. ed L. J. Davis (New York, NY: Routledge), 275-282.

Beresford, P. (2002). User involvement in research and evaluation: liberation or regulation? Soc. Policy Soc. 1, 95-106. doi: 10.1017/S1474746402000222

Bhambra, G. (2011). Talking among themselves? Weberian and Marxist historical sociologies as dialogues without "others." J. Int. Stud. 39, 667-681. doi: 10.1177/0305829811401119

Blakey, H. (2005). Participation... Why Bother? The Views of Black and Minority Ethnic Mental Health Service Users on Participation in the NHS in Bradford. Bradford: International Centre for Participation Studies, University of Bradford and Sharing Voices.

Campbell, P. (2005/1985). "From little acorns. The mental health service user movement. Beyond the Water Towers," in The Unfinished Revolution in Mental Health Services, eds A. Bell, and P. Lindley (London: Sinsbury Centre for Mental Health), 73-82.

Campbell, P., and Rose, D. (2011). "Action for change in the UK: Thirty years of the user/survivor movement," in The SAGE Handbook of Mental Health and Illness, eds D. Pilgrim, A. Rogers, and B. Pescosolido (London: Sage), 452-470. doi: 10.4135/9781446200988.n22

Care Quality Commission (2017). 2017 Community Mental Health Survey: Statistical Release. London: Care Quality Commission.

Chamberlin, J. (1978). On Our Own: Patient-Controlled Alternatives to the Mental Health System. New York, NY: McGraw-Hill.

Chamberlin, J. (1990). The ex-patients movement: where weve been and where were going. J. Mind Behav. 11, 323-336.

Chamberlin, J. (2005). User/consumer involvement in mental health service delivery. Epidemiol. Psichiatria Soc. 14, 10-14. doi: 10.1017/S1121189X00001871

Constand, M. K., MacDermid, J. C., Dal Bello-Haas, V., and Law, M. (2014). Scoping review of patient-centered care approaches in healthcare. BMC Health Services Res. 14:271. doi: 10.1186/1472-6963-14-271

Crenshaw, K. (1991). Mapping the margins: intersectionality, identity politics, and violence against women of color. Stanford Law Rev. 46, 1241-1299. doi: $10.2307 / 1229039$

Dabashi, H. (2015). Can Non-Europeans Think? London: Zed Books.

Davar, B. V. (2012). Legal frameworks for and against people with psychosocial disabilities. Econ. Political Weekly 47, 123-131.

Department of Health (1990a). NHS and Community Care Act. London: The Stationary Office.

Department of Health (1990b). Caring for People: The Care Programme Approach for People with a Mental Illness Referred to Specialist Mental Health Services. Joint Health/Social Services Circular C(90)23/LASSL(90)11. London: Department of Health.

Department of Health (2008). Refocusing the Care Programme Approach: Policy and Positive Practice Guidance. London: Department of Health.

\section{FUNDING}

Wellcome Trust IA 203237/Z/16/ awarded to DR and enrichment project of same, Still we Rise, led by JK. We have received no other fund for open access fees but have a Research Support Account.

DiAngelo, R. (2010). Why Cant we all Just be Individuals? Countering the Discourse of Individualism in Anti-racist Education. InterActions: UCLA Journal of Education and Information Studies, 6. Available online at: https://escholarship. org/uc/item/5fm4h8wm

Edmonds, D., and Warburton, N. (2012). Interview with Hanna Pickard. Philosophy Bites. Available online at: https://secure-hwcdn.libsyn.com/p/9/ 1/1/9117f1dac5d99c98/Hanna_Pickard_on_Responsibility_and_Personality_ Disorder.mp3?c_id=4681789\&cs_id=4681789\&expiration $=1540894502 \&$ hwt $=$ 048aa0dd00106bbe7d520858bbf899fe

Eze, E. C. (1997). Race and the Enlightenment: A Reader. Oxford: Blackwell Publishing Ltd.

Faulkner, A. (2015). 4Pi National Involvement Standards: Involvement for Influence. London: NSUN.

Faulkner, A. (2017). Survivor research and Mad Studies: the role and value of experiential knowledge in mental health research. Disability Soc. 32, 500-520. doi: 10.1080/09687599.2017.1302320

Faulkner, A., and Kalathil, J. (2012). The Freedom to Be, the Chance to Dream: Preserving User-led Peer Support in Mental Health. London: Together for Wellbeing.

Fernando, S. (2017). Institutional Racism in Psychiatry and Clinical Psychology: Race Matters in Mental Health. London: Palgrave Macmillan. doi: 10.1007/978-3-319-62728-1

Fernando, S., and Keating, F. (eds.). (2009). Mental Health in a Multiethnic Society: A Multidisciplinary Handbook. London: Routledge. doi: 10.4324/9780203895535

Filipe, A., Renedo, A., and Marston, C. (2017). The co-production of what? Knowledge, values, and social relations in health care. PLoS Biol. 15:e2001403. doi: 10.1371/journal.pbio.2001403

Francis, E. (1993). "Psychiatric racism and social police: black people and psychiatric services," in Inside Babylon: The Caribbean Diaspora in Britain, eds J. Winston and C.Harris (London: Verso), 179-205.

Freeman, M. C., Kolappa, K., de Almeida, J. M. C., Kleinman, A., Makhashvili, N., et al. (2015). Reversing hard won victories in the name of human rights: a critique of the General Comment on Article 12 of the UN Convention on the Rights of Persons with Disabilities. Lancet Psychiatry. 2, 844-850. doi: 10.1016/S2215-0366(15)00218-7

Frickel, S., Gibbon, S., Howard, J., Kempner, J., Ottinger, G., and Hess, D. J. (2010). Undone science: Charting social movement and civil society challenges to research agenda setting. Sci. Technol. Hum. Values 35, 444-473. doi: $10.1177 / 0162243909345836$

Frodeman, R., and Mitcham, C. (2007). New directions in interdisciplinarity: Broad, deep, and critical. Bull. Sci. Technol. Soc. 27, 506-514. doi: $10.1177 / 0270467607308284$

Gilroy, P. (2013). There Ain't no Black in the Union Jack: The Cultural Politics of Race and Nation. London, Routledge. doi: 10.4324/9780203995075

Gorman, R., Saini, A., Tam, L., Udegbe, O., and Usar, O. (2013). Mad People of Colour-A Manifesto. Asylum winter, 27. Available online at: https:// asylummagazine.org/2013/12/mad-people-of-color-a-manifesto-by-rachelgorman-annu-saini-louise-tam-onyinyechukwu-udegbe-onar-usar/

Gould, D. (2012). Service Users Experiences of Recovery under the 2008 Care Programme Approach. London: Mental Health Foundation \& NSUN.

Greenhalgh, T., and Hurwitz, B. (1999). Narrative based medicine: why study narrative? Br. Med. J. 318:48. doi: 10.1136/bmj.318.7175.48

Hall, B. L. (2005). In from the cold? Reflections on participatory research from 1970-2005. Convergence 38, 5-24.

Hall, S. (1997). The local and the global: globalization and ethnicity. Cultural Politics 11, 173-187.

Haraway, D. (1988). Situated knowledges: the science question in feminism and the privilege of partial perspective. Femin. Stud. 14, 575-599. doi: 10.2307/3178066 
Hartsock, N. C. (1983). "The feminist standpoint: developing the ground for a specifically feminist historical materialism," in Discovering Reality, Synthese Library, eds S. Harding, and M. B. Hintikka (Dordrecht: Springer), 161.

Hooks, B. (1982). Ain't I a Woman? Black Women and Feminism. Boston: South End Press.

Jackson, V. (2002). In our own voice: African American stories of oppression, survival and recovery in mental health systems. Int. J. Narrative Ther. Community Work 2, 11-31.

Jackson, V. (2018). Power: A Users Manual. Atlanta: Healing Circles.

Jacobs, J. A., and Frickel, S. (2009). Interdisciplinarity: A critical assessment. Ann. Rev. Sociol. 35, 43-65. doi: 10.1146/annurev-soc-070308-115954

Johnson, K., and Martínez Guzmán, A. (2013). Rethinking concepts in participatory action research and their potential for social transformation: Post- structuralist informed methodological reflections from LGBT and trans- collective projects. J. Community Appl. Soc. Psychol. 23, 405-419. doi: $10.1002 /$ casp. 2134

Jones, N., and Kelly, T. L. (2015). "Inconvenient complications: on the heterogeneities of madness and their relationship to disability," in Madness, Distress and the Politics of Disablement, eds. H. Spandler, B. Sapey, and J. Anderson 43-57. (London: Polity Press). doi: 10.2307/j.ctt1t898sg.8

Kalathil, J. (2009). Dancing to Our Own Tunes: Reassessing Black and Minority Ethnic Mental Health Service User Involvement. London: NSUN \& Catch-aFiya.

Kalathil, J. (2013). "Hard to reach? Racialised groups and mental health service user involvement," in Mental Health Service Users in Research: Critical Sociological Perspectives, ed P. Staddon (Bristol: Policy Press), 121-134. doi: 10.1332/policypress/9781447307334.003.0009

Kalathil, J., Bhakta, R., Daniel, O., Joseph, D., and Trivedi, P. (2011). Recovery and Resilience: African, African-Caribbean and South Asian Womens Narratives of Recovering from Mental Distress. London: Mental Health Foundation \& Survivor Research.

Kalathil, J., and Jones, N. (2016). Unsettling disciplines: madness, identity, research, knowledge. PPP 23, 183-188. doi: 10.1353/ppp.2016.0016

King, C. (2016). "Whiteness in psychiatry: the madness of European misdiagnoses," in Searching for a Rose Garden: Challenging Psychiatry, Fostering Mad Studies. eds J. Russo and A. Sweeney (Monmouth: PCCS Books), 69-76.

Kuhn, T. S. (2012). The Structure of Scientific Revolutions. Chicago: University of Chicago Press. doi: 10.7208/chicago/9780226458144.001.0001

Latour, B., and Woolgar, S. (2013). Laboratory Life: The Construction of Scientific Facts. Princeton, MA: Princeton University Press. doi: 10.2307/j.ctt32bbxc

Lopez- Baez, S. I., and Paylo, M. J. (2009). Social justice advocacy: community collaboration and systems advocacy. J. Counsel. Dev. 87, 276-283. doi: 10.1002/j.1556-6678.2009.tb00107.x

Ludden, D. (2002). Reading Subaltern Studies: Critical History, Contested Meaning and the Globalization of South Asia. London: Anthem Press.

Madden, M., and Speed, E. (2017). Beware zombies and unicorns: Toward critical patient and public involvement in health research in a neoliberal context. Front. Sociol. 2:7. doi: 10.3389/fsoc.2017.0 0007

Mason, R., and Boutilier, M. (2009). The challenge of genuine power sharing in participatory research: the gap between theory and practice. Can. J. Community Mental Health 15, 145-152. doi: 10.7870/cjcmh-1996-0015

McCall, L. (2005). The complexity of intersectionality. Signs 30, 1771-1800. doi: $10.1086 / 426800$

McIntosh, P. (2007). "White privilege and male privilege," in Race, Ethnicity and Gender: Selected Readings, eds J. F. Healey and E. Obrien (Thousand Oaks, CA: Pine Forge Press), 377-385.

Mead, S. (2014). Intentional Peer Support: An alternative approach. West Chesterfield: Intentional Peer Support.

Meerai, S., Abdillahi, I., and Poole, J. (2016). An introduction to anti-Black sanism. Intersectionalities 5, 18-35.

Molyneux, J., and Irvine, J. (2004). Service user and carer involvement in social work training: a long and winding road? Soc. Work Educ. Int. J. 23, 293-308. doi: 10.1080/0261547042000224047

Nash, J. C. (2008). Re-thinking intersectionality. Femin. Rev. 89, 1-15. doi: $10.1057 /$ fr. 2008.4

Pearce, S., and Pickard, H. (2009). The moral content of psychiatric treatment. Br. J. Psychiatry 195, 281-282. doi: 10.1192/bjp.bp.108.062729
Pembroke, L. R. (ed.) (1994). Eating Distress: Perspectives from Personal Experience. London: Survivors Speak Out.

Plsek, P. E., and Greenhalgh, T. (2001). Complexity science: the challenge of complexity in health care. Br. Med. J. 323:625. doi: 10.1136/bmj.323. 7313.625

Rahman, M. A. (2008). "Some trends in the praxis of participatory action research," The SAGE Handbook of Action Research: Participative Inquiry and Practice, eds P. Reason and H. Bradbury. (London: Sage), 49-62. doi: $10.4135 / 9781848607934 . n 9$

Reason, P., and Bradbury, H. (2008). "Introduction," in The SAGE Handbook of Action Research: Participative Inquiry and Practice, eds P. Reason and H. Bradbury (London: Sage), 1-10. doi: 10.4135/97818486 07934

Reynolds, D. (2010). Human kindness, compassion and love: the hospital ward visiting scheme designed and delivered by Canerows and Plaits. Mental Health Soc. Inclusion 14, 6-9. doi: 10.5042/mhsi. 2010.0438

Rose, D. (2001). Users' Voices. London: Sainsbury Centre for Mental Health.

Rose, D. (2003). Collaborative research between users and professionals: peaks and pitfalls. Psychiatric Bull. 27, 404-406. doi: 10.1192/pb.27. 11.404

Rose, D. (2017). Service user/survivor-led research in mental health: epistemological possibilities. Disabil. Soc. 32, 773-789. doi: $10.1080 / 09687599.2017 .1320270$

Rose, D., Carr, S., and Beresford, P. (2018). "Widening cross-disciplinary research for mental health": what is missing from the Research Councils UK mental health agenda? Disabil. Soc. 33, 476-481. doi: 10.1080/09687599.2018. 1423907

Rose, D., Evans, J., Sweeney, A., and Wykes, T. (2011). A model for developing outcome measures from the perspectives of mental health service users. Int. Rev. Psychiatry 23, 41-46. doi: 10.3109/09540261.2010.5 45990

Rose, D., Fleischmann, P., Wykes, T., Leese, M., and Bindman, J. (2003). Patients' perspectives on electroconvulsive therapy: Systematic review. Br. Med. J. 326:1363. doi: 10.1136/bmj.326.7403.1363

Rose, D., Perry, E., Rae, S., and Good, N. (2017). Service user perspectives on coercion and restraint in mental health. BJPsych Int. 14, 59-61. doi: 10.1192/S2056474000001914

Rutherford, J. (1990). "The third space: interview with homi bhabha," in Identity: Community, Culture, Difference, ed J. Rutherford (London: Lawrence and Wishart), 207-221.

Sackett, D. L. (1997). Evidence-based medicine. Semin. Perinatol. 21, 3-5. doi: 10.1016/S0146-0005(97)8 0013-4

Shapin, S. (2010). Never Pure: Historical Studies of Science as if it was Produced by People with Bodies, Situated in Time, Space, Culture, and Society, and Struggling for Credibility and Authority. New York, NY: JHU Press.

Slade, M., Bird, V., Chandler, R., Fox, J., Larsen, J., Tew, J., et al. (2010). The contribution of advisory committees and public involvement to large studies: Case study. BMC Health Serv. Res. 10:323. doi: 10.1186/1472-6963-1 $0-323$

Slay, J., and Stephens, L. (2013). Coproduction: A Literature Review. London: new economics foundation.

Spivak, G. C. (1988). Can the subaltern speak? Marxism and the Interpretation of Culture, eds C. Nelson and L. Grossberg (Illinois: University of Illinois Press), 271-316. doi: 10.1007/978-1-349-19059-1_20

Staley, K. (2009). Exploring Impact: Public Involvement in NHS, Public Health and Social Care Research. Eastleigh: INVOLVE.

Tam, L. (2013). "Whither indigenizing the mad movement? Theorizing the social relations of race and madness through conviviality," in Mad Matters: A Critical Reader in Canadian Mad Studies, eds B. A. LeFrançois, R. Menzies and G. Reaume (Toronto: Canadian Scholars Press Inc), 281-297.

The Survivors History Group (2012). "The survivors history group takes a critical look at historians," in Critical Perspectives on User Involvement. P. M. Barnes and M. Cotterell (Bristol, Policy Press), 7-18. doi: 10.1332/policypress/9781847427519.0 03.0002 
Trivedi, P. (2009). "Black service user involvement: Rhetoric or reality?, in Mental Health in a Multi- Ethnic Society: A Multidisciplinary Handbookm eds S. Fernando and F. Keating (London: Routledge), 136-146.

UN HRC (2017). Report of the Special Rapporteur on the Right of Everyone to the Enjoyment of the Highest Attainable Standard of Physical and Mental Health. Geneva: United Nations. A/HRC/35/21.

Van Dijk, T. A. (1992). Discourse and the denial of racism. Discourse Soc. 3, 87-118. doi: 10.1177/095792659200300 1005

Voronka, J. (2017). Turning mad knowledge into affective labor: the case of the peer support worker. Am. Q. 69, 333-338. doi: 10.1353/aq.2017.0029

Wilson, A. (2006). Dreams, Questions, Struggles: South Asian Women in Britain. (London: Pluto Press).
Zuberi, T., and Bonilla-Silva, E. (2008). White Logic, White Methods: Racism and Methodology. Plymouth: Rowman and Littlefield.

Conflict of Interest Statement: The authors declare that the research was conducted in the absence of any commercial or financial relationships that could be construed as a potential conflict of interest.

Copyright (c) 2019 Rose and Kalathil. This is an open-access article distributed under the terms of the Creative Commons Attribution License (CC BY). The use, distribution or reproduction in other forums is permitted, provided the original author(s) and the copyright owner(s) are credited and that the original publication in this journal is cited, in accordance with accepted academic practice. No use, distribution or reproduction is permitted which does not comply with these terms. 


\section{Plain English Summary \\ Public and patient involvement and the right to health in England}

\section{Maria Stuttaford, Therese Boulle, Hanne Jensen Haricharan, Zingisa Sofayiya}

This article is about public and patient involvement and the right to health in England. In recent years there have been a number of high-profile cases in the media reporting formalized mechanisms of public and patient involvement in health care provision in England (for example consultations on health service changes).

The first example we have chosen is the review of child heart surgery launched after the deaths of children at Bristol Royal Infirmary. In February 2011 it was recommended that 4 out of 11 units in England would no longer offer such surgery, including Leeds General Infirmary Children's Heart Surgery. Following a social and legal campaign by Save Our Surgery (SOS), the High Court over-turned the decision to stop surgery at Leeds saying that participation in the decision-making process had been flawed.

The second example is the Francis Inquiry into the Mid Staffordshire NHS Foundation Trust following a failure of patient care between 2005 and 2008. Published in February 2013, Francis pointed out that it was only because of a group of concerned patients that the poor performance of the Trust came to light. The inquiry found many failings including the failure to be accountable to the public and patients. The formal governance systems and formal mechanisms for involving patients (for example through patient surveys) failed. In the recommendations, Francis highlighted the need for a change in culture. He explained that it was not enough to only have formal regulation mechanisms in place and that there needs to be a culture, or set of values, to commit to use the monitoring data and genuinely involve the public.

In this paper we use these two cases to reflect on public and patient involvement and the right to health We argue that the new models of formalized participation have focused on the mechanisms of participation and accountability. Human rights principles such as dignity, respect and equality, provide a set of values for strengthening participation. For example, participation is not simply about having procedures in place. It is also about making sure that everyone participating in those procedures have access to accurate information and decisions are made fairly.

Our reflections illustrate the challenges posed by formalized participation. Where there have been investigations into healthcare failures, it has been found that there have been formal mechanisms for public and patient participation in place. However, people's voices have not been listened to and the evidence and data collected through formalized participation is often ignored. For example, complaints procedures have not been strong enough to hold people accountable.

These two cases show how weak formalized participation and accountability have only come to light because of the less formalized, civil society-led action of public and patient groups, such as the action of Leeds SOS and Mid Staffordshire Cure NHS. This paper argues that by embracing participation not only as a mechanism but also as part of a set of values linked to the right to health, formalized participation could be strengthened, and accountability improved. 


\section{OPEN ACCESS}

Edited by:

Ewen Speed,

University of Essex, UK

Reviewed by:

Martha Judith Chinouya, University of Liverpool, UK Felismina Rosa Mendes, University of Évora, Portugal

*Correspondence:

Maria Clasina Stuttaford stuttafordm@cardiff.ac.uk

Specialty section: This article was submitted to Medical Sociology, a section of the journal

Frontiers in Sociology

Received: 08 December 2016 Accepted: 22 March 2017

Published: 10 April 2017

Citation:

Stuttaford MC, Boulle T, Haricharan HJ and Sofayiya Z (2017)

Public and Patient Involvement and the Right to Health: Reflections from England.

Front. Sociol. 2:5.

doi: 10.3389/fsoc.2017.00005

\section{Public and Patient Involvement and the Right to Health: Reflections from England}

\author{
Maria Clasina Stuttaford ${ }^{1,2 *}$, Therese Boulle ${ }^{2}$, Hanne Jensen Haricharan ${ }^{2}$ \\ and Zingisa Sofayiya ${ }^{2}$
}

${ }^{1}$ Centre for Global Health, Old Dominion University, Norfolk, VA, USA, ${ }^{2}$ School of Public Health and Family Medicine, University of Cape Town, Cape Town, South Africa

In this paper, we reflect on public and patient involvement (PPI), the right to health and how human rights principles provide values for implementing mechanisms of participation and accountability. Globally, new models of formalized participation, imposed topdown by State institutions, have emerged in recent health system reforms. There is an on-going challenge to ensure that the prescribed mechanisms, or procedural rights, for implementing the substantive right to heath influence social accountability. Participation is linked to procedural rights, e.g., through right to information and fair decision-making processes. We explore recent examples from England to illustrate the challenges posed by formalized participation. Inquiries into health-care failures have found participatory mechanisms to be in place but evidence and data collected through formalized participation often ignored. Complaints procedures have not been sufficiently robust to hold duty bearers to account. The examples expose how weak formalized participation and weak accountability have only come to light through civil society-led participation. It is argued that by embracing participation not merely as a mechanism but also as part of a set of values linked to the right to health, formalized participation could be strengthened. Data, evidence, and knowledge gathered through formalized participation and civil society-led participation should be valorized alongside other forms of evidence. The indivisibility of the right to health should be recognized through participation across sectors. Adopting $\mathrm{PPI}$ as comprising mechanisms and values poses renewed challenges to those with obligations of service provision and to public participants to integrate diverse forms of participation and knowledge that contributes to social accountability.

\footnotetext{
Keywords: right to health, participation, accountability, public and patient involvement, mechanisms of participation, procedural rights, values of participation, valorize diverse knowledge
}

\section{INTRODUCTION}

In recent health system reforms in England, there have been a myriad of mechanisms implemented as part of formalizing participation. However, as this paper illustrates, there are shortcomings with such approaches to formalized participation. It is argued in this paper that the right to health and a focus on participation as a value are important aspects of promoting genuine participation and accountability in health systems. In the recent past, there has been some investigation by the National Health Service (NHS), England into rights-based approaches. In 2007, the British Medical Association and Commonwealth Medical Trust published "The right to health: a toolkit for health professionals," however, this was largely aimed at health-care professionals going to work abroad and reflected the belief that human rights was something for the "overseas development" 
agenda, not relevant or necessary in England. Also in 2007, the British Institute for Human Rights published "Human Rights in Healthcare-A Framework for Local Action" which focused on the UK context for implementing the right to health and signaled the start of several pilot projects in the NHS as part of the Human Rights in Healthcare Program. This program was suspended in 2013. Nevertheless, some local programs continued. For example, Mersey Care's Learning Disability Service continued using a human rights-based approach. ${ }^{1}$ As part of this approach, participation of service users was maximized, and human rights were seen as a unifying framework to integrate equality and diversity into risk management (Dyer, 2010). The evaluation of the program found that service user involvement led to patients reporting improved well-being as well as to health services changes (Dyer, 2015). Embedding participation as a value and as a mechanism was facilitated by a human rights-based approach and led to improved patient reported outcomes.

Participation is a component of strengthening health systems (Hunt and Backman, 2008). Public and patient involvement (PPI) includes participation in decisions relevant to health care at all levels, from individual personal care to national policy. For the purposes of this paper, we distinguish between formalized participation, which is instigated by the State, and civil society-led participation, which is initiated by civil society. Participation is linked with the right to health and social accountability (Potts, 2008a,b). The right to health is enshrined in international, regional, and domestic law. As such, realizing the right to health relies on States ratifying international covenants and including the right to health in legislation and having a judicial process and democratic structures to uphold the right. United Nations (UN) General Comment 14 on the right to the highest standard of health details State obligations to respect, protect, and fulfill the right to health and this includes ensuring that mechanisms of participation and procedural rights are in place (UN, 2000). Procedural rights are the formal mechanisms necessary for implementing substantive rights such as the right to health. They are an "important aspect in the participation of the population in all health-related decisionmaking at the community, national and international levels" (UN, 2000, paragraph 11) and include access to information and involvement in fair decision-making processes. In addition to the legal framework, in order for the right to health to become a reality, civil society participation and action is necessary (London, 2007). Participation and accountability are interdependent (Potts, 2008a). We draw in particular on the work of Bovens (2010) who argues for the virtue of accountability to be developed alongside the mechanisms of accountability. We apply this use of the concept of virtue to participation, arguing that values of participation require development alongside the mechanisms of participation. For the purposes of this paper, we use the Oxford English Dictionary definition of values as: "one's principles or standards." We prefer the term "values" where Bovens uses virtue for several reasons. The term virtue implies something morally good, and it is possible that participation may not always be for benevolent

${ }^{1}$ http://www.merseycare.nhs.uk/our-services/a-z-of-services/learning-disabilitycommunity-teams/. purposes or have positive outcomes. The term "values" is a more inclusive term acknowledging that there may be a diversity of principles and lived experiences of participation. Bradby (2016) posed the challenge "to interrogate the social processes of health and illness, to contribute to more humane, equitable, and effective health that integrates scientific evidence with people's values and experience." We explore the values of participation as part of these social processes.

The focus here is on the benefits of rights-based approaches to health, including the ability to hold States accountable (Yamin, 2008). We acknowledge the critique of rights-based approaches to health (Preis, 1996; De Cock et al., 2002; Mchangama, 2009; Reubi, 2011) including that such an approach may silence the voices of the most vulnerable (Ferraz, 2009). Linked to this is the argument that a vocal elite drives the "judicialization of health" with access to the legal system and resources necessary to file lawsuits. However, research from Brazil shows that it is in fact the most vulnerable that make use of judicial accountability and that participation is an important instrument of civil society organizations (CSOs) (Biehl et al., 2016, p. 2010). We also acknowledge the wealth of literature on participation and research (e.g., Evans et al., 2010) and participation and health improvement (e.g., Rifkin, 2014) but we focus here on participation and accountability. We draw on our experiences from these fields. We acknowledge the reality that participation is becoming mainstreamed and the danger that participation becomes appropriated and another word for limited consultation. In order to guard against this, human rights defenders need to find ways of reclaiming participation and of ensuring it influences social accountability and the enforcement of legal remedies through compensation, prevention and redress of human rights violations (Boaz et al., 2014).

We begin with an overview of key literature on the right to health and participation. We then present the value of participation and accountability and the importance of valorizing diverse knowledge as our conceptual framework for reflecting on the right to health and participation. Following an outline of methods used, three examples are reflected on. The first is the consultation around the proposed closure of Leeds General Infirmary Children's Heart Surgery Unit. The second is on the findings of the Mid Staffordshire NHS Foundation Trust Public Inquiry into hospital patient care. The third is the presentation of these two examples to a workshop of two Healthwatch organizations. Healthwatch organizations are a type of formalized participation established by the State nationally to promote PPI at a local level. Workshop participants reflected on their experiences of PPI using the conceptual framework of values of participation and valorizing diverse knowledge in an intersectoral approach. These three examples provide reflections on formalized participation and have relevance to a growing global trend of States implementing participation from the top-down.

\section{THE RIGHT TO HEALTH AND PARTICIPATION}

The United Kingdom (UK) has ratified several key international conventions as well as regional treaties relevant to the right to health and participation. Recent health system reforms have 
sought to formalize participation, making England a relevant context for reflecting on participation as a value, valorizing diverse knowledge, and how a rights-based approach might assist in developing participation and accountability. The Universal Declaration of Human Rights (1948) established the right to health and the International Covenant on Economic, Social, and Cultural Rights (ICESCR) (UN, 1966) sets out a requirement that legally States parties (countries that have ratified the ICESCR, including the UK) recognize the right of everyone to the enjoyment of the highest attainable standard of physical and mental health. The indivisibility of the right to health from other rights is reflected in the ICESCR and in the inclusion of health in other UN conventions such as the International Convention on the Elimination of All Forms of Racial Discrimination (1965), the Convention on the Elimination of All Forms of Discrimination Against Women (1979), the Convention on the Rights of the Child (1989), and the Convention on the Rights of Persons with Disabilities (2006). In addition to referring to the right to health, the Conventions incorporate participation. For example, the UN Special Rapporteur report on poverty and human rights places participation as a human right in itself and as a requirement or catalyst for overcoming inequalities (UN, 2013). UN General Comment 14 on the right to health, while not legally binding, provides robust and widely accepted guidance on implementing State obligations and stipulates that "the participation of the population in all health-related decision-making at the community, national and international levels" is a part of the determinants of health (UN, 2000, article 5). States are obliged to implement a health strategy that includes participatory methods of monitoring the progressive realization of the right to health. In addition, the right to health includes "the right to seek, receive and impart information and ideas concerning health issues" (UN, 2000, article 12b). Regional frameworks exist not only in terms of individual signatory countries but also in regional charters, conventions, and agreements. Together, these international and regional Conventions and General Comments form the basis for participation and accountability implemented through national law and policies. However, they do not specify who the participants should be or how they should work.

In several countries, alongside health sector reforms, there has been an increase in formalized participation such as Healthwatch in England (Thorlby et al., 2014), health committees (Boulle, 2008; Haricharan, 2012), citizens' juries (Whitty et al., 2014), and deliberative public participation (Abelson et al., 2007). In the context of the right to health, Potts (2008a) defines participation as individual and group participation with government in decisions that affect the people participating. Furthermore, fair and transparent participation includes institutional mechanisms; capacity building to ensure that people can participate; participation in agenda setting, policy choices, implementation, and monitoring and evaluation; accountability mechanisms and remedies (Potts, 2008a). In the context of human rights, accountability refers to the compliance of duty bearers to fulfilling obligations under international, regional, and domestic laws and treaties (Potts, 2008b). Social accountability is here defined as "citizen action to oversee government conduct" (Potts, 2008b). For the purposes of this paper, we see participation as an element of accountability; participation with government leading to accountability with concomitant health system reforms and remedies for violations of the right to health.

Recent reviews of research into the benefits of participation (McCoy et al., 2011; Mockford et al., 2011; Rifkin, 2014) have found weak evidence in support of the added benefit of participation and little reported research of good practice in relation to the implementation of participation. Nevertheless, participation has been found to improve: quality and coverage of health care; health outcomes; service planning and development; information development and dissemination; and attitudes of service users and providers (McCoy et al., 2011; Mockford et al., 2011). Achieving successful participation, whether implemented in a formalized way or civil society led way, faces numerous challenges, related to contextual factors and power relations. These include resources, skills, access to appropriate media, trust, ethics, and motivations for participating (Fienieg et al., 2011). In addition, an exclusionary "participatory mainstream" (Philo and Metzel, 2005, p. 77) comprising a self-selecting, unrepresentative minority might dominate or, people may seek to influence the encouragement of "uncivil" society not motivated by benevolence (Mosse, 2001, p. 16). Finally, one of the limitations of participation is that people may become "voices without influence" (Cornwall and Gaventa, 2001, p. 40) in which people are repeatedly engaged with but then without any action being taken as a result of the engagement. Furthermore, while in this paper we focus on the local we recognize there is a global context which influences and may even manipulate local participation (Mohan and Stokke, 2000 , p. 263). Human rights defenders need to guard against participation being about a discrete State and a discrete civil society and rather acknowledge the need to transcend local/global and State/civil society binaries (Mohan and Stokke, 2000, p. 263). Participation is therefore situated at the intersection of different forms of power, spheres of influence, and levels of actions and policies, creating sites for health rights across spheres of power and influence (Stuttaford et al., 2014). These sites may support or hinder the implementation of the right to health (Stuttaford et al., 2009). There are different mechanisms of participation relevant to different contexts. Participation, whether formalized, civil society-led, or a combination of these, can all have weaknesses. We argue that the focus has remained on mechanisms of participation rather than a consideration of the values of participation. Not all knowledges and evidence gathered through different formal and civil society-led participation has been treated equally and there have been limited attempts at intersectoral formalized participation. In order for formalized participation to not simply be consultation, the values of participation need to be embraced along with valorizing diverse knowledge and adopting intersectoral approaches that achieves the fair and transparent participation defined by Potts (2008a) as a part of wider social accountability.

\section{VALUES OF PARTICIPATION AND ACCOUNTABILITY}

Accountability is not only about remedying violations but also about participating in health system reform (Yamin, 2008). In designing accountability mechanisms, attention needs to be paid to the values of health sector management, public, and patients 
(Cleary et al., 2013). In order for there to be accountability, i.e., in order for States parties to engage in accountability processes, it is important for accountability to be seen as a virtue as well as ensuring that mechanisms of accountability are in place (Bovens, 2010). In the same way, there are mechanisms for accountability, there are mechanisms for participation. Similarly, in the same way, accountability needs to be seen as a virtue, we argue that participation should be seen as part of a set of values.

General Comment 14 highlights human rights principles of non-discrimination, participation, and accountability in relation to the accessibility, availability, acceptability, and quality of health services and the determinants of health (UN, 2000). A human rights-based approach to health uses the full complement of international covenants and soft law (non-legally binding instruments, e.g., policies, codes of conduct, professional guidelines, and patient charters) and includes the principles of information, transparency, accountability, and participation (WHO, 2002). Potts' monographs on participation and the right to health (Potts, 2008a) and accountability (Potts, 2008b) illuminate and describe in clear terms State obligations around participatory processes. She identifies five broad mechanisms of accountability, which are linked to participation: judicial, quasi-judicial, administrative, political, and social accountability. While civil society may participate in all five mechanisms of accountability in some way, it is the social mechanisms that are focused on in this paper. Potts is also clear that accountability is not the same as responsiveness, responsibility, answerability, or evaluation because none of these necessarily lead to a remedy of past violations or mitigation of current or future violations. Remedies to redress violations include restitution, compensation, rehabilitation, and satisfaction and guarantee of non-repetition of human rights violations (Potts, 2008b). The guarantee of non-repetition includes health system and organizational changes through, for example, changes in accountability, policy formulation, budgeting, and training (Potts, 2008b). In implementing the right to health and social accountability, participation by CSOs is vital (London, 2007). CSOs may participate in advocacy, developing policies and programs, monitoring State obligations, and addressing violations of the right to health (London, 2007). Participation in these ways should lead to restitution, compensation, rehabilitation, and satisfaction and guarantee of non-repetition of human rights violations. However, there is a danger that social accountability mechanisms become focused on simply monitoring. While this monitoring may collect valuable evidence of violations or data to support health system reform, if there is no remedy then such participation through monitoring fails to link to social accountability. Simply monitoring, without leading to a remedy is a weak form of participation leading to weak accountability. In order for participation to lead to social accountability with a remedy, both parti-cipation and accountability need to be seen as values.

Accountability as a virtue has positive implications and is often synonymous with norms of behavior (Bovens, 2010) congruent with human rights norms that include transparency, responsibility, and participation. As a mechanism, accountability can be seen as a social relationship that involves an obligation to explain decisions and actions. This means there is a relationship of participation between the rights duty bearers (actors, usually
State actors, with obligations to protect, respect, and fulfill human rights) and rights holders (people entitled to the rights). Potts (2008a,b) and Bovens (2010) make the link between participation and accountability. We propose extending this link in two ways. First, by arguing that in the same way that accountability should be seen as both a mechanism and virtue, so participation should also be seen as both a mechanism and a value. Second, we suggest that a human rights framework provides guidance on what these values of participation might be.

\section{VALORIZE DIVERSE KNOWLEDGE}

General Comment 14 on the right to health includes an obligation of State parties:

To adopt and implement a national public health strategy and plan of action, on the basis of epidemiological evidence, addressing the health concerns of the whole population; the strategy and plan of action shall be devised, and periodically reviewed, on the basis of a participatory and transparent process; they shall include methods, such as right to health indicators and benchmarks, by which progress can be closely monitored; the process by which the strategy and plan of action are devised, as well as their content, shall give particular attention to all vulnerable or marginalized groups (UN, 2000, article 43f).

While this establishes participation as part of accountability mechanisms, it suggests only a narrow definition of evidence and gives primacy to epidemiological evidence alone. Furthermore, there is little guidance on who will participate or how they will participate.

Participation requires engagement with a diversity of knowledges from civil society, the rights holders, and also the multiple knowledges of the duty bearers. Whereas General Comment 14 emphasizes epidemiological evidence, this is only one form of data, emanating from one source. A broader and deeper view of evidence and who provides evidence is required than simply relying on epidemiological data. Self-reflection on diverse views of human rights, forms of oppression and resistance, and social practices leads to the production of a plurality of knowledge (de Sousa Santos et al., 2007). From this practice, we learn that "there are neither pure nor complete knowledges; there are constellations of knowledges" (de Sousa Santos et al., 2007, p. xl). While General Comment 14 focuses on epidemiological data that is reviewed using participatory mechanisms, here we argue that the data and evidence considered should itself be sourced from participatory approaches and methods. If participation through social accountability is to lead to restitution, compensation, rehabilitation, and satisfaction, guarantee of non-repetition of rights violations and health system reform, a deeper form of participation beyond simply reviewing epidemiological data is needed. All data, whether collected through traditional methods such as epidemiological studies, civil society-led participation or formalized participation should be valorized to ensure constellations of knowledges contribute to participation that is part of social accountability. 
When seeking the inclusion of diverse knowledges in participation and accountability, from a range of CSOs, an intersectoral approach is necessary. In addition to developing the values of participation and valorizing all knowledge, there needs to be participation across sectors. General Comment 14 emphasizes the right to health as including the determinants of health as well as health care (UN, 2000) and in this way provides guidance on the indivisibility of socio-economic and cultural rights and civil and political rights. The groundwork is therefore laid within international guidance for an intersectoral approach at the national and local level for participation in a rights-based approach to health. In order for the right to health to be implemented as integral to the health system, collective civil society participation is necessary (London, 2007). As Yamin (2008) points out, "a rights-based approach calls for an authentic devolution of power within and beyond the health sector, with a transfer of planning and decision-making capacities to the individuals and communities served" (Yamin, 2008, p. 13). Individual litigation (e.g., a case of medical malpractice) at the national level might be useful in specific cases and at an international level, the UN Committee on Economic, Social and Cultural Rights has the authority to link international norms to individual complaints (Murphy, 2013). However, the strength of a rights-based approach lies not so much in individual litigation but rather in the recognition that where there are individual cases of poor care, this is usually symptomatic of wider health system failures (Yamin, 2008). In Argentina and Colombia, there are examples of judicial accountability in which the Constitutional Court has not only sought to remedy rights violations through compensation, restitution, and guarantees of non-repetition but have also called for reform of the health system in terms of greater public participation (Yamin, 2008). In Brazil's health system, the establishment of a legal framework for participation, the engagement with participatory institutions, and the link to social accountability mechanisms have led to "extend[ing] the capillary reach of the democratizing effects of engagement" into the whole of the health system (Cornwall and Shankland, 2008, p. 2173). Valuing diverse knowledge not only extends who participates and what evidence is gathered but also extends participation to include all sectors across society to deepen the recognition of the indivisibility of the right to health.

In this paper, we apply the above framework of recognizing diverse knowledge in participation and implementing both mechanisms and values of participation to three examples of formalized participation in England. The first example is a reflection of a consultation process in Leeds. The second example is a reflection on monitoring patient care in Mid Staffordshire. The final example is from a workshop with two Healthwatch organizations that reflected on their own experiences, based on the findings from the first two examples.

\section{METHODS}

The research was primarily a desk-based study reviewing and reflecting on examples from England and as such did not obtain institutional ethical approval. We originally prepared this paper as a comment piece on the right to health, participation, and accountability. It came about as a result of a series of conversations between the authors during which we encouraged each other to read and reflect on each of our differing contexts. Maria Clasina Stuttaford identified examples from England, reflecting on them with colleagues as examples of formalized participation.

Following the process of reflection on the examples, Maria Clasina Stuttaford was invited by two Healthwatch organizations to develop a joint workshop on the right to health and participation. Healthwatch organizations are social enterprises and a type of formalized participation established nationally to promote PPI at a local level. Maria Clasina Stuttaford presented a draft of this paper to the two Healthwatch organizations and their partners in London, England in June 2016. At the outset of the workshop, the participants asked Maria Clasina Stuttaford if the workshop could be recorded for dissemination to wider members and this was agreed. Maria Clasina Stuttaford explained that participants could complete paper handouts in groups or individually, anonymously, if they so wished. At several moments, the presentation was paused, and Maria Clasina Stuttaford asked small groups to discuss key questions and capturekey points on the handouts. Responses about individual affiliations on the 11 handouts returned at the end of the workshop were incomplete but it is likely that 2 handouts were completed as a whole group (about 20 people in total) and individuals completed 9 handouts. Participants included health professionals, patient participation group members, trustees of patient networks and academics. During the presentation, workshop participants were asked to reflect on elements of participation and accountability in their practice and experiences of Healthwatch activities. The aim of the workshop was to move away from simply listing the well-rehearsed and-documented challenges of participation to attempt to consider more broadly how the right to health might inform PPI and accountability. Maria Clasina Stuttaford typed up responses on the handouts and disseminated these back to the Healthwatch organizations for their further use. Participants verbally consented that material captured on the handouts would contribute to this paper and that they would receive copies of the paper upon publication.

\section{Setting}

We selected England for the focus of this paper because the introduction of formalized mechanisms of participation has been a part of recent health system reform. England provides an opportunity to consider the extent to which participation is seen as part of a set of values and the how diverse knowledge is valorized. The UK has ratified the ICESCR (1966) and several other key international conventions as well as regional treaties relevant to the right to health and participation. Formal mechanisms of participation and social accountability in England include national and local elections, boards of enquiry, judicial reviews, and cross party parliamentary committees. In this paper, we consider direct participation through local structures. The focus is on England as some of the functions of health and social care in the UK are devolved to Scotland, Wales, and Northern Ireland.

The mechanisms for public participation and accountability in England are set out in The Health and Social Care Act (2012). ${ }^{2}$

${ }^{2}$ http://www.legislation.gov.uk/ukpga/2012/7/contents/enacted. 
A key mechanism of formalized participation is through local Healthwatch organizations that are social enterprises established within national, set guidelines and with specified functions. They operate locally with government and primary and secondary health and social care providers and are inclusive of other sectors such as housing, education, and transport. They also engage with other community-based and non-government organizations. Local Healthwatch organizations are represented nationally by Healthwatch England, which reports to the Secretary of State for Health.

In terms of the values associated with participation and accountability, these are enshrined in the NHS England Constitution. The principles of the NHS Constitution include accountability to elected parliament and local people and the: "system of responsibility and accountability for taking decisions in the NHS should be transparent and clear to the public, patients and staff" (NHS, 2015, p. 4). The NHS Constitution also includes the values of: "[w] orking together for patients.... We fully involve patients, staff, families, carers, communities, and professionals inside and outside the NHS" (NHS, 2015, p. 5). These values include core human rights principles of dignity and non-discrimination. The NHS Constitution explicitly sets out rights of participation to include:

the right to be involved, directly or through representatives, in the planning of healthcare services commissioned by NHS bodies, the development and consideration of proposals for changes in the way those services are provided, and in decisions to be made affecting the operation of those services (NHS, 2015, p. 9).

As part of these rights, the NHS Constitution pledges, "to make decisions in a clear and transparent way" (NHS, 2015, p. 7) and "to provide you with the information and support you need to influence and scrutinize the planning and delivery of NHS services" (NHS, 2015, p. 10).

In England, whereas mechanisms of formalized participation and accountability are enshrined in the Health and Social Care Act, the values of participation are detailed simply in the soft law of the NHS Constitution. Reflecting on the examples below illustrates how greater emphasis on human rights principles may assist in enhancing the application of the soft law and hard law to improve overall participation and accountability, not only in individual care but also in health system reform.

\section{EXAMPLES AND DISCUSSION OF PARTICIPATION IN ENGLAND}

Formalized participation in England is moving ahead as local Healthwatch organizations extend their work. However, it is useful to consider the challenges of other formalized participation to ensure that the mechanisms and values of participation and accountability are embedded in these relatively new and evolving structures. Examples of consultation around changes in service provision in Leeds and monitoring care in Mid Staffordshire are now presented. They are used to reflect on the challenges of more recent mechanisms of formalized participation, namely Healthwatch, and the importance of civil society-led participation and the need to embrace the values of participation, to valorize all knowledge, and to work across sectors.

\section{Leeds General Infirmary Children's Heart Surgery Unit: Values of Participation in Health System Reform}

The debacle about the closure of Leeds General Infirmary Children's Heart Surgery Unit highlights some of the challenges of participation when there is weak or flawed participation and the importance of following values of participation in health system reform. The Leeds example illuminates the importance of the right to information as part of the right to health, as stipulated in the UN General Comment 14 which States that the right to health includes "the right to seek, receive and impart information and ideas concerning health issues" (UN, 2000, p. 12b) and that there should be "the participation of the population in all health-related decision-making at the community, national and international levels." The Leeds example is an illustration of civil society-led participation and how such non-formalized accountability engages with and amplifies judicial accountability.

Between 1991 and 1995, 30-35 more children under 1-year old died after open-heart surgery at Bristol Royal Infirmary than would have been expected at a typical, similar unit in England (Kennedy Report, 2001). In 2008, a review of child heart surgery was launched and in February 2011, it was recommended that 4 out of 11 units in England no longer offer surgery. On the 1st of March 2011, parents led a delegation to parliament to lobby to save the surgery unit at Leeds and on the 15th of March the "Save Our Surgery" (SOS) campaign was launched comprising patients, activists, and health workers. In July/August, there was a formalized consultation exercise. The civil society-led campaign by SOS continued in parallel to the formalized participation. In July 2012, the NHS Joint Committee of Primary Care Trusts announced surgery at Leeds would stop, however, the SOS campaign continued and in October SOS applied to the High Court for a judicial review.

Social rights are not recognized as such in English law and there is therefore no right to health on which to hang legal arguments about participation. Other grounds for the right to health are required. Therefore, SOS did not challenge the legal merits of whether the Joint Committee of Primary Care Trusts decision was right or wrong. The challenge was to the process of participation. As part of the review of services, a panel of experts visited each unit and a score based on performance was assigned to a Quality of Services assessment. The sub-scores were not made available to all involved in the participation process. In the High Court decision, issues were raised about the lack of disclosure of all relevant information to all parties, the reliability of data in the assessment, the weighting of scores related to quality, and the importance assigned to factors related to accessibility and availability. On the 7th of March 2013, the High Court quashed the decision to stop surgery at Leeds ruling that the participation process and decision-making process underpinning the assessment was unfair and legally flawed. Cheng (2013) from SOS said: 
Winning this case in the High Court proves once and for all that the supposed consultation was a rubberstamping exercise conducted with an outcome in mind, with clinicians, MPs and patients fooled into feeling they had influence.

The Leeds case raises a number of important issues. First, it provides helpful guidance to those embarking on formalized participation as to what constitutes lawful involvement. In its decision, the High Court set out that:

Lawful consultation requires that: i) it is undertaken at a time when proposals are still at a formative stage; ii) it must include sufficient reasons for particular proposals to allow those consulted to give intelligent consideration and an intelligent response; iii) adequate time must be given for this purpose; iv) the product of the consultation must be conscientiously taken into account when the ultimate decision is taken (EWHC, 2013).

While this guidance speaks to the mechanisms of participation, it also speaks to the values of participation in that the product of discussion must be "conscientiously taken into account." Second, the case alerts us to the potential limits of relying purely on formalized participation. Ultimately, the rights holders, through civil society-led participation by SOS, took responsibility for establishing social accountability first through the formation of SOS and then by engaging with judicial accountability mechanisms to hold the rights duty bearers which in this case was, the Joint Committee of Primary Care Trusts, to account. While formalized participation is meant to be a way of leveling the participatory playing field, where such participation is weak it may be as unequal and unrepresentative as civil society-led participation can be. Third, the High Court ruling illuminates the importance placed on social accountability and the need for the duty bearer to ensure all relevant data and evidence is made available to the rights holders.

Save Our Surgery took action to influence formalized participation and power relations in physical spaces of protest and courts, creating sites in which duty bearers were held accountable for the right to health. Through their actions, SOS influenced future policies related to information sharing and participation. It is possible to think of the mechanisms of participation as relating to procedural rights. In the Leeds example, the State has not been held accountable in relation to the substantive right to health, but rather to procedural rights related to transparent information sharing and fair participation in decision-making. This example provides useful lessons in demonstrating the importance of human rights principles of access to information, transparency, and accountability through participation as part of a set of values linked to the norms of procedural rights.

\section{Mid Staffordshire NHS Foundation Trust Public Inquiry: Valorizing Diverse Evidence}

The Mid Staffordshire example highlights the importance of not simply putting mechanisms or procedural rights in place but also valorizing all evidence and adopting values of participation.
Following a failure in patient care between 2005 and 2008, the Mid Staffordshire NHS Foundation Trust Public Inquiry was launched and its findings published in February 2013 by Robert Francis QC. In his introduction, Francis (2013) acknowledged that it was only as a result of the concern for care and attention to mortality rates by a "a determined group of patients" called Cure NHS and led by Julie Bailey, that the situation in Mid Staffordshire NHS Foundation Trust came to light. Francis (2013) found not only a failure of the Foundation Trust Board but also of the regulatory system that was meant to ensure governance and care standards were met. Evidence and information were not given sufficient importance: "Statistics and reports were preferred to patient experience data, with a focus on systems, not outcomes" (Francis, 2013). For example, the 2007 in-patient survey, for some items, placed the Trust in the worst performing 20\% of Trusts in the country yet no action was taken (Francis, 2013).

Trust management had no culture of listening to patients. There were inadequate processes for dealing with complaints and serious untoward incidents. Staff and patient surveys continually gave signs of dissatisfaction with the way the Trust was run, and yet no effective action was taken and the Board lacked an awareness of the reality of the care being provided to patients. The failure to respond to these warning signs indicating poor care could be due to inattention, but is more likely due to the lack of importance accorded to these sources of information" (Francis, 2013).

Furthermore, there was a failure of LINks-the precursor to Healthwatch - as well as locally elected representatives. Although the mechanisms for social accountability were in place through formalized participation, these procedural rights failed.

The Francis Inquiry cautioned that reforms established after LINks, namely the establishment of Healthwatch, are in danger of repeating the same failings as LINks. There was an exclusion of patients and a failure of participation mechanisms:
[A] system of small, virtually self-selected volunteer groups which were free to represent their own views without having to harvest and communicate the views of others ... The system gave rise to an inherent conflict between the host, which was intended to provide a sup- port service but in practice was required to lead with proposals and initiatives offered to lay members, and members of the forum, who were likely to have no prior relevant experience and to be qualified only by reason of previous contact with the hospital to be scrutinized ... A preoccupation with constitutional and procedural matters and a degree of diffidence towards the Trust prevented much progress (Francis, 2013).

The report went on to recommend that in order to put patients first, there does not need to be reorganization, but a shift in culture, including "Emphasis on and commitment to common values throughout the system by all within it" (Francis, 2013). These reforms are not about changing the accountability mechanisms, 
but about shifting values of accountability and ensuring: "There must be real involvement of patients and the public" (Francis, 2013). The 290 recommendations from the Francis Inquiry refer to all aspects of the health system including putting the patient first; simplifying regulation; monitoring and enforcement of compliance; accountability of Board and enhancement of governor's roles; effective complaints procedures; training and education; patient and public participation; transparency and candor; caring and compassion; and leadership.

In addition to the ongoing reform of the NHS as set out in the Health and Social Care Act (2012; see text footnote 2), the government presented its response to each of the Francis Inquiry recommendations in Hard Truths: The journey to putting patients first (Department of Health England, 2013). Hard Truths accepts that the NHS Constitution should be the main reference point for patients and staff, including where services are outsourced (i.e., private sector accountability) and that patients should be put first. Methods of making a complaint or comment must be readily available to patients-both individually and collectively and should be investigated and handled appropriately. Commissioners, scrutiny committees, and others with oversight must have access to complaints [response to recommendations 109-122 (Department of Health England, 2013)]. Local oversight and scrutiny of quality of care will take place through local authorities, Health and Wellbeing Boards, NHS commissioners and providers, and local Healthwatch organizations. While each Healthwatch develops their own roles and responsibilities locally, there is national guidance encouraging joint working to improve the quality of services (response to recommendations 145-147). It is recognized that training for people volunteering for these structures is important (response to recommendation 148 and 149) and that some functions, such as inspections may be better suited to local authority scrutiny committees than patient participation structures (response to recommendation 149). Furthermore, "Every healthcare organization and everyone working for them must be honest, open and truthful in all their dealings with patients and the public" (recommendation 173) and in response to this the Government has introduced a new statutory duty of candor on providers that will ensure patients are given the truth when things go wrong, and that honesty and transparency are the norm in every organization (response to recommendations 173-184). The government response, at least on paper, therefore includes the values of participation, valorizing all data, and working across sectors.

One year after the Francis Inquiry, the Nuffield Trust explored the implementation of its recommendations (Thorlby et al., 2014). They found that hospital trusts had welcomed the Inquiry as it added legitimacy to ongoing efforts to improve care, while also meeting financial and performance targets. In particular, the Inquiry was said to be useful for developing work on handling complaints, and improving both staffing levels and engagement with staff. It was found that Trusts had developed their own initiatives to gather data about quality of care, particularly at hospi-tal ward level, including combining clinical and patient repor-ted data. This is evidence of a move toward valorizing clinical data alongside other data including that provided through the participation of patients. However, writing in a national newspaper The Sunday Telegraph (2 February 2014), the head of the Care Quality Commission, David Prior, highlighted two on-going concerns. First, the division between managers and clinicians leading to poor quality care. Second, inappropriate forms of accountability, such as waiting time targets, diverting attention from achieving quality care. In order to implement the Inquiry recommendations, the voices of patients and health professionals need to be listened to. The scrutiny powers of elected local authorities and the participation of civil society through local Heath and Wellbeing Boards will be essential (Roderick and Pollock, 2014). As the Chair of the Commons Public Administration Select Committee, Bernard Jenkin, commented in April 2014, "Unless and until we have a culture of leadership in public services that listens to, values and responds to complaints, from service users and staff, there will always be the potential for tragedies like Mid-Staffs." These concerns highlight the need to establish appropriate targets and for participation to include managers, health professionals and patients in holding duty bearers accountable to targets.

In Mid Staffordshire although the mechanisms for accountability were in place through formalized participation, these procedural rights failed. The duty bearers did not "conscientiously take into account" evidence and listen to rights holders. The government response to the Francis Inquiry in Hard Truths includes embracing the values of participation through, for example, a renewed emphasis on the NHS Constitution. There is also evidence of a move away from valorizing clinical data and toward finding new ways to include evidence provided through the participation of patients. However, concerns remain about the extent to which new formalized mechanisms of participation will also embrace values of participation. In a recent review of the process for drafting Sustainability and Transformation Programmes for the latest round of NHS reforms, it was found that PPI has been largely absent and in some areas has been actively discouraged (Alderwick et al., 2016). This is in direct contravention of the NHS Constitution as well as contradictinglessons learned from previous weak formalized participation as detailed in the Francis Inquiry. With these cautions about the implementation of participation as values, following the Leeds example and the Francis Inquiry, we used a framework of the right to health to ask two Healthwatch organizations about their experiences of participation.

\section{Workshop with Two London Healthwatch: Reflections on Participation through a Right to Health Lens}

Since the 1990s reform of NHS, England has been moving away from State-provided comprehensive health care toward discretionary health care (Pollock et al., 2012). There has been a simultaneous formalization of participation. Scrutiny powers of elected local authorities and participation of civil society will be essential to holding in check the reduction of State-provided services (Roderick and Pollock, 2014). Healthwatch is an example of formalized participation and accountability in the UK. While Healthwatch has been established by the State as a mechanism 
of participation and accountability, following Potts (2008a,b) and Bovens (2010), it is vital to ensure that the State also engage with Healthwatch as part of a set of values of participation.

At a workshop involving two Healthwatch organizations from London, small groups of workshop participants were asked to list the various mechanisms of participation that individuals were involved in. These included being active in patient groups around particular conditions or issues such as stroke, accident, and emergency, older people, disability; accountability roles such as governor or trustee; working across sectors for example with transport and housing bodies; and engaging with formalized participation mechanisms such as Healthwatch public meetings, responding to local authority consultations, submitting evidence to members of parliament. Participants were therefore engaging across sectors, demonstrating recognition of the indivisibility of the right to health.

Participants were then asked: "Do you experience fair and transparent participation in decisions that affect you?" Responses to this question were variable. One respondent wrote: "everyone's views and opinions are taken into consideration" and another wrote "the advisory group can change and influence the way our services are led" with "ample opportunity to become involved." However, other people described limitations to participation, mainly around communication and, similar to the Leeds example, access to information. One person wrote "groups may not have access to information so wouldn't know if it was fair" and another person commented "local authority's information provided too late so not real consultation." Other people said that people do not know about opportunities for participation. The reported lack of information provided to the Healthwatch organization, as with the Leeds example, does not adhere to the guidance offered in UN General Comment 14 or the NHS Constitution related to providing access to information and involvement in decision-making.

Workshop participants were then asked, "Is the participation you are involved with seen as a virtue?" People said that participation "works and has improved services" and that it provides "good advice and feedback." Patient "involvement in their care is seen as important" and "working together is key." However, others wrote how "cynicism about consultation is deeply engrained." Similar to SOS in Leeds, people see participation as consultation toward "a politically decided outcome." There needs to be "process and human willingness." This demonstrates how people see participation as not simply monitoring but also about remedying human rights violations and/or influencing health system reform.

Next, workshop participants were asked "Is all knowledge and evidence treated equally in the participation you are involved with?" One respondent wrote, "Everyone has their say and a right to question anything they're not happy with." However, others said that "in theory, yes-the records are good (e.g., the data) but in practice, no" and another person wrote, "patient voice not really "heard" and there is "tick box superficial information." These mixed experiences reflect the concerns following Mid Staffordshire where data were collected but not utilized and in which evidence gathered through participation was not valorized alongside other forms of evidence.

Finally, participants were asked, "Does the participation you are involved with include all sectors? Respondents named links with several organizations, including the local authority, housing, education, transport and other organizations in the health sector. They also wrote that "we are constantly looking for new members from different backgrounds and sectors as it will help us to cover different aspects" recognizing that "person-centered healthcare is necessarily multidisciplinary with multi-stakeholder involvement." However, others said that there is currently no involvement with other sectors or that while there is the potential for working across sectors, this is "not yet evident in decision-making."

The Mid Staffordshire example demonstrates the importance of not simply collecting indicators but also analyzing and reacting to them; a role that Healthwatch organizations can adopt. In a review of Healthwatch, Patient Library (2016) highlighted Healthwatch as the biggest single contributor to the qualitative evidence of patient experience, offering analysis that extends statistical performance indicators. The role of Healthwatch organizations as providers of evidence and users of information in participation therefore potentially extends the forms of evidence available to duty bearers and rights holders. However, Patient Library (2016) also found that across Healthwatch organizations there is variability in terms of quality of reporting and joining up learning indicating the need for support and development of Healthwatch organizations to ensure they can fully realize their role.

The relationship between the rights duty bearer (here the State) and the rights holder (here the Healthwatch) relies on three elements of accountability (Bovens, 2010): (1) the State feels obliged to inform the specific Healthwatch organization about performance, procedures, and outcomes; (2) the Healthwatch organization has the opportunity to question the information provided; and (3) the Healthwatch organization has the possibility of applying positive or negative consequences. These three elements of the accountability relationship can be classified according to three questions adapted from Bovens (2010). First, who is the rights holder? Here, it is local Healthwatch organizations engaging in social accountability. Second, who is the duty bearer? Here, it might be locally elected officials, local civil servant managers, and front line workers from several sectors. Third, do these duty bearers feel obliged to appear to the Healthwatch? Here, there are obligations of participation and accountability as part of the right to health-which crucially assume a legal framework and that duty bearers will embrace values of participation and accountability to appear before the rights holders. From the data presented, it is not clear that duty bearers do feel obliged to appear in front of Healthwatch. Workshop participants were found to have mixed experiences of social accountability and mixed experiences of values that would lead to involvement in health system reform and restitution, compensation, rehabilitation, and satisfaction and guarantee of non-repetition of violations.

\section{CONCLUSION}

The consideration of shortcomings in values of participation and valorizing knowledge gained through different forms of participation at the Leeds Children's Heart Surgery Unit and Mid Staffordshire NHS Foundation Trust serves to underscore the importance of procedural rights of participation and accountability 
in implementing the right to health and also the challenges of implementing formalized participation. In both cases, violations of procedural rights to health were brought to light through civil society-led participation, rather than through formalized mechanisms. The development of PPI in England has focused on mechanisms of participation. Even where legislation and soft law exists, the Leeds and Mid Staffordshire cases demonstrate that implementation of the values of participation and accountability can be as challenging as the implementation of the right to health itself.

We have framed this paper using a rights-based approach to health, which is enshrined in international and regional conventions and includes participation as a vital part of holding State parties accountable. All mechanisms of participation have weaknesses and in order to overcome these, human rights defenders could consider a combination of formalized (e.g., Healthwatch) and civil society-led participation (e.g., SOS Leeds) where different mechanisms counter the flaws of other mechanisms. However, for this combination to lead to accountability and remedy of human rights violations participation needs to be seen as part of a set of values within health systems. There is a danger of relying on flawed civil society-led participation or weak formalized participation alone. Participation in whatever form needs to be strong in order to ensure accountability. PPI in health could draw on values enshrined in human rights-based approaches such as transparency, access to information, and fair decision-making processes to guide the implementation of the procedural rights of participation. We have argued for extending General Comment 14 on the right to health in two ways: first, by strengthening the values of participation and accountability in the integration of civil society-led and formalized participation. Second, by valorizing data and knowledge gathered through participation alongside more traditional forms of evidence such as epidemiological data.

\section{REFERENCES}

Abelson, J., Forest, P., Eyles, J., Casebeer, A., Martin, E., and Mackean, G. (2007). Examining the role of context in the implementation of a deliberative public participation experiment: results from a Canadian comparative study. Soc. Sci. Med. 64, 2115. doi:10.1016/j.socscimed.2007.01.013

Alderwick, H., Dunn, P., McKenna, H., Walsh, N., and Ham, C. (2016). Sustainability and Transformation Plans in the NHS. How Are They Being Developed in Practice? London: Kings Fund.

Biehl, J., Socal, M. P., and Amon, J. J. (2016). The judicialization of health and the quest for state accountability: evidence from 1,262 lawsuits for access to medicines in southern Brazil. Health Hum. Rights J. 18, 209-220.

Boaz, A., Chambers, M., and Stuttaford, M. (2014). Public participation: more than a method? Comment on 'Harnessing the potential to quantify public preferences for healthcare priorities through citizens' juries'. Int. J. Health Policy Manag. 3, 1. doi:10.15171/ijhpm.2014.102

Boulle, T. (2008). Promoting Partnership between Communities and Frontline Health Workers: Strengthening Community Health Committees in South Africa. Community Development Unit Nelson Mandela Metropolitan University South Africa with the Regional Network for Equity in Health in East and Southern Africa (EQUINET). Available at: http://www.equinetafrica.org/bibl/ docs/CDU\%20PRArep\%20Final.pdf

Bovens, M. (2010). Two concepts of accountability: accountability as a virtue and as a mechanism. West Eur. Polit. 33, 946. doi:10.1080/01402382.2010.486119

Bradby, H. (2016). Research agenda in medical sociology. Front. Sociol. 1:14. doi:10.3389/fsoc. 2016.00014

\section{AUTHOR NOTES}

An early draft was presented at the seminar "Human Rights in Essential Public Service Participation," 20 March 2014, Faculty of Law, University of Groningen, Netherlands. A later draft was presented at the symposium "Exploring and Theorising the Nature of Participation as Evidence in Health Research, Policy and Practice," 22-23 September 2014, Warwick Medical School, University of Warwick, UK, supported by a Symposium Support Grant from the Foundation for the Sociology of Health and Illness. A recent substantially reworked draft was presented at a seminar with two London Healthwatch and Kingston University and St George's University of London, 21 June 2016.

\section{AUTHOR CONTRIBUTIONS}

All authors contributed to the development of the conceptual framework adopted in the research. MS identified the examples and presented an early analysis of the examples to co-authors. The examples were discussed as part of an iterative process of reflection by all authors. MS drafted the paper and co-authors provided detailed feedback on drafts.

\section{ACKNOWLEDGMENTS}

The authors have come together as a result of their participation in the Learning Network based on Cape Town most recently funded by EuropeAID, and the authors wish to thank all our colleagues, especially Leslie London, for on-going and stimulating engagement in this program of action research. Informal discussions with Gillian Lewando Hundt, Annette Boaz, Karien Stronks, and Janneke Harting have continued to challenge us. Special thanks to John Harrington and Brigit Toebes for comments on an early draft of this paper.

Cheng, S. (2013). Campaigners Win Leeds Heart Surgery Legal Challenge. Available at: http://www.bbc.com/news/uk-england-leeds-21697947

Cleary, S. M., Molyneux, S., and Gilson, L. (2013). Resources, attitudes and culture: an understanding of the factors that influence the functioning of accountability mechanisms in primary health care settings. BMC Health Serv. Res. 113:320. doi:10.1186/1472-6963-13-320

Cornwall, A., and Gaventa, J. (2001). Bridging the gap: citizenship participation and accountability. PLA Notes. 40, 32.

Cornwall, A., and Shankland, A. (2008). Engaging citizens: lesson from building Brazil's national health system. Soc. Sci. Med. 66, 2173. doi:10.1016/j.socscimed. 2008.01.038

De Cock, K., Mbori-Ngacha, D., and Marum, E. (2002). Shadow on the continent: public health and HIV/AIDS in Africa in the 21st century. Lancet 360, 67. doi:10.1016/S0140-6736(02)09337-6

de Sousa Santos, B., Nunes, J. A., and Meneses, M. P. (2007). "Introduction: opening up the canon of knowledge and recognition of difference," in Another Knowledge is Possible: Beyond Northern Epistemologies, ed. B. de Sousa Santos (London: Verso), ix-xii.

Department of Health England. (2013). Hard Truths: The Journey to Putting Patients First. London: Department of Health.

Dyer, L. (2010). A human rights-based approach to involving service users and carers. Br. J. Wellbeing 3, 26. doi:10.12968/bjow.2010.1.3.48643

Dyer, L. (2015). A review of the impact of the human rights in healthcare programme in England and Wales. Health Hum. Rights J. 17, 111.

Evans, D., Pilkington, P., and McEachran, M. (2010). Rhetoric or reality? A systematic review of the impact of participatory approaches by UK public health units 
on health and social outcomes. J. Public Health 32, 418. doi:10.1093/pubmed/ fdq014

EWHC. (2013). R on the Application of SOS Limited $v$ Joint Committee of Primary Care Trusts [2013] EWHC 439 (Admin) [27, i]. London: Royal Courts of Justice.

Ferraz, O. L. (2009). The right to health in the courts of Brazil: worsening health inequities? Health Hum. Rights 11, 33.

Fienieg, B., Nierkens, V., Tonkens, E., Plochg, T., and Stronks, K. (2011). Why play an active role? A qualitative examination of lay citizens' main motives for participation in health promotion. Health Promot. Int. 27, 416. doi:10.1093/ heapro/dar047

Francis, R. (2013). Report of the Mid Staffordshire NHS Foundation Trust Public Inquiry Executive Summary. London: The Stationary Office, 7.

Haricharan, H. (2012). Extending Participation: Challenges of Health Committees as Meaningful Structures to Community Participation. Cape Town: Health and Human Rights Programme, School of Public Health and Family Medicine, University of Cape Town and The Learning Network on Health and Human Rights.

Hunt, P., and Backman, G. (2008). Health systems and the right to the highest attainable standard of health. Health Hum. Rights 10, 181. doi:10.2307/20460089

Kennedy Report. (2001). Bristol Royal Infirmary Inquiry, Learning from Bristol: The Report of the Public Inquiry into Children's Heart Surgery at the Bristol Royal Infirmary (1984-1995). London: HM Government.

London, L. (2007). "Issues of equity are also issues of rights": lessons from experiences in Southern Africa. BMC Public Health 7:14. doi:10.1186/1471-2458-7-14

McCoy, D. C., Hall, J. A., and Ridge, M. (2011). A systematic review of the literature for evidence on health facility committees in low and middle income countries. Health Policy Plan. 27, 449. doi:10.1093/heapol/czr077

Mchangama, J. (2009). Health as a Human Right: The Wrong Prescription. International Policy Network. Available at: http://www.medlib.ch/documents/2010\%20Righttohealth.pdf

Mockford, C., Staniszewska, S., Griffiths, F., and Herron-Marx, S. (2011). The impact of patient and public involvement on UK NHS health care: a systematic review. Int. J. Qual. Health Care 24, 28. doi:10.1093/intqhe/mzr066

Mohan, G., and Stokke, K. (2000). Participatory development and empowerment: the dangers of localism. Third World Q. 21, 247-263. doi:10.1080/01436590050004346

Mosse, D. (2001). 'People's Knowledge', Participation and Patronage: Operations and Representations in Rural Development in Participation: The New Tyranny? eds B. Cooke and U. Kothari (London: Zed Books), 16-35.

Murphy, T. (2013). Health and Human Rights. Oxford: Hart.

NHS. (2015). The NHS Constitution. Available at: https://www.gov.uk/government/ uploads/system/uploads/attachment_data/file/480482/NHS_Constitution_ WEB.pdf

Patient Library. (2016). Healthwatch: The Power of the Network. Available at: https://www.google.ch/url? sa $=t \& r c t=j \& q=\& e s r c=s \&$ source $=w e b \& c d=$ 1 \&ved=0ahUKEwis4YSPi4jTAhUrL8AKHcdkDugQFggaMAA\&url= https\%3A\%2F\%2Fwww.patientlibrary.net\%2Fcgi-bin\%2Fdownloadhw. cgi\%3Ffile\%3D111759\&usg=AFQjCNE_5DooxZQvKIOdcjs4Ic9OrXomJQ\&bvm=bv.151325232,d.bGs\&cad=rja

Philo, C., and Metzel, D. S. (2005). Introduction to theme section on geographies of intellectual disability: 'outside the participatory mainstream?'. Health Place 11, 77. doi:10.1016/j.healthplace.2004.10.005

Pollock, A. M., Price, D., Roderick, P., Treuherz, T., McCoy, D., McKee, M., et al. (2012). How the Health and Social Care Bill 2011 would end entitlement to comprehensive health care in England. Lancet 379, 387. doi:10.1016/S0140-6736 (12)60119-6

Potts, H. (2008a). Participation and the Right to the Highest Attainable Standard of Health. Colchester: Human Rights Centre, University of Essex.

Potts, H. (2008b). Accountability and the Right to the Highest Attainable Standard of Health. Colchester: Human Rights Centre, University of Essex.

Preis, A. S. (1996). Human rights as cultural practice: an anthropological critique. Hum. Rights Q. 18, 2. doi:10.1353/hrq.1996.0022

Reubi, D. (2011). The promise of human rights for global health: a programmed deception? A commentary on Schrecker, Chapman, Labonte and De Vogli (2010) 'Advancing health equity in the global market place: how human rights can help'. Soc. Sci. Med. 73, 625. doi:10.1016/j.socscimed.2011.06.047

Rifkin, S. B. (2014). Review: examining the links between community participation and health outcomes: a review of the literature. Health Policy Plan. 29, ii98. doi:10.1093/heapol/czu076

Roderick, P., and Pollock, A. M. (2014). A wolf in sheep's clothing: how monitor is using licensing powers to reduce hospital and community services in England under the guise of continuity. BMJ 349, g5603. doi:10.1136/bmj.g5603

Stuttaford, M., Kiewiets, D., Nefdt, W., Reynolds, V., Rhodes, G., Sigasana, L., et al. (2014). "Conceptualising implementation of the right to health: the learning network for health and human rights, Western Cape, South Africa," in Law and Global Health Current Legal Issues, eds M. Freeman, S. Hawkes, and B. Bennett (Oxford: OUP), 76-93.

Stuttaford, M., Lewando Hundt, G., and Vostanis, P. (2009). Sites for health rights: the experience of homeless families in England. J. Hum. Rights Pract. 1, 257. doi:10.1093/jhuman/hup004

Thorlby, R., Smith, J., Williams, S., and Dayan, M. (2014). The Francis One Year on the Response of Acute Trusts in England. London: Nuffield Trust.

UN. (1966). International Covenant on Economic, Social and Cultural Rights. Available at: http://www2.ohchr.org/english/law/cescr.htm

UN. (2000). UN General Comment 14 on the Right to Health. Available at: https:// documents-dds-ny.un.org/doc/UNDOC/GEN/G00/439/34/PDF/G0043934. pdf?OpenElement

UN. (2013). Report of the Special Rapporteur on Extreme Poverty and Human Rights, Magdalena Sepúlveda Carmona. New York: UN General Assembly Human Rights Council.

Whitty,J. A., Burton, P., Kendall,E., Ratcliffe,J., Wilson, A., Littlejohns, P., etal. (2014). Harnessing the potential to quantify public preferences for healthcare priorities through citizens' juries. Int. J. Health Policy Manag. 3, 57-62. doi:10.15171/ ijhpm.2014.61

WHO. (2002). Health and Human Rights 25 Questions and Answers. Geneva: WHO. Yamin, A. (2008). Beyond compassion: the central role of accountability in applying a human rights framework to health. Health Hum. Rights 10, 1.

Conflict of Interest Statement: The authors declare that the research was conducted in the absence of any commercial or financial relationships that could be construed as a potential conflict of interest.

Copyright $\odot 2017$ Stuttaford, Boulle, Haricharan and Sofayiya. This is an open-access article distributed under the terms of the Creative Commons Attribution License (CC BY). The use, distribution or reproduction in other forums is permitted, provided the original author(s) or licensor are credited and that the original publication in this journal is cited, in accordance with accepted academic practice. No use, distribution or reproduction is permitted which does not comply with these terms. 


\section{Plain English Summary}

\section{Exploring the relationship (and power dynamic) between researchers and public partners working together in applied health research teams}

\section{Gill Green and Tracey Johns}

In recent years members of the public have been getting more involved in planning and carrying out health research. For example, in the UK, public involvement must be included to obtain funding from some funding agencies such as the National Institute for Health Research.

However, the ways that members of the public have been involved have often been criticized for being tokenistic. Professional researchers still hold most of the decision-making power and public members' voices can be repressed or ignored.

To counteract this, more inclusive approaches to public involvement, such as co-production, are becoming more popular. In co-production, researchers and members of the public work together, sharing power and responsibility from the beginning to the end of the project. This kind of joint, equal working creates projects that are meaningful to members of the public and are also recognised as high quality, scientific research.

To find out more about how inclusive methods work in practice, we talked to members of the public and researchers involved in projects that were identified as having elements of co-production. We recorded these interviews and analysed the way that people talked about public involvement in research. In summary we found that:

- In practice researchers regularly end up keeping most of the decision-making power and that often patient/public representatives are 'invited' to give opinions once the key ideas have already been decided. 'Adding on' the public's contribution in this way means that the relationship between researchers and public partners is not equal.

- Many of the people we talked to (both researchers and the public) were keen to establish equal relationships. However, they recognised that it would take a real effort to break down the idea that researcher knowledge is more valuable than knowledge based on lived experience.

- One obstacle to using more inclusive methods is the inflexible way that scientific research is run (e.g. deadlines, complicated paper work, legal rules about responsibility). One of the reasons why researchers tend to keep hold of the power and decision-making is because they are legally responsible for the research.

Our findings suggest that the culture of research needs to change in order to break down the idea that the scientific knowledge of researchers is more valuable than the experience-based knowledge of the public. One way forward is for the scientific community to learn lessons from user-led research, which is more inclusive and enables public partners to more readily share power. 
OPEN ACCESS

Edited by:

Nina Hallowell,

University of Oxford, United Kingdom

Reviewed by:

Vinita Agarwal,

Salisbury University, United States

Felicity Boardman,

University of Warwick

United Kingdom

*Correspondence:

Gill Green

gillgr@essex.ac.uk

Specialty section: This article was submitted to

Medical Sociology,

a section of the journal

Frontiers in Sociology

Received: 11 October 2018

Accepted: 01 March 2019

Published: 29 March 2019

Citation:

Green $G$ and Johns $T$ (2019) Exploring the Relationship (and Power Dynamic)

Between Researchers and Public Partners Working Together in Applied Health Research Teams.

Front. Sociol. 4:20

doi: $10.3389 /$ fsoc.2019.00020

\section{Exploring the Relationship (and Power Dynamic) Between Researchers and Public Partners Working Together in Applied Health Research Teams}

\author{
Gill Green* and Tracey Johns \\ School of Health and Social Care, University of Essex, Colchester, United Kingdom
}

Public involvement in applied health research in the UK has become a pre-requisite for receiving funding from some bodies including the National Institute of Health Research. However, much of this involvement has been criticized as being tokenistic with an unequal power dynamic whereby the public voice is consulted but may be ignored. To redress this imbalance more participatory methods of involvement, such as co-production have emerged. This paper explores the relationship and power dynamic between researchers and public partners through the thematic analysis of interviews with fourteen researchers and six public contributors who were involved in projects that were identified as having many features associated with inclusive co-produced research. Public involvement was valued but the integration of scientific and lay knowledge on an equal basis was problematic. In practice, "co-opted relationships" were most common whereby public partners were slotted into a designated role created for them by the researcher/research team. There were though some examples of more equal partnerships being established to share power and decision-making including two cases where the research idea was initiated by the public partner. However, establishing an equal relationship and sharing power was constrained by the hierarchical nature of applied health research as well as issues around governance and accountability. Specifically, the positivist paradigm that predominates in applied health research and tends to privilege classically scientific ways of thinking, was a barrier to experiential knowledge being equally valued. This demonstrates the challenges inherent in establishing equal relationships and suggests that a transformation of research practices, culture and hierarchies is required for power sharing to become a reality. Specifically, the culture of applied health research needs to embrace more democratic participatory approaches, such as those used in research originating from the service user movement, as it is within these ways of working that public partners can more readily share power.

Keywords: public involvement, co-production of research, PPI in research, partnerships with the public, applied health research 


\section{INTRODUCTION}

There is a proliferation of experiential or lay expertise in current knowledge societies (see Lambert and Rose, 1996; Grundmann, 2017) and a growing number of well-qualified citizens are knowledgeable and interested in issues that were previously the exclusive domain of professionals and scientists. This is pronounced in the world of health research where people with a health condition have a wealth of experiential expertise to draw upon. Public involvement (PI) in applied health research has increased dramatically in many parts of the world (Evans, 2014; Wicks et al., 2018), and in the UK, engagement with the public in constructing a research proposal is a pre-requisite for obtaining funding from the National Institute of Health Research (NIHR). By the term "public" we include members of the community, patients, carers, and people who use health and social care services. Our definition of applied health research includes research into treatments, devices, and procedures, and translation into practice to improve care. This includes health services research but not laboratory research. A PI infrastructure has subsequently developed whereby research organizations and funders develop relationships with members of the public, patients and charitable health organizations to ensure that PI is embedded in research (Department of Health, 2015).

However, this movement has been critiqued for being conceptually and theoretically vague (Madden and Speed, 2017), having evolved from a range of rationales, values, epistemologies, and political movements (Paylor and McKevitt, in press). PI has its theoretical roots in two entirely separate traditions, one based on human rights whereby citizens have rights and responsibilities and the other upon consumerist neo-liberalism (Taylor, 2007). There is consensus that the consumerist managerial model has tended to dominate PI and delineate the scope of involvement in that the role of public partners is primarily consultative; they provide feedback to the researchers but do not drive the project (Beresford, 2002). As a result the democratizing and emancipatory potential of PI as conceptualized through Paolo Freire's (1921-1997) process of "conscientization" (Freire, 1993) is limited. Furthermore, participation without a redistribution of power serves to maintain rather than challenge the status quo (Arnstein, 1969).

Green (2016) reviewed the landscape of PI in applied health research to identify the extent to which there is evidence of power shifting from the scientific research community to the public. She found that whilst patients and the public are a key part of the applied health research infrastructure in the UK and their contribution is evident in a range of decision-making processes from identifying priority areas for commissioning research to making decisions about aspects of research design and which projects are funded, there has not been a transformation of the social relations or power dynamic between the scientific research community and the public.

However, the democratizing pressure that comes from service users organizations and the conscientization process itself, whereby participation fuels a thirst for further involvement, have resulted in a growing appetite among the public and some researchers for the public to have a stronger voice. Thus, more inclusive methods of involvement, such as co-production, have become firmly identified as a way to strengthen PI in applied health research (Department of Health, 2015; Staniszewska et al., 2018). To provide clarity and guidance about co-production, INVOLVE, the organization that drives PI in research for NIHR, produced a report which defines co-production as "an approach in which researchers, practitioners and the public work together, sharing power and responsibility from the start to the end of the project, including the generation of knowledge" (Hickey et al., 2018). In this scenario, public contributors are regarded as assets and active agents in order to share power and co-produce research (Department of Health, 2015). Putting this into practice can though be problematic. One example is a Patient Led Research hub that has been established by a clinical trials unit to enable patients and the public not only to propose research questions, but to design, initiate, and deliver their own research with support from research professionals. However, some researchers are skeptical of this approach and the focus of the patient led hub rarely aligns with existing funding streams (Mader et al., 2018).

"Co-production" is closely associated with and builds on traditions of participatory research as well as that originating from the service user movement (Beresford, 2019). The value attributed to such approaches in academic cultures is variable and they have not traditionally been dominant in applied health research. Notwithstanding the growth of qualitative research and sociological approaches in applied health research, including health services research, which sometimes use participatory methods, the biomedical model based on a positivist approach remains dominant. This places meta analyses followed by randomized controlled trials (RCTs) at the top of the methodological pyramid and qualitative studies and anecdotal evidence at the bottom. There are critiques of the hierarchy of evidence, as RCTs are only appropriate to evaluate the effectiveness of interventions. They cannot assess acceptability to the patient which is why process evaluations using qualitative methods are now embedded into many trials (Moore et al., 2015). Nevertheless, the positivist approach tends to remain dominant in most applied health research. This privileges scientific knowledge over lay understanding, which creates significant difficulties in accessing and articulating views of publics (Taylor, 2007). The value of lay experiential knowledge sits uneasily with the predominantly positivist approach of biomedical research which is based on controlled conditions, isolated variables and measurement requiring scientific expertise.

For experiential knowledge to have full value, there must be a space in which both expert and lay knowledge can interact with each other on an equal basis and this space has yet to materialize in applied health research (Gibson et al., 2012). However, it is not entirely clear what constitutes an "equal basis" as the integration of experiential knowledge with scientific expertise is complex.

Firstly, from a theoretical perspective both types of knowledge are often synergistic and should not necessarily be seen as competing (Callon, 1999). There is no fixed boundary between lay and expert knowledge, rather if has been conceptualized as a continuum of different forms of knowledge (McClean and Shaw, 
2005) and researchers with lived experience combine both types of knowledge. It is the differing perspectives that both "experts" and "publics" bring that it seen as so valuable in producing research that is both high quality and relevant to the real lives of patients and the public. However, in practice, disparities between research knowledge produced through the research process and knowledge based on lived experience can create binary polarities.

Secondly, operating on an "equal basis" does not equate to researchers and public partners having equal power in all decision-making. They are part of a research team which is likely to include different grades of research staff (with one being the designated "Chief investigator"), clinicians and managers as well as public members. Decision-making will vary according to the expertise required, e.g., determining the size of the sample needs the expertise of a statistician rather than someone who has little understanding of a power calculation. What seems key is sharing power and for each member of the research team to feel empowered to make decisions in areas where they have the requisite expertise (Hickey et al., 2018). Thus, to operate on an "equal basis" a public partner would expect to be the dominant voice in decisions about aspects of the research related to the patient experience but not in decisions related to the scientific method.

Thirdly, failure to establish an equal relationship is often attributed to the researcher not fully recognizing the value of lay knowledge and being unwilling to share power (see Brett et al., 2014; Wicks et al., 2018). Whilst this may sometimes be evident, a focus on the individual researcher detracts from the broader contextual constraints within which PI operates. The consumerist managerialism which dominates the implementation of PI in applied health research may place limits on the opportunities for collaborative democratic approaches and also explain the negative attitudes of some researchers (Paylor and McKevitt, in press).

In an attempt to define what constitutes more inclusive methods of involvement, key principles of co-production have been identified as: sharing of power; including all perspectives and skills; respecting and valuing the knowledge of all those working together on the research; reciprocity; building and maintaining relationships (Hickey et al., 2018). Whilst these seem relatively straightforward, the challenge is the translation into practice. How these principles can be achieved amidst the maelstrom of competing priorities to complete a research project is not well-understood.

Furthermore, much of the evidence about the integration of expert and experiential knowledge in applied health research is based on critical/ theoretical review of policy and practice rather than empirical research (see Green, 2016; Madden and Speed, 2017; Beresford, 2019; Paylor and McKevitt, in press). Whilst this points to the dominance of consumerist approaches and a need for more equal relationships, some redistribution of power and a more influential public voice, there is a lack of empirical data to explore the barriers that may prevent this and the tensions and complexities about how this might be achieved. This paper aims to fill this gap by conducting secondary analysis of a commissioned data set generated from semi-structured interviews with researchers and public partners, identified by PI experts as being demonstrably inclusive in their research, to see how this plays out in practice. What is the role of the public partners? To what extent do researchers and public partners perceive that they are operating on an "equal basis" in practice? What facilitates/prevents this happening? How is power expressed and negotiated and is there any evidence of a shift from more hierarchical toward more equal relationships?

\section{METHODS}

\section{Design}

We adopted a qualitative inductive approach to achieve a contextualized understanding of the relationship between applied health researchers and public partners. In-depth semi structured interviews with both researchers and public partners enabled us to explore the development, scope and limitations of the relationship established between the two and the negotiation and expression of the power dynamic within the relationship.

\section{Sample and Participants}

The data set was originally collected to inform the development of guidance about co-production being produced by an INVOLVE working group. The authors were commissioned to carry out 10-20 interviews with applied health researchers and their public partners involved in NIHR, or other national peer reviewed funded, research projects in the UK. We specifically sought participants who were identified either by the INVOLVE working group or other NIHR contacts as demonstrating a commitment to inclusivity. This was key to sample selection and was operationalized as public contributors taking part in a range of different activities throughout the life cycle of the project including research design thus requiring the development of an on-going relationship between the professional researcher and public contributor. We also aimed for maximum variability in terms of research topic and research design in order to have representation from those involved in areas such as mental health and qualitative research where the value of experiential knowledge is relatively well-established and those topics and methodologies where it is less so.

As the interviews were conducted, either the participants themselves or others, highlighted other projects which they perceived as demonstrably inclusive or using a different type of research design, and the chief researcher of these projects was subsequently contacted. Thus, a mixture of purposive and snowball sampling was used resulting in a sample of twenty, 14 of whom were professional researchers (including two with lived experience as a service user) and six public partners. We had hoped to include an equal number of researchers and public partners but in most cases the initial contact was with the researcher and getting details from them of public partners who we could contact was not always forthcoming. All interviewees were sent a letter of invitation, participant information sheet and consent form and offered the choice of being interviewed in person, by phone or video call. Verbal consent was recorded at the start of the interview and the project was approved by the University of Essex ethics committee. 
TABLE 1 | List of participants.

\begin{tabular}{|c|c|c|c|}
\hline ID & Gender & Role in research & Partners \\
\hline \multicolumn{4}{|c|}{ ACADEMIC RESEARCH/CLINICAL PARTNERS (R) } \\
\hline $\mathrm{R} 1$ & Female & Principal investigator/senior research fellow & P6 \\
\hline $\mathrm{R} 2$ & Female & Programme manager/research fellow & \\
\hline R3 & Female & Principal investigator/professor & P3 \\
\hline R4 & Female & NIHR fellow & \\
\hline R5 & Female & Research fellow mental health & \\
\hline R6 & Female & Research fellow mental health & \\
\hline$R 7$ & Female & Principal investigator/professor & P1 \\
\hline R8 & Female & Principal investigator/qualitative researcher & \\
\hline R9 & Female & Principal investigator/clinical lecturer & P4 \\
\hline $\mathrm{R} 10$ & Female & Principal investigator/research fellow & P5 \\
\hline $\mathrm{R} 11$ & Male & Principal investigator/professor & \\
\hline $\mathrm{R} 12$ & Male & Clinical trialist & \\
\hline $\mathrm{R} 13$ & Male & Research associate & \\
\hline R14 & Male & Clinical professor & P2 \\
\hline \multicolumn{4}{|c|}{ PUBLIC PARTNERS (P) } \\
\hline P1 & Female & Mental health service user researcher & $\mathrm{R} 7$ \\
\hline P2 & Female & Public co applicant & $\mathrm{R} 14$ \\
\hline P3 & Female & Patient advisory group member & R3 \\
\hline P4 & Female & Patient advisory group member & R9 \\
\hline P5 & Male & Patient advisory group member & $\mathrm{R} 10$ \\
\hline P6 & Female & Patient advisory group member/lay researcher & $\mathrm{R} 1$ \\
\hline
\end{tabular}

The participants are listed in Table 1. The six public partners had all worked with one of the academic research participants (see Table 1). To preserve their anonymity we have not included details of participants' research topic or type of design. In total, there were more female participants (10 female and 4 male researchers and 5 female and 1 male public contributor) which reflects the gender composition of the public involved in research. Project areas included: arthritis, dermatology, two stroke, two musculoskeletal, diabetes, three mental health, dementia, renal, social care, community health. Methodologies used in the projects included four RCTs, two mixed methods, qualitative, systematic review, two feasibility trials, knowledge transfer, experience based co-design, two critical evaluations. Of the public participants, four had professional experience, three in education. All had experience of being involved in NIHRfunded research projects, ranging from large scale multi-site complex clinical trials to individual fellowships. All the six dyads (researcher and public partner) interviewed had a durable longstanding working relationship having worked together on more than one project, generally from the beginning or early stages of designing the project proposal to the dissemination of results.

\section{Data Collection}

The interviews were conducted February-April 2017 by one of the authors who is employed as a public involvement lead for an NIHR organization. They were conducted either face to face or via phone or skype using an interview framework informed by an INVOLVE co-production working group and reviewed by public representatives. The interviews asked about specific research projects and the role of the public contributor(s), the relationship between the researcher(s) and the public partner(s), how they conceptualized co-production, and the extent to which the research they were involved with was co-produced, and what barriers did they face when using more inclusive methods of involvement.

\section{Data Analysis}

Interviews were recorded, transcribed verbatim and used initially to inform guidance on co-production produced by the INVOLVE working group (Hickey et al., 2018). Our secondary analysis of the data focused on the identification of salient themes related to the relationship between the researchers and public partners and the power dynamic between them. There were no questions in the interviews specifically about power but this was identified as a key theme in the initial analysis conducted to inform the INVOLVE working group. We coded the data using standard inductive thematic analysis (Braun and Clarke, 2006). A theme was defined as "a patterned response or meaning within the data set" (Braun and Clarke, 2006, p. 11). Codes were grouped together and initial theme titles were generated. This was firstly done independently by the two co-authors to identify preliminary first order codes. These were then shared and discussed at an interpretive level. This focused on discussions about commonalities and differences between the codes of both authors to determine key categories. We explored the meaning of each category and linkages between them to further refine/collapse them to identify core themes relating to the relationship and power dynamic between researchers and public partners.

We were reflexive throughout this process in terms of critically examining potential subjectivities in the data. This included thinking about the impact of the public partners being nominated by the researcher, which will have had a direct impact on the sample as those nominated were likely to have had a positive relationship with the researcher. The fact that the interviewer was a professional PI facilitator is likely to have influenced the content of the interview. We were also aware during the analysis that the lack of a public representative to assist with analysis of the data will have impacted upon the interpretation of the data.

\section{RESULTS}

Having identified the main categories related to the role of public partners, the types of relationship between researchers and public partners and the barriers to operating on an equal basis, we refined these to locate stable key themes to emerge from the interviews (see Table 2). These are discussed below and analyzed to explore the exercise and expression of power.

\section{The Value and Contribution of Public Partners}

Both the researchers and the public partners described a range of PI activities and roles. These included the public partner being a named co-applicant on a research project and/or being members of a project steering group. This involved participation in strategic discussions such as priority/research agenda setting 
TABLE 2 | Key themes.

\begin{tabular}{|c|c|}
\hline Initial category & Final theme \\
\hline $\begin{array}{l}\text { Role of public partners: they are a } \\
\text { necessary and valued part of team with a } \\
\text { unique perspective }\end{array}$ & $\begin{array}{l}\text { The value and contribution of } \\
\text { public partners }\end{array}$ \\
\hline \multicolumn{2}{|l|}{$\begin{array}{l}\text { PI not valued by parts of the scientific } \\
\text { establishment }\end{array}$} \\
\hline $\begin{array}{l}\text { Public partners need support, training and } \\
\text { management }\end{array}$ & A co-opted relationship \\
\hline \multicolumn{2}{|l|}{$\begin{array}{l}\text { Public partners are empowered through } \\
\text { their involvement }\end{array}$} \\
\hline \multicolumn{2}{|l|}{$\begin{array}{l}\text { Public partners are grateful for the } \\
\text { opportunity }\end{array}$} \\
\hline $\begin{array}{l}\text { Need to build trust/relationships between } \\
\text { researchers and the public partners }\end{array}$ & Equal partners \\
\hline \multicolumn{2}{|l|}{$\begin{array}{l}\text { Need to share power between researchers } \\
\text { and the public }\end{array}$} \\
\hline User led research & A user-led relationship \\
\hline $\begin{array}{l}\text { Governance and bureaucracy of research } \\
\text { creates logistical challenges }\end{array}$ & $\begin{array}{l}\text { Constraints/barriers linked to } \\
\text { public involvement in applied } \\
\text { health research }\end{array}$ \\
\hline \multicolumn{2}{|l|}{$\begin{array}{l}\text { Research is time pressured and public } \\
\text { involvement is time consuming }\end{array}$} \\
\hline \multicolumn{2}{|l|}{ Accountability } \\
\hline Hierarchy of applied health research & \\
\hline
\end{tabular}

and developing outcome measures as well as project oversight (e.g., recruitment monitoring). Public participants were also involved in operational research activities such as: developing research tools; co-designing information sheets for research participants; interviewing research participants (alongside the researcher); helping to interpret the results; presenting the results including co-authoring articles. Two of the public members interviewed had become so involved in these types of activities that they defined themselves as "user researchers." Most of the public partners were involved in projects directly related to their health condition, but some were also part of a generic research user group.

There was consensus about the inherent value of including public partners in research teams and many examples of it being integral to the research project. According to one dyad (R3 and P3), the public partners give the research credibility as they represented "an authentic voice, they will sit with us, they're on our side" (R3). The public partner felt that their voice was important to ground the research in the lived experience of the public to ensure that it would benefit patients, saying, "we do have a voice and if we think that the research is going off at a tangent or in fact there is not going to be any benefit for Joe Public at the end of it, we will say so, and that has to be taken account" (P3). She explained how the public contributors had been "integral in the design of this study" and felt that "it could not have been done I think without us" (P3).

However, all participants cited examples of some researchers being more skeptical about the benefits of PI. According to the researcher R9, "there's obviously a lot of um varying, still I think acceptance of patient involvement in the clinical research field," a sentiment echoed by the public participant P5 who noted, "you can feel there are perhaps undercurrents of that, that not everyone thinks that PPI is a good idea." Some of the research participants attributed this to working in a context where PI was not well-aligned to research timetables and changing research in response to public feedback may result in missed deadlines harming people's research career. As one researcher put it (although he personally did not share this view):

R12: so it's not attractive often, to academic researchers to do this [listen to the public voice], to say well actually let me just get side-tracked here and do....it's a mad idea if you're an academic researcher, it's frankly idiotic, why would you?!

Others reported that PI was not always valued by the scientific establishment. One researcher noted that she had recently submitted a paper to a journal but purposely omitted to mention that it was based on a co-produced survey as "it might even count negatively" (R9). The lack of evidence about the impact of PI in general, and more inclusive methods such as co-production in particular was a barrier. According to R11, "Where's the impact, how am I going to sell this to the chief exec, this is the way you should be working, there is very little in the literature."

\section{A Co-opted Relationship}

In this theme the public member is framed as slotting into a space created for them by the researcher/research team who assign them a designated role. This includes provision of training and other support to equip them to perform this "co-opted" role. It is well illustrated by the quote below:

R4: Um and the thing about patient representatives coming on to a research panel, ... there's often a pre-existing structure for how you manage a research process and the patient representatives are added onto that, what already exists, and they're given training so that they learn how to fit in with the pre-existing structure.

The emphasis here is on how public contributors are slotted into a framework rather than being core members from the start. They are "added-on" and training is positioned as showing the public member how to communicate in an appropriate manner to fit in with "that pre-existing structure." In so doing, it closes down opportunities for discussion about whether the addition of public members to the research team might open up new ways of assembling the "pre-existing structure."

This type of co-opted training was also noted by the public participants:

P4: there certainly has been a lot of training and I think it has been
done very well and it has been very much appreciated ..., but I
think the challenge all the time um is whether you are trying to
turn patients into mini medics, in other words are you actually
trying to make the patients conform to what, y'know what the
researchers need, or are you adapting the research?.... um on
balance, in the past, it has been very much the former.

This quote with its emphasis on "trying to make the patients conform" suggests an inherent power imbalance. The speaker is 
explicit that the researchers want the "patients" to "conform" to "what the researchers need" rather than "adapting the research" based on input from the public contributors. She went on to say that she occasionally "has to bite her tongue a bit," i.e., her voice is contained and constrained.

The co-opted relationship is thus characterized by an unequal power dynamic as the researcher is in control and provides "support" so that the public partner understands and is equipped for their role. It emphasizes how public members are guided and inducted into the research environment, rather than how the public member may shape that environment. From the perspective of the public contributor, this may be represented as alienating, such as in the case below where a researcher's use of medical/scientific language was not understood:

P5: We had a very nice presentation on the value of ablating nodes in fibrillation and I honestly saw a load of my colleagues [other public contributors] wilting under the onslaught.

The assimilation of public partners in a co-opted relationship is generally represented as relatively straightforward. The public partners referred to the skills they had acquired from their professional backgrounds (e.g., as a teacher) as assisting this process and being "really helpful" (P3). However, there were examples of assimilation being problematic:

R2: he [public contributor], was quite spiky about um, being involved, [saying] 'I don't want to be involved if I'm just a checkbox, I don't want to sit through meetings where I don't understand where any of you are going on about', y'know that sort of thing? ....., he's not that communicative, so um, and I sometimes feel like he's getting cross but he doesn't say and then he'll go 'rahhhh y'know I can't keep up' so um it's quite, he's a more difficult, it's more difficult .... I think if they [the public partners] don't have experience of research, then there does need to be quite a significant training programme.

While this quote is from a researcher who is committed to inclusive methods of PI, she nevertheless locates the problem in the public contributor who is "spiky," "not that communicative" "more difficult." For her the solution is to preserve the existing power relations through the provision of more training to help him conform to the role. The problematizing by researchers of views or behaviors of public contributors which do not "fit" their designated role illustrates the unequal power relationship.

A further illustration of a power differential in the co-opted relationship was the way that public partners expressed their gratitude for the opportunities that came with the role. Being a co-applicant, co-authoring a paper, traveling to conferences overseas to give a presentation about the research were hugely valued and appreciated. The public partners said many times that they were "lucky," with one saying, "I felt very privileged to be able to contribute my opinion." Somewhat ironically, given the power differential evident in the co-opted relationship, the notion of "empowerment" of public contributors was emphasized. Experiences such as being invited to present to an all-party political group at the UK parliament were reported to be empowering.
The co-opted relationship was described as being akin to that between parent-child and supervisor-student. Take for example, the excerpt below about the researcher trying to get the public partners to conform to the "researcher way" of doing data analysis.

R1: but it was really quite difficult, not difficult, it was quite challenging to keep them [the public partners] on the point... Because they would see things that would start conversations going and we always had limited time....they had to learn over the time that we can't keep adding stuff now....

The emphasis on this being "quite difficult" which was then modified to "challenging" was in reference to the "limited time" available but nevertheless is an illustration of how the co-opted relationship serves to preserve the existing power differential by emphasizing the need to "tame/control" the public voice to meet the research agenda.

\section{Equal Partners}

This theme focuses on the equal value of researchers and public contributors and stresses the need to build bridges to connect their world views in order to share power and decision-making. The added value of the public voice is largely absent from this theme, rather it accentuates the knowledge of all members of the research team which is viewed as having equal value. This was clearly articulated by both researchers and public partners as illustrated below:

R4: ... it's basic principles for participatory approaches which is um everybody has an equal seat at the table, um, we try to facilitate environments and settings where people recognize that each other have unique knowledge and skills.

Here, the researcher explicitly mentions having an "equal seat" and emphasizes the "unique knowledge" that each brings. The public partners expressed this as having a different perspective based on their experiential knowledge.

P2: But the whole point for patients, if they want to do this kind of thing, is never to feel as though you are inferior, you're just different, with a different perspective, they are the experts about the disease and all of that, you actually suffer from it, so your input is incredibly important in how they design the trials and the outcomes they expect from the treatment.

The "equal partners" theme was most evident in the interview with a researcher (R4) who had a background in community based participatory research. Her approach began by contacting community organizations to ask them what support and outcomes they would value and then contacting commissioners of services in order to "co-design programme specifications rather than doing a bit of consulting and putting together what they think a service ought to look like." She highlighted the need for partnership, sharing, respect and developing relationships to establish productive communication between researchers and public partners so that both parties come to understand the perspective of the other. Training is still required but unlike the 
"co-opted relationship" where the public need to be trained in the world view of the researcher, in the "equal partners" theme, everyone needs training to work together and "see through the eyes of somebody in a different culture."

R4: And what I'm trying to do is build little bridges across them ... so that they know how to communicate and get along or y'know bringing academics into a community setting and training them so they know how to get along.....so that they start to look at the issues through the lens of the other person... to be able to see something through the eyes of somebody that's in a really different, different organizational culture.

Participants explicitly acknowledged the need to challenge and change existing power relations and hierarchies to achieve a shared space:

R6: I think a lot of it is about respect and sharing, sharing the space so sharing the voice in terms of design and respect for other people's opinions, um, I think um it's a partnership..... so I think it's about breaking down a hierarchy so if you are going to do any research that's co-produced, it can't have a hierarchy there, um, it has to be equal value.

Being "equal partners" was seen as important for co-production, which was framed not only as different from traditional or mainstream patient and public involvement (PPI), but also as radical and creative:

(R11) Well, I think um, I think PPI has become sort of mainstream and for me, co-production is, if it's not radical then there is nothing to it, it's that radical element of bringing service users, providers together um to shape the delivery of services and ...... I mean one of the things about co-production, co-design is you never know, quite know where these projects are going to end up, that's the whole point, they are creative, they are emergent.

Thus, the equal partners theme highlights a fresh and radical approach in which researchers and the public share power.

\section{User-Led Relationship}

There were two examples of public partners initiating and leading or co-leading projects. In both cases they were motivated by their own experiences as service users and were not representing a user organization. The user-led relationship theme can be viewed as an extension of the equal partners theme and there is evidence of a discernible shift in the power dynamic between the public partner and the researchers. In the first case the public partner approached a researcher about the lack of evidence about her condition and following this became the co-ordinator for a systematic review. She clearly affirmed "I am the lead ... No question, they came to me, I dished out the work, I told them the deadlines, I organized the whole thing, I didn't do the work" (P2). She drew upon her organizational and librarianship skills developed in her working career as well as her lived experience of the condition to drive the project and this was confirmed by her research partner (R14). She described her relationship with the researchers as "Equal, equal footing, great respect on both sides, no condescension." Her selection of the phrase "no condescension" suggests that there is an expectation that professional researchers may sometimes adopt a patronizing attitude toward public partners. She was clear about when her input was and was not required saying, "There are times when I can't have any input, when it comes to statistics y'know, forget it, I haven't got a clue, or the methodology, but there are times when what I think will make a difference or will make them rethink."

In the other case (P1), the public partner had the initial idea for the project and contacted the director of services, who responded enthusiastically, and they became the co-leads. The public partner reported that it took time to establish a relationship and break down the power differential and that this process was initially daunting:

P1: Um, so in that first meeting [with the Director of acute services], I think it's fair to say I felt pretty um nervous, um because obviously the power differential was huge y'know um, he was someone in considerable power and I was someone who didn't have that sort of feeling. Um, so I went into that room feeling very, I remember feeling very anxious um and so it took a while before I really felt um that we established a relationship where we were more, much more on an equal footing.

This illustrates how power relations are negotiated and performed between someone perceived as having "considerable power" in comparison to her own as she "didn't have that sort of feeling." She had to overcome anxiety and persevere over time to establish being "much more on an equal footing." The qualifier "more" rather than being "on an equal footing" suggests that some power differential may still exist.

\section{Constraints Linked to Applied Health Research}

This theme relates to applied health research and in the interviews was interwoven with both the co-opted and equal partners themes. It was present in interviews with all the participants but most prominent in interviews with researchers. It was used to frame narratives to explain the challenges, constraints and limits of PI in research. These constraints included: barriers linked to the governance and bureaucracy of research; the imperative of research protocols and deadlines; the hierarchy of applied health research; and issues around accountability for the research.

Research governance procedures were reported to be bureaucratic and time consuming requiring negotiation with a complex field of actors and processes:

R6: we have found one of the major challenges was, with involving
service users in the actual data collection is all of the um pre-
engagement checks and DBS [Disclosure and Barring Service to
check for criminal record] and all of those kind of things, they're
a massive hurdle, trying to get research passports is, does take a
prolonged amount of time, maybe 6 to 9 months in some cases
....it does become a case of banging your head against the wall...

In this case, the governance requirements resulted in some of the public partners being unable to take part in the project. 
Another feature of research, which acted as a constraint, was the imperative of following a detailed and complex research protocol and working to tight deadlines. One participant talked about the, "complex day-to-day running of things which you can't practically involve with at every step...I am thinking of big trials I'm involved in....Y'know the machine that is the clinical trials unit" (R9). The time required to build relationships with public partners and involve them in all decisions is not compatible with the operation of the clinical trial "machine." All the researchers were adamant that "at the end I have to produce a report, I have to make my deadlines to my funder" (R10).

The hierarchy that privileges scientific knowledge associated with much applied health research was also constraining. This is well-illustrated by a researcher (R5) who said she was committed to: "power sharing" and "doing things differently" but was thwarted "cos research doesn't seem to think, doesn't look like that... It's a very hierarchical environment to work in so when you then introduce um co-production into it, it's really difficult I think." She related the following experience:

R5: the research team had basically decided that ...they [the service user advisory group] had done really good work but now they really didn't want them to meet very often and the advisory group were really, really passionate about this topic and ...they wanted a bigger role... I felt stuck between the team who I knew were really busy um and just want to get on, collect data and a passionate advisory group that really can't be tokenistic otherwise just don't bother with us and I was stuck in the middle.

This illustrates the power differential and constraints of PI in health research. Having been mobilized the user group want to carry on influencing the research whereas the researchers feel that this would not add value. The user researcher who coordinated the user group was indeed "stuck in the middle."

A further constraint was accountability. This was rarely raised in relation to public contributors and when it was there was a generalized acceptance that they could and should not be accountable for the research. This was even the case when a public partner was named as a co-applicant suggesting that this status was mainly tokenistic. The quote below from a public participant explicitly links accountability to the power dynamic:

P4: very conscious of the unequal power relations and um, but in a way, that's, at, in some ways, that's as it should be because of the accountability factor and um, it is at the end of the day, it's the researchers and the medics and er, y'know they are the people that are accountable for the research that they do and um y'know we are, y'know we make a voluntary contribution and I think it is very, very important that that is increased and is listened to but we can't be held accountable for the outcome of the research and therefore that, that does make co-production a slightly problematic concept.

Accountability here is identified as a key issue in power-sharing as it involves a sharing of responsibility and in the quote above it uses this to problematize co-production and power-sharing.

\section{DISCUSSION AND CONCLUSION}

The findings of our research clearly indicate that, in the area of applied health research, both professional researchers and public representatives place a high value on the integration of scientific and lay perspectives. There was also evidence that it is clearly possible for public partners to feel sufficiently empowered to voice their opinions and play a significant role in decision-making in areas where expertise based on experience is demonstrably useful. In these contexts, our participants reported working together synergistically in co-opted, equal partner and user-led relationships. In their accounts they talked about producing high quality research using and blending the unique types of knowledge, experience and perspective held by all team members. However, some clear power differentials were apparent in their accounts and the narratives of both researchers and public partners suggested that their collaboration was characterized by the "co-option" of patient and public representatives into a professional/scientific framework, rather than vice-versa. It should also be noted that some of the participants in our project felt that the wider research establishment is not yet ready or able to accept that "experiential knowledge" is a distinct way-of-knowing which merits parity or equality with "scientific knowledge."

Our findings suggest that this continuing "inequality" is not necessarily due to the researchers being unwilling to share power. It should be remembered that our research participants were purposively selected on the grounds that they were identified by colleagues as being involved in projects known to be enthusiastic about public participation. It follows then that the people we gathered data from tended to be committed to a progressive involvement agenda. Specifically, they were committed to:-strengthening public voices; sharing power over decision-making and; trying to achieve "co-production" in research (although not all of them used this terminology). That even this identifiably "radical" group struggled to demonstrate an equal power dynamic throughout the research process suggests that significant challenges and barriers are inherent in the development of these ways of working.

One key barrier is the "positivist paradigm" that predominates in applied health research. This overall philosophy tends to privilege classically scientific ways of thinking such as structured sampling and standardized measurement, thus creating significant difficulties in articulating and including lay views (see Taylor, 2007). This happens because "experiential knowledge" is by its very nature based on individual perception and observation and thus easily characterized as at best "sui generis" and at worst "anecdotal." Concretely in our data this tendency to perceive experiential knowledge as problematic from a methodological point of view is discernible in the fact that all the researchers we spoke to emphasized the importance of a "hierarchy of research" when explaining why public involvement in general, and the establishment of equal relationships in particular, is challenging. In this light, our analysis highlights how the sharing of power is generally incompatible with the existing research hierarchy, which is why co-opted relationships are most common. 
In addition, the time taken to build and maintain relationships is often compromised by the imperative to follow research protocol deadlines. Neither is there a clear mechanism for public partners to take accountability for research as they generally do not routinely have access to protection such as insurance indemnity which is available to academic researchers from their employing institutions. The principles of inclusivity and "sharing power and responsibility" which are central to the definition of co-production (Hickey, 2018; Hickey et al., 2018) therefore do not fit with the dominant research culture which remains a hierarchical environment in which researchers are at the top and public contributors are at the bottom (Crowe and Giles, 2016). This tends to frustrate the process of the "conscientization" of the public through participation mentioned in the introduction to this paper.

Our analysis thus provides empirical evidence supporting the theoretical argument put forward by others that the way that research is organized creates a barrier to more inclusive methods of involvement. This in turn suggests that a major shake up of research practices, culture and hierarchies may be required for power sharing to become a reality (Hickey, 2018; Wicks et al., 2018). The notion of co-production and inclusivity arises from a tradition that sees people as assets of equal worth. It thus has an uneasy fit with the hierarchical model of scientific research. The culture of research therefore needs to change and embrace more democratic participatory approaches. There are examples of such approaches from the health user movement (Beresford, 2019), such as emancipatory disability research (Barnes C., 2003) and "Mad studies" (Beresford, 2016) where users have challenged the hierarchy of the research community which privileges scientific knowledge. This does not mean that methodologies and research plans based on a traditional positivist approach should be abandoned, but rather that to attain equal relationships in research we will need to broaden the range of research approaches

\section{REFERENCES}

Arnstein, S. R. (1969). A ladder of citizen participation. J. Am. Inst. Plann. 35, 216-224. doi: 10.1080/01944366908977225

Barnes C. (2003). What a difference a decade makes: reflections on doing 'emancipatory' disability research. Disabil. Soc. 18, 3-17. doi: 10.1080/713662197

Beresford, P. (2002). User involvement in research and evaluation: liberation or regulation? Soc. Policy Soc. 1, 95-105. doi: 10.1017/S1474746402000222

Beresford, P. (2016). All Our Welfare: Towards Participatory Social Policy. Bristol: Policy Press.

Beresford, P. (2019). Public participation in health and social care: exploring the co-production of knowledge. Front. Sociol. 3:41. doi: 10.3389/fsoc.2018. 00041

Braun, V., and Clarke, V. (2006). Using thematic analysis in psychology. Q. Res. Psychol. 3, 77-101. doi: 10.1191/1478088706qp063oa

Brett, J., Staniszewska, S., Mockford, C., Herron-Marx, S., Hughes, J., Tysall, C., et al. (2014). A systematic review of the impact of patient and public involvement on service users, researchers and communities. Patient. 7, 387-395. doi: 10.1007/s40271-014-0065-0

Callon, M. (1999). The role of lay people in the production and dissemination of scientific knowledge. Sci. Technol. Soc. 4, 81-94. doi: 10.1177/097172189900400106 supported by funding agencies such as NIHR. A greater focus on community and social care research will likely require different methodologies and more participatory approaches and it is within these ways of working that public partners can more readily share power. However, whether such a culture shift is achievable given the wider neoliberal forces and consumerism that dominates the implementation of PI in applied health research is uncertain.

\section{DATA AVAILABILITY}

The datasets for this study will not be made publicly available because Interviewees were not informed that they would be publicly available.

\section{AUTHOR CONTRIBUTIONS}

TJ initiated the study and its design, conducted the interviews, collated all the data, and identified the preliminary themes. GG and TJ discussed the interpretation of the analysis, contributed to this study, read and approved the content. GG drafted the paper.

\section{FUNDING}

This article was based on the analysis of interviews that were commissioned by NIHR INVOLVE to inform an INVOLVE working group about co-production.

\section{ACKNOWLEDGMENTS}

We would like to thank NIHR INVOLVE who provided funding for data collection. We would also like to thank the research participants who generously shared their time and insight.

Crowe, S., and Giles, C. (2016). Making patient relevant clinical research a reality. BMJ. 355:i6627 doi: 10.1136/bmj.i6627

Department of Health (2015). Going the Extra Mile: Improving the Nation's Health and Wellbeing Through Public Involvement in Research. Available online at: http://www.nihr.ac.uk/documents/about-NIHR/NIHR-Publications/Extra \%20Mile2.pdf

Evans, D. (2014). Patient and public involvement in research in the English NHS: A documentary analysis of the complex interplay of evidence and policy. Evid. Policy. 10, 361-377. doi: 10.1332/174426413X662770

Freire, P. (1993). Pedagogy of the Oppressed. New York, NY: Continuum.

Gibson, A., Britten, N., and Lynch, J. (2012). Theoretical directions for an emancipatory concept of patient and public involvement. Health. 16, 531-547. doi: $10.1177 / 1363459312438563$

Green, G. (2016). Power to the people: to what extent has public involvement in applied health research achieved this? Res. Invol. Engage. 2:28. doi: 10.1186/s40900-016-0042-y

Grundmann, R. (2017). The problem of expertise in knowledge societies. Minerva. 55, 25-48. doi: 10.1007/s11024-016-9308-7

Hickey, G. (2018). Co-production from proposal to paper: share power in five ways. Nature 562, 29-30. doi: 10.1038/d41586-018-0 6861-9

Hickey, G., Brearley, S., Coldham, T., Denegri, S., Green, G., Staniszewska, S., et al. (2018). Guidance on Co-producing a Research Project. Southampton: 
INVOLVE. Available online at: http://www.invo.org.uk/wp-content/uploads/ 2018/03/Copro_Guidance_Mar18.pdf

Lambert, H., and Rose, H. (1996). "Disembodied knowledge? Making sense of medical science," in Misunderstanding Science? The Public Reconstruction of Science and Technology, eds A. Irwin and B. Wynne (Cambridge: Cambridge University Press), 65-83. doi: 10.1017/CBO97805115637 37.004

Madden, M., and Speed, E. (2017). Beware zombies and unicorns: toward critical patient and public involvement in health research in a neoliberal context. Front. Sociol. 2:7. doi: 10.3389/fsoc. 2017.00007

Mader, L.B., Harris, T., Kläger, S., Wilkinson, I. B., and Hiemstra, T. F. (2018). Inverting the patient involvement paradigm: defining patient led research. Res. Involv. Engage. 4:21. doi: 10.1186/s40900-0180104-4

McClean, S., and Shaw, A. (2005). From Schism to Continuum? The problematic relationship between expert and lay knowledge-an exploratory conceptual synthesis of two qualitative studies. Q. Health Res. 15, 729-749. doi: $10.1177 / 1049732304273927$

Moore, G. F., Audrey, S., Barker, M., Bond, L., Bonell, C., Hardeman, W., et al. (2015). Process evaluation of complex interventions: Medical Research Council guidance. BMJ. 350:h1258. doi: 10.1136/bmj.h1258

Paylor, J., and McKevitt, C. (in press). The possibilities and limits of 'coproducing' research.
Staniszewska, S., Denegri, S., Matthews, R., and Minogue, V. (2018) Reviewing progress in public involvement in NIHR research: developing and implementing a new vision for the future. BMJ Open. 8:e017124. doi: 10.1136/bmjopen-2017-017124

Taylor, P. (2007). 'The lay contribution to public health," in Public Health for the 21st Century: Policy, Participation and Practice, 2nd Edn, eds J. Orme, M. Grey, T. Harrison, J. Powell, and P. Taylor (Berkshire: Open University Press/McGraw Hill Education), 100-101.

Wicks, P., Richards, T., Denegri, S., and Godlee, F. (2018). Patients' roles and rights in research full partnership with patients is essential to any modern research enterprise. BMJ. 362:k3193. doi: 10.1136/bmj. k3193

Conflict of Interest Statement: The authors declare that the research was conducted in the absence of any commercial or financial relationships that could be construed as a potential conflict of interest.

Copyright (c) 2019 Green and Johns. This is an open-access article distributed under the terms of the Creative Commons Attribution License (CC BY). The use, distribution or reproduction in other forums is permitted, provided the original author(s) and the copyright owner(s) are credited and that the original publication in this journal is cited, in accordance with accepted academic practice. No use, distribution or reproduction is permitted which does not comply with these terms. 


\title{
Plain English Summary
}

\section{A Hierarchy of Power: The Place of Patient and Public Involvement in Healthcare Service Development in the NHS}

\author{
Alison O'Shea, Annette L. Boaz, Mary Chambers
}

Over recent years, patients and other members of public have become increasingly involved in NHS healthcare research and in decisions about NHS healthcare services. This is because patient and public involvement is seen as helping improve health outcomes for people using healthcare services. The belief is that people who use healthcare services, or who know others who have used healthcare services, have valuable knowledge of the ways those services can work to best help patients and their families and carers.

This paper presents findings from a research study that looked at some of the ways people are involved in decisions about NHS healthcare services. This involved looking at meetings held in an NHS clinical commissioning group (CCG) that patients and other members of public were involved in. CCGs are responsible for arranging, buying and monitoring healthcare services in their local area. There are 195 CCGs in England.

The study's researchers attended CCG meetings that members of public took part in. During these meetings, the researchers watched, listened and made notes of the different ways that members of public were involved. Researchers also noted the ways and how much members of public were able to influence the work of the CCG. Researchers then interviewed some of the members of public who took part in meetings and some staff members of the CCG to learn more about how they felt about patient and public involvement.

The study's findings indicate that some members of public are able to have more influence on the CCG's work than others, often depending on their background and the knowledge they were viewed as having. Despite the support shown for patient and public involvement by the CCG, the knowledge of staff members tended to be more highly valued than the knowledge of members of public. The different levels of influence that different staff and members of public have on the CCG are viewed by the researchers as a hierarchy or ladder of power. Staff members take up the most powerful positions over the members of public who are further down the ladder. The CCG controls patient and public involvement and has power over who influences its work.

The researchers suggest that good communication between the CCG and members of public could help members of public feel more valued. It could also make clearer everyone's expectations of what patient and public involvement in the CCG should look like and could achieve. Also, a formal assessment of PPI showing its strengths could help create greater influence on healthcare services. It could also help narrow the power gap which seems to exist between staff and members of public. 


\section{OPEN ACCESS}

Edited by:

Tiago Correia

Instituto Universitario de Lisboa (ISCTE), Portugal

Reviewed by:

Doreen Tembo,

University of Southampton,

United Kingdom

Andy James Gibson,

University of the West of England,

United Kingdom

Ewen Speed

University of Essex, United Kingdom

${ }^{*}$ Correspondence:

Alison O'Shea

a.oshea@sgul.kingston.ac.uk

Specialty section:

This article was submitted to Medical Sociology,

a section of the journal

Frontiers in Sociology

Received: 16 October 2018

Accepted: 11 April 2019

Published: 08 May 2019

Citation:

O'Shea A, Boaz AL and Chambers M (2019) A Hierarchy of Power: The

Place of Patient and Public Involvement in Healthcare Service Development. Front. Sociol. 4:38. doi: 10.3389/fsoc.2019.00038

\section{A Hierarchy of Power: The Place of Patient and Public Involvement in Healthcare Service Development}

\author{
Alison O'Shea*, Annette L. Boaz and Mary Chambers \\ Centre for Health and Social Care Research, Kingston University \& St. George's University, London, United Kingdom
}

Amidst statutory and non-statutory calls for effective patient and public involvement (PPI), questions continue to be raised about the impact of PPI in healthcare services. Stakeholders, policy makers, researchers, and members of the public ask in what ways and at what level PPI makes a difference. Patient experience is widely seen as an important and valuable resource to the development of healthcare services, yet there remain legitimacy issues concerning different forms of knowledge that members of the public and professionals bring to the table, and related power struggles. This paper draws on data from a qualitative study of PPI in a clinical commissioning group (CCG) in the UK. The study looked at some of the activities in which there was PPI; this involved researchers conducting observations of meetings, and interviews with staff and lay members who engaged in CCG PPI activities. This paper explores power imbalances when it comes to influencing the work of the CCG mainly between professionals and members of public, but also between different CCG staff members and between different groups of members of public. The authors conclude that a hierarchy of power exists, with some professionals and public and lay members afforded more scope for influencing healthcare service development than others - an approach which is reflected in the ways and extent to which different forms and holders of knowledge are viewed, managed, and utilized.

Keywords: patient and public involvement, healthcare, power, hierarchy, influence, lay members, public members, professionals

\section{INTRODUCTION}

It is widely accepted that quality in the delivery of healthcare is more than purely good clinical care. Quality is now defined to include dimensions such as clinical effectiveness, safety, and patientcentredness (Institute of Medicine (US) Committee on Quality of Health Care in America, 2001). The experience and voice of the patient has increasingly become integrated as a core dimension of health care consultation and planning. The idea is that patient and public involvement will improve quality and implementation of healthcare services, address population expectations and needs and foster healthcare choices and shared decision-making (Boivin et al., 2010).

Patient and public involvement (PPI) in healthcare services has become an international phenomenon over recent years in western and developing countries (Oliver et al., 2007). A PPI working group created in 2007 by the Guideline International Network Patient and Public Involvement Working Group (G-I-N PUBLIC) aims to support PPI globally in the development 
and implementation of clinical practice guidelines (Boivin et al., 2010). The UK is viewed as one of the "pioneers" in demonstrating a national commitment to public involvement (Gauvin et al., 2010). Regulations stipulate that all NHS organizations must have PPI in the planning, development, and operational aspects of healthcare services (Barnes and Schattan Coelho, 2009).

Statutory policy produces guidance on patient and public participation for commissioners of health services (NHS England, patient, and public participation policy $)^{1}$. Statutory guidance, however, is open to interpretation (Martin, 2008a) which often results in contrasting approaches to PPI and outcomes. Madden and Speed point out: "At its best, PPI may have the potential for increased democratic accountability, for improving health outcomes, and for addressing the social determinants of health, through for example, improved understanding of different cultures of research and engagements with evidence. At its worst, however, PPI runs the risk of being insignificant, tokenistic, and overly managerialist" (2017, p. 1).

Attempts to broaden and strengthen PPI continue in response to calls for more effective involvement. Frameworks have been developed for exploring the nature of PPI in the context of different approaches used and the differences between professionals and the public in relation to the challenges, demands and expectations around PPI (e.g., Tritter, 2009; Gibson et al., 2012). However, questions continue to be raised about the level and impact of PPI in decision-making and more recently research and literature has highlighted the importance addressing various challenges associated to these issues (e.g., Mockford et al., 2011; Staniszewska et al., 2011; Brett et al., 2012). Moreover, whilst patient experience is viewed as an important and valuable resource to the development of healthcare services, there are concerns about the legitimacy of the type of knowledge that patients and members of the public possess and are therefore able to contribute to healthcare decision-making (Daykin et al., 2007; Martin, 2008b; Boivin et al., 2010).

One of the challenges facing effective PPI relates to the differences between professionals and patients and the public in terms of motivations, expectations, and perceptions of PPI (Rise et al., 2011). Calls have been made for "professionals and users [...] to reconceptualize the traditional category of patient to one that understands that service users can contribute to service planning and development" (Petsoulas et al., 2014, p. 10).

This paper stems from a study which set out to explore PPI in a clinical commissioning group (CCG). Clinical commissioning groups are clinically-led statutory NHS bodies. Since April 2013, following a shift in commissioning powers from the former Primary Care Trusts, CCGs have held responsibility for commissioning secondary and community care services for their local populations. Clinical commissioning groups control around two-thirds of the NHS budget. All general practices in England are legally obliged to be a member of a CCG (Naylor et al., 2013; p. ix).

\footnotetext{
${ }_{1}^{1}$ Available online at: https://www.england.nhs.uk/publication/patient-and-publicparticipation-policy/ (accessed September 10, 2018).
}

The principles of PPI have been formally incorporated within the structure of CCGs through regulations which stipulate that the governing body of each CCG must include eight statutory roles, of which two must be occupied by lay members. Involvement from public and patient representatives is emphasized within reformed commissioning structures and procedures which require CCGs to liaise with Health and Well-being Boards to plan and deliver services. Healthwatch representatives form part of these Health and Well-being Boards and are described as the "patient voice" or "consumer champion" (Department of Health, 2012).

The CCG PPI study revealed that a key dimension of PPI related to a system of stratification within which individuals occupied positions that reflected their capacity to influence the work of the CCG. Stratification systems are a common feature of developed societies where a dominant hierarchy exists to maintain stability. As such, stratification engenders inequalities around power and other valued resources (Cheng et al., 2013). Raphael and Bryant (2015) provide a useful characterization of stratification: "In addition to affecting the social determinants of health, stratification is related to the power and ability of those so stratified to influence public policy" (Raphael and Bryant, 2015, p. 248).

Stratification constitutes a hierarchy which distinguishes between individuals on the basis of power to influence. Variations in power status within healthcare structures are widely documented, with reference to paid professionals occupying more dominant positions than members of public (e.g., Martin, 2008b; Ocloo and Matthews, 2016).

Foucault (1972) describes power as typically residing in medical structures, institutions, and discourses. The growth of PPI and the resulting increased potential it brings for patients and the public to have a voice in healthcare decision-making might potentially counteract this view. However, the question in reality is whether the growth of PPI translates into patients and the public having power to influence healthcare service development. Themes of power, dominance, and hierarchy are prevalent analytical terms in sociological studies of health care, and Foucault's concepts around power and knowledge can be applied to traditional views of the doctor-patient interactions. In historical contexts, Foucault theorized power of knowledge as embedded in dominant discourses and systems, and viewed critiques of knowledge and truths as both pervasive and dominant. Under such an analysis of power and hierarchy, the medical profession maintained the upper hand by having greater knowledge, expertise, prestige, organizational support, and stability. The patient/public with historically less power such as women, minority groups, and the poor would have been more vulnerable playing "second fiddle" to medical authority and lacked the resources to question medical decisions or challenge prescribed care (Foucault, 2003). However, as the modern day patient/public has become better informed about illnesses and forms of treatment, they have become self-advocates for their own health care and perhaps, in this sense, as a consequence have acquired the potential to narrow the power disparity.

There are various definitions of power that have emanated from different theoretical and conceptual perspectives. A neutral 
meaning of power cannot be found, since the meaning of power is always embedded in a theoretical context (Guzzini, 2005). It is not the intention here to provide an in-depth discussion of the different perspectives of the meaning of power. However, one example of a classical sociological concept of power comes from Weber's definition, presented by Rutar (2017):

\begin{abstract}
"For him (Weber, 1978 [1922], p. 53) power is, as is well known, "the probability that one actor within a social relationship will be in a position to carry out his own will despite resistance, regardless of the basis on which this probability rests." This can be, and usually is, further condensed. Social power is simply the ability of agent A to influence agent B in such a way (with the help of either personal or impersonal means) that agent $\mathrm{B}$ does something he/she otherwise would not have done, or does not do something he/she otherwise would have done (cf. Dahl, 1961)" (2017, p. 153).
\end{abstract}

\section{METHODS}

The aim of this paper is to explore the differences between individuals in their potential to influence the work of the CCG and to consider these differences in terms of the positions they occupy in a hierarchical structure.

The use of the term "public member" refers to a member of public; the term "lay member" refers to a member of public who is a member of a formal PPI group.

\section{Study Design}

This study forms part of a wider research project exploring PPI in a CCG in England. It is a single case study set in a large, diverse inner city. The study used a qualitative approach drawing on ethnographic methods. Ethnographic research "seeks to understand people's opinions, beliefs, motivations, interactions, and the structures in which they are involved or are influenced by, and above all, the social contexts in which people live and interact [...]. [Ethnographic research] observes what people do in their everyday practices, and tries to understand the motivations and explanations for people's actions." (Potrata, 2005, p. 131).

PPI in the CCG comprised GP surgery patient groups, public consultations, public attendance at CCG board public meetings, and various clinical reference groups (CRGs). Our study explored two of these activities: (i) CCG board public meetings and (ii) the CRG for PPI (PPI CRG). These settings were identified by a PPI lay member of the CCG board who was involved in developing the study.

\section{Data Collection}

Data were collected over an 18 month period between February 2014 and August 2015 and methods comprised observations, informal interactions, interviews, and a focus group.

\section{Observations}

Researchers made handwritten notes of observations which were entered as soon as possible after each meeting onto a data collection tool (form) that was designed for the study. The tool enabled researchers to document the type of meeting, number of people present and their roles, diagram/notes on physical layout, agenda items discussed, and researchers' general notes.

\section{Clinical commissioning group board public meetings}

CCG board public meetings were held monthly on a weekday morning in a CCG meeting room. Observations of 14 meetings were conducted. Meetings lasted two and a half hours; this constituted $\sim 35 \mathrm{~h}$ of observation. Researchers considered it necessary to carry out this number of observations because meetings covered a range of topics which often varied from month to month. This generated attendance from different public and staff members depending on the agenda items under discussion.

The board was made up of 15 voting members and six non-voting members. Voting members included two lay members, one with responsibility for governance and one with responsibility for PPI. Other voting members comprised clinicians (GPs and a secondary care doctor), a registered nurse and managers of finance/accounts. Non-voting board members included directors of services and a Healthwatch representative.

\section{Patient and public involvement clinical reference group meetings}

PPI CRG meetings took place bimonthly on a weekday afternoon in a CCG meeting room. Observations of 10 of these meetings were carried out. Meetings lasted $\sim 3 \mathrm{~h}$, amounting to $30 \mathrm{~h}$ of observation.

The PPI CRG was relatively newly developed and observing 10 meetings over an 18 month period enabled researchers to gain insight into the nature and progression of the group and the relationships within. There were 11 lay members of the group, made up of individuals and community representatives, voluntary and community sector representatives, locality representatives, and a lay member chair of the group (who was also one of the voting lay members on the CCG board). The group comprised five staff members: a clinical lead, a PPI manager, an engagement manager, an administrator and a CCG board member with a remit for PPI. The CCG board member's attendance reduced regarding the amount of time spent in meetings and ceased altogether less than half way through observations. This was reportedly because their attendance was seen by the CCG as necessary only during the early stages of the group's development to provide support until the group had become more established.

Meeting attendance numbers varied (in terms of both staff and lay member attendance), with a minimum of five members in just one meeting observed and a maximum of 15 in another.

\section{Informal Interactions}

Informal interactions between researchers and meeting attendees often occurred following CCG board public meetings and PPI CRG meetings. Interactions provided valuable insight into the views, beliefs and experiences of public, lay and staff members in terms of the respective meeting and PPI itself. Handwritten notes of interactions were added to the relevant observation notes on the data collection tool.

\section{Interviews}

A total of 14 interviews, both face to face and by telephone (according to the preference of interviewees), were carried out 
TABLE 1 | Number of interviews conducted with CCG staff and public/lay members.

\begin{tabular}{llll}
\hline CCG staff & & Public/lay members & \\
\hline Board members & $n=3$ & $\begin{array}{l}\text { Public member attendee of } \\
\text { CCG board meeting }\end{array}$ & $n=1$ \\
PPI CRG & $n=2$ & $\begin{array}{l}\text { PPI CRG lay members } \\
\text { (inc lay chair board member) }\end{array}$ & $n=8$ \\
lead/manager & & & \\
\hline
\end{tabular}

with staff, public, and lay members. These comprised three with CCG board members, one with a public member who regularly attended CCG board public meetings, two with PPI CRG staff, and eight with PPI CRG lay members (Table 1).

Interview schedules for public and lay members addressed the following areas: how and why they became involved in the CCG and associated expectations; the PPI role; representation as a lay/public member; CCG support for and commitment to PPI; impact/influence of PPI. Public members who attended CCG board public meetings were also asked about PPI in meetings and the structure and content of meetings. Staff member interview schedules explored issues around the importance, benefits and challenges, and influence of PPI.

\section{Focus Group}

A focus group took place 12 months into data collection activities with five PPI CRG lay members. In particular, discussion focused on issues around representation. Three focus group lay members also took part in the interviews.

\section{Data Analysis}

Analysis was an iterative process carried out at different stages starting from the collection of data during observations through to writing up findings of the study. Analysis of observation and interaction notes and interview and focus group transcripts took place using a thematic framework approach (Pope et al., 2000). Data were coded into themes from which interpretations were generated. This process was carried out inductively, identifying key issues, concepts and themes emerging from data, and deductively in line with interview and focus group schedules. During data collection activities and early coding we observed that power imbalance was a key feature within the different data sources: observations of meetings, interviews, informal interactions and the focus group. Ongoing coding and analysis generated the themes presented in Table 2. The three layers represent the final set of themes and codes underpinning our analysis: Overarching theme (power, control, PPI impact); Organizing theme (PPI, power to influence, time, meeting arrangements, recruitment, knowledge, accountability, and feedback); Components of organizing theme.

Two researchers independently carried out analysis of half the data. Following discussion and agreement about the coding and subsequent themes identified, one researcher continued the process across the other half of data. Papers and documents from meetings observed were collated and used for reference during data analysis.
TABLE 2 | Data coding themes.

\begin{tabular}{|c|c|c|}
\hline $\begin{array}{l}\text { Overarching } \\
\text { theme }\end{array}$ & Organizing theme & Components of organizing theme \\
\hline \multirow[t]{2}{*}{ Power } & Power over PPI & $\begin{array}{l}\text { Type of involvement } \\
\text { Level of involvement } \\
\text { Timing of involvement } \\
\text { Place of PPI } \\
\text { PPI CRG role unclear } \\
\text { Challenges - limited resources for PPI } \\
\text { in commissioning }\end{array}$ \\
\hline & Power to influence & $\begin{array}{l}\text { Unequal between professionals and } \\
\text { public/lay members } \\
\text { Unequal between different public/lay } \\
\text { members } \\
\text { Decision-making } \\
\text { Status of relationships }\end{array}$ \\
\hline \multirow[t]{3}{*}{ Control } & $\begin{array}{l}\text { Time (CCG board } \\
\text { public meetings) }\end{array}$ & $\begin{array}{l}\text { Short of time-PPI reduced } \\
\text { Changes to PPI timeslot } \\
\text { Written public questions not always } \\
\text { responded to }\end{array}$ \\
\hline & Meeting arrangements & $\begin{array}{l}\text { Time, venue, frequency } \\
\text { Agenda setting and discussion } \\
\text { Leadership of meetings - staff; lay } \\
\text { member } \\
\text { Supporting PPI }\end{array}$ \\
\hline & Recruitment & $\begin{array}{l}\text { PPI CRG membership and } \\
\text { skills/attributes required, determined } \\
\text { by the CCG } \\
\text { Leadership of PPI CRG }\end{array}$ \\
\hline \multirow[t]{2}{*}{ PPI Impact } & Knowledge & $\begin{array}{l}\text { Capacity to influence/make a } \\
\text { difference } \\
\text { Legitimacy } \\
\text { Skills and experience } \\
\text { Value of PPI }\end{array}$ \\
\hline & $\begin{array}{l}\text { Accountability and } \\
\text { feedback }\end{array}$ & $\begin{array}{l}\text { Role of PPI unclear } \\
\text { Feedback not shared with PPI CRG } \\
\text { Accountability-one way } \\
\text { Monitoring/evaluation of PPI }\end{array}$ \\
\hline
\end{tabular}

\section{Patient and Public Involvement}

The original idea for this study emerged from a discussion between a lay member of the CCG board (who was our gatekeeper to the meetings observed) and the investigators. Many of our research participants were lay and public members. Subsamples of three lay members volunteered and were subsequently involved in the design of the research, data collection, and analysis.

\section{Ethics}

This study was granted ethical approval on $14 / 02 / 14$ by the East of Scotland Research Ethics Service.

\section{RESULTS}

Findings from our data reveal that the CCG retained power and control over PPI in different ways.

\section{Clinical Commissioning Group Board Public Meetings}

CCG board public meetings were intended to enable public participation. Through open discussion, meetings would inform 
the public of service developments and provide opportunity for questions about issues under debate. Whilst discussions about service development took place between board members, there appeared to be little opportunity for public participation.

\section{Control}

The CCG board controlled all the meeting and PPI arrangements and agenda items for discussion. For one public member there was:

a slight tendency to listen to things that fit into their agendaslightly [...] if someone raises something pertinent, they might be useful to the board with their knowledge then maybe they should be following up on that rather than seeing it as "oh god, that's something else to do and that's another problem you've given us."

At times meetings did not feel open to public participation:

[...] so if [they] think it's not a relevant question, [they'll] close down quite quickly I think on the question. And [they are] very clear of the direction [they] want to go in and I don't know that [they're] terribly open to other people.

Researchers observed that public comments and questions were "closed down" at times if they were deemed not relevant to agenda items, if they were too subjective, or if time was running short.

During earlier observations of meetings a time-slot was included at the end of each agenda item for public members to give comments and ask questions, allowing them to comment directly on the item under current discussion. In later observations a $10 \mathrm{~min}$ time-slot for public questions and comments was relocated to the very end of meetings. This meant public members had to wait until the end of the meeting to comment, by which time discussion of a given item had already taken place. This was perceived by public members as a way of "saving time": by moving (thereby reducing) the public time-slot, the board would have longer to discuss agenda items. One public member commented:

The public involvement is confined to $10 \mathrm{~min}$ at the end of the meeting [... ] I think $10 \mathrm{~min}$ for people to ask questions is certainly nowhere near long enough.

Eventually the arrangements for public involvement changed again. The board asked for questions to be submitted in writing ahead of meetings; these would receive priority over verbal questions on the day. Sometimes, however, meetings over-ran and there was insufficient time for responses to written questions. On these occasions, the board announced they would respond in writing at a later date. This was seen as unhelpful by one public member because:

[...] it means all the people here [at the board public meeting] don't get to hear what others are concerned about and the board's response.

\section{Patient and Public Involvement Clinical Reference Group}

Researchers observed two dimensions to the work of the PPI CRG: (i) facilitating development of greater PPI across the borough (e.g., by ensuring on-going communication with and support for other CRGs relating to building PPI) and (ii) supporting the CCG in gaining public feedback about healthcare service development plans (e.g., via public consultations and rolling out public surveys).

The PPI CRG terms of reference stated the overall purpose of the group was to "ensure effective PPI and to deliver to the CCG a vision for PPI." However, the document lacked detail and was unclear in terms of the role of group members, for example expected achievements and who they were representing and informing-questions that were repeatedly raised by PPI CRG lay members during meetings.

\section{Control}

Membership to the PPI CRG was controlled by CCG staff regarding the attributes required of new lay members, who would occupy a leadership role and what leadership involved.

Lay members of the PPI CRG had undergone a formal recruitment process to become members of the group. This had involved completing and submitting an application form and $\mathrm{CV}$ and attending interview with the lay chair and two or three staff members of the group. Lay members on the whole had previous experience and knowledge of NHS services-some of them in a professional capacity-not only from the patient perspective but also through involvement in other voluntary and community groups.

During researcher observations of PPI CRG meetings two lay members consecutively occupied the role of chair, the first leaving the position when research observations were at an early stage. The second chair was a lay member of the PPI CRG and applied for the position through a formal application process. Senior CCG board members had conducted interviews and appointed the lay member as chair. This appointment automatically afforded the lay member a position on the CCG board as representative for PPI.

The interim period between the first chair leaving the role and recruitment of the second chair was managed by staff members of the group who took on a leadership role and chaired meetings. This received mixed reactions from lay members who, on the one hand, recognized and appreciated the commitment and support of staff members. On the other hand, lay members were at times dissatisfied with the way the group's work and meetings were "managed." One lay member spoke about feeling:

[...] a bit uncomfortable about the power balance between the staff and the punters.

Notwithstanding this, lay members acknowledged the accountability of staff members to the CCG. Part of the staff's role was to provide written documents (e.g., PPI CRG reports, with input from lay members) about the group's work in developing PPI across the borough. Researcher observations noted perceptions of staff members feeling under pressure 
when deadlines for producing documents to the CCG board were approaching.

\section{Valuing Patient and Public Involvement Accountability and Feedback}

Lay members expressed a need for stronger lines of accountability in both directions between the PPI CRG and the CCG. Some lay members felt that PPI should be audited to monitor and facilitate progress. This would go some way to strengthening lines of accountability, in turn enabling greater recognition, and value to be placed on PPI:

I do bang on about outcome measurement because I always want to have some demonstration be it qualitative or quantitative that there is a difference being made to actions and outcomes as a result of the conversations that we're having.

However, during observations of PPI CRG meetings, the group did not receive any feedback from the CCG about the work the group had been involved in. One interviewee reported that the only feedback the PPI CRG had received related to the group's written report on developing PPI. The board was interested to know how PPI in the CCG was developing compared with other CCGs and shared the view that PPI in the area was "far ahead in all respects in patient and public involvement." Lay members expressed a need for meaningful feedback from the CCG:

We don't get much sense when we've done these reports, of has it made any difference [...] We keep on trying [to make a difference] without taking stock of whether anybody's hearing what we're saying [...] but it would've been quite nice to have got something back from those around us about whether or not they've found anything we've ever done of any use to them.

\section{Patient and Public Input \\ Linking With the Clinical Commissioning Group}

Some lay members had stronger relations with the CCG board, in turn greater levels of input, than other lay and public members. The Healthwatch lay representative and another Healthwatch colleague would meet with the board chair and the chief executive approximately every couple of months "in a private forum" to discuss any issues regarding PPI that came to the representative's attention outside of public meetings:

So in a sense that's not good that the public is excluded from that small meeting but it does help to put across the thoughts and ideas that are coming up from the public through the Healthwatch. They all seem to get a chance to get their message across-why commissioning this or not commissioning that.

The PPI CRG lay chair was also able to speak informally with the CCG board chair and chief executive:

[... ] all sorts of conversations take place outside the board and not just involving me, other people have contact with staff, executives or someone [...] most of it less than formal meeting level.
The dual role of the PPI CRG lay chair, as a voting board member also, meant they were able to "keep the PPI CRG informed of the bigger picture" regarding the CCG's work and to act as a link between the two. They were also able to give comments on agenda items under discussion at CCG board public meetings and ask questions relating to PPI from their own perspective and/or on behalf of other PPI CRG lay members.

The approach and involvement in the CCG of the PPI CRG lay chair was greatly valued by staff and lay members alike. The lay chair's extensive knowledge and experience and the way they were able to support the development of PPI moving forward, was held in high regard.

\section{Influence}

Public members who attended CCG board public meetings appeared to have considerably less input to the CCG's work than PPI CRG lay members. One of the reasons relates to the way public involvement in meetings was managed. Another possible reason was that their input may have been viewed as less legitimate-there were no formal recruitment processes to participation. Public members were "independent" and came from a range of backgrounds, particularly different to the backgrounds of PPI CRG lay members. Some public members spoke from personal experience of healthcare services as patients or carers, some spoke from particular political standpoints and most had no "professional" experience of NHS structures and processes.

There were differences in how and at what stage public and lay members wanted to be involved in the CCG's work and how and when the CCG wanted them to be involved. This led to some frustration about the type of involvement lay and public members could or should expect to have. At times PPI CRG lay members perceived their input as "low level":

Some discussions have come to the [PPI] reference group for input at an early stage [...] but they tend to be slow-burning, less high profile issues.

[...] the input was looking at the types of questions that were being asked like, "is this questionnaire okay?"

Some lay members had volunteered their involvement in a commissioning subgroup in order to bear some influence at a higher level, but their involvement had come to an end when, after one meeting, the subgroup stopped meeting.

Lay members wanted to influence commissioning decisions and for the public more broadly to do the same. However, it was emphasized by two staff members that after "essential" healthcare services costs were factored in by commissioners there was very little finance remaining "to play around with." It was also pointed out that allocating limited resources was a significant responsibility which involved a great deal of skill and particular experience. Based on these restrictions, irrespective of the CCG's approach to PPI, this suggests public and lay members could not have as much input to commissioning decision-making as they believed was or should have been possible. 


\section{Decision-Making}

Researchers did not observe CCG strategic decision-making taking place; agenda items in meetings observed tended not to require decision-making at a strategic level either with or without PPI. CCG board public meetings facilitated discussion amongst board members and other staff, with some input from public members (e.g., around hospital bed arrangements; patient number increase and capacity to meet healthcare needs; plans for patient self-management of clinical conditions; expenditure issues). CRG PPI meetings tended to discuss and respond to CCG requests to build greater PPI more broadly across the borough.

Lay and public members expressed doubts about being heard in a way that made a difference to CCG decision-making at a strategic level including around procurement, commissioning, and future priorities and developments of healthcare services:

I want to know really where people are having an influence and making changes for the better [...] but I can't actually get a grasp of where any of us have actually managed to influence spending decisions.

I don't feel we're very influential-I really don't.

For some, the CCG would take notice of PPI only if views matched those of the CCG's:

If it works in the favor of the CCG they'll love it, otherwise they don't want to know.

Public members who attended CCG board public meetings felt that this was not where decision-making in reality took place. It was pointed out that public members were invited to ask questions "which is great" but that:

[...] decisions are obviously made somewhere behind the scenes and they come to the board for ratification.

CCG board public meetings were viewed as a means to public members hearing about changes to services the CCG was planning, but that decisions around those changes had likely already been taken.

\section{DISCUSSION}

Researchers' observations of meetings, interviews conducted, and informal interactions provide insight into the approach, views, and attitudes toward and experiences of PPI in the CCG. Data reveal there are different layers to PPI which reflect different lay and public members' capacity to influence the CCG's work. These layers form part of a hierarchy in which professionals occupy the most powerful positions.

Researchers identified two co-existing dimensions to power. One relates to CCG power over PPI and the other relates to having power to influence the CCG's work. If the CCG has power over PPI, it is reasonable to assume this will affect the nature and extent of PPI input. However, our findings reveal that the different positions of individuals afford them different levels and types of input. Our discussion below considers power imbalances between different individuals and the positions they occupy with regards both dimensions of power: the power over PPI and the power to influence CCG decision-making.

\section{Power Over Patient and Public Involvement}

Issues emerging from our study relating to imbalances of power support findings of previous research regarding the control and restrictions of statutory bodies over public involvement (Baker, 2007; Stern and Green, 2008; Peckham et al., 2014).

Much of the CCG's PPI could be considered low level. Consultation-type PPI is widely recognized as a low level form of involvement (Hickey and Kippling, 1998; Renedo and Marston, 2011). Callaghan and Wistow (2006) found that health boards were viewed as controlling which of its public consultation findings to respond to and concluded that consultation is used to confirm the dominant (professionals') views and not necessarily the public's views. This corresponds with the views of some public and lay members in our study who believed that the CCG would act on PPI only if it corresponded with its own plans.

Direct PPI in CCG decision-making was not evident and neither was there feedback to the PPI CRG from the CCG or outcome measurement of actions resulting from PPI CRG discussions. CCG board public meetings might have intended public participation but in reality there was relatively little. These factors made public and lay members feel underutilized and undervalued highlighting a further aspect of power inequalities. Tritter's (2009) framework for conceptualizing PPI helps us understand the nature of PPI in our study and the power dynamics between professionals and public/lay members. It comprises three dimensions: direct/indirect (the degree of direct decision-making around healthcare service development); individual/collective (the extent that patients and public act as sole agents or as part of a group); proactive/reactive (how much PPI is responding to a pre-existing agenda or is helping to shape it) (2009 p. 277). The PPI in our study can be considered indirect (there was no evidence of direct involvement in decisionmaking); it is both individual and collective (individual referring to public members at CCG board public meetings and the PPI CRG as the collective). Finally it is both reactive and proactive: public members at CCG board public meetings were reactive because of their capacity to respond only to meeting agenda items and in allocated ways and times. The PPI CRG was reactive in the broad context of the CCG's PPI agenda which determined the nature and level of involvement in the CCG's work. The group was proactive, however, in shaping the PPI agenda to develop PPI more broadly across the borough. Yet even this proactive dimension was conducted under the supervision of the CCG through the support, leadership (at times), and reporting back to the CCG by PPI CRG staff members. Our findings support Tritter's point about the power of professionals to both influence the legitimacy of PPI and limit the type of involvement. Professional support is both an enabler and a restrictor (Tritter, 2009). 


\section{Power to Influence: A Stratified System}

The varying degrees of power held by different individuals to influence the CCG's work reflect a system of stratification. Kerckhoff (2001) makes a useful distinction between stratification as a condition and as a process:

Social stratification as a condition refers to the fact that members of a population have characteristics that differentiate them into levels or strata. Social stratification as a process refers to the ways in which members of a population become stratified (Kerckhoff, 2001, p. 3).

In our study, social stratification as a condition relates to the differences in knowledge, qualifications, and experience between professionals and lay members. As a process it relates to how the CCG decides the type and level of PPI afforded to public and lay members.

The stratification system constitutes a hierarchy of power. Different positions occupied by professionals and public and lay members reflect different levels of power ownership. Power imbalances existed not only between professionals and lay members (although this distinction was the most pronounced), but also amongst different CCG staff and board members and amongst different lay members (Figure 1).

Situated at the top, occupying the most powerful position, were the CCG's 15 voting members. These included two lay members: the PPI CRG chair, and a lay member for governance. Non-voting board members occupied a position below voting members; one of these was the Healthwatch representative. By virtue of sitting on the board, non-voting members nonetheless had the resources to give input and raise questions. Together with other staff members (managers and colleagues) not on the board they were accountable to voting board members when producing service development proposals for approval.

Further down the hierarchy were the CRGs. Within the PPI CRG itself a sub-stratification system or hierarchy existed, starting at the upper end occupied by the lay chair and staff members. The lay chair was a voting CCG board member which automatically afforded a more prominent position, not least by having direct access to CCG board members. They were also involved in separate, smaller meetings with board members outside of CCG board public meetings. Staff members occupied a position somewhere in between the lay chair and other lay members of the group: they were not members of the board but they chaired PPI CRG meetings when there was no lay chair in post. In liaison with the lay chair, they also regulated PPI CRG meetings and agendas.

Other lay members sat on the lower end of the PPI CRG sub-stratification system. They did not have equal access to, or involvement with, CCG board members in comparison to the lay chair and staff members. The privileged position of the lay chair as a CCG board voting member combined with the wider group's involvement in developing broader PPI, its written reports and other tasks requested by the CCG, meant that the PPI CRG as a whole occupied a higher position in the hierarchy than other types of public involvement observed.

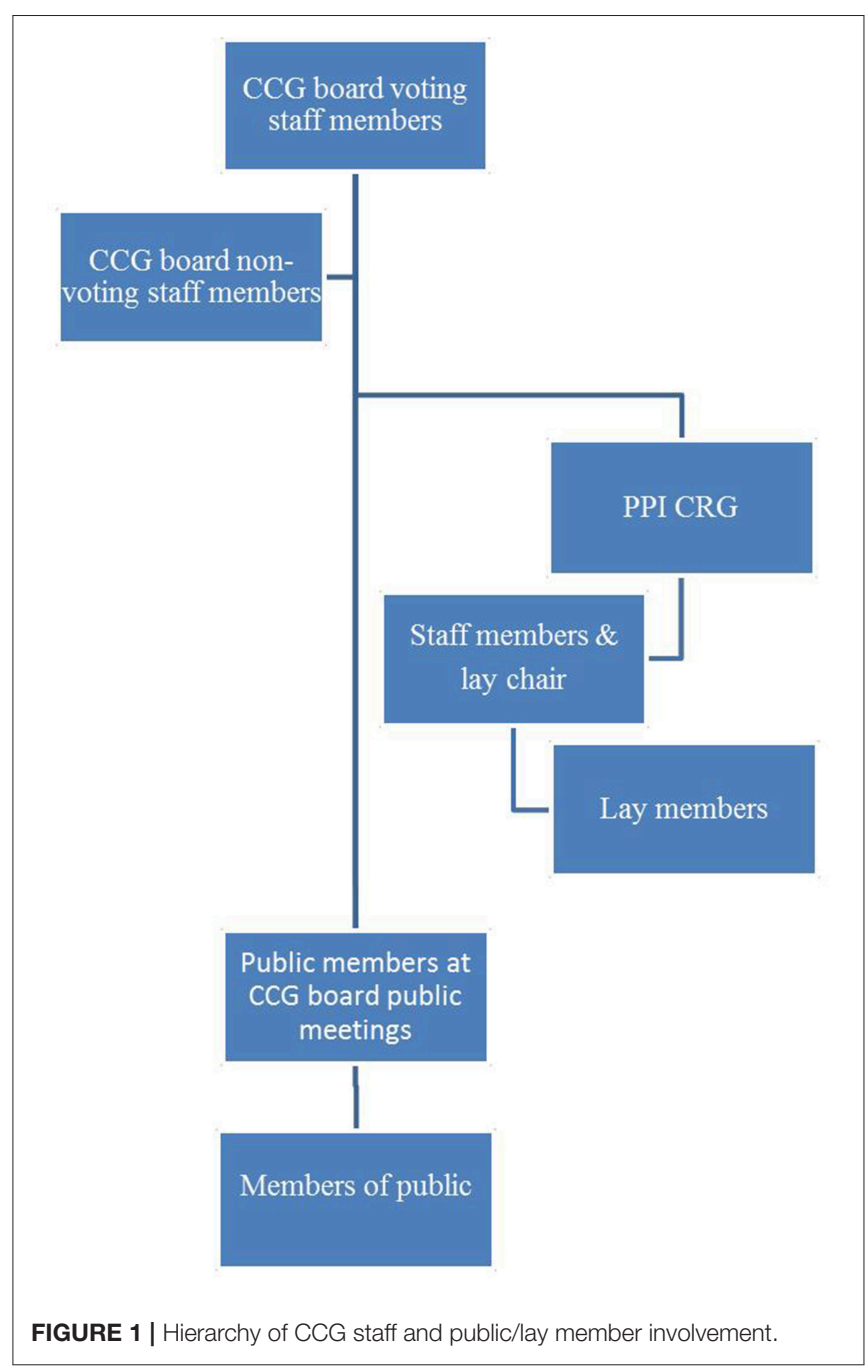

In the lower echelons of the hierarchy was involvement from public members who attended CCG board public meetings but whose participation had less potential to influence the CCG's work.

Situated at the bottom of the hierarchy were members of public who did not sit on committees, belong to a formal CRG or attend CCG board public meetings, but took part in CCG public activities, for example consultations. On the one hand, these members of public had least capacity to influence the CCG's work. On the other hand it is possible that public consultations bore some influence on discussions around service development. However, researchers did not observe decision-making taking place. Neither were the CCG's public consultations findings accessed. Without these data we can neither confirm nor refute this point.

Overall, what we see is an example of a hierarchy of power in which, predictably, professionals occupy positions at the top and public members at the bottom. However, we suggest this system has complex dimensions. The dual or overlapping roles of lay members and professionals place them simultaneously on 
different hierarchical levels. For example the lay chair occupies a position near the top as a voting board member, whilst also being a lay member of the PPI CRG which occupies a lower position. Similarly, staff members of the PPI CRG occupy the same hierarchical position as lay members. Yet as CCG employees with access to senior professionals, and who to a large extent lead and make decisions about the PPI CRG, they also occupy a higher status than their lay member colleagues of the same group.

The hierarchy also demonstrates how positions occupied reflect both the individual and collective dimensions of Tritter's model at the same time. Also in relation to Tritter's model, PPI in CCG board public meetings is at an individual level and at the lower end of the hierarchy while PPI CRG lay members function at a collective level and are positioned higher up. The lay chair of the (collective) PPI CRG, however, is also involved at an individual level but occupies one of the highest positions in the hierarchy. This indicates that having greater or lesser influence is not determined by whether involvement is individual or collective. Further, the only individuals with direct involvement in decision-making are CCG board staff members. Other individuals' involvement may best be described as indirect.

\section{Structure and Power}

The structure and organization of PPI in the CCG was an important factor in governing the flow of power. In order to help inform our interpretations of this finding it is useful to draw on theoretical perspectives.

Power is a core theoretical construct in the field of sociology. It has been a key area of interest in sociological analysis and the impact of power relations on individuals, groups, and organizations over many years.

Paradigms have naturally evolved and shifted in sociology from the 1960s to current day. During the 1960s structural functionalism was a dominant theoretical perspective which attracted critics (e.g., symbolic interactionist Herbert Blumer) for its emphasis on maintaining social orderliness within social and cultural structures, sustaining pre-existing social inequalities and the power of established elite groups. In structural functionalist theory, social stratification is a functional necessity. Stratification as a structure refers to a system of positions (as opposed to individuals in the stratification system) which contain different levels of status. Symbolic interactionism theory criticized the model of structural functionalism for its disregard of individual creativity and micro-level social processes (Cockerham, 2013).

The realm of symbolic interactionism helps to identify the important interaction between structure, culture and action, and provides significant understanding into the relational nature of power, not only in terms of macro structures but also with regard to micro structures and the individual roles that people play within more established organized structures. It is widely recognized that social structures can fashion and influence social interactions and that social interactions can influence, reproduce, and sometimes alter social structures (e.g., Giddens, 1984; Turner, 1992). Established structures, such as macro structures like health organizations, have the potential to promote actions and behaviors among individuals which in turn promotes them to form and continue relationships or affiliations with the dominant structure.

The post-structuralism movement acknowledges the importance of structures. Theorist Michel Foucault, widely associated with post-structuralism, focuses on power and specifically the link between knowledge and power within such structures. Foucault (1980) describes hierarchical bodies and powerful social and cultural structures as having far-reaching, controlling impacts, stretching out and working through every situation in which individuals find themselves (Clark, 2010). Foucault's work reflects how dominant groups, professions and organizations can control agendas to promote or protect their dominance.

The structure and organization of PPI in the CCG reflects a top-down model in which the CCG (the macro structure) is the dominant system and PPI represents social processes at the micro level. The CCG is formed of a board of members which largely comprises medical professionals. Other professionals such as directors and managers of various services also make up board membership. In keeping with Foucault's perspective of power residing in medical structures, institutions and discourses, our findings indicate that the professional status of CCG board members, or the CCG as a structure, places professionals at the top of the hierarchy affording them power over all aspects of the CCG's work. The status of professionals gives them power as professionals in the realm of healthcare services and provisions. Lay and public members, in contrast, are not professionals in this realm; they are recipients of healthcare services and provisions. Attempts are made by the CCG to work collaboratively with lay and public members, but ultimately the professionals represent the dominant structure.

Features of the dominant structure are apparent such as centralized decision-making which appeared to be taking place behind doors that were closed to the public. Although meetings observed were not overly bureaucratic, the CCG board also controlled arrangements around PPI, exemplified for example by the CCG board in public meetings determining when the public could speak, what they could speak about and for how long. By controlling PPI, the status quo is maintained. However, this is not to say the CCG maintained such a level of control in order to promote or protect its dominance. Such an organization with responsibility for making impactful and complex decisions around healthcare service provision would need a level of social orderliness in order to achieve outcomes necessary to provide a service that meets bureaucratic and practical demands.

In theory, the structural model of PPI meetings potentially offered a more collaborative approach to the work of the CCG. In theory, our study was potentially observing a decentralized model through which the public could have strategic input into local healthcare service development. Yet in reality a centralized system governed, facilitating a hierarchy in which the right of the CCG to determine strategy continued largely unchallenged. Lay members showed on-going commitment and support toward (or at the very least involvement in) the work of the CCG which might somewhat reflect a propensity to reinforce power structures through their already established affiliation with the organization. 


\section{Holders of Knowledge}

Findings indicate a relationship between knowledge and power when it comes to who can become involved in the work of the CCG, at what level and the extent of influence individuals can have. Foucault's critique of dominant power and knowledge and the disparities between those who possess these resources (professionals) and those who do not (non-professionals) is particularly relevant.

The many different sources and types of knowledge around healthcare [e.g., clinicians', patients/carers', research or evidencebased (Rycroft-Malone et al., 2004)] do not receive equal status and give rise to battles over power and control between competing forms (Shortall, 2012) with professionals questioning the legitimacy of public knowledge (Callaghan and Wistow, 2006). Gibson et al. (2012) emphasize that lay people even on committees are not seen as equal as they do not have the same access to resources as professionals. Whilst our study showed no evidence of professionals questioning the legitimacy of lay members, the more marginal role of lay members in the work of the CCG suggests an unequal balance of potential to influence and ultimately of power between professionals and lay members.

The issue of power imbalances between the different groups of individuals involved in the CCG can be explained by ownership of particular resources, relating to Gibson et al.'s point. CCG board members have professional status. The resources they possess include professional qualifications, knowledge, and expertise. It is ownership of these resources that determines professionals' positions, and it is through these relative positions that they establish levels of power greater than that of other CCG staff and lay and public members. Other CCG staff members possess qualifications, knowledge and expertise but in different areas and at different levels to board member professionals. Lay and public members may also have qualifications, knowledge and expertise but again in areas different to those of the CCG board and to other staff members and, importantly, with less relevance to the CCG's work. When it comes to power imbalances-or more precisely differences in levels of influence-between lay and public members, the former are perhaps viewed as having greater legitimacy because of the particular resources (knowledge, skills, experience, and in some lay members, professionalism) they bring to the CCG. Procedures for recruitment to the PPI CRG suggest that lay members were "cherry-picked" on the basis of these resources. Power imbalances ultimately relate not only to the professional status of individuals and the level and type of resources they possess, but also to perceptions of the legitimacy and relevance of those resources to the CCG's work, and to the access of other individuals to the more powerful professionals.

The position of individuals in the CCG hierarchy is largely governed by professionals' perceptions of lay members' knowledge and based on what type of knowledge is valued. This affords some lay members a higher status (as in the case of the lay chair) but not equal to that of the professionals due to the relativity of the positions they occupy. Where lay people are metaphorically placed is determined by those in positions of power (the professionals) because it is they who control PPI. As Callaghan and Wistow (2006) emphasize, barriers to power-sharing include the beliefs held by professionals about what participation can contribute. A higher position in the CCG hierarchy might enable different PPI and even a greater level of involvement, but does not necessarily translate into a system of equality between the professionals and non-professionals when it comes to influencing the work of the CCG.

\section{LIMITATIONS AND STRENGTHS}

A main aim of our study was to explore PPI in CCG decision-making. However, we were unable to yield data relating specifically to this due to CCG arrangements around decisionmaking and around PPI which appeared not to combine the two. It is important at this point to note, though, that our study focused on two particular areas in which there was PPI and not all CCG PPI activities; exploration of other PPI activities may have generated different findings. One way of potentially establishing PPI in strategic decision-making would have been through accessing data from CCG public consultations. These data would then have needed to be compared with decisions the CCG had subsequently taken on the same issues that public consultations addressed, thus becoming more of an evaluation of PPI than an exploration.

A further issue relates to the scale of the study. As a single case study, generalizations about the commissioning arrangements of other CCGs on a national and international level are limited.

The majority of data relating to power derived from researcher observations of meetings and from interviews with public and lay members. Relatively little came from staff interviews. However, the data yielded provide insight into how two types of PPI activity operated in a CCG in England and the views and experiences of many individuals involved.

Contemplating PPI in the context of a stratification system helps us understand the relative position and value accorded to PPI, the different layers to PPI and the levels and types of PPI within those layers. It is appropriate to acknowledge, however, that the hierarchy we present here comprises only those groups and individuals that we observed and conducted interviews with. There would indisputably be other groups and individuals within the CCG (staff and lay members) who would also occupy positions in the hierarchy; it is not by any means exhaustive.

\section{CONCLUDING COMMENTS}

We suggested in our introduction that modern day changes to the way healthcare services are sought, delivered and have facilitated the growth of PPI might have narrowed the power gap between professionals and lay and public members. Consistent with theory and previous research, however, our findings support the premise that professionals hold the most power and therefore continue to dominate; PPI is unable to permeate healthcare commissioning and procurement at an equal level. PPI might have become more integrated into healthcare service development but it still has less status than that of professionals, hence the potency of PPI remains questionable.

The main facilitator of PPI in our study relates to the support provided by the CCG in terms of the functioning of various 
PPI activities and groups, and the provision of staff and admin support. The barriers to PPI are less tangible but are linked to the legitimacy of public knowledge, an issue that has been widely referred to as restricting effective involvement (e.g., Martin, 2008b; Barnes and Schattan Coelho, 2009; Renedo et al., 2015). It is knowledge (the legitimacy of which is determined by the CCG) and recruitment (which is controlled by the CCG), which are interlinked, that appear to determine where individuals in our study sit in the hierarchy.

We suggest that another related factor of substantial importance when it comes to PPI and power to influence is communication. Effective and on-going communication between public and lay members and professionals could generate greater potential to make public and lay members feel more valued. It could also, importantly, facilitate clarity on all individuals' expectations of the type and level of PPI. An overall more collaborative approach to developing a PPI role which meets the expectations of patients, public, and professionals might go some way toward reducing the power gap between them.

Previous research highlights the need for formal evaluation or monitoring of PPI whilst also underlining associated complexities (e.g., Staniszewska et al., 2011; Brett et al., 2012; Petsoulas et al., 2014). Evaluation would facilitate greater understanding of the strengths of PPI and areas where it could be further developed, in turn enabling greater potential for PPI to have a direct influence on strategic decision-making. In this sense, evaluation of PPI could be an important contribution to narrowing the power disparity between professionals and public and lay members.

\section{ETHICS STATEMENT}

The study was granted ethical approval on 14/02/14 by the East of Scotland Research Ethics Service. Permission for conducting

\section{REFERENCES}

Baker, A. (2007). Patient involvement in a professional body: reflections and commentary. J. Health Organ. Manag. 21, 460-469. doi: $10.1108 / 14777260710778970$

Barnes, M., and Schattan Coelho, V. (2009). Social participation in health in Brazil and England: inclusion, representation and authority. Health Expect. 12, 226-236. doi: 10.1111/j.1369-7625.2009. 00563.x

Boivin, A., Currie, K., Fervers, B., Gracia, J., James, M., Marshall, C., et al. (2010). Patient and public involvement in clinical guidelines: international experiences and future perspectives. Qual. Saf. Health Care 19:e22. doi: 10.1136/qshc.2009.034835

Brett, J., Staniszewska, S., Mockford, C., Herron-Marx, S., Hughes, J., Tysall, C., et al. (2012). Mapping the impact of patient and public involvement on health and social care research: a systematic review. Health Expect. 17, 637-650. doi: 10.1111/j.1369-7625.2012.00795.x

Callaghan, G. D., and Wistow, G. (2006). Publics, patients, citizens, consumers? Power and decision making in primary health care. Public Adm. 84, 583-601. doi: $10.1111 / j .1467-9299.2006 .00603 . x$

Cheng, J. T., Jessica, T. L., Foulsham, T., Kingstone, A., and Henrich, J. (2013). Two ways to the top: evidence that dominance and prestige are distinct yet viable avenues to social rank and influence. J. Pers. Soc. Psychol. 104, 103-125. doi: $10.1037 / \mathrm{a} 0030398$ observations was obtained from the clinical commissioning group, the patient and public lead, and from lay members of meetings. Informed consent was gained in writing from individuals who participated in interviews and the focus group.

\section{AUTHOR CONTRIBUTIONS}

All authors contributed to the design of the study and the data collection and analysis activities. AO produced an initial draft of the manuscript, in on-going discussion with $A B$ and MC. All authors contributed significantly to the development and revision of the manuscript and have approved the final version.

\section{FUNDING}

This study/project is supported by the National Institute for Health Research (NIHR) Collaboration for Leadership in Applied Health Research and Care South London (NIHR CLAHRC South London) (award no.: NIHR, CLAHRC-2013-10022) at King's College Hospital NHS Foundation Trust, and the Faculty of Health, Social Care and Education, Kingston University \& St. George's University of London. The views expressed are those of the author(s) and not necessarily those of the NIHR or the Department of Health and Social Care.

\section{ACKNOWLEDGMENTS}

We would like to thank the NHS clinical commissioning group for permitting access to the study site to conduct the research. Our special thanks go to the many staff, lay and public members involved in the clinical commissioning group for accommodating us during data collection activities and for their valuable contributions to the study.

Clark, F. A. (2010). Power and confidence in professions: lessons for occupational therapy. Can. J. Occup. Ther. 77, 264-269. doi: 10.2182/cjot.2010.01.77.5.2

Cockerham, W. C. (2013). Sociological theory in medical sociology in the early twenty-first century. Soc. Theory Health 11, 241-255. doi: 10.1057/sth.2013.12

Dahl, R. A. (1961). In Rutar, T. (2017). Clarifying power, domination, and exploitation: between "classical" and "foucauldian" Concepts of Power. Revija Za Sociologiju. 2, 151-175.

Daykin, N., Evans, D., Petsoulas, C., and Sayers, A. (2007). Evaluating the impact of patient and public involvement initiatives on UK health services: a systematic review. Evid. Policy 3, 47-65. doi: 10.1332/174426407779702201

Department of Health (2012) Summary Report: Issues Relating to Local Healthwatch Regulations. Available online at: https://assets.publishing. service.gov.uk/government/uploads/system/uploads/attachment_data/file/ 216865/Summary-Report-Issues-relating-to-local-Healthwatch-regulations. pdf (accessed January 6, 2019).

Foucault, M. (1972). The Archaeology of Knowledge. London: Tavistock.

Foucault, M. (1980). "Power/knowledge: selected interviews and other writings, 1972-1977," ed C. Gordon (New York, NY: Pantheon), 122.

Foucault, M. (2003). The Birth of the Clinic. London: Routledge (original work published 1963).

Gauvin, F.-P., Abelson, J., Giacomini, M., Eyles, J., and Lavis, J. N. (2010). "It all depends": conceptualizing public involvement in the context of health technology assessment agencies. Soc. Sci. Med. 70, 1518-1526. doi: 10.1016/j.socscimed.2010.01.036 
Gibson, A., Britten, N., and Lynch, J. (2012). Theoretical directions for an emancipatory concept of patient and public involvement. Health 16, 31-547. doi: $10.1177 / 1363459312438563$

Giddens, A. (1984). The Constitution of Society: Outline of the Theory of Structuration. Cambridge: Polity Press.

Guzzini, S. (2005): The concept of power: a constructivist analysis. Millennium 33, 495-521. doi: 10.1177/03058298050330031301t

Hickey, G., and Kippling, C. (1998). Exploring the concept of user involvement in mental health through a participation continuum. J. Clin. Nurs. 7, 83-88. doi: 10.1046/j.1365-2702.1998.00122.x

Institute of Medicine (US) Committee on Quality of Health Care in America (2001). Crossing the Quality Chasm: A New Health System for the 21st Century. Washington, DC: National Academies Press (US).

Kerckhoff, A. C. (2001). Education and social stratification processes in comparative perspective. Sociol. Educ. 74, 3-18. doi: 10.2307/2673250

Martin, G. (2008a). 'Ordinary people only': knowledge, representativeness, and the publics of public participation in healthcare. Sociol. Health Illn. 30, 35-54. doi: $10.1111 /$ j.1467-9566.2007.01027.x

Martin, G. (2008b). Representativeness, legitimacy and power in public involvement in health-service management. Soc. Sci. Med. 67, 1757-1765. doi: 10.1016/j.socscimed.2008.09.024

Mockford, C., Staniszewska, S., Griffiths, F., and Herron-Marx, S. (2011). The impact of patient and public involvement on UK NHS health care: a systematic review. Int. J. Qual. Health Care 24, 28-38. doi: 10.1093/intqhc/mzr066

Naylor, C., Curry, N., Holder, H., Ross, S., Marshall, L., and Tait, E. (2013). Clinical Commissioning Groups. Supporting Improvement in General Practice? The King's Fund and Nuffield Trust. Available online at: https://www.kingsfund.org. uk/publications (accessed August 9, 2018).

Ocloo, J., and Matthews, R. (2016). From tokenism to empowerment: progressing patient and public involvement in healthcare improvement. BMJ Qual. Saf. 25, 626-632. doi: 10.1136/bmjqs-2015-004839

Oliver, S., Rees, R. W., Clarke-Jones, L., Milne, R., Oakley, A. R., Gabbay, J., et al. (2007). A multidimensional conceptual framework for analysing public involvement in health services research. Health Expect. 11, 72-84. doi: 10.1111/j.1369-7625.2007.00476.x

Peckham, S., Wilson, P., Williams, L., Smiddy, J., Kendall, S., Brooks, F., et al. (2014). Commissioning for long-term conditions: hearing the voice of and engaging users - a qualitative multiple case study. Health Serv. Deliv. Res. 2:44. doi: $10.3310 /$ hsdr02440

Petsoulas, C., Peckham, S., Smiddy, J., and Wilson, P. (2014). Primary care-led commissioning and public involvement in the English National Health Service. Lessons from the past. Prim. Health Care Res. Dev. 16, 289-303. doi: 10.1017/S1463423614000486

Pope, C., Ziebland, S., and Mays, N. (2000). Qualitative research in health care: analysing qualitative data. BMJ. 320, 114-116.

Potrata, B. (2005). "She did, he said": the use of ethnography in CAM research. Complement. Ther. Med. 13, 131-138. doi: 10.1016/j.ctim.2005.03.003

Raphael, D., and Bryant, T. (2015). Power, intersectionality and the life-course: identifying the political and economic structures of welfare states that support or threaten health. Soc. Theory Health. 13, 245-266. doi: 10.1057/sth.2015.18
Renedo, A., and Marston, C. (2011). Healthcare professionals' representations of 'patient and public involvement' and creation of 'public participant' identities: implications for the development of inclusive and bottom-up community participation initiatives. J. Community Appl. Soc. Psychol. 21, 268-280. doi: 10.1002/casp.1092

Renedo, A., Marston, C. A., Spyridonidis, D., and Barlow, J. (2015). Patient and public involvement in healthcare quality improvement: how organizations can help patients and professionals to collaborate. Public Manag. Rev. 17, 17-34. doi: 10.1080/14719037.2014.881535

Rise, B. M., Solbjør, M., Lara, M. C., Westerlund, H., Grimstad, H., and Steinsbekk, A. (2011). Same description, different values. How service users and providers define patient and public involvement in health care. Health Expect. 16, 266-276. doi: 10.1111/j.1369-7625.2011. 00713.x

Rutar, T. (2017). Clarifying power, domination, and exploitation: between "classical" and "foucauldian" concepts of power. Rev. Sociol. 2, 151-175. doi: $10.5613 /$ rzs.47.2.2

Rycroft-Malone, J., Seers, K., Titchen, A., Harvey, G., Kitson, A., and McCormack, B. (2004). What counts as evidence in evidence-based practice? J. Adv. Nurs. 47, 81-90. doi: 10.1111/j.1365-2648.2004.03068.x

Shortall, S. (2012). The role of subjectivity and knowledge power struggles in the formation of public policy. Sociology 47, 1088-1103. doi: $10.1177 / 0038038512454950$

Staniszewska, S., Adebajo, A., Barber, R., Beresford, P., Brady, L., Brett, J., et al. (2011). Developing the evidence base of patient and public involvement in health and social care research: the case for measuring impact. Int. J. Consum. Stud. 35, 628-632. doi: 10.1111/j.1470-6431.2011.01020.x

Stern, R., and Green, J. (2008). A seat at the table? A study of community participation in two Healthy Cities Projects. Crit. Public Health 18, 391-403. doi: 10.1080/09581590801959337

Tritter, J. (2009). Revolution or evolution: the challenges of conceptualizing patient and public involvement in a consumerist world. Health Expect. 12, 275-287. doi: 10.1111/j.1369-7625.2009.00564.x

Turner, B. S. (1992). Regulating Bodies: Essays in Medical Sociology. London: Routledge.

Weber, M. (1978 [1922]). In Rutar, T. (2017). Clarifying power, domination, and exploitation: between "classical" and "foucauldian" concepts of power. Rev. Sociol. 2, 151-175. doi: 10.5613/rzs.47.2.2

Conflict of Interest Statement: The authors declare that the research was conducted in the absence of any commercial or financial relationships that could be construed as a potential conflict of interest.

Copyright (c) 2019 O'Shea, Boaz and Chambers. This is an open-access article distributed under the terms of the Creative Commons Attribution License (CC BY). The use, distribution or reproduction in other forums is permitted, provided the original author(s) and the copyright owner(s) are credited and that the original publication in this journal is cited, in accordance with accepted academic practice. No use, distribution or reproduction is permitted which does not comply with these terms. 


\section{Plain English Summary \\ Co-producing Randomised Controlled Trials: How Do We Work Together?}

\section{Lucy P. Goldsmith, Rosaleen Morshead, Charlotte McWilliam, Gordon Forbes, Michael Ussher, Alan Simpson, Mike Lucock, Steve Gillard}

We report on a project in which service users, experts in peer support and professionals worked together to design and run a randomised controlled trial. This way of working together is called co-production. Knowledge from lived experience of mental health problems was used to make or influence key decisions about how the work was carried out. Working in a co-produced way includes making sure service users are involved in all aspects of the research process and addressing any power differences between service users and academics/professionals. In the past, co-production has typically been used in smaller research studies. Using co-production in a randomised controlled trial is very new.

The setting of this study is a large randomised controlled trial into peer support for discharge from inpatient mental health care. A randomised controlled trial is a study in which the individuals taking part are randomly allocated to receive a therapy in addition to care as usual or to receive care as usual alone (a control group). This is so that the difference that the therapy makes can be identified by comparing between the two groups. In this study, the individuals taking part would either receive peer support upon discharge from hospital or be put into the control group.

Peer support in this study refers to support provided by individuals (peer workers) to service users as they were being discharged from hospital back to the community. Peer workers have lived experience of using mental health services and receive specialist training and supervision. They work in paid employment. The study team included a panel of local service users, a panel of national experts in peer support, clinicians and a group of specialist academics, some of whom have both lived experience of mental health problems and academic training. Having people with lived experience on the study team meant that issues that are important to service users were included.

We recommend:

- Honestly acknowledging differences in power, co-producing from the planning (grant application) stages and building in the costs of co-production.

- Co-producing the analysis plans with clear information about which things are fixed and which things can be changed.

- Reflecting on and recording how co-production has worked to build the literature about the barriers and enablers of co-production. 


\section{OPEN ACCESS}

Edited by:

Gill Green,

University of Essex, United Kingdom

Reviewed by:

Alex Muller,

University of Cape Town, South Africa

Elspeth Jane Mathie,

University of Hertfordshire,

United Kingdom

${ }^{*}$ Correspondence: Lucy Pollyanna Goldsmith

Igoldsmi@sgul.ac.uk

Specialty section: This article was submitted to

Medical Sociology,

a section of the journal

Frontiers in Sociology

Received: 23 October 2018 Accepted: 05 March 2019

Published: 29 March 2019

Citation:

Goldsmith LP, Morshead R, McWilliam C, Forbes G, Ussher M, Simpson A, Lucock M and Gillard S (2019) Co-producing Randomized Controlled Trials: How Do We Work

Together? Front. Sociol. 4:21 doi: 10.3389/fsoc.2019.00021

\section{Co-producing Randomized Controlled Trials: How Do We Work Together?}

\author{
Lucy Pollyanna Goldsmith ${ }^{1 *}$, Rosaleen Morshead ${ }^{1}$, Charlotte McWilliam ${ }^{1}$, \\ Gordon Forbes ${ }^{2}$, Michael Ussher ${ }^{1}$, Alan Simpson ${ }^{3}$, Mike Lucock ${ }^{4}$ and Steve Gillard ${ }^{1}$ \\ ${ }^{1}$ Population Health Research Institute, St George's, University of London, London, United Kingdom, ${ }^{2}$ Pragmatic Clinical \\ Trials Unit, Queen Mary University of London, London, United Kingdom, ${ }^{3}$ Institute of Psychiatry, Psychology \& Neuroscience, \\ and Florence Nightingale Faculty of Nursing, Midwifery \& Palliative Care, King's College London, London, United Kingdom, \\ ${ }^{4}$ School of Human and Health Sciences, University of Huddersfield, Huddersfield, United Kingdom
}

In the light of the declaration "Nothing about us without us" (Charlton, 2000), interest in co-production, and coproduced research is expanding. Good work has been done establishing principles for co-production (Hickey et al., 2018) and for good quality involvement (Involve, 2013; 4Pi, 2015) and describing how this works in practice in mental health research (Gillard et al., 2012a,b, 2013). In the published literature, co-production has worked well in qualitative research projects in which there is often methodological flexibility. However, to change treatment guidelines in the UK, e.g., the National Institute for Health and Care Excellence guidelines, and influence service commissioning, high quality quantitative research is also needed. This type of research is characterized by formal methodological rules, which pose challenges for the scope of co-production. In this paper we describe the significant challenges and solutions we adopted to design and deliver a coproduced randomized controlled trial of mental health peer support. Given the methodological rigidity of a randomized controlled trial, establishing clearly which methodological and practical decisions and processes can be coproduced, by whom, and how, has been vital to our ongoing co-production as the project has progressed and the team has expanded. Creating and maintaining space for the supported dialogue, reflection, and culture that co-production requires has been vital. This paper aims to make our learning accessible to a wide audience of people developing co-production of knowledge in this field.

\begin{abstract}
Keywords: coproduction, randomized controlled trial (RCT), quantitative research approaches, reflective practice, methodology and methods of sociological research, peer support (PS)
\end{abstract}

\section{INTRODUCTION}

We discuss co-production in quantitative research (with a specific focus on randomized controlled trials), how it can work in practice, and the barriers and enablers of co-production. We understand co-production in research in terms of a knowledge framework. Using standpoint epistemologies familiar to feminism (Harding, 1991) and other critical disciplines, the active involvement of people who have made use of healthcare services as researchers, brings a service user knowledge (Beresford, 2013), or experiential knowledge (Rose, 2017), critiquing and challenging dominant and universalizing ways of knowing about health, with a primary objective of democratizing research (Pinfold et al., 2015). This experientially grounded, or tacit knowledge, acquired through private and personal ways of knowing the mind and body, differs from a more codified or theoretical knowledge acquired through study and training (Mol and Law, 2004), and offers a competing 
Box 1 | Co-production (Gillard et al., 2012a).

1. High-value research decision-making roles distributed across the research team.

2. Different interpretations of data within the research team owned and understood in terms of how who we are has shaped the knowledge we have produced.

3. Consideration given to whether all members of the team were involved in the production of knowledge throughout the research project and the impact of this considered.

4. Methodological flexibility allowed in the research process where scientific conventions constrains the input of particular team members.

5. Rigorous and critical reflection on why the research was done in the way it was as integral to the conduct of the research.

6. Research outputs that report critically on how knowledge was produced.

discourse in a healthcare context (Nowotny et al., 2001; Mockford et al., 2012). A definition of co-production in the context of multidisciplinary mental health research involving people who have used mental health services as members of the research team is given in Box $\mathbf{1}$ below.

Roper et al. (2018) outline three core principles of coproduction in the context of mental health research. First "consumers being partners from the outset" means service users should be involved in all aspects of the research process from the beginning and be privy to all information. Professionals implicitly or explicitly valuing the knowledge of professionals over lived experience (Scholz et al., 2017), or equating people who use mental health services with their diagnoses or symptoms, may hamper their ability to perceive the value in what service users say (Happell et al., 2015; Kopera et al., 2014). The second principle states power differentials and tokenism must be "acknowledged, explored and addressed." Power differentials exist within the relationship between professionals and service users and present a challenge to genuine co-production (McDaid, 2009; Rose et al., 2010). Whilst is it suggested that co-production helps transform relationships, co-production can create power sharing risks that will lead to both parties (professionals and people who use services) feeling uncomfortable at times. For those with lived experience, the power differentials can echo disempowering experiences of using services, resulting in a reluctance to coproduce (Lwembe et al., 2016). Reluctance to coproduce can also be experienced by professional researchers. One strong description of the demands placed on researchers by coproduction is that they are required to renounce their privileged position as sovereign experts and their monopoly on scientific knowledge and step down from the proverbial ivory tower of the academy to enter into dialogue with the world around them (Phillips, 2009). An exploratory study of Recovery Colleges found a willingness on the part of the professionals working in mental health to embrace co-production and relinquish the traditional power differences (Dalgarno and Oates, 2018). Roper et al. (2018) third core principle of co-production is the need to encourage and provide the means for people who use mental health services to take leadership and develop their capacity within services and research. In practice, this is difficult to achieve as there are often insufficient resources to allow full participation, and welfare benefits can be compromised, acting as a barrier to co-production (Lambert and Carr, 2018). Scholz et al. (2017) identifies unclear roles within a structure and a resistance to viewing people who use services as leaders as barriers to leadership.

Co-production of data analysis needs further development as this is currently unusual (e.g., Jennings et al., 2018). There is potential for service user-, clinical-, and academic researchers to coproduce a richer, integrated analytical narrative through challenging the previously taken for granted researcher assumptions and cultural perspectives, producing a more thorough examination of the data (Tuffrey-Wijne and Butler, 2010). In a qualitative study, additional themes were found in the data by service user researchers who coded data in terms of experience and emotions rather than the procedures and processes typically coded by university researchers (Gillard et al., 2012b). Despite the difficulties highlighted, studies cited demonstrate that co-production can work well in qualitative research projects. There is a relative lack of studies reporting attempts to co-produce quantitative research, where there are likely to be additional challenges. We discuss randomized controlled trial methodology and review the critical literature in this area before discussing co-production in the context of randomized controlled trials. Within quantitative research, a randomized controlled trial (RCT) is considered the "gold standard" (Barton, 2000) as randomization reduces the risk of confounding (where the observed effect is due to an inseparable mix of the treatment effect and other effects). Randomized controlled trials generally use blinding of treatment allocation (for researcher) or double blinding (for researcher and participant) to eliminate bias (in which a belief in the therapy can also affect the outcome). Efforts are made to ensure that interactions with the researcher do not have an effect on the outcome, although the effect of the researcher on the research process or participants is not usually measured. Commonly, the researcher attempts to be an impartial observer, and their emotions are not considered relevant to the research [i.e., an "objectivist" approach (Ratner, 2002)]. The main analysis is pre-specified to avoid bias. Research teams can be hierarchical as particular members of the team provide expert authority in aspects of the research (e.g., statistical, clinical, research governance).

Randomized controlled trial methodology has been criticized for producing misleading results (e.g., poor quality trials produce inflated treatment effect estimates; Moher et al., 1998). For trials of complex interventions (in which the treatment contains a mix of interacting elements, e.g., talking therapies, residential interventions, social support), appropriate questions go beyond "does it work" to probe the underlying mechanisms of how, why, for whom and under what conditions interventions work (MRC, 2008; Blackwood et al., 2010). Randomized controlled trials used in health research typically fall into the area of "evidence based medicine," aiming to mobilizing research to inform healthcare. However, Greenhalgh et al. (2015), for example, argue that evidence based medicine may inadvertently devalue the patient and carer agenda by: (i) limiting patient input into research 
design; (ii) giving low status to individual experience in the hierarchy of research evidence; (iii) minimizing or ignoring power imbalances that suppress patient voice; (iv) focusing on people who seek and can access care thus ignoring those who do not access services; (v) overlooking the importance of the patient-clinician relationship; (vi) underestimating the value of self-management and lay networks of support.

In summary, co-production can deliver research which incorporates the perspectives of service users and other nontraditional members of the research team; fundamentally changing the knowledge production approach, offering social accountability, and a richer analysis of data, possibly generating conclusions with more relevance to service users. The challenges to working meaningfully in this way are substantial, including tokenism, power differentials, the need for emotional, and practical support for service users. Randomized controlled trials are a powerful tool for finding out "what works" in mental health services, yet the methodology has been criticized in a number of ways, including unrealistic expectations that the research process itself has no effect while suppressing knowledge from lived experience. These criticisms suggest co-production might improve, rather than weaken the randomized controlled trial methodology. For example, some of the challenges in trials (especially of complex interventions with a social component) might be usefully addressed by integrating other types of expertise-including patient and carer insight-into the research process. We identified no prior publications exploring these potentials in a randomized controlled trial. To address this, this paper reports the possibilities and challenges of coproducing a randomized controlled trial.

\section{Setting}

The setting for the research is multisite randomized controlled trial of peer support for discharge from inpatient to community mental health services in the UK (Gillard and Marks, 2016). The trial aimed to recruit 590 participants, randomized 50:50 to peer support and care as usual. The trial hypothesized that participants receiving peer support would be less likely to be readmitted to inpatient psychiatric care in the year post-discharge than participants receiving care as usual. Peer support was provided individually by peer workers-people with previous experiences of using mental health services-selected and trained to provide peer support for the discharge transition and supervised by an experienced peer worker. We note that peer workers did not occupy any other roles within the project (e.g., they were not also researchers).

\section{Research Team}

The research was undertaken by a research team that included a Chief Investigator (a health services researcher), four clinical academics (a psychiatrist, two psychiatric nurses and a clinical psychologist), three statisticians, a health economist, a health psychologist, two managers of peer support services (one working in the NHS and one in the not-for-profit sector), an experienced peer worker (working in the NHS) and two experienced service user researchers. A trial manager who also brought experience of having used mental health services, and a total of nine further service user researchers joined the team to undertake recruitment of participants and data collection. The aim was to coproduce throughout the study, using the framework cited above as a starting point (Gillard et al., 2012a), with all members of the research team involved in the initial conception of the research and the extended team (including trial manager and all service user researchers) involved in decisions made about conducting the trial (i.e., how to put the trial protocol into action) once the research programme was underway.

\section{METHOD}

Two methods were used to explore co-production in the trial. First, members of the team co-authoring the paper selected examples of decision-making about the design of the trial. We select examples which, to a greater and lesser degree, include a range of members of the research team, and service user researchers working on the trial in the decision-making process (i.e., where there was more or less co-production involved). We illustrate the decision-making process by citing directly from minutes of the different meetings that collectively, manage the trial. These include: the Trial Management Group (TMG-a subgroup of people involved in managing the trial who meet on a monthly basis including Chief Investigator, Senior Trial Statistician, Trial Manager, one of the two experienced service user researchers, Health Economist, the academic psychiatrist plus a data management and a quality assurance advisor); the Lived Experience Advisory Panel (LEAP - a group of people independent from the trial who have personal experience of peer support, using mental health services and working as service user researchers who meet biannually to advise on conduct of the trial from a lived experience perspective); and investigator meetings (large biannual meetings where the whole research team come together). We reviewed those minutes to identify how, when and why the decisions which shaped the scope and focus of the research were reached and the potential impact of those decisions on the research process and outputs (extracts of these are quoted and labeled as "minutes" in the text below).

Second, members of the team who were involved in either making those decisions or implementing them into practice wrote reflections on the decision-making process and consequences (extracts of these are labeled "reflections" where quoted below). Drawing on a sequential method of analysis (Simons et al., 2008), accounts of these meetings and our reflections were iteratively co-edited by the authors as this paper was written. In this sense our shared writing and re-writing was an integral part of our method of enquiry (Richardson, 2000; Simons et al., 2008).

\section{FINDINGS}

We present three key decisions at which co-production was most challenged and/or most productive. We focus on these to illustrate the different perspectives and how these were discussed and resolved. We then reflect on the implications of the decisions made. These decisions relate to: (i) Identification of trial 
population; (ii) Choice of psychometric measures and outcomes; (iii) Development of the trial statistical analysis plan.

\section{Trial Population}

Defining the eligibility criteria potential participants must meet to join the study is an important decision as it determines the group of people to whom trial results may be generalized. There was a structured discussion at the first investigator meeting about targeting the peer support intervention. The chief investigator leading the meeting used a graphic to launch the discussion in which the central zone refers to the ideal targeting of the intervention as an intersection of (1) people most likely to benefit (i.e., where need is highest), (2) existing evidence about what is most likely to work best, (3) what is known about how peer support works (the change mechanism). Figure $\mathbf{1}$ is a smarter version of the original graphic used in the meeting.

Concern was expressed by clinical academics around the table that if the trial showed a very weak or not statistically significant effect of peer support because we had not chosen the trial population carefully enough then we would do a disservice to peer support services (as these might be less likely to be commissioned going forward). Minutes from the meeting show that concern was raised that:

A negative result would have the potential to undermine peer support work as it is. (minutes)

Members of the team with lots of experience working on randomized controlled trials argued that a discrete rather than heterogeneous diagnostic population be chosen to ensure the methodological quality and subsequent impact of the trial on treatment guidelines:

The trial is not powered for subgroup analysis and if the result turns out to be negative then it will not be recognised in

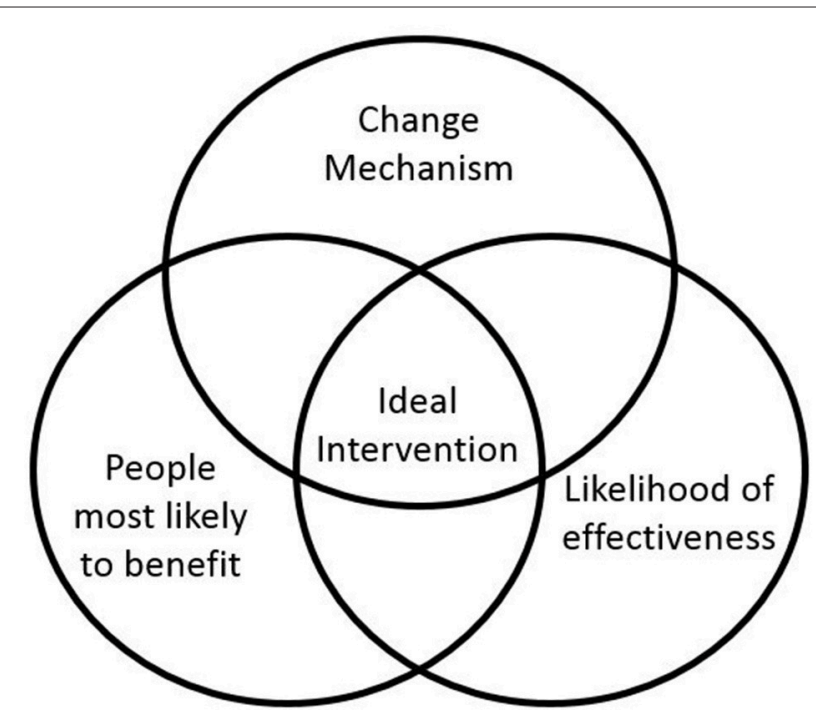

FIGURE 1 | Graphic to aid discussion about the trial population. the international community nor adopted by guidelines ... a specific population [should be] chosen, for example psychosis, for inclusion criteria. (minutes)

The two service user researchers on the team at that time and other members of the team involved in delivering peer support argued strongly against restricting inclusion by diagnosis on the grounds that peer support was not usually provided like this in practice and that the connections peers made were generally not on the basis of shared diagnosis. Minutes from the discussion record the following comment:

The essence of peer support must not be compromised and the peer support service developed and tested for the research must be one that is workable and justifiable to inpatient peers and peer workers in practice. Reasons for peer support being offered to one person over another have to be credible in the real world. Peer worker and peer support leader members of our team must be included in this design decision, it can't be made simply for research trial success purposes. We have not set out to design a diagnosis specific peer support service, we have set out to offer people support with discharge from inpatient to psychiatric care. Diagnoses can shift with each progressive encounter with secondary care and are culturally bound and are imposed and often not owned by the service users or peers themselves. We should be asking who the peer support would be most useful to. (minutes)

In later discussions about how a suitable population might be identified, clinical academics responding by suggesting an approach based on known predictors of our primary outcome (psychiatric readmission within 1 year of discharge):

... identifying people most likely to be readmitted, using numbers of readmissions as a predictor. (minutes)

It was agreed by the team that this approach would satisfy both the need for a discrete population that findings could be generalized to (ensuring methodological quality) while also retaining the integrity of peer support (by not defining peer relationships by diagnostic categories). A plan was put in place to approach trial sites for data about their inpatient populations so that a final decision could be made on eligibility criteria that would also enable us to feasibly deliver recruitment targets.

\section{Reflections About the Trial Population}

Three service user researchers who co-authored the paper reflected on their experience of applying the eligibility criteria in practice. It was noted that not using diagnosis as the main eligibility criteria supported researchers in working from a service user researcher perspective:

The non-diagnostic approach to recruitment fits well with the service user researcher approach to recruitment (e.g., being alongside someone as they considered whether to join the study, and communicating what peer support is). Overall, this has been a positive way of working - the reduced focus on diagnosis felt less discriminatory, medicalised, or pathologising. We appreciated the 
fact that it doesn't disclose to other service users on the ward the diagnosis of our participants or potential participants. (reflection)

The text above demonstrates a good amount of agreement between the perspectives of the service user researchers and the perspectives of others with lived experience who had been involved in the study at the time when this decision was made. In this example, although this was a decision that was taken before many of the service user researchers joined the project, the coproduced decision fitted well with the service user researchers' feelings about the "ethos" of the project.

\section{Trial Psychometric Measures and Outcomes}

All trials define in advance a primary outcome used as the main measure to determine whether the intervention had an effect. The primary outcome is also used to calculate the necessary sample size for the trial. In addition, it is common to select a number of secondary outcomes, for which it is expected that the intervention will also have an effect. The primary outcome for this trial-psychiatric readmission within 12 months of discharge-had been suggested by the research funder, at review of the funding application, as an example a concrete indicator of patient benefit they would expect as the primary outcome of the trial. As such we note an absence of wider co-production across the team about the selection of the primary outcome.

The secondary outcomes were selected at two meetings as part of the development of the proposal. The meetings included academics and clinicians involved in evaluating peer support and conducting trials, as well as people with experience of developing, delivering and evaluating peer support services from a lived experience perspective. These discussions were informed by a peer support change model developed by the team based on previous qualitative research (Gillard et al., 2017), which had been coproduced by service user researchers, peer workers, clinicians and researchers. The change model suggested that peer support had an effect on hope, experience and anticipation of stigma, strength of therapeutic relationship and social connectivity.

There was no measure of clinical severity in the original proposal but a measure of clinical severity-the Brief Psychiatric Rating Scale (Overall and Gorham, 1962) — was added as a secondary outcome as a direct consequence of the decision not to define the population by diagnosis. This decision was taken by the chief investigator on the advice of members of the Trial Management Group with experience running randomized controlled trials in order to be able to describe, clinically, an otherwise diagnostically heterogeneous population. This was done largely so that the trial would meet peer review expectations for inclusion in high impact journals and systematic reviews, as well as to enable comparison with other peer support trials. The minutes of several meetings of the Lived Experience Advisory Panel document the reactions of members of the team to implementing this decision. There was an extended discussion about the use of the Brief Psychiatric Rating Scale at a Lived Experience Advisory Panel meeting held shortly after recruitment to the pilot trial began. It was noted that:
The service user researcher team have been arguing against doing it since this came to light as they started preparation for the data collection part of their role ... the solution has been for service user researchers to decide how they will do this measure, do it openly, change some of the language of the tool and explain that they are rating it on the basis of conversation with the service users they are interviewing 'peering through the psychiatric lens together'. (minutes)

And that:

The concerns service user researchers raised included using the wrong measure for peer support - clinical symptom change is not a particular aim of peer support; the potential for distress to service user researcher or participant due to similarity with previous experiences of psychiatric assessment, non-service user researcher/service user friendly language and administration, challenge to service user researcher role - service user researchers employed for lived experience perspective being asked and trained to take a psychiatric perspective. (minutes)

However it was also noted by the Lived Experience Advisory Panel that:

Co-production is maybe about being willing to keep going together and not "strutting out" when things don't fit with our ideas. (minutes)

Nonetheless, Lived Experience Advisory Panel meeting notes report the need for caution in interpreting the data produced by Brief Psychiatric Rating Scale:

We need to take care in our interpretation of the Brief Psychiatric Rating Scale data. Since if peer support goes well service users could be more open to sharing difficulties with the service user researcher at the second assessment; this could be (mis)interpreted as peer support making people worse. (minutes)

There was some discussion of the way in which delivery of the Brief Psychiatric Rating Scale had been adapted by the service user researchers:

The Brief Psychiatric Rating Scale would have damaged rapport if it had come anywhere but the end of the interview but service user researchers are happy with the way they have been able to make it more person friendly and be open about what it is. [Only] one participant so far shut down the interview at this point (i.e., when the Brief Psychiatric Rating Scale questions were asked). (minutes)

As a result of these discussions changes were made to the trial database to enable service user researchers to omit the Brief Psychiatric Rating Scale if it wasn't completed due to, for example, objections or distress from the participant. 


\section{Reflections About the Trial Psychometric Measures and Outcomes}

Service user researchers who were co-authors of this paper reflected on the decision to include the Brief Psychiatric Rating Scale as an outcome measure. These reflections tell us about how co-production works in practice with respect to the consequences of the decision to include this very clinical measure. One described the initial plan of how to conduct this part of the interview as follows:

In practice, using the Brief Psychiatric Rating Scale means being transparent with service users; we are able to be honest about the very psychiatric approach of the Brief Psychiatric Rating Scale which does not necessarily fit with many aspects of the ethos of the project. (reflection)

This means taking a stance toward the measure which makes it clear that we wouldn't use this type of medical approach to understanding psychological distress as a first preference. Coauthor service user researchers reflect that, despite approaching the issue as described above, it can still be difficult to conduct this assessment:

We often spend a lot of time building rapport with a participant, talking about lived experience, and working hard to create a safe, supportive environment, attempting to equalise inequalities in power. Using such a psychiatric measure abruptly changed the dynamics we had worked hard to create with the participant causing a sense of unease due to appearing contrary to the principles of survivor research, and can be uncomfortable to conduct from a service user perspective. This becomes even more difficult at follow up. At follow up, the Brief Psychiatric Rating Scale has to be scored in the middle of the interview to prevent scoring whilst un-blinded which means completing it in front of participants. (reflection)

Beyond the way that the rating scale affects the interviews with participants, there are additional issues with the use of the scale, as outlined in the following reflection:

The Brief Psychiatric Rating Scale is quite skewed toward psychotic type symptoms. Consequently, we have often felt the measure does not reflect the state of someone's emotional wellbeing accurately as, for example, there are only two or three places in which trauma or suicidality may affect the score. We have quite lengthy discussions with service users, sometimes spending 3 hours with each person, and it seems reductive to then use a number score on the Brief Psychiatric Rating Scale as this does not wholly capture the wealth of information communicated. (reflection)

The above statement communicates a frustration that can often be felt by researchers with a qualitative interest when they conduct semi-structured interviews which are used to generate numerical scores in quantitative research. The statement again reflects that this way of summarizing the trial population does not sit easily with many of the service user researchers, and would not be their first choice of method. The reflections continue:
Most of the service user researchers were not involved in the decision making process around using the Brief Psychiatric Rating Scale as we were not in post then, meaning there has been a lack of opportunity to coproduce in this area. This issue is aggravated as the research is a randomized controlled trial, for which the protocol needs to be fixed early on in the project. It is not possible to adapt many things as time goes on, unlike with our qualitative interview schedules which have been reworked and adapted after the pilot quite significantly, and have afforded plenty of opportunity to coproduce. (reflection)

This scenario, in which research decisions are coproduced, but many of the team of service user researchers did not have the opportunity to be involved in that co-production, seems likely to be commonly experienced in the context of randomized controlled trials. This is because these decisions are made well in advance of the start of data collection. The fact that the service user researcher jobs are advertised as working on a coproduced project can therefore raise unrealistic expectations of influencing key decisions. The chief investigator of the trial also reflected on the decision around including a clinical measure, illustrating how tension might remain long after a decision is taken:

I had misgivings about using Brief Psychiatric Rating Scale in the trial. All our other research has suggested that peer support works socially, it's about relationships and connections, rather than clinically. We didn't expect peer support to have an impact on clinical outcomes when we were developing the study, and that is also what the literature tells us. I knew that there would be a tension between the very clinical nature of the measure and the values underpinning peer support and service user research. However I could see the rationale for using a clinical measure to describe the trial population so that we would be able to say, if the peer support works, who it works for. We know that people are discharged from hospital when they are more or less well depending on very transient things like demand for beds and variations in how services are set up locally, so we did need something else here or it would be difficult for people to draw any conclusions about how relevant any findings from ENRICH would be in different parts of the UK or in different countries. (reflection)

In the following text, reflections about alternatives to the Brief Psychiatric Rating Scale, alongside alternative ways that this part of the project could have unfolded are explored:

Perhaps including a clinical measure was an executive decision I would have always felt I needed to make but there were consequences of not including the wider team, and especially service user researchers in that decision. First, we might have identified a different measure that could have been less challenging to use, which might have addressed many of the issues raised by the (service user researcher) team, issues that they had to work with on a daily basis. Second, had people felt involved in the decision, even if they had disagreed with it, then the subsequent discussion around how to implement Brief Psychiatric Rating Scale might have felt more collaborative and have been more productive of valuable learning about how best to measure things like 'severity'. And finally, all our discussions were tinged by the decision having been already made, and then guillotined anyway 
as we needed to register the trial, which wasn't good for our sense of working co-productively as a team. (reflection)

The text above demonstrates the difficulty of coproducing whilst using a research method for which many things need to be specified in advance. The importance of planning plenty of time to coproduce at the stages of the project in which key decisions are made are highlighted, alongside the difficulty of trying to coproduce with people who were not on the project at a time when key decisions were made.

\section{Trial Statistical Analysis Plan}

It is best practice in a trial to publish a statistical analysis plan demonstrating that analyses have been specified before outcomes data have been viewed (rather than analyses conducted to fit the data). The primary analysis was specified in the protocol, but additional analyses where the wider team might have meaningful input, included identification of groups for any subgroup analysis and specification of the Complier Average Causal Effect (CACE) analysis (see below).

Primary trial analyses examine "intention to treat"; i.e., all participants randomized to receive the intervention-whether they took up the offer or not-are compared with all participants randomized to care as usual (White et al., 2011). This is because people do not always take up treatment offers. We can additionally examine the effect of treatment receipt using a CACE analysis. A definition of what constitutes having received the intervention is needed; a minimum level of engagement with the intervention, below which participants can be assumed to have had no benefit. Subgroup analyses explore whether there was any difference in effect of the intervention for different groups of participants (e.g., men and women).

These analyses were initially discussed at meetings of the investigator team and the Trial Management Group where it was decided that the input of the Lived Experience Advisory Panel and service user researcher team was needed to inform these decisions. One of the trial statisticians held workshops with the Lived Experience Advisory Panel and service user researcher team; co-facilitated by the chief investigator. These meetings introduced and explained the statistical analysis plan as a whole, indicating where and why certain analyses had already been decided, and where there was scope for more co-production. Within the service user researcher team, two members had particularly valuable prior experience for this discussion, one from working in epidemiology and one from $\mathrm{PhD}$ research with a high degree of statistical content.

Discussions on the CACE analysis included "how many contacts" between participant and peer worker were enough to benefit from the intervention; the statistician and chief investigator suggested a single contact is potentially beneficial. However, notes from the service user researcher meeting indicate, based on their experiences of working on the trial, that:

First session with peer worker often focuses around logistical aspects of relationship and if this is the only session to occur it is unlikely that therapeutic benefit will have been delivered. (minutes)

Furthermore, service user researchers reminded the meeting of the importance of choice in developing peer support relationships, suggesting that:

A session in the community indicates that the participant has chosen to engage with the peer worker. Whilst in hospital participant may be visited by peer worker without them actively deciding to engage. (minutes)

From these discussions it was decided that the threshold for receipt of intervention for the CACE analysis is at least two contacts with peer worker, at least one of which should be in the community post-discharge. The discussions with both Lived Experience Advisory Panel and service user researcher team about potential subgroup analyses were wide-ranging. The statistician suggested to both meetings that we consider either a single subgroup analysis of a small number of study outcomes, or a small number of subgroup analyses of just the primary outcome. Both Lived Experience Advisory Panel and service user researchers felt that the latter option would be more useful as their experiences of involvement in and researching peer support suggested that there were a number of meaningful relationships between group identity and the way in which peer support might work.

The draft plan prepared by the statistician included broad diagnostic groups (psychotic disorders, personality disorders, and other non-psychotic disorders) as potential subgroups. The service user researchers had reservations about this due to the transitory nature of many participants' diagnoses and because they felt diagnoses did not always match the way participants described their own experiences:

Participants may have other diagnoses or may have a primary diagnosis that is not the cause of the current admission. We collect other data on medical history via self-report. This data may be challenging to use, it is collected as free text, includes diagnosis as described by participants that might not use standard terminology. (minutes)

The chief investigator argued in favor of keeping broad diagnostic category in the analysis because, irrespective of the validity of a diagnosis, people receive different treatment depending on their diagnosis which may interact with their experiences of peer support. Thus, diagnostic group was retained as a subgroup with the qualification that we would interpret any findings in relation to people's experiences of using different mental health services, rather than evidence that "peer support worked for some diagnoses, but not for others."

Finally the Lived Experience Advisory Panel suggested that the mechanisms of peer support are in large part socialenabling people to connect to community-and so might work differentially in people who were already well connected socially compared to people who were isolated in the community, a 
suggestion which was well received and has been adopted to define suitable subgroups.

\section{Reflections on Developing the Trial Statistical Analysis Plan}

The statistician who led the workshops on the statistical analysis plan reflected on the involvement of service user researchers and the Lived Experience Advisory Panel in developing elements of the plan.

The input from service user researchers and the Lived Experience Advisory Panel was vital in deciding what assumptions were reasonable to make in carrying out this analysis. The decision to carry out an analysis using a binary cut off as to whether treatment was received did not address all the questions the service user researchers and Lived Experience Advisory Panel would have liked to ask. Other questions considered included what the effect would be of receiving only one session, or in response to different numbers of sessions. As a statistician I felt that I needed to guide the group away from more complex questions as I felt that limitations imposed by the study design and methods available would not allow us to get good answers to these questions. (reflection)

Service user researchers working on the project were positive and enthusiastic about their input into the statistical analysis plan and felt that co-production had worked really well in this area, as the following text demonstrates:

I felt that, from the start, the statisticians on the project were really interested in, and supportive of, incorporating ideas from members of the team with lived experience into the analysis plan. Co-production felt really well planned, smooth and organized. We had the opportunity to ask all the questions we'd like to about the plan, which were answered in full. Our suggestions were really well received and had a big impact on the plan. Co-production worked really well for all parties involved. (reflection)

In the above texts, the practice of combining statistical knowledge with clinical knowledge (from clinicians or those with lived experience), to inform the statistical methods used and the way those methods are applied is illustrated. Statisticians specializing in analysis of randomized controlled trials always work in interdisciplinary teams, drawing on the knowledge of others in the team to develop the statistical plan. Perhaps for this reason, developing a coproduced trial statistical analysis plan was one of the easier areas in which to coproduce the research.

\section{DISCUSSION}

This paper set out to explore the possibilities and challenges of coproducing randomized controlled trials, focussing on a randomized controlled trial of a peer support intervention in mental health which explicitly set out to coproduce knowledge and employed service user researchers. We illustrated this through examples of where co-production seemed to go well and where it was challenging, covering the three key areas of: identifying our trial population, creating a trial statistical analysis plan and selecting psychometric outcome measures. The decision around identifying our trial population involved a wide range of team members who also very explicitly identified the perspectives they were working from, as clinical academics, trialists, and service user researchers, and how that informed the views they brought to the discussion. The importance of not just including different perspectives, but of being explicit about those perspectives has been identified as key to the coproduction of knowledge (Gillard et al., 2012a) and indicative of the social accountability of the knowledge production process (Nowotny et al., 2001). As such, we did not find that the knowledge of our research professionals was valued over the experiential knowledge of other team members (see also Scholz et al., 2017). The service user researchers' lived experience was valued as primary expertise on peer support and as such contributed in equal measure to our final decision about the trial population, alongside methodological insight. Service user researchers and team members involved in peer support took on a leadership role in advocating forcefully, at the outset of the project, that the essence of peer support not be undermined by the study design. Roper et al. (2018) indicate that having the means to take a leadership role in this way, especially for non-conventional research team members, characterizes nontokenistic peer support. The initial research team meeting began with a discussion about research co-production, and team members were invited to describe in some length their role in the research and what they felt their priorities for the project were. Perhaps this approach, alongside the fact that nearly half the members of the research team were working from a lived experience perspective, enabled people to take on this leadership role. In this respect, at this stage of the project, co-production had been sufficiently resourced (Lambert and Carr, 2018).

As evidenced in the discussions around the statistical analysis plan and in the reflections of the statistician, we neither found that lived experience was devalued as a source of knowledge (Scholz et al., 2017), nor did we encounter reservations about the abilities of service user researchers to hold educated positions on the technical issues raised by the plan that have been cautioned against elsewhere as a barrier to co-production (Happell et al., 2015). Perhaps that was a reflection of the research literacy and expertise of our team. However, as identified by Roper et al. (2018), we did see open acknowledgment of power differentials that existed in the team in this phase of the study. The statistician was, in effect, the arbiter of what potential changes could be made to the plan, and made it very clear at the outset of both meetings where aspects of the analysis had already been determined-and why, methodologically, that needed to be the case-and where there remained meaningful opportunities for the analysis process to be shaped. This approach was appreciated in feedback from both the Lived Experience Advisory Panel and members of the service user researcher team.

We note how the co-production of decisions around trial population and statistical analysis plan had been made possible by the retention of a certain amount of flexibility in the research process. As regards selecting psychometric outcome measures, this flexibility was absent from the decision about including the Brief Psychiatric Rating Scale-it was presented as 
a fait accompli-and so limited opportunity for co-production. It is clear from the discussions referred to above that the team worked hard to address the challenges raised by the inclusion of the Brief Psychiatric Rating Scale but these efforts were imposed on the team post-hoc, rather than engaged in from the outset as a collaborative endeavor. In these circumstances co-production could be described as tokenistic, limited by the power imbalance in the team that flowed from that executive decision (Rose et al., 2010), especially for those service user researchers who came later to the team. Indeed wider members of the team had not been privy at all to that particular decision (Roper et al., 2018) and it is possible that the undermining of trust in the researchparticipant relationship that is referred to in the service user researcher reflections mirrors a damage to trust in the team at this point.

\section{IMPLICATIONS}

On balance we reflect that it is possible to incorporate a coproduction approach to research-as defined in Box 1 aboveinto a randomized controlled trial, especially with respect to the role of service user researchers in the research team. However, we also note that there are multiple challenges that need to be addressed to optimize co-production across all aspects of the project. Clarity around which aspects of decisions can be coproduced is essential, as is clear communication of the knockon implications of any decision for the rest of the project. Our findings suggested that, in a randomized controlled trial, the methodology demands that co-production is front-loaded wherever possible as it could be challenging for service user researcher members of the team to implement some research decisions into practice where they had not been involved in early decision-making. This means most of the time for co-production must be scheduled toward the start of the project. However, we also found that co-production of the trial analysis strategy worked well within circumscribed and wellcommunicated limits.

\section{RECOMMENDATIONS}

Scheduling time to co-produce decisions and recognize that much of this needs to be done at the planning (grant application) stages and early in the trial is recommended. It is likely that researchers will find that co-production occurs more or less completely in different areas of the project. We recommend reflecting on and documenting this to build the literature of the barriers and enablers of co-production in randomized controlled trials so that all interested parties can develop their skills and plan to coproduce research. Co-production of the analysis strategy, with clear explanations of the implications of the questions and the scope for co-production is recommended and can be very successful.

The expectations for influencing the methodology of the research in co-production can be high for all parties. Many contrasting views can be presented and not all these views can always be incorporated into the research. Team members can be very committed to the positions they bring to the research and expectations are not always met. We recommend regular reflection on the impact of co-production to support emotional well-being, morale and team cohesion.

Power differentials are always present in teams but creating an environment in which they can be honestly acknowledged and challenged when discussing co-production enables those in less powerful positions to have an impact on high value decisionmaking. Co-production adds time to a research project, which must be costed appropriately. Co-production in some aspects of a large research project, despite best intentions, may become tokenistic if those conditions are not met. Co-producing can be considered to be an additional variable when assessing quality of research (Sweeney et al., 2019).

\section{STRENGTHS AND LIMITATIONS}

The study is limited by the constraints imposed by our approach to capturing and analyzing data about the research process. We rely on minutes from team meetings and the written first person reflections of team members as our case study data. Not all co-production takes place in team meetings and neither is co-production confined to decision making, while minutes and reflections do not necessarily include the views and experiences of all team members (arguably our data is somewhat selective). An ethnographic approach to exploring co-production and the randomized controlled trial, comprising observations and interviews conducted by a researcher who was not a team member might have offered a more comprehensive data set and a more systematic approach to analysis. However, as an initial exploration our approach offered feasibility. A focus on decision making, critical reflection on the inclusion of the diversity of voices in the team in those decisions, and consideration of the implementation of those decisions into practice does offer meaningful insight into key aspects of co-production (Gillard et al., 2012a). We were careful to select a range of positive and challenging experiences of research decision making and our findings were given external validity by our reading of the co-production literature.

\section{CONCLUSIONS}

Co-production challenges and potentially changes aspects of randomized controlled trial methodology through the inclusion of a wider range of voices in the research-decision making process, including non-traditional expertise such as the lived experience of people who have used mental health services. Through balancing all the factors relevant for a decision, contributed by all the experts (methodological, clinical, and experts by experience), randomized controlled trials can be conducted in a way which incorporates and values service user perspectives, delivering research with greater social accountability which is also hopefully of higher quality and more relevant to service users and their mental health journeys. 


\section{DATA AVAILABILITY}

The datasets generated for this study are available on request to the corresponding author.

\section{ETHICS STATEMENT}

This study was carried out in accordance with guidance including but not limited to, the Human Rights Act 1998, the Data Protection Act 1998, the Human Medicines Regulations 2012, ICH GCP, the World Medical Association Declaration of Helsinki, the NHS Research Governance Framework for Health and Social Care. The protocol was approved by the NHS Health Research Authority (HRA) on 19/05/2016 and the HRA London Bridge Research Ethics Committee on the 10/05/2016. All subjects gave written informed consent in accordance with the Declaration of Helsinki.

\section{AUTHOR CONTRIBUTIONS}

This is a coproduced paper. LG, SG, RM, and CM each produced first drafts of independent sections of this paper and reworked

\section{REFERENCES}

4Pi 4Pi 'Why use 4Pi National Involvement Standards?' (2015). 4Pi 'Why use $4 P i$ National Involvement Standards?' Available online at: https://www. nsun.org.uk/Handlers/Download.ashx?IDMF=f231d7e7-80db-49c9-ad8946d049ae6566

Barton, S. (2000). Which clinical studies provide the best evidence? BMJ 321:255. doi: $10.1136 /$ bmj.321.7256.255

Beresford, P. (2013). From 'other' to involved: user involvement in research: an emerging paradigm. Nordic Soc. Work Res. 3, 139-148. doi: 0.1080/2156857X.2013.835138

Blackwood, B., O’Halloran, P., and Porter, S. (2010). On the problems of mixing RCTs with qualitative research: the case of the MRC framework for the evaluation of complex healthcare interventions. J. Res. Nurs. 15, 511-521. doi: $10.1177 / 1744987110373860$

Charlton, J. I. (2000). Nothing About us Without us. Berkeley, CA: University of California Press.

Dalgarno, M., and Oates, J. (2018). The meaning of co-production for clinicians: an exploratory case study of practitioner trainers in one recovery college. $J$. Psychiatr Ment. Hlt. 25, 349-357. doi: 10.1111/jpm.12469

Gillard, S., Borschmann, R., Turner, K., Goodrich-Purnell, N., Lovell, K., and Chambers, M. (2012b). Producing different analytical narratives, coproducing integrated analytical narrative: a qualitative study of UK detained mental health patient experience involving service user researchers. Int. J. Soc. Res. Method 15, 239-254. doi: 10.1080/13645579.2011.572673

Gillard, S., Foster, R., Gibson, S., Goldsmith, L., Marks, J., and White, S. (2017). Describing a principles-based approach to developing and evaluating peer worker roles as peer support moves into mainstream mental health services. Ment. Health Soc. Inclusion 21, 133-143. doi: 10.1108/MHSI-03-2017-0016

Gillard, S., and Marks, J. (2016). Peer Support for Discharge From Inpatient to Community Mental Health Services. ISRCTN10043328.

Gillard, S., Simons, L., Turner, K., Lucock, M., and Edwards, C. (2012a). Patient and public involvement in the coproduction of knowledge. Qualt. Health Res. 22, 1126-1137. doi: 10.1177/1049732312448541

Gillard, S., Turner, K., and Neffgen, M. (2013). How does who we are shape the knowledge we produce? doing collaborative research about personality disorders. in Mental health service users in research. ed P. Staddon (Bristol: Policy Press), 53-68. doi: 10.1332/policypress/9781447307334.003.0005 coproduced drafts of the paper. LG also co-ordinated wider coproduction for the paper. RM, GF, SG and LG wrote reflections. GF, MU, ML, and AS contributed feedback to drafts of the paper. All authors read and approved the final draft.

\section{FUNDING}

This project was funded by the National Institute of Health Research (NIHR) Programme Grant for Applied Research (PGfAR 1212/20019), United Kingdom. The views and opinions expressed therein are those of the authors and do not necessarily reflect those of the NIHR PGfAR programme, NIHR, NHS, or the Department of Health.

\section{ACKNOWLEDGMENTS}

We would like to acknowledge the help and support of Drs. Stephen Bremner, James Byrne, Kati Turner, Sarah Gibson, and Katy Stepanian in helping this paper come to fruition and the wider ENRICH team, including all our collaborators, and the LEAP for their commitment to coproducing a randomized controlled trial and working through any difficulties together.

Greenhalgh, T., Snow, R., Ryan, S., Rees, S., and Salisbury, H. (2015). Six 'biases' against patients and carers in evidence-based medicine. BMC Med. 13:200. doi: 10.1186/s12916-015-0437-x

Happell, B., Bennetts, W., Platania-Phung, C., and Tohotoa, J. (2015). Consumer involvement in mental health education for health professionals: feasibility and support for the role. J. Clin. Nurs. 24, 3584-3593. doi: 10.1111/jocn. 12957

Harding, S. (1991). Whose Science? Whose Knowledge? Thinking From Women's Lives. Ithaca, NY: Cornell University Press.

Hickey, G., Brearley, S., Coldham, T., Denegri, S., Green, G., Staniszewska, S., et al. (2018). Guidance on Co-producing a Research Project. Southampton: INVOLVE. Available online at: http://www.invo.org.uk/posttypepublication/guidance-onco-producing-a-research-project/

Involve 'Values, principles and standards for public involvement in research' (2013). Involve 'Values, Principles and Standards for Public Involvement in Research'. Available online at: http://www.invo.org.uk/

Jennings, H., Slade, M., Bates, P., Munday, E., and Toney, R. (2018). Best practice framework for Patient and Public Involvement (PPI) in collaborative data analysis of qualitative mental health research: methodology development and refinement. BMC Psych. 18:213. doi: 10.1186/s12888-018-1794-8

Kopera, M., Suszek, H., Bonar, E., Myszka, M., Gmaj, B., Ilgen, M., et al. (2014). Evaluating explicit and implicit stigma of mental illness in mental health professionals and medical students. Comm. Ment. Hlt. J. 51, 628-634. doi: 10.1007/s10597-014-9796-6

Lambert, N., and Carr, S. (2018). 'Outside the original remit': Co-production in UK mental health research, lessons from the field. Int. J. Ment. Health Nu. 27, 1273-1281. doi: 10.1111/inm.12499

Lwembe, S., Green, S. A., Chigwende, J., Ojwang, T., and Dennis, R. (2016). Coproduction as an approach to developing stakeholder partnerships to reduce mental health inequalities: an evaluation of a pilot service. Prim. Health Care Res. 18, 14-23. doi: 10.1017/S1463423616000141

McDaid, S. (2009). An equality of condition framework for user involvement in mental health policy and planning: evidence from participatory action research. Disabil. Soc. 24, 461-474. doi: 10.1080/096875909028 79064

Mockford, C., Staniszewska, S., Griffiths, F., and Herron-Marx, S. (2012). The impact of patient and public involvement on UK NHS health care: a systematic review. Int. J. Qual. Health Care 24, 28-38. doi: 10.1093/intqhc/mzr066 
Moher, D., Pham, B., Jones, A., Cook, D. J., Jadad, A. R., Moher, M., et al. (1998). Does quality of reports of randomised trials affect estimates of intervention efficacy reported in meta-analyses?. Lancet 352, 609-613. doi: 10.1016/S0140-6736(98)01085-X

Mol, A., and Law, J. (2004). Embodied action, enacted bodies. The Example of Hypoglycaemia. Body Soc. 10, 43-62. doi: 10.1177/1357034X040 42932

MRC (2008). Developing and Evaluating Complex Interventions: New Guidance. Available oniline at: www.mrc.ac.uk/complexinterventionsguidance

Nowotny, H., Scott, P., and Gibbons, M. (2001). Re-Thinking Science. Cambridge: Polity Press.

Overall, J. E., and Gorham, D. R. (1962). The brief psychiatric rating scale. Psychol. Rep. 10, 799-812. doi: 10.2466/pr0.1962.10.3.799

Phillips, L. J. (2009). Analysing the dialogic turn in the communication of researchbased knowledge: an exploration of the tensions in collaborative research. Public Underst. Sci. 20, 80-100. doi: 10.1177/0963662509340092

Pinfold, V., Szymczynska, P., Hamilton, S., Peacocke, R., Dean, S., Clewett, N., et al. (2015). Co-production in mental health research: reflections from the people study. Ment. Health Rev. J. 20, 220-231. doi: 10.1108/MHRJ-09-2015-0028

Ratner, C. (2002). Subjectivity and objectivity in qualitative methodology. Forum: Qual. Soc. Res. 3. doi: 10.17169/fqs-3.3.829

Richardson, L. (2000). "Writing: a method of enquiry," in Handbook of Qualitative Research, 2nd edn. eds N. Denzin, and Y. Lincoln (London: Sage), 923-948

Roper, C., Grey, F., and Cadogan, E. (2018). Co-production: Putting Principles into Practice in Mental Health Contexts. Available online at: https://recoverylibrary. unimelb.edu.au/_data/assets/pdf_file/0010/2659969/Coproduction_puttingprinciples-into-practice.pdf $~$

Rose, D. (2017). Service user/survivor-led research in mental health: epistemological possibilities. Disabil. Soc. 32, 773-789. doi: $10.1080 / 09687599.2017 .1320270$
Rose, D., Fleischmann, P., and Schofield, P. (2010). Perceptions of user involvement: a user-led study. Int. J. Soc. Psychiatr. 56, 389-401. doi: 10.1177/0020764009106618

Scholz, B., Bocking, J., and Happell, B. (2017). Breaking through the glass ceiling: consumers in mental health organisations' hierarchies. Issues Ment. Health N. 38, 374-380. doi: 10.1080/01612840.2017.1280106

Simons, L., Lathlean, J., and Squire, C. (2008). Shifting the focus: sequential methods of analysis with qualitative data. Qual. Health Res. 18, 120-132. doi: $10.1177 / 1049732307310264$

Sweeney, A., Clement, S., Gribble, K., Jackson, E., Carr, S., Catty, J., et al. (2019). A systematic review of qualitatitve research studies of adult's experiences of being assessed for psychological therapies. Health Expect. doi: 10.1111/hex.12844. [Epub ahead of print].

Tuffrey-Wijne, I., and Butler, G. (2010). Co-researching with people with learning disabilities: an experience of involvement in qualitative data analysis. Health Expect. 13, 174-184. doi: 10.1111/j.1369-7625.2009.00576.x

White, I. R., Carpenter, J., and Horton, N. (2011). Strategy for intention to treat analysis in randomised trials with missing outcome data. BMJ 7:342. doi: $10.1136 /$ bmj.d40

Conflict of Interest Statement: The authors declare that the research was conducted in the absence of any commercial or financial relationships that could be construed as a potential conflict of interest.

Copyright (c) 2019 Goldsmith, Morshead, McWilliam, Forbes, Ussher, Simpson, Lucock and Gillard. This is an open-access article distributed under the terms of the Creative Commons Attribution License (CC BY). The use, distribution or reproduction in other forums is permitted, provided the original author(s) and the copyright owner(s) are credited and that the original publication in this journal is cited, in accordance with accepted academic practice. No use, distribution or reproduction is permitted which does not comply with these terms. 


\section{Plain English Summary}

\section{Is co-production just a pipe dream for applied health research commissioning? An exploratory literature review}

\section{Doreen Tembo, Elizabeth Morrow, Louise Worswick, Debby Lennard}

Background: The idea of 'co-production' is becoming more popular in health research because it describes a partnership between researchers and patients which creates research that focuses on patient's needs. Patient and public involvement (PPI) at an early stage in deciding what research should be funded can improve the quality and impact of research. PPI facilitates the public's right to be involved in publically funded research that affects them. However, internationally there are few examples of research funders wanting to involve patients or the public in shared-decision making about what research should be funded, especially for research that is mainly focused on basic research that may not lead to immediate outcomes for direct patient benefit.

Aim: A review of the international health research literature to find out what is known about PPI and power relations in the early stages of health research commissioning.

Method: Using pre-defined search terms, we systematically searched published academic journals and 'grey' or non academic literature using electronic databases and key search words. The key themes found in the literature were explored.

Results: The review found that there is very limited evidence on how best to use PPI in the early stages of research commissioning. This is particularly true for research that may have less practically applicable outcomes for direct patient benefit. PPI at this stage can be very limited, leaving public members feeling unheard or excluded from the actual processes of decision making. Four themes which emerged from the review are: reasons for PPI in research commissioning; benefits of PPI at strategic levels of research commissioning; contributions of patients and members of the public; improving PPI in research commissioning.

Conclusions: Although the public are involved in some countries at some stages of the research commissioning process, it is clear that the process of agreeing research priorities is a long way from being co-produced. PPI could change from a minimal and minor role to a true partnership role, if improvements were made to communication, practices, systems, structures and cultures that stop patients and the public from contributing in meaningful ways. Research commissioners need to prioritise having policies and strategies that allow them to move towards co-production of research commissioning so that research better reflects the needs of the people. 


\section{OPEN ACCESS}

Edited by:

Annette Louise Boaz,

Kingston University, United Kingdom

Reviewed by:

Alison O'Shea,

Kingston University, United Kingdom

Hana Asfour

Parallel Perspective Consulting

(Q Perspective), Jordan

${ }^{*}$ Correspondence:

Doreen Tembo

d.tembo@soton.ac.uk

Specialty section

This article was submitted to

Medical Sociology

a section of the journal

Frontiers in Sociology

Received: 13 February 2019

Accepted: 27 May 2019

Published: 24 June 2019

Citation:

Tembo D, Morrow E, Worswick L and

Lennard D (2019) Is Co-production

Just a Pipe Dream for Applied Health

Research Commissioning? An

Exploratory Literature Review.

Front. Sociol. 4:50

doi: 10.3389/fsoc.2019.00050

\section{Is Co-production Just a Pipe Dream for Applied Health Research Commissioning? An Exploratory Literature Review}

\author{
Doreen Tembo ${ }^{1 *}$, Elizabeth Morrow ${ }^{2}$, Louise Worswick ${ }^{3}$ and Debby Lennard ${ }^{4}$ \\ ${ }^{1}$ Wessex Institute, University of Southampton, Southampton, United Kingdom, ${ }^{2}$ Independent Researcher, Research Support \\ Northern Ireland, Killyleagh, Ireland, ${ }^{3}$ NHS England, Taunton, United Kingdom, ${ }^{4}$ Public Member of National Institute for \\ Health Research Evaluation Trials and Studies Coordinating Centre Patient and Public Involvement Reference Group, \\ University of Southampton, Southampton, United Kingdom
}

Background and Rationale: Internationally, the idea of "co-production' has become more popular in health research because of the promise of partnership between researchers and patients to create research that focuses on patients' needs. Patient and public involvement (PPI) at an early stage in deciding what research should be funded, can improve the quality and impact of research. However, professional power over the process places limits on the public practising their participatory rights for involvement in commissioning research that affects them and can leave members of the public feeling unheard or excluded, particularly within the context of early phase applied health research.

Aim: This article explores whether and how the public can be involved in the co-production of research commissioning early on in the process, with a focus on the power relations that pervade basic and early phase translational applied health research.

Methods: An exploratory literature review of international peer-reviewed and gray health research literature using structured searches of electronic databases and key search terms.

Results: There is very little literature that critically evaluates how PPI is embedded into the early phases of the commissioning process. The field of basic or early translational applied research appear to be particularly challenging. Four themes which emerged from the review are: reasons for PPI in research commissioning; benefits of PPI at strategic levels of research commissioning; contributions of patients and members of the public; improving PPI in research commissioning.

Conclusion: Although the public are being consulted at some stages of the research commissioning process, it is evident that the process of determining research priorities and agendas is far from being widely co-produced. Moving PPI from a consultative paternalistic model to a collaborative partnership model should be a priority for commissioners. Significant changes to communication, practices, systems, structures, or cultures that exclude patients and the public from contributing in meaningful ways, are needed to fulfill the potential of co-produced models of research commissioning.

Keywords: patient and public involvement, public engagement, co-creation of knowledge, co-production, research commissioning, research priority setting, citizen participation, biomedical 


\section{INTRODUCTION}

\section{The Promise of Co-production}

Internationally, the idea of "co-production" has become more popular in health research because of the promise of partnership between researchers and patients to create research that focuses on patient's needs. Patient and Public Involvement (PPI) at an early stage in deciding what research should be funded can improve the quality and impact of research. However, internationally there are very few examples of research commissioners involving patients or the public in decisions about research. This can leave members of the public feeling unheard or excluded by professionals.

Research commissioning is the most important stage of the research process for patients and the public to be involved as it gives the greatest potential to shape research agendas and to influence research funding (Oliver, 1996). However, research on decision making about future research priorities shows this rarely involves patients or the public. Decisions are more often made on the basis that technical rationalization of what research should be done, is more applicable than what is important to end users of research outputs.

Internationally in health services research PPI is widely recognized as being essential to the development of quality health services that are fit for purpose (Minogue and Girdlestone, 2010). Compared to health service delivery, PPI in health research management is globally a more recent movement and set of practices (Abrahams et al., 2004; Elberse et al., 2012; Gagnon et al., 2014; NIHR, 2015; PCORI, 2018).

Involving patients and the public in research, and especially in the early phases of research commissioning, such as research question or topic identification, priority setting, prioritization, and developing calls or advertisements for funding is thought to be crucial to overcome differential priorities between research funders, pharmaceutical companies and researchers, and the priorities of clinicians, patients and the public (Caron-Flinterman et al., 2005; Crowe et al., 2015). The consequences, as Chalmers and Glasziou (2009) describe of poor involvement of relevant stakeholders such as clinicians and patients in priority setting is an estimated avoidable waste of 85 per cent of global health research funding (Minogue et al., 2018).

\section{Defining PPI and Co-production}

The history of involving the public in service provision in the UK, one of the earliest adopters of PPI, was catalyzed by the rise in consumerist thinking in the 1960s and 1970s, and democratic or rights-based approaches that arose thereafter (Ridley et al., 2002). Under the UK Health and Social Care Act 2001 publicly-funded organizations have a duty to involve the public in the planning and provision of health services.

In the UK in 2006 the National Institute for Health Research (NIHR) was established with a mandate to involve patients and the public in commissioning and delivering publiclyfunded applied health research. The organization "consumers in research" now known as INVOLVE, a national advisory group for PPI, also joined the NIHR in the same year. A legacy of this organization is its widely used definition of PPI, which we utilize in this paper:

"Research being carried out "with" or "by" members of the public rather than "to", "about" or "for" them" (INVOLVE ${ }^{1}$ ).

There is variation internationally in definitions, models and ways of thinking about PPI. There is for example no agreed nomenclature with participation, engagement and involvement often being used interchangeably. There is also great variation, dependant on the country's historical development of democracy, in the mix of institutionalized vs. contestory forms of involvement in healthcare (Slutsky et al., 2016). Within the UK context, involvement within health research funding tends be embedded within institutionalized mechanisms and processes.

Theoretically there are different levels at which people can be involved, as highlighted in Hogg's (1999) models of involvement in service development which closely relate to the INVOLVE levels of involvement in research (consultation, collaboration, user-led and co-production). Paternalistic models of involvement, assume that professionals know best, and hence lend themselves to involvement at the consultative level. The Partnership models of involvement lend themselves more to collaborative approaches to involvement. The Consumerist model describes consumers in charge or user-driven or controlled involvement. Finally the Autonomy model emphasizes the importance of valuing individuals and the different perspectives patients and professionals bring, and is closely aligned with involvement at the co-produced level as defined by INVOLVE (Hickey et al., 2018).

Co-produced research harnesses the principles of sharing of power, including all perspectives and skills, respecting values and the knowledge of all those working together on the research, reciprocity and building and maintaining relationships. However, this understanding of co-production, while acknowledged to be valuable, has been criticized as being idealistic given current cultural, institutional and regulatory constraints (Madden and Speed, 2017; Green and Johns, 2019; Paylor and McKevitt, 2019).

\section{Previous Research}

The evidence base for PPI, and especially effective co-produced approaches in the early phases of research commissioning is underdeveloped (Nilsen et al., 2006; Oliver et al., 2008), especially when compared to PPI elsewhere in research (Shippee et al., 2015) or health services commissioning (Sheaff et al., 2015). A rapid review carried out by Manafò et al. (2018), which we include in this review, utilized rapid review methodology to explore existing evidence around the different approaches that could be utilized to enable PPI in priority setting in health ecosystems and health research. There is a need to further explore these and other different approaches and mechanisms, and the influence and impact PPI might have in the early phases of the research commissioning context (Staniszewska et al., 2011). This information could inform innovative collaborative and

${ }^{1}$ INVOLVE. What is public involvement in research? Retrieved from: http://www. invo.org.uk/find-out-more/what-is-public-involvement-in-research-2/ 
co-produced approaches which maximize the benefits of PPI through the research commissioning process.

PPI is perceived to be particularly challenging in the commissioning of clinical research, which might not have direct relevance to human health or patient outcomes, due to its early placement in the applied health research translational pathway (Caron-Flinterman et al., 2005; Dobbs and Whittaker, 2006). Some researchers might assume that patients may be put off engaging in such research due to finding science boring, irrelevant, or intimidating (Dobbs and Whittaker, 2006). Other researchers may be apprehensive because PPI can mean a different way of working that challenges established notions of professionalism (Thompson et al., 2009).

Concerns about tokenism and meaningful PPI are found throughout the research literature but are used as a catchall term that may not fully convey the limiting forces of professional power. Tokenism can be defined as the policy or practice of making only a symbolic effort to involve people (Domecq et al., 2014) or failure to develop approaches that enable people to contribute in meaningful ways (Supple et al., 2015). Unequal power relations between experts and the public can be challenging for both parties, and co-production and power sharing may be an unfulfilled ideological goal.

\section{Aims of the Review}

The aim of this exploratory literature review was to draw on international health research literature to explore some of the contextual complexities and the potential challenges of PPI in the early stages of research commissioning, with a particular focus on early translational applied health research.

The questions we explored were (a) whether and how the public can be involved in the co-production of knowledge in research commissioning? (b) What are the specific challenges in the context of basic and early phase translational applied health research? The paper draws on the findings of the exploratory literature review to address these questions.

We used the notion of co-production to consider how research might overcome differentials in power between professional and public members, which may limit meaningful PPI. Drawing on examples and findings from the literature, in the discussion, we suggest possible ways forward for innovation and improvement of meaningful PPI.

Our focus is the potentially challenging field of commissioning early phase applied health research because it is here that commissioning is far less likely to involve PPI than in the later phases of the "bench-to-bedside' research process (Callard et al., 2012). The reasons for which we will also explore.

\section{METHODS}

\section{Approach}

An exploratory literature review was carried out between May and August 2018. Owing to the disparate and scarce nature of evidence on PPI in research commissioning, a systematic review was unlikely to yield useful results that can inform practice. Therefore, an exploratory approach was chosen to seek out relevant published literature to allow us to consider the issues and challenges of PPI in research commissioning. The method is illustrated by Figure 1 .

We sought information about how to enable meaningful and effective approaches to involvement, as well as clarification about the meaning of tokenistic PPI in this context. We were interested in learning about ways of working that enable patients/public representatives to contribute to decision-making processes and the types of impact that PPI can have. The study team included two public contributors who were consulted throughout study.

\section{Inclusion/Exclusions}

The review explored issues about PPI in the commissioning of health research, including health services, health care, public health, clinical, and biomedical research. Included articles were those that addressed issues about: (i) any type of patients and public groups involved and their roles e.g., public reviewers, patient representatives or lay members, (ii) contexts of involvement in stages of the commissioning process, (iii) approaches to involvement, for example commenting on commissioning materials or involvement in face-to-face meetings, informing decisions, or shared decision-making practices, (iv) evidence of influence or impact of involvement on commissioning decisions, practices, or outcomes.

We sought journal articles (including empirical studies and literature reviews) and gray literature (including reports, discussion papers, commentary, and opinion pieces) where these offered useful insights and learning and were published in the English language.

Due to the limitations of time and resources we excluded articles published in other languages. We excluded articles that did not relate to health research commissioning, for example PPI in commissioning social care research or health professional education.

\section{Search Strategy}

The search strategy was to identify relevant evidence and information using:

- web-based searches of Web of Science, Google Scholar and PubMed to search the international scholarly literature; explore related works, citations, authors, and publications; and the retrieval of documents through online libraries or on the web.

- searches of the INVOLVE Evidence Library for gray literature e.g., $\mathrm{PhD}$ studies, organizational reports, and bibliographies.

- searches for NIHR unpublished reports and documents relating to PPI in commissioning.

\section{Key Search Terms}

Searches used the key term "patient and public involvement in research commissioning' and variations on the term (e.g., patient involvement in funding agencies). A comprehensive search drew on the search terms used by Brett et al. (2014) in their systematic review of the impact of PPI. It combined sets of terms including and relating to patient and public involvement (consumer, citizen, client, carer, lay, service users, survivor, stakeholder, family, relative); type of involvement (particp*, collaborat*, engage*, partner*, consult*, evaluat*) 

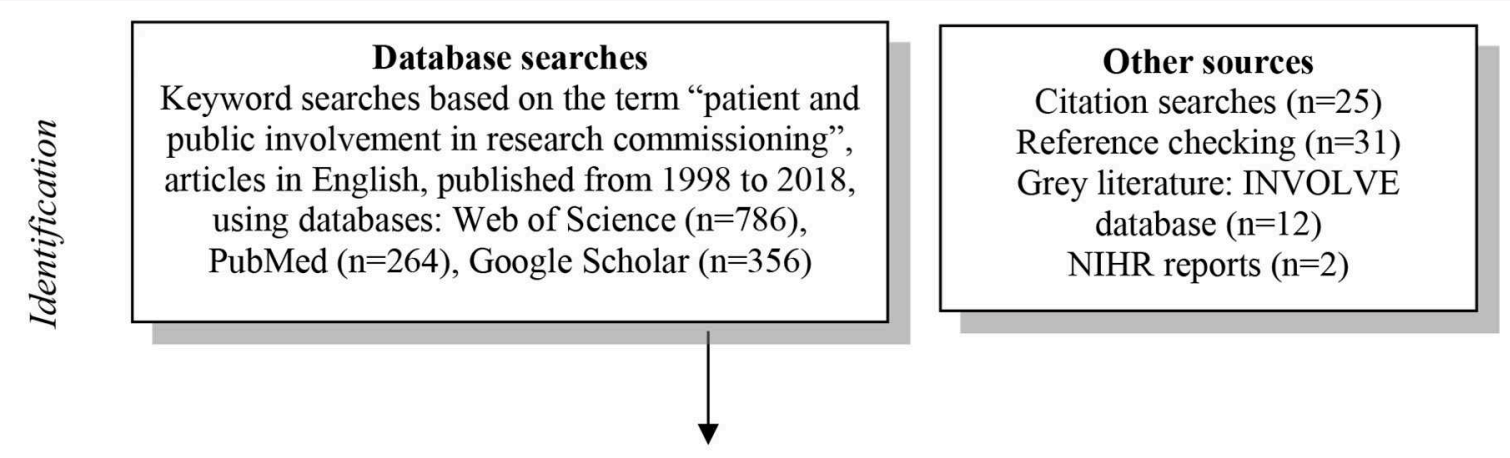

0
$\frac{5}{3}$
0
0
0
0

\section{Duplicates removed $(\mathrm{n}=112)$}
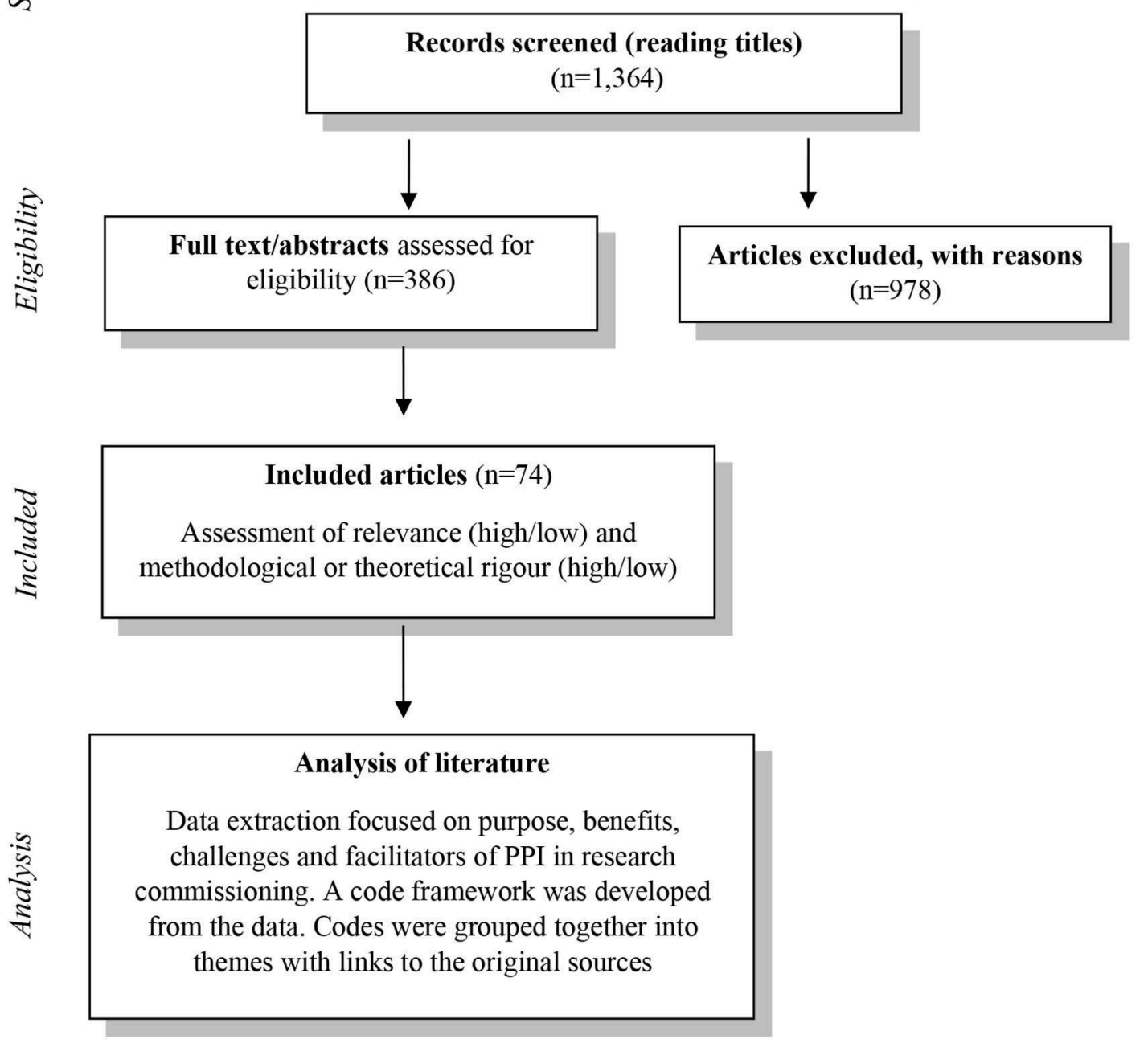

FIGURE 1 | Flow chart of exploratory review method.

and commissioning (funding agencies, research briefs, research funding, identifying research priorities, research priority setting, scoping review). MeSH terms were used to expand the searches (patients, public, economics, research, funding).

\section{Data Extraction}

Identified articles deemed to be relevant to the aim of the review were retrieved in full for analysis. Data were extracted into themed categories in Microsoft Word and key data extracted 
included the following: the author; the year and country; the aims or focus of the article; the methods used for PPI; the type of patients or groups of the public involved; key issues, findings or implications.

\section{Analysis}

The approach to the analysis was to explore and identify themes in the data (Denzin and Lincoln, 2005) reflecting the aims of the review to explore some of the contextual complexities and the potential challenges of PPI in the early stages of research commissioning. We read each article and considered the main issues raised in relation to the questions of whether and how the public can be involved and specific challenges associated with involvement in the commissioning context. As issues were identified, these were given a code (a title phrase or word representing the issue), and in this way a code framework was developed from the data to indicate patterns across the data (Braun and Clarke, 2006). Codes were grouped together into emerging themes (purpose, benefits, challenges, facilitators) with links to the original sources (Denzin and Lincoln, 2005). In the analysis the notion of co-production was used as a lens through which to consider issues of power (Hickey et al., 2018) between professionals and public members. For example we looked for examples of power sharing in the data, e.g., new roles and responsibilities of PPI members, evidence of shared decisionmaking, and approaches to supporting positive interactions and communication. Tables were used to present synthesized themes and links to original sources.

\section{Rigor}

A study protocol for the review was developed and revised by team members, including identification of databases to be searched and key search terms. Strategies for minimizing biases in the search strategy were as follows. (a) One team member independently cross-checked a sample of 20 returned papers against included/exclusion criteria. (b) Members of the team discussed and reached agreement on the importance of emerging themes in the analysis. (c) Inclusion and use of gray literature to extend the searches beyond peer reviewed articles.

\section{RESULTS}

The review identified 74 relevant papers, reports and articles about PPI in health research commissioning. The results of the review confirmed the lack of published material specifically around PPI in the early phases of the commissioning processes of early phase applied health or basic health research. The review did yield results on PPI in commissioning of applied health research that was further along the translational pathway. Here we present summary results of the main findings with some representative references to the body of literature from the review.

The structure of the results is presented according to four themes that emerged:

- Reasons for PPI in research commissioning

- Benefits of PPI at strategic levels of research commissioning
- Contributions of patients and members of the public

- Improving PPI in research commissioning.

\section{Reasons for PPI in Research Commissioning}

The review demonstrated that PPI in research commissioning predominantly operated within a paternalistic model, with public members being consulted rather than more inclusively involved in the commissioning processes as co-creators of knowledge and co-producers of commissioning decisions and processes. Reasons for PPI were rarely given or explained, which could reflect the fact that PPI is often a requirement of being awarded central funding in the UK context. However, this is not the case in other countries or for all health research that is funded by other means.

\section{Benefits of PPI at Strategic Levels of Research Commissioning}

Despite operating within a paternalistic environment, several benefits to involving patients and the public, beyond getting them to provide views about priorities for research, were identified in the literature. These are summarized in Table 1 and include research priorities becoming more relevant to users; broader perspectives being brought into commissioning decisions; research being more likely to be ethical, inclusive and fair; the contribution of public contributors' skills and knowledge to commissioning decisions; and encouragement of PPI in funded research.

\section{Contributions of PPI Members}

The review also highlighted specific activities and contributions patients and public members make to the overall commissioning process. These have been summarized in Table 2 and include identifying topics, prioritizing topics, assessment, review of evidence, synthesizing results, and writing research briefs.

\section{Improving PPI in Research Commissioning}

The review discovered that new priority setting projects are being developed around the world (in the UK, US, Australia, Netherlands, and Canada) to build partnerships between patients and professionals (Bragge et al., 2011; Gagnon et al., 2014; Tong et al., 2015; Pratt et al., 2016; Ghisoni et al., 2017; Abma, 2018; JLA, 2018; Manafò et al., 2018) (see Table 3).

Manafò et al. (2018) review of these priority-setting approaches concluded they are inclusive and objectively based, while being specific to the priorities of stakeholders engaged in the process. Key limitations identified were a lack of evaluation data on the success and extent to which patients were engaged, issues pertaining to feasibility of stakeholder engagement, coordination, communication, and limited resources.

Evaluation of nine projects that used the Dialogue Model (Abma et al., 2015) found patient involvement in agendasetting is not automatically followed by patient involvement in programming and implementation. The authors recommend that support is needed during the process to organize patient involvement and adapt organizational structures like review procedures. Facilitating factors for success of the model include the importance of ownership; the value of dialogue for 
TABLE 1 | Benefits of PPI in research commissioning.

Possible benefits Ways PPI influences commissioning

Research priorities are more relevant to users

Broader perspectives are brought to commissioning decisions

Research is more likely to be ethical, inclusive and fair

PPI members contribute skills and knowledge to commissioning decisions

PPI in commissioning encourages PPI in research

Commissioning processes are more transparent and accountable
- PPI members are likely to ask how the research will benefit patients (Brett et al., 2014; Domecq et al., 2014; Shippee et al., 2015)

- PPI in developing the focus and aims of research can mean it is more likely to meet the needs of patients (Rhodes et al., 2002; O’Donnell and Entwistle, 2004; Abma, 2005; Caron-Flinterman et al., 2005; Hewlett et al., 2006; Howe et al., 2006; Nilsen et al., 2006; Lindenmeyer et al., 2007; Shah and Robinson, 2007; Gagnon et al., 2011)

- Research questions or hypotheses can be developed to focus on issues that are important to beneficiaries (McCormick et al., 2004; O'Donnell and Entwistle, 2004; Viswanathan et al., 2004; Abma, 2005; Hailey and Nordwall, 2006; Howe et al., 2006)

- Poor research ideas are abandoned (Boote et al., 2014)

- Patients or members of the public may contribute experiential knowledge, which can corroborate or enhance scientific or professional knowledge; (Andejeski et al., 2002; Oliver et al., 2009)

- Experiential knowledge can enhance the research brief through co-production or co-design of solutions (Crowe et al., 2015; Manikam et al., 2017)

- PPI members are likely to ask whether the research is ethical or moral (Morgan et al., 2005; Staley, 2009; Brett et al., 2014; van Bekkum et al., 2016)

- PPI can enhance research practices such as ethical recruitment (Oliver et al., 2009; NIHR CLAHRC, 2017) and transparency (Hutchison et al., 2017)

- Researchers develop skills and knowledge in partnership working (Brett et al., 2014; Gagnon et al., 2014)

- Involving members of the public can encourage interdisciplinarity (Oliver and Gray, 2006)

- Patients and members of the public bring personal assets to commissioning processes, such as skills, abilities and links to charities or community organizations (Coulter, 2004; Abma, 2018)

- Patients and members of the public provide time and support e.g., comments that lead to clearer briefs (Brett et al., 2014)

- People can benefit from their involvement and be more likely to engage in research or civic activities in the future (Fudge et al., 2007)

- PPI can support access to community networks and wider groups of the public or disseminate information (Brett et al., 2014; Crowe et al., 2015; Manikam et al., 2017; Simpson et al., 2018)

- The public oversee research and are given access to research information (Greenhalgh et al., 2017)

- Research organizations are publicly accountable (Resnik, 2001) personal and mutual understanding; relational empowerment and critical awareness raising among patients; the importance of responsibility, responsiveness and trust; support in working with co-researchers; and the issue of representation (Abma, 2018).

Gagnon and colleagues of the Canadian Health Technology Assessment (HTA) programme have generated a conceptual framework for interventions to promote patient involvement in the early stages of HTA (Gagnon et al., 2014). Outcomes of PPI are evaluated with patients and their representatives using interviews and observations. These priority-setting projects and activities are promising but more needs to be done to test them out in different research funding contexts and particularly in early translational applied health research commissioning.

The review found examples of ways to facilitate PPI in commissioning, which could be utilized for the identification and prioritization stages of the process within early stage applied health research. In summary, these are:

- Planning for meaningful involvement all the way through the commissioning process (Oliver et al., 2004, 2009)

- Finding ways to expand opportunities for wider and effective participation and engagement with the public (Willis, 1995; Abelson et al., 2003; Oliver et al., 2008; INVOLVE, 2012; Morrow et al., 2013; Rikkers et al., 2015; Franck et al., 2018; Rawson et al., 2018; Simpson et al., 2018; Truitt et al., 2018)

- Building positive attitudes toward PPI as well as positive relations between stakeholders (Pittens et al., 2014; Abma et al.,
2015; Abma, 2018). This could be facilitated by developing guidance, training and support for patient and the public contributors, Chairs of commissioning bodies and teams, including opportunities for shared learning (Boote et al., 2002; Caron-Flinterman et al., 2005; Oliver et al., 2008; INVOLVE, 2012)

- Encouraging organizations to assess the quality and impact of public involvement in commissioning (Oliver et al., 2015)

- Supporting commissioning teams to assess and provide feedback about processes and outcomes (O'Donnell and Entwistle, 2004; Howe et al., 2017).

\section{DISCUSSION}

\section{Variation in Opportunities for PPI in Commissioning}

The review reveals a story of PPI opportunities for involvement in commissioning that ranges from ineffectual tokenism to meaningful co-creation of knowledge. Our findings suggest that while some research funders are fully committed to PPI at every stage, others have not given sufficient consideration to the benefits of PPI identified in this review. Indeed our findings do little to contest previous observations that commissioners may be concerned that PPI will distort research agendas (O'Donnell and Entwistle, 2004). Improved utilization of the review identified activities that patient and public representatives can be involved 
TABLE 2 | Contributions of PPI members to research commissioning.

\begin{tabular}{|c|c|}
\hline Activities & Examples of PPI roles/contributions \\
\hline Identifying topics & $\begin{array}{l}\text { - Inviting members of the public to suggest an issue, condition or problem that research could help to address (Oliver et al., } \\
\text { - } 2004 \text {; Royle and Oliver, 2004; Menon and Stafinski, 2011; PCORI, 2018) } \\
\text { - Ruture research (Moran and Davidson, 2011; Franck et al., 2018) } \\
\text { - Patients with a common interest raising issues or bringing issues to the attention of the research community through their } \\
\text { engagement with health services or patient networks (Morris et al., 2011; Brady and Preston, 2017) }\end{array}$ \\
\hline Prioritizing topics & $\begin{array}{l}\text { - Convened groups (e.g., focus groups) of patients participating in activities to vote for, or rank, priority areas (Husereau et al., } \\
\text { 2010; Gagnon et al., 2014; Pittens et al., 2014; Rikkers et al., 2015; NIHR CLAHRC, 2017; Parsons et al., 2017; Rawson } \\
\text { et al., 2018; Truitt et al., 2018) } \\
\text { - Consensus exercises or dialogue on research priorities (Smith et al., 2005; Abma, 2018) } \\
\text { - Patient groups or voluntary organizations putting forward a case for research into topics that are felt to be important (JLA, } \\
\text { 2018) } \\
\text { - Contributing to developing or implementing a commissioning body's research strategy (Oliver and Gray, 2006; Moran and } \\
\text { Davidson, 2011; Gamble et al., 2014; NIHR, 2015) }\end{array}$ \\
\hline Assessment & $\begin{array}{l}\text { - PPI members of research advisory panels and boards (Entwistle and O'Donnell, 2003; Oliver and Gray, 2006) } \\
\text { - Expert patients and/or carers with direct experience of a health condition or illness providing comments on the value of } \\
\text { research from a patient's perspective (Brett et al., 2014) } \\
\text { - Representatives of patient groups or organizations advising on the feasibility of patient participation in research studies } \\
\text { (Crocker et al., 2017) }\end{array}$ \\
\hline Review of evidence & $\begin{array}{l}\text { - Scoping the field for existing evidence involving patients and the public in identifying evidence or to identify needs (Smith } \\
\text { et al., 2008; Oliver et al., 2009; Bragge et al., 2011) } \\
\text { - Reports of research undertaken by voluntary organizations or patient groups which are fed into a review (Abma, 2018) } \\
\text { - Evidence generated through focus groups, citizens juries (Entwistle et al., 2008; Gooberman-Hill et al., 2008) or action } \\
\text { research (Greenhalgh et al., 2017) }\end{array}$ \\
\hline Synthesizing results & $\begin{array}{l}\text { - Public reviewers pointing out where there might be gaps in understanding (NIHR BRCU, 2017) } \\
\text { - Raising patient perspectives of what is important to know (Caron-Flinterman et al., 2005; Crocker et al., 2017; JLA, 2018) } \\
\text { - Patient reviewers contributing to committee meetings about research briefs (NIHR BRCU, 2017) }\end{array}$ \\
\hline Writing research briefs & $\begin{array}{l}\text { - Contributing to specifying the focus of research briefs (Oliver et al., 2004) } \\
\text { - Commenting on draft research briefs (Brett et al., 2014) } \\
\text { - Reviewing research briefs (NIHR BRCU, 2017) } \\
\text { - Reviewing plain English summaries of briefs (Oliver et al., 2009) }\end{array}$ \\
\hline
\end{tabular}

in by research funders would move the involvement model and levels from one of paternalism and consultation to one that is partnership-based and collaborative.

Most research funding organizations are open to asking patients to submit their views about priorities for research (e.g., a website where people can make suggestions for research), and some organizations go out and engage patients and groups of the public about their views about research needs. While the review highlighted novel and effective approaches to priority setting that include patients and the public, it also demonstrated that there is relatively little evidence, beyond identification and prioritization of research topics (e.g., James Lind Alliance Priority Setting Partnerships), of wide-spread co-production or co-creation in the development of prioritized research areas and funding calls.

The study by van Bekkum et al. (2016) which looked at ten UK agencies that fund health or medical research found involvement was not routinely incorporated into the planning of funding calls and there was little evidence of PPI being driven by democratic imperatives or rights-based arguments. Agencies and commissioning groups working within specific areas of health and medicine tend to promote particular definitions and practices which determine the boundaries in which researchers in these areas understand and practice PPI (van Bekkum et al., 2016). Professionals may be generally in favor of PPI but may believe that ultimately decisions about which research gets funded should be made by the professionals who are held accountable for these decisions (Oliver et al., 2004).

There are some strong examples of how the public can be involved in the co-production of knowledge in research commissioning. For example, some UK research funders, such as the NIHR and Medical Research Council, and US funders such as the Patient Centered Outcomes Research Institute, have research management frameworks for PPI which may include patients and members of the public being asked to review documentation that support prioritization of research topics or act as members of research prioritization committees (Oliver et al., 2009). However, even within this framework, it appears that some commissioning activities (e.g., defining assessment criteria, reviewing evidence, synthesizing results, writing documents for the consideration by committees, and funding decisions) may be undertaken by professionals without public input. Power is therefore balanced more toward researchers and funding organization staff than patients and public representatives. This is often the case for basic and the early applied health research commissioning context.

\section{The Effects of Power Differentials}

The review did not identify literature that focused on early stage commissioning processes for basic or early phase applied health research. The literature reveals some of the specific challenges in the context of basic and early phase translational applied 
TABLE 3 | Priority setting approaches that involve patients and the public.

\begin{tabular}{|c|c|}
\hline Model and setting & Model description \\
\hline $\begin{array}{l}\text { James Lind Alliance Priority Setting } \\
\text { Partnerships (UK) }\end{array}$ & $\begin{array}{l}\text { - Priority Setting Partnerships (PSPs) enable clinicians, patients and carers to work together to identify and prioritize } \\
\text { uncertainties about the effects of treatments that could be answered by research. PSPs identify treatment uncertainties } \\
\text { (questions about treatments which cannot be answered by existing research) which are important to all groups (often a } \\
\text { Top } 10 \text { list) of jointly agreed priorities which are publicized widely (JLA, 2018) }\end{array}$ \\
\hline $\begin{array}{l}\text { Dialogue Model for research } \\
\text { agenda-setting (Netherlands) }\end{array}$ & $\begin{array}{l}\text { - The Dialogue Model actively engages patients in research agenda setting to balance power. It provides guidelines to } \\
\text { develop a shared research agenda among patients and other stakeholders. The approach involves phases of exploration, } \\
\text { consultation, prioritization, integration, programming, implementation (Abma, 2018) }\end{array}$ \\
\hline Global Evidence Mapping (Australia) & $\begin{array}{l}\text { - Evidence mapping describes the quantity, design and characteristics of research in broad topic areas, in contrast to } \\
\text { systematic reviews, which usually address narrowly-focused research questions. The breadth of evidence mapping helps } \\
\text { to identify evidence gaps and may guide future research efforts (Bragge et al., 2011) }\end{array}$ \\
\hline $\begin{array}{l}\text { Deep Inclusion Method/CHoosing All } \\
\text { Together (US) }\end{array}$ & $\begin{array}{l}\text { - This model consists of three dimensions: breadth, qualitative equality, and high-quality non-elite participation. Deep } \\
\text { inclusion is captured not only by who is invited to join a decision-making process but also by how they are involved and at } \\
\text { what point in the process non-elite stakeholders are involved (Pratt et al., 2016) }\end{array}$ \\
\hline $\begin{array}{l}\text { Health Technology Assessment } \\
\text { conceptual framework for patient } \\
\text { involvement (Canada) }\end{array}$ & $\begin{array}{l}\text { - Patients and their representatives are involved in activities to identify potential HTA topics, review vignettes or research } \\
\text { briefs developed to inform the prioritization of topics, participate in deliberation sessions for prioritizing HTA topics, and } \\
\text { develop the assessment plan of the topic prioritized (Gagnon et al., 2014) }\end{array}$ \\
\hline
\end{tabular}

health research. Perhaps most significant, is that professional skepticism and resistance manifest in subtle yet powerful ways that can limit co-production to a pipe dream (Chase et al., 2000). Even though the usefulness of patients' experiential knowledge alongside professional and clinical knowledge is widely accepted (Boote et al., 2002; Brett et al., 2014), it can be less clear how to integrate this type of knowledge into decision-making (CaronFlinterman et al., 2005), to share ownership of decisions, and to assess decision-making effectiveness (Entwistle and O'Donnell, 2003). Researchers and funders may therefore employ tokenistic PPI, especially within the UK context where PPI is either increasingly encouraged or mandated.

The literature indicates that tokenism can be caused by lack of awareness or resistance to involvement amongst professionals, but can also be caused by practices, systems, structures or cultures that exclude patients and the public from contributing in meaningful ways (Supple et al., 2015). The technical nature of early phase translational research and the bureaucratic nature of commissioning may be a reason why the public are excluded from some commissioning activities. However, the literature demonstrates that public contributors' understanding of the technical clinical subjects, the language and science are not a necessary barrier to involvement.

When investigating patient and public involvement in biomedical research, Caron-Flinterman et al. (2005) asserted that training may support patients and the public to understand highly scientific or technical research. Further widespread use of non-technical language by professionals and plain English summaries may better enable involvement. Training for commissioning teams could cover inclusion strategies in patient-expert partnerships thereby enabling a better platform for both parties to effectively communicate and contribute to collaborative or co-produced approaches (Elberse et al., 2011).

\section{Areas for Innovation and Improvement}

Commissioning research requires informed judgements to be made about what research is important, and could lead to potentially significant results and impactful outcomes (Oliver et al., 2009). A sole focus on PPI as a participatory right endangers the involvement process into becoming a tokenistic activity that is consultative at best. Previous discursive papers on PPI suggests three different lines of thinking about the reasons for PPI in commissioning. These are: moral (to assure participative rights to involvement) (Boote et al., 2002; Coulter, 2004), methodological (to improve the quality and relevance of research to society) (Fisher, 2002; Chalmers and Glasziou, 2009), and impact (health, political, legislative, economic and societal impact). Moral or rights-based arguments suggest that PPI should be integral to research from the earliest stages as an intrinsic participatory right (Boote et al., 2002; Coulter, 2004). Methodological and impact based motivations, on the other hand, do not necessarily recommend involvement through the whole processes where it does not add value. It remains imperative that commissioners embed the moral or participatory rights-based driver as a key underlying factor that propels involvement in the system. Additionally an effective commissioning system must also consider and harness the methodological and impact drivers and benefits of PPI, such as those identified in this review, to create buy-in from all stakeholders.

Increasingly commissioning bodies are recognizing that the issue of what constitutes a rational discourse for future research, is a complex interplay of issues about how principles of patient need and rights translate into research contexts. Arguments against PPI warn against the lack of objectivity, possible bias, and individual self-interest of members of the public when it comes to making decisions about the allocation of research funds. Notions of the rights of the public to participate in all areas of health care-captured in the phrase "nothing about us without us"-are undermined by the apparent irrationality of involving members of the public in rational decisions about the allocation of research funds based on gaps in the evidence base and the feasibility, methods, and merit of the science in question.

Preoccupation with representation issues and concerns about the professionalization of lay members has directed 
too much attention to questions about the effectiveness of individual PPI representatives. Instead, PPI could be improved by examining the presuppositions and validity dimensions of everyday communication (normalized discourse) between professionals and PPI members. In relation to PPI in research commissioning this could include using reflective studies, to activate reflection on the unease, tensions and concerns about tokenism.

Improving opportunities for PPI requires the provision of meaningful spaces for dialogue, exchange and decision-making that suit different types of professionals and PPI representatives, as well as the public more generally. Early explicit exploration of different PPI roles and contributions with members of the public may assist effective participation and satisfaction. Singular PPI models are unable to effectively respond to the pluralism in experiences, values and opinions that different members of society hold.

Much could be gained from the involvement of third sector groups with local, regional or sector-wide views. Other approaches could be e-consultation or crowd-sourcing research topics and prioritizing them with a virtual public and professional community of practice, democratic prioritization (through voting), use of social media, or holding James Lind Alliance style priority-setting and consensus-building exercises to identify and prioritize areas of future focus (Rawson et al., 2018; Simpson et al., 2018; Truitt et al., 2018). In their review, Oliver et al. (2008) suggest a particularly fruitful method for involving the public in setting large-scale research agendas. The method was a combination of collaboration and consultation, with lay people taking leading roles in consulting peers in their networks.

There is a need for more innovative thinking about ways to relate to "seldom heard" and "hard to reach" populations, such as black and minority ethnic groups and persons with disabilities, by diversifying languages and mechanisms of communication. Creating mechanisms for engagement in commissioning that are more inclusive of diversity (e.g., by age, gender, ethnicity, socioeconomic background, and other characteristics) and reach out to wider groups of patients and the public (e.g., different experiences of health and illness, different patient groups, carers and those who are well) can help to stimulate interest and participation in commissioning. Combining different approaches can bring a more diverse range of people and their perspectives and views to the commissioning process that are more representative of diverse service user needs and priorities (Oliver et al., 2008).

More could be done to find ways to talk about complex technical ideas and research methods in accessible plain English (and to celebrate those professionals who find comprehensible expression), and to raise awareness of behavior that intimidates, side-lines or stigmatizes individuals. If we do not want PPI to be tokenistic in this area, it is important to develop policy, standards, guidance, roles, training, information, communication technologies and digital platforms (e.g., websites and social media) to support patient and public involvement in different research commissioning activities.

It is vital for people who find themselves occupying positions of power in the commissioning system to turn a critical eye toward the system. Research areas that appear to be far removed from immediate patient benefit due to being positioned early in the applied research translational pathway, especially need to better engage the public. Those in power should seek to show how the system is responsive to societal needs, for example showing the impact of commissioned research on patients or other beneficiaries (Pramesh et al., 2016). Therefore, a key issue for funders going forward is how to build capacity to adapt and absorb change brought about through co-production and the co-creation of new ways of commissioning.

\section{Limitations}

This review does not cover some of the practical challenges of PPI funders may face, including access and issues of reimbursement and payment. These issues, in different contexts, have been explored elsewhere in the literature and guidance to overcome some of these challenges is available from INVOLVE (Snape et al., 2014). The main limitation of the review is the focus on professionally defined commissioning approaches and models. It does not include lay groups taking the initiative through user-led research, or commissioning practices of user-led research organizations.

Limitations of the literature reviewed are the deficit of high-quality research studies (no trials were identified), the reliance on literature reviews, and small-scale evaluation studies carried out on single units or programmes. While international literature was included, differences in language and terminology of involvement, engagement and participation between countries are a limitation of the searches. Including languages other than English would have reduced bias but this was not possible within the limited resources for the review.

\section{CONCLUSIONS}

Although the public are involved in some countries, at some stages of the research commission process, it is clear that the process of agreeing research priorities is a long way from being co-produced and can be tokenistic. Tokenism can be caused by lack of awareness or resistance to involvement amongst professionals, but it can also be caused by highly structured commissioning systems, technically defined subject areas, and tasks that may exclude patients and the public from contributing in meaningful ways.

Addressing concerns about tokenism requires commissioners to critically reflect on current PPI practices and to devise ways of working that are meaningful and worthwhile for everyone involved. PPI could change from a minimal and minor role to a true partnership role, if improvements were made to communication, practices, systems, structures and cultures that stop patients and the public from contributing in meaningful ways.

If we want to avoid tokenism in PPI, it is important that commissioning organizations develop mechanisms to enable commission teams to secure the involvement of patients and the public through a range of options for engagement and 
involvement, including use of face-to-face methods and digital platforms. New, more distributed approaches to commissioning could be based on collaboration or partnership models, which bring together patients, carers and clinicians to create truly coproduced research agendas.

\section{DATA AVAILABILITY}

No datasets were generated or analyzed for this study.

\section{AUTHOR CONTRIBUTIONS}

All authors are part of the project team comprising the larger work programme from which this paper draws its data. All authors contributed to the development of the paper, with DT

\section{REFERENCES}

Abelson, J., Eyles, J., McLeod, C. B., Collins, P., McMullan, C., and Forest, P. G. (2003). Does deliberation make a difference? Results from a citizens panel study of health goals priority setting. Health Policy 66, 95-106. doi: 10.1016/S0168-8510(03)00048-4

Abma, T. (2005). Patient participation in health research: research with and for people with spinal cord injuries. Qual. Health Res. 15, 1310-1328. doi: $10.1177 / 1049732305282382$

Abma, T. (2018). Dialogue and deliberation: new approaches to including patients in setting health and healthcare research agendas. Action Res. 1476750318757850. doi: $10.1177 / 1476750318757850$

Abma, T., Pittens, C. A. C. M., Visse, M., Elberse, J. E., and Broerse, J. E. W. (2015). Patient involvement in research programming and implementation: a responsive evaluation of the dialogue model for research agenda setting. Health Expect 18, 2449-2464. doi: 10.1111/hex.12213

Abrahams, N., Adhikari, R., Bhagwat, I. P., Christofides, N., Djibuti, M., Dyalchand, A., et al. (2004). Changing the debate about health research for development. international health research awards recipients. J. Public Health Policy 25, 259-287. doi: 10.1057/palgrave.jphp.3190028

Andejeski, Y., Breslau, E. S., Hart, E., Lythcott, N., Alexander, L., Rich, I., et al. (2002). Benefits and drawbacks of including consumer reviewers in the scientific merit review of breast cancer research. J. Womens Health Gend. Based Med. 11, 119-136. doi: 10.1089/152460902753645263

Boote, J., Dalgleish, M., Freeman, J., Jones, Z., Miles, M., and Rodgers, H. (2014). 'But is it a question worth asking?' a reflective case study describing how public involvement can lead to researchers' ideas being abandoned. Health Expect 17, 440-451. doi: 10.1111/j.1369-7625.2012.00771.x

Boote, J., Telford, R., and Cooper, C. (2002). Consumer involvement in health research: a review and research agenda. Health Policy 61, 213-236. doi: 10.1016/S0168-8510(01)00214-7

Brady, L., and Preston, J. (2017). Evaluating the Extent and Impact of Young People's Involvement in National Institute for Health Research (NIHR) Studies: An Assessment of Feasibility. Report of a project commissioned by the James Lind Initiative. Retrieved from http://generationr.org.uk/?p=1375 (accessed July 9,2018 ).

Bragge, P., Clavisi, O., Turner, T., Tavender, E., Collie, A., and Gruen, R. L. (2011). The global evidence mapping initiative: scoping research in broad topic areas. BMC Med. Res. Methodol. 11:92. doi: 10.1186/1471-2288-11-92

Braun, V., and Clarke, V. (2006). Using thematic analysis in psychology. Qual. Res. Psychol. 3, 77-101. doi: 10.1191/1478088706qp063oa

Brett, J., Staniszewska, S., Mockford, C., Herron-Marx, S., Hughes, J., Tysall, C., et al. (2014). Mapping the impact of patient and public involvement on health and social care research: a systematic review. Health Expect 17, 637-650. doi: 10.1111/j.1369-7625.2012.00795.x

Callard, F., Rose, D., and Wykes, T. (2012). Close to the bench as well as at the bedside: involving service users in all phases of translational research. Health Expect 15, 389-400. doi: 10.1111/j.1369-7625.2011.00681.x and EM taking primary leadership in drafting and co-authors (LW, DL) providing detailed feedback on drafts.

\section{FUNDING}

The literature review was conducted as part of a work programme around an internal evaluation in the UK National Institute of Health Research Evaluation Trials and Studies Coordinating Center (NETSCC).

\section{ACKNOWLEDGMENTS}

We would like to thank members of project team of the NETSCC internal evaluation and in particular Alice Hawliczek (NETSCC) and Jane Putsey (Public Member).

Caron-Flinterman, J. F., Broerse, J. E. W., and Bunders, J. F. G. (2005). The experiential knowledge of patients: a new resource for biomedical research? Soc. Sci. Med. 60, 2575-2584. doi: 10.1016/j.socscimed.2004.11.023

Chalmers, I., and Glasziou, P. (2009). Avoidable waste in the production and reporting of research evidence. Lancet 374, 86-89. doi: 10.1016/S0140-6736(09)60329-9

Chase, D., Milne, R., Stein, K., and Stevens, A. (2000). What are the relative merits of the sources used to identify potential research priorities for the NHS HTA programme? Int. J. Technol. Assess. Health Care 16, 743-750. doi: 10.1017/S0266462300102028

Coulter, A. (2004). Perspectives on health technology assessment: response from the patient's perspective. Int. J. Technol. Assess. Health Care 20, 92-96. doi: 10.1017/S0266462304000856

Crocker, J. C., Boylan, A. M., Bostock, J., and Locock, L. (2017). Is it worth it? patient and public views on the impact of their involvement in health research and its assessment: a UK-based qualitative interview study. Health Expect. 20, 519-528. doi: 10.1111/hex.12479

Crowe, S., Fenton, M., Hall, M., Cowan, K., and Chalmers, I. (2015). Patients', clinicians' and the research communities' priorities for treatment research: there is an important mismatch. Res. Involv. Engage. 1:2. doi: 10.1186/s40900-015-0014-7

Denzin, N., and Lincoln, Y. (2005). "Introduction: the discipline and practice of qualitative research," In The Sage Handbook of Qualitative Research 3rd ed, eds N. K. Denzin, and Y. S. Lincoln (Thousand Oaks, CA: Sage), 1-32.

Dobbs, T., and Whittaker, I. (2006). Patient and public involvement in basic science research - are we doing enough? BMJ Opin. Available online at: https://blogs.bmj.com/bmj/2016/05/11/ppi-in-basic-science-research-arewe-doing-enough

Domecq, J. P., Prutsky, G., Elraiyah, T., Wang, Z., Nabhan, M., Shippee, N., et al. (2014). Patient engagement in research: a systematic review. BMC Health Serv. Res. 14:89. doi: 10.1186/1472-6963-14-89

Elberse, J. E., Caron-Flinterman, J. F., and Broerse, J. E. (2011). Patientexpert partnerships in research: how to stimulate inclusion of patient perspectives. Health Expect 14, 225-239. doi: 10.1111/j.1369-7625.2010. 00647.x

Elberse, J. E., Pittens, C. A., de Cock Buning, T., and Broerse, J. E. (2012). Patient involvement in a scientific advisory process: setting the research agenda for medical products. Health Policy 107, 231-242. doi: 10.1016/j.healthpol.2012.05.014

Entwistle, V., Calnan, M., and Dieppe, P. (2008). Consumer involvement in setting the health services research agenda: persistent questions of value. J. Health Serv. Res. Policy 13(Suppl. 3), 76-81. doi: 10.1258/jhsrp.2008.007167

Entwistle, V., and O'Donnell, M. (2003). Research funding organisations and consumer involvement. J. Health Serv. Res. Policy 8, 129-131. doi: $10.1258 / 135581903322029458$

Fisher, M. (2002). The role of service users in problem formulation and technical aspects of social research. Soc. Work Educ. 21, 305-312. doi: $10.1080 / 02615470220136885$ 
Franck, L. S., McLemore, M. R., Cooper, N., De Castro, B., Gordon, A. Y., Williams, S., et al. (2018). A novel method for involving women of color at high risk for preterm birth in research priority setting. J. Vis. Exp. 131:56220. doi: $10.3791 / 56220$

Fudge, N., Wolfe, C. D. A., and McKevitt, C. (2007). Involving older people in health research. Age Ageing 36, 492-500. doi: 10.1093/ageing/afm029

Gagnon, M. P., Candas, B., Desmartis, M., Gagnon, J., Roche, D. L., Rhainds, M., et al. (2014). Involving patient in the early stages of health technology assessment (HTA): a study protocol. BMC Health Serv. Res. 14, 273-273. doi: 10.1186/1472-6963-14-273

Gagnon, M. P., Desmartis, M., Lepage-Savary, D., Gagnon, J., St-Pierre, M., Rhainds, M., et al. (2011). Introducing patients' and the public's perspectives to health technology assessment: a systematic review of international experiences. Int. J. Technol. Assess. Health Care 27, 31-42. doi: 10.1017/S0266462310001315

Gamble, C., Dudley, L., Allam, A., Bell, P., Goodare, H., Hanley, B., et al. (2014). Patient and public involvement in the early stages of clinical trial development: a systematic cohort investigation. BMJ Open 4:e005234. doi: 10.1136/bmjopen-2014-005234

Ghisoni, M., Wilson, C. A., Morgan, K., Edwards, B., Simon, N., Langley, E., et al. (2017). Priority setting in research: user led mental health research. Res. Involve. Engage. 3:4. doi: 10.1186/s40900-016-0054-7

Gooberman-Hill, R., Horwood, J., and Calnan, M. (2008). Citizens' juries in planning research priorities: process, engagement and outcome. Health Expect 11, 272-281. doi: 10.1111/j.1369-7625.2008.00502.x

Green, G., and Johns, T. (2019). Exploring the relationship (and power dynamic) between researchers and public partners working together in applied health research teams. Front. Sociol. 4:20. doi: 10.3389/fsoc.2019.00020

Greenhalgh, T., Ovseiko, P. V., Fahy, N., Shaw, S., Kerr, P., Rushforth, A. D., et al. (2017). Maximising value from a United Kingdom biomedical research centre: study protocol. Health Res. Policy Syst. 15:70. doi: 10.1186/s12961-017-0237-1

Hailey, D., and Nordwall, M. (2006). Survey on the involvement of consumers in health technology assessment programs. Int. J. Technol. Assess. Health Care 22, 497-499. doi: 10.1017/S0266462306051427

Hewlett, S., Wit, M., Richards, P., Quest, E., Hughes, R., Heiberg, T., et al. (2006). Patients and professionals as research partners: challenges, practicalities, and benefits. Arthritis Rheum. 55, 676-680. doi: 10.1002/art.22091

Hickey, G., Brearley, S., Coldham, T., Denegri, S., Green, G., Staniszewska, S., et al. (2018). Guidance on Co-producing a Research Project. Southampton: INVOLVE.

Hogg, C. (1999). Patients, Power and Politics: From Patient to Citizens. London: Sage.

Howe, A., MacDonald, H., Barrett, B., and Little, B. (2006). Ensuring public and patient participation in research: a case study in infrastructure development in one UK research and development consortium. Primary Health Care Res. Develop. 7, 60-67. doi: 10.1191/1463423606pc269oa

Howe, A., Mathie, E., Munday, D., Cowe, M., Goodman, C., Keenan, J., et al. (2017). Learning to work together - lessons from a reflective analysis of a research project on public involvement. Res. Involve. Engage. 3:1. doi: 10.1186/s40900-016-0051-x

Husereau, D., Boucher, M., and Noorani, H. (2010). Priority setting for health technology assessment at CADTH. Int. J. Technol. Assess. Health Care 26, 341-347. doi: 10.1017/S0266462310000383

Hutchison, K., Rogers, W., and Entwistle, V. A. (2017). Addressing deficits and injustices: the potential epistemic contributions of patients to research. Health Care Anal. 25, 386-403. doi: 10.1007/s10728016-0323-5

INVOLVE (2012). Tip Sheets: Recruiting Members of the Public to Get Involved in Research Funding and Commissioning Processes. Available online at: http://www.invo.org.uk/wp-content/uploads/2012/04/Recruitmenttips-sheet.pdf (accessed July 9, 2018).

JLA (2018). James Lind Alliance Priority Setting Partnerships. Available online at: http://www.jla.nihr.ac.uk/news-and-publications/psp-articles-andpublications.htm (accessed July 9, 2018).

Lindenmeyer, A., Hearnshaw, H., Sturt, J., Ormerod, R., and Aitchison, G. (2007). Assessment of the benefits of user involvement in health research from the warwick diabetes care research user group: a qualitative case study. Health Expect 10, 268-277. doi: 10.1111/j.1369-7625.2007. 00451.x
Madden, M., and Speed, E. (2017). Beware zombies and unicorns: toward critical patient and public involvement in health research in a neoliberal context. Front. Sociol. 2:7. doi: 10.3389/fsoc.2017.00007

Manafò, E., Petermann, L., Vandall-Walker, V., and Mason-Lai, P. (2018). Patient and public engagement in priority setting: a systematic rapid review of the literature. PLoS ONE 13:e0193579. doi: 10.1371/journal.pone.0193579

Manikam, L., Shah, R., Reed, K., Santini, G., and Lakhanpaul, M. (2017). Using a co-production prioritization exercise involving South Asian children, young people and their families to identify health priorities requiring further research and public awareness. Health Expect 20, 852-861. doi: 10.1111/hex.12524

McCormick, S., Brody, J., Brown, P., and Polk, R., (2004). Public involvement in breast cancer research: an analysis and model for future research. Int. J. Health Services 34, 625-646. doi: 10.2190/HPXB-9RK8-ETVM-RVEA

Menon, D., and Stafinski, T. (2011). Role of patient and public participation in health technology assessment and coverage decisions. Expert Rev. Pharmacoecon. Outcomes Res. 11, 75-89. doi: 10.1586/erp.10.82

Minogue, V., Cooke, M., Donskoy, A.-L., Vicary, P., and Wells, B. (2018). Patient and public involvement in reducing health and care research waste. Res. Involve. Engage. 4:5. doi: 10.1186/s40900-018-0087-1

Minogue, V., and Girdlestone, J. (2010). Building capacity for service user and carer involvement in research: the implications and impact of best research for best health. Int. J. Health Care Qual. Assur. 23, 422-435. doi: 10.1108/09526861011037470

Moran, R., and Davidson, P. (2011). An uneven spread: a review of public involvement in the national institute of health research's health technology assessment program. Int. J. Technol. Assess. Health Care 27, 343-347. doi: $10.1017 /$ S0266462311000559

Morgan, L. J., Chambers, R., Banerji, J., Gater, J., and Jordan, J. (2005). Consumers leading public consultation: the general public's knowledge of stroke. Fam. Pract. 22, 8-14. doi: 10.1093/fampra/cmh709

Morris, C., Shilling, V., McHugh, C., and Wyatt, K. (2011). Why it is crucial to involve families in all stages of childhood disability research. Dev. Med. Child Neurol. 53, 769-771. doi: 10.1111/j.1469-8749.2011.03984.x

Morrow, E., Cotterell, P., Robert, G., Grocott, P., and Ross, F. (2013). Mechanisms can help to use patients' experiences of chronic disease in research and practice: an interpretive synthesis. J. Clin. Epidemiol. 66, 856-864. doi: 10.1016/j.jclinepi.2012.12.019

NIHR (2015). Going the Extra Mile: Improving the Nation's Health and Wellbeing Through Public Involvement in Research. Available online at: https://www.nihr. ac.uk/patients-and-public/documents/Going-the-Extra-Mile.pdf (accessed July 7, 2018).

NIHR BRCU (2017). NIHR Biomedical Research Centres and Units Annual Reports 2016/17. Available online at: https://www.nihr.ac.uk/about-us/how-we-aremanaged/managing-centres/nihr-central-commissioning-facility/ccf-ppi/ ppie-annual-reports.htm (accessed July 9, 2018).

NIHR CLAHRC (2017). Collaboration for Leadership in Applied Health Research and Care East of England. Patient and Public Involvement in Research Handbook. Available online at: http://www.clahrc-eoe.nihr.ac.uk/wp-content/ uploads/2018/01/CLAHRC-EoE-PPI-IN-Research-Handbook_December2017.pdf (accessed July 8, 2018).

Nilsen, E. S., Myrhaug, H. T., Johansen, M., Oliver, S., and Oxman, A. D. (2006). Methods of consumer involvement in developing healthcare policy and research, clinical practice guidelines and patient information material. Cochrane Database Syst. Rev. 3:Cd004563. doi: 10.1002/14651858.CD004563.pub2

O'Donnell, M., and Entwistle, V. (2004). Consumer involvement in decisions about what health-related research is funded. Health Policy 70, 281-290. doi: 10.1016/j.healthpol.2004.04.004

Oliver, S. (1996). The progress of lay involvement in the NHS research and development programme. J. Eval. Clin. Pract. 2, 273-280. doi: 10.1111/j.1365-2753.1996.tb00057.x

Oliver, S., Armes, D. G., and Gyte, G. (2009). Public involvement in setting a national research agenda: a mixed methods evaluation. Patient 2, 179-190. doi: 10.2165/11314860-000000000-00000

Oliver, S., Clarke-Jones, L., Rees, R., Milne, R., Buchanan, P., Gabbay, J., et al. (2004). Involving consumers in research and development agenda setting for the NHS: developing an evidence-based approach. Health Technol. Assess 8, 1-148, iii-iv. doi: $10.3310 /$ hta8 8150 
Oliver, S., and Gray, J. (2006). A Bibliography of Research Reports About Patients', Clinicians' and Researchers' Priorities for New Research. London: James Lind Alliance.

Oliver, S., Liabo, K., Stewart, R., and Rees, R. (2015). Public involvement in research: making sense of the diversity. J. Health Serv. Res. Policy 20, 45-51. doi: $10.1177 / 1355819614551848$

Oliver, S., Rees, R. W., Clarke-Jones, L., Milne, R., Oakley, A. R., Gabbay, J., et al. (2008). A multidimensional conceptual framework for analysing public involvement in health services research. Health Expect. 11, 72-84. doi: 10.1111/j.1369-7625.2007.00476.x

Parsons, S., Thomson, W., Cresswell, K., Starling, B., and McDonagh, J. E. (2017). What do young people with rheumatic disease believe to be important to research about their condition? a UK-wide study. Pediatr. Rheumatol. Online J. 15:53. doi: 10.1186/s12969-017-0181-1

Paylor, J., and McKevitt, C. (2019). The possibilities and limits of "Co-producing" research. Front. Sociol. 4:23. doi: 10.3389/fsoc.2019.00023

PCORI (2018). How We Select Research Topics. Available online at: https://www. pcori.org/research-results/about-our-research/how-we-select-research-topics (accessed July 9, 2018).

Pittens, C. A. C. M., Elberse, J. E., Visse, M., Abma, T. A., and Broerse, J. E. W. (2014). Research agendas involving patients: Factors that facilitate or impede translation of patients' perspectives in programming and implementation. Sci. Public Policy 41, 809-820. doi: 10.1093/scipol/scu010

Pramesh, C. S., Venkataramanan, R., Suvarna, V., Goel, N. S., Lakshman, S., Venkatesh, V., et al. (2016). Involvement of general public in biomedical research. Perspect. Clin. Res. 7, 152-155. doi: 10.4103/2229-3485.192029

Pratt, B., Merritt, M., and Hyder, A. A. (2016). Towards deep inclusion for equityoriented health research priority-setting: a working model. Soc. Sci. Med. 151, 215-224. doi: 10.1016/j.socscimed.2016.01.018

Rawson, T. M., Castro-Sanchez, E., Charani, E., Husson, F., Moore, L. S. P., Holmes, A. H., et al. (2018). Involving citizens in priority setting for public health research: implementation in infection research. Health Expect. 21, 222-229. doi: 10.1111/hex.12604

Resnik, D. (2001). Setting biomedical research priorities: justice, science, and public participation. Kennedy Inst. Ethics J. 11, 181-204. doi: 10.1353/ken.2001.0017

Rhodes, P., Nocon, A., Booth, M., Chowdrey, M. Y., Fabian, A., Lambert, N., et al. (2002). A service users' research advisory group from the perspectives of both service users and researchers. Health Soc. Care Commu. 10, 402-409. doi: $10.1046 / j .1365-2524.2002 .00376 . x$

Ridley, J., Jones, L., and Scottish Health Feedback. (2002). User and Public Involvement in Health Services: A Literature Review. Edinburgh: Project Report. NHS Scotland/Scottish Executive.

Rikkers, W., Boterhoven de Haan, K., Lawrence, D., McKenzie, A., Hancock, K., Haines, H., et al. (2015). Two methods for engaging with the community in setting priorities for child health research: who engages? PLOS ONE 10:e0125969. doi: 10.1371/journal.pone.0125969

Royle, J., and Oliver, S. (2004). Consumer involvement in the health technology assessment program. Int. J. Technol. Assess. Health Care 20, 493-497. doi: $10.1017 /$ S0266462304001412

Shah, S. G., and Robinson, I. (2007). Benefits of and barriers to involving users in medical device technology development and evaluation. Int. J. Technol. Assess. Health Care 23, 131-137. doi: 10.1017/S0266462307051677

Sheaff, R., Charles, N., Mahon, A., Chambers, N., Morando, V., Exworthy, M., et al. (2015). NHS commissioning practice and health system governance: a mixedmethods realistic evaluation. Health Serv. Deliv. Res. 3. doi: 10.3310/hsdr03100

Shippee, N. D., Domecq Garces, J. P., Prutsky Lopez, G. J., Wang, Z., Elraiyah, T. A., Nabhan, M., et al. (2015). Patient and service user engagement in research: a systematic review and synthesized framework. Health Expect 18, 1151-1166. doi: $10.1111 /$ hex. 12090
Simpson, S., Cook, A., and Miles, K. (2018). Patient and public involvement in early awareness and alert activities: an example from the United Kingdom. Int. J. Technol. Assess. Health Care 34, 10-17. doi: 10.1017/S0266462317004421

Slutsky, J., Tumilty, E., Max, C., Lu, L., Tantivess, S., Hauegen, R. C., et al. (2016). Patterns of public participation: opportunity structures and mobilization from a cross-national perspective. J. Health Organ. Manag. 30, 751-768. doi: 10.1108/JHOM-03-2016-0037

Smith, E., Ross, F., Donovan, S., Manthorpe, J., Brearley, S., Sitzia, J., et al. (2008). Service user involvement in nursing, midwifery and health visiting research: a review of evidence and practice. Int. J. Nurs. Stud. 45, 298-315. doi: 10.1016/j.ijnurstu.2006.09.010

Smith, E., Ross, F. M., Mackenzie, A., and Masterson, A. (2005). Developing a service-user framework to shape priorities for nursing and midwifery research. J. Res. Nurs. 10, 107-118. doi: 10.1177/136140960501000101

Snape, D., Kirkham, J., Britten, N., Froggatt, K., Gradinger, F., Lobban, F., et al. (2014). Exploring perceived barriers, drivers, impacts and the need for evaluation of public involvement in health and social care research: a modified Delphi study. BMJ Open 4:e004943. doi: 10.1136/bmjopen-2014004943

Staley, K. (2009). Exploring Impact: Public Involvement in NHS, Public Health and Social Care Research. Eastleigh: INVOLVE.

Staniszewska, S., Adebajo, A., Barber, R., Beresford, P., Brady, L.-M., Brett, J., et al. (2011). Developing the evidence base of patient and public involvement in health and social care research: the case for measuring impact. Int. J. Consum. Stud. 35, 628-632. doi: 10.1111/j.1470-6431.2011.01020.x

Supple, D., Roberts, A., Hudson, V., Masefield, S., Fitch, N., Rahmen, M., et al. (2015). From tokenism to meaningful engagement: best practices in patient involvement in an $\mathrm{EU}$ project. Res. Involve. Engage. 1:5. doi: 10.1186/s40900-015-0004-9

Thompson, J., Barber, R., Ward, P. R., Boote, J. D., Cooper, C. L., Armitage, C. J., et al. (2009). Health researchers' attitudes towards public involvement in health research. Health Expect 12, 209-220. doi: 10.1111/j.1369-7625.2009.00532.x

Tong, A., Chando, S., Crowe, S., Manns, B., Winkelmayer, W. C., Hemmelgarn, B., et al. (2015). Research priority setting in kidney disease: a systematic review. Am. J. Kidney Dis. 65, 674-683. doi: 10.1053/j.ajkd.2014.11.011

Truitt, A. R., Monsell, S. E., Avins, A. L., Nerenz, D. R., Lawrence, S. O., Bauer, Z., et al. (2018). Prioritizing research topics: a comparison of crowdsourcing and patient registry. Qual. Life Res. 27, 41-50. doi: 10.1007/s11136-017-1566-9

van Bekkum, J. E., Fergie, G. M., and Hilton, S. (2016). Health and medical research funding agencies' promotion of public engagement within research: a qualitative interview study exploring the United Kingdom context. Health Res. Policy Syst. 14:23. doi: 10.1186/s12961-016-0093-4

Viswanathan, M., Ammerman, A., Eng, E., Garlehner, G., Lohr, K. N., Griffith, D., et al. (2004). Community-based participatory research: assessing the evidence. Evid. Rep. Technol. Assess. (Summ). 99:1-8. doi: 10.1037/e439622005-001

Willis, K. (1995). Imposed structures and contested meanings: Policies and politics of public participation. Austr. J. Soc. Issues. 30, 211-227. doi: 10.1002/j.1839-4655.1995.tb01036.x

Conflict of Interest Statement: The authors declare that the research was conducted in the absence of any commercial or financial relationships that could be construed as a potential conflict of interest.

Copyright $\odot 2019$ Tembo, Morrow, Worswick and Lennard. This is an open-access article distributed under the terms of the Creative Commons Attribution License (CC $B Y)$. The use, distribution or reproduction in other forums is permitted, provided the original author(s) and the copyright owner(s) are credited and that the original publication in this journal is cited, in accordance with accepted academic practice. No use, distribution or reproduction is permitted which does not comply with these terms. 


\title{
Plain English Summary \\ Dilemmas of Ethics in Practice in Longitudinal Health Research: Identifying Opportunities For Widening Participation of Residents
}

\author{
Rhian Twine, Gillian A. Hundt, Kathleen Kahn
}

It is important to understand how health research over long periods of time in the same population affects those involved. In this study we recorded the views of residents, health service providers and local and foreign researchers. The research focused on 31 villages in an under-developed rural area of South Africa which had been strongly affected by apartheid. There are some signs of development with better access to schooling, water, electricity and shops. However, employment remains low.

Research in this study area started in 1992 with the goal of generating health and population data to inform district health systems policy and planning. Information about the characteristics of the entire population of 120000 people is updated annually. More recently, other studies such as testing of health service interventions have been carried out in the same study area. More effort has been put into meaningful engagement with the people taking part in research and trying to see that they benefit.

We held group discussions and had individual interviews with 80 residents, 56 local leaders and health service providers. We also asked for written reflections from 11 researchers. The topics that we were interested in, determined as important through analysis of our fieldnotes, were:

- Informed consent. For example, why do participants agree to take part in research even when they don't really understand what the research will involve?

- Feeding back personal results from medical screening tests to each individual research participant.

Our results showed that the people taking part in the health research had to sign multiple consent forms in order to be included in the research. We found that they often did not understand the research. We learnt that we need to put more effort and time into training of our fieldworkers so that they fully understand the research project. Standardised training and clear guidelines for researchers about how to train and monitor fieldworkers are needed.

Those taking part in the research were clear that individual results from screening tests should be delivered personally or at the time of doing the test. Researchers agreed that this was important, and that they needed to plan how to do, and pay for, this activity and include these costs in the study budget. We also learnt that we need to think more about our employment plans - for example, employing female fieldworkers to interview females if sensitive issues are discussed.

All the people taking part said that activities to encourage earlier involvement of local residents might prevent some of the problems that arise during research, such as rumours regarding the reasons for collection of blood samples, and high refusal rates. Earlier involvement of those taking part in the research may help to ensure that researchers are accountable, and that residents receive full benefit from research. 


\section{OPEN ACCESS}

Edited by:

Annette Louise Boaz, Kingston University, United Kingdom

Reviewed by: Simone Louise Sherriff, Sax Institute, Australia Dorcas Kamuya KEMRI Wellcome Trust Research

Programme, Kenya

*Correspondence: Rhian Twine rhian.twine@wits.ac.za

Specialty section: This article was submitted to

Medical Sociology,

a section of the journal

Frontiers in Sociology

Received: 09 October 2018 Accepted: 03 April 2019

Published: 25 April 2019

Citation:

Twine R, Lewando Hundt $G$ and Kahn K (2019) Dilemmas of Ethics in

Practice in Longitudinal Health Research: Identifying Opportunities for Widening Participation of Residents.

Front. Sociol. 4:33.

doi: 10.3389/fsoc.2019.00033

\section{Dilemmas of Ethics in Practice in Longitudinal Health Research: Identifying Opportunities for Widening Participation of Residents}

\author{
Rhian Twine ${ }^{1 *}$, Gillian Lewando Hundt ${ }^{1,2}$ and Kathleen Kahn ${ }^{1,3,4}$ \\ ${ }^{1}$ MRC/Wits Rural Public Health and Health Transitions Research Unit (Agincourt), School of Public Health, Faculty of Health \\ Sciences, University of the Witwatersrand, Johannesburg, South Africa, ${ }^{2}$ Division of Health Sciences, Warwick Medical \\ School, University of Warwick, Coventry, United Kingdom, ${ }^{3}$ INDEPTH Network, Accra, Ghana, ${ }^{4}$ Epidemiology and Global \\ Health Unit, Department of Public Health and Clinical Medicine, Umeå University, Umeå, Sweden
}

Background: Mechanisms for widening participation of local participants in research studies can improve governance of public health research. Research conducted in longitudinal health study areas depends on there being mutual trust and respect over time between the local residents and researchers. Ethics in practice needs consideration alongside procedural ethics. By widening participation of the experimental public-local residents and resident service providers-ethics in practice and accountability are strengthened.

Methods: The study was undertaken in a longitudinal health study area in rural South Africa using multiple qualitative methods. The sample included 35 individual and five group interviews with resident local leaders and service providers, 24 individual and eight group interviews with residents of the study area, and ten researchers' reflections on two critical incidents from ethnographic field notes on dilemmas of ethics in practice. The interviews were all audio-recorded (besides one where consent to record was not given) and then transcribed verbatim and translated from Shangaan into English. Thematic analysis was conducted.

Results: Residents requested the reporting back of personal screening test results from research studies, and raised informed consent issues. Researchers recognized the importance of mechanisms to increase their accountability to residents throughout the research process, and the complexity of informed consent and fieldwork procedures within research studies.

Conclusion: This study elicited the views of residents and researchers in a longitudinal health study area to seek guidance on how to strengthen participation in research governance. Three strategies were identified by participants to widen participation of the experimental public. Firstly, increasing study budgets so that individual screening test results could be personally delivered back to participants. Secondly, more rigorous field staff training in informed consent and study procedures with ongoing monitoring and supervision from researchers. Thirdly, increased earlier involvement of residents in research protocol development through study advisory groups. Additional 
strategies include deeper involvement of Community Advisory Groups and more focused dissemination of research results to specific audiences. In general, there is a need to identify strategies for increased accountability of researchers and participatory governance through involvement of the experimental public in all aspects of longitudinal public health research as part of the ethics in practice and democratization of science.

Keywords: ethics in practice, longitudinal health research, widening participation, informed consent, returning individual results

\section{LAY SUMMARY}

This paper is an analysis of the views residents, service providers, and local and foreign researchers had about being involved in health research in one study area over a long period of time. It is important to understand how long term health research over long periods of time in the same population affects those involved. In this study we recorded the views of residents, service providers, and local and foreign researchers involved in health research in 31 villages in an under-developed rural area of South Africa strongly affected by the legacy of apartheid. There are some signs of development with better access to schooling, water, electricity, and shops. However, employment remains low.

Research in this study area started in 1992 to generate health and population data to inform decentralized district health systems development, policy, and planning. Health and sociodemographic information about the entire population of 120,000 people is updated annually. More recently, other studies such as testing of health service interventions have been carried out in the same study area. More effort has been put into involving research participants in research, and trying to see that they get fair benefit.

To this end we held group discussions and had individual interviews with residents, local leaders and service providers. We also asked for written reflections from researchers. The table below shows who we gathered information from:

\begin{tabular}{lclc}
\hline & $\begin{array}{c}\text { Individual } \\
\text { interviews }\end{array}$ & $\begin{array}{l}\text { Group } \\
\text { discussions }\end{array}$ & $\begin{array}{c}\text { Written } \\
\text { reflections }\end{array}$ \\
\hline Residents & 24 & $\begin{array}{l}56 \text { participants in } \\
8 \text { groups }\end{array}$ & \\
$\begin{array}{l}45 \text { participants in } \\
\text { vervice providers and }\end{array}$ & 11 & 5 groups & \\
Researchers & & 11 & 11 \\
\hline
\end{tabular}

The topics that we were interested in, determined as important through analysis of ethnographic fieldnotes, were:

- Informed consent, for example, why participants agree to participate in research even when they don't really understand what the research will involve

- Feeding back personal results from medical screening tests to each individual research participant.

Our results showed that health research participants needed to agree to sign multiple consent forms in order to be included in the research. We found that residents often did not understand the research. We learnt that we need to put more effort and time into training of our fieldworkers so that they fully understand the research project. Standardized training and clear guidelines for researchers about how to train and monitor fieldworkers are needed.

Participants were clear that individual results from screening tests should be delivered personally or at the time of doing the test. Researchers agreed that this was important, and that they needed to plan how to do, and pay for, this activity and include these costs as an integral part of the study budget. We also learnt that we need to think more about our employment strategiesfor example, employing female fieldworkers to interview females if sensitive issues are discussed.

All participants said that activities to encourage earlier involvement and widening participation of local residents throughout the research process might prevent some of the problems that arise during research, such as rumors regarding the reasons for collection of blood samples, and consequent high refusal rates. These may help to ensure that researchers are accountable, and that residents receive full benefit from research.

\section{INTRODUCTION}

Research conducted in health and demographic surveillance systems (HDSSs), aims to provide information that allows health policy makers and planners to deliver better health services for their populations (INDEPTH, 2012). These longitudinal centers are mostly in resource poor areas, and it is important to ensure that fair benefit of the research is considered at the local level. Public engagement activities in these centers build partnerships with local residents and service providers and support the ethical conduct of research in the field (Participants in the 2001 Conference on ethical aspects of research in developing countries, 2002; Tindana et al., 2007; Lairumbi et al., 2011; Allotey et al., 2014; Simwinga et al., 2018).

Guillemin and Gillam (2004) have suggested that ethics in practice (dealing with situations occurring during field research), needs consideration alongside procedural ethics (theory and regulatory board requirements). These situations can be called "ethically important moments" (Guillemin and Gillam, 2004: p.266), and involve "critical reflection both on the kind of knowledge produced from research and how that knowledge is generated" (Guillemin and Gillam, 2004: p. 274). Researchers working in African HDSS sites have pointed out that consideration of different cultural and social world views between participants and themselves is crucial (Duombo, 2005; Molyneux 
and Bull, 2013). Actions taken to alleviate these situations can lead to more nuanced and enlightened ethical theory (Guillemin and Gillam, 2004). Geissler and Molyneux (2011) utilize the term "ethos" of medical research to distinguish this type of socio-political approach to ethics in practice, which draws on sociology and anthropology in relation to a contextual approach and reflexivity in the field.

Part of ethics in practice is the important issue of fair benefit to research participants. The challenge of what is fair benefit from research has received increasing attention. The International Ethical Guidelines for Biomedical Research Involving Human Subjects, with specific reference to research in resource poor countries, state that "Before instituting a plan to undertake research in a population or community in low-resource settings, the sponsor, researchers, and relevant public health authority must ensure that the research is responsive to the health needs or priorities of the communities or populations where the research will be conducted ... and ... also make every effort, in cooperation with government and other relevant stakeholders, to make available as soon as possible any intervention or product developed, and knowledge generated, for the population or community in which the research is carried out" (CIOMS, 2016: p. 3). In their systematic review of nine African and seven international ethics guidelines, Lairumbi et al. (2011) found that half of the guidelines specifically discussed benefits to participants, communities and to society in general, both during and after research studies. There was considerable variation between the guidelines regarding how much responsibility researchers should have for giving benefit, as well as what these benefits might be. While there have been gains in developing ethical guidelines for health research in resource poor areas, this lack of consensus could result in different interpretations and practices regarding ensuring fair benefit from research (Nuffield Council on Bioethics, 2002; Participants in the 2001 Conference on ethical aspects of research in developing countries, 2002; Lairumbi et al., 2011; Molyneux et al., 2012).

Feeding back biomedical results that might have an impact on the health needs of individual research participants is a controversial topic that can be included in ethics in practice. Giving back results is part of the ethical imperatives of respect for person, reciprocity, beneficence, and justice (Shalowitz and Miller, 2005; Bledsoe et al., 2012), and can foster a positive attitude toward health research. Those against giving individual results argue that specimens should be given for the good of science and mankind and results might cause harm if they have not been validated, or tracking has not been adequate and the wrong result is returned (Bledsoe et al., 2012). However, in their review of articles published prior to 2005, Shalowitz and Miller (2005) found that there were very few reports of such harm, and most individuals found their test results beneficial. There is also a concern that giving back individual biomedical results might lead to "therapeutic misconception" (Appelbaum et al., 1987). This term alludes to participant's possible confusion between research and medical care and has been documented (Molyneux et al., 2005; Tekola et al., 2009). There may also be difficulties in deciding what is a "clinically relevant" result and whether only results that indicate a condition for which care can be locally obtained be returned (Murphy et al., 2008). There is an additional concern regarding cost, as giving back of individual results adds to project budgets (Bledsoe et al., 2012).

International public health research has been viewed as being carried out on "experimental publics" (Kelly et al., 2016; Montgomery and Pool, 2017; Twine et al., 2017). This term has been applied in recent public health literature to the research population in clinical trials or in this case in a health surveillance study area. The term is used as the research participants are defined by the research design and do not form a community with administrative and geographical boundaries for other purposes. In longitudinal health surveillance sites, there are regular, often more than annual updates of individual and household demographic data, Geographical Information System maps of villages, and specific smaller, nested research studies (Ye et al., 2012). Ethics in practice when working with experimental publics in these settings is particularly critical, so that vital processes of research governance which consider and include the participation and views of local residents are routinized (Nuffield Council on Bioethics, 2002; Kamuya et al., 2013; MacQueen et al., 2015).

In their work in rural Kenya and South Africa, Molyneux et al. (2009) emphasized that the relationships with fieldworkers who are locally recruited are ongoing before, during and after the research are a factor in ethics in practice. Given that in most HDSSs, there may be inequities between the researchers and locals, Emmanuel et al. suggest that considerable attention needs to be given to finding avenues to create collaborative partnerships between these parties. These partnerships allow for discussion and resolution of dilemmas, in a manner that allows different points of view to be heard, and compromises to be negotiated (Emmanuel et al., 2004).

Key to partnerships between the researcher and participants is the relationship between the field worker and the participant (Molyneux et al., 2013; Kamuya et al., 2015), which starts with informed consent. While individual informed consent is seen as a prerequisite in procedural ethical reviews, it has complexities in execution. These include how field workers understand the research processes, how they explain the methodology, how household dynamics play themselves out, local cultural beliefs, how the participants understand the information, what information is included and how the final decision is made, communicated and influenced (Tekola et al., 2009; Kamuya et al., 2015). Matters influencing the final decision can include attributes of the field worker such as whether he/she is known to the participant, age or gender disparities between the fieldworker and the participant, the real or perceived benefits from participating in the study and the level of trust placed in the researchers/research institution. In poorly resourced settings, with few opportunities for health care, decisions to participate in research may be taken in the hope that despite being informed otherwise, care might be given (Molyneux et al., 2005).

Increasingly, public engagement and participation in research is being called for at all stages of the research process, from design, through fieldwork planning, and implementation, to monitoring and analysis and distribution of results in guidelines 
on good fieldwork practice (South African Department of Health, 2007; UNAIDS/WHO, 2007; HPTN, 2009; UK National Institute for Health Research, 2014). Literature on public participation in science recognizes that data collection is dependent on the willingness of people to not only participate in research by answering questions and giving of their time but also sharing their local expertise and knowledge (Fortmann, 2014). Public participation in science, especially in research governance is related to civic science (Bäckstrand, 2003; Levine, 2011) and the idea that science, and health, are public goods. The notion of access to health care as a human right and as such a public good, is upheld both by the UN Universal Declaration of Human Rights-Article 25 (United Nations, 1948) - and in three sections of the South African Constitution (South African Government, 1996). The focus of this paper is on participation of the experimental public in research governance processes and will make a contribution to the growing literature on ethics in practice (Guillemin and Gillam, 2004) in longitudinal health study areas.

\section{RESEARCH DESIGN}

\section{Setting}

This study was conducted in the Agincourt Health and SocioDemographic Surveillance System (Agincourt HDSS) study area, hosted by the MRC/Wits Rural Public Health and Health Transitions Research Unit (Agincourt) (MRC/Wits-Agincourt Unit) in the rural Bushbuckridge Municipal sub-district of Mpumalanga Province, South Africa. Established in 1992, the original aim was to contribute to developing decentralized district health systems. The area is situated in the former Mhala District of the Gazankulu "homeland" formed during the apartheid years. These areas, under self-rule but not independent, suffered limited development and poor investment in health, infrastructure and education (Niehaus et al., 2001). In 1994, South Africa held its first democratic elections, and a new democracy was born. Under this new system, over a period of time, the area was renamed Bushbuckridge. The area is situated $500 \mathrm{~km}$ north east of Johannesburg, and is still characterized by high unemployment, with high rates of labor migration and a legacy of the apartheid system of forced labor migration. Poor education standards persist and, although infrastructure has seen some considerable development since 1994, there are still poor roads and limited water supply (Kahn et al., 2012; Collinson et al., 2014). Annual health and socio demographic census updates have been conducted with the 116,500 people residing in 21300 households in the 27 adjacent villages in the Agincourt HDSS since 1992. Updates include information on births, deaths, in and out migration, education and socio-economic status, family structure and various, scheduled updates on, for example, food security, and health care utilization.

Despite an increased focus on access to health care postapartheid, access remains inequitable in South Africa (Harris et al., 2014). Findings from the Agincourt HDSS and its nested studies, particularly those that indicate rapid health, social, and demographic transitions, contribute to health policy and planning (Tollman, 2008). The objectives of the MRC/WitsAgincourt Unit have expanded to include reasons for, and dynamics of, these transitions, deepening observational work through cohort studies. The unit also conducts intervention studies with cross-site collaboration, and produces public access datasets, with the goal of mounting more effective public health, public sector and social responses (Kahn et al., 2012).

The work of the MRC/Wits-Agincourt Unit is collaborative, international and the boundaries of the work are global. It is one of the few HDSS sites worldwide that is led by an academic institution based in the host country. Other research studies, including trials, observational, and intervention studies, run by local and international collaborators have been nested in the Agincourt HDSS using the HDSS dataset for sampling (Gómez-Olivé et al., 2013; Thorogood et al., 2014; Pettifor et al., 2016; Gaziano et al., 2017). Although most projects are still internationally sponsored, there are growing numbers of South African principal investigators, and South African and African project managers working in the site. In 2018, there were 30 nested studies at various stages of which nine were led by international collaborators, 13 South African led and eight jointly led (Figure 1).

All projects based in the MRC/Wits-Agincourt HDSS can be classified as community-based, and public engagement is intrinsic to such research. A Public Engagement Office (PEO) was formally started in 2004, to formalize and expand previous public engagement activities. RT leads this office. The PEO works with Principal Investigators and project managers of studies, keeping investigators alert to ethics in practice issues. There is a Community Advisory Group (CAG) consisting of one person elected by the Community Development Forum (CDF) of each village that meets monthly. Smaller study advisory groups, comprising eight randomly selected CAG members are formed for most nested studies. There are village-based meetings and targeted briefings with traditional and civic village leaders, local, district, and provincial governmental and relevant non-governmental service providers, before a study commences to discuss the upcoming project, and at its conclusion to disseminate results (Twine et al., 2017).

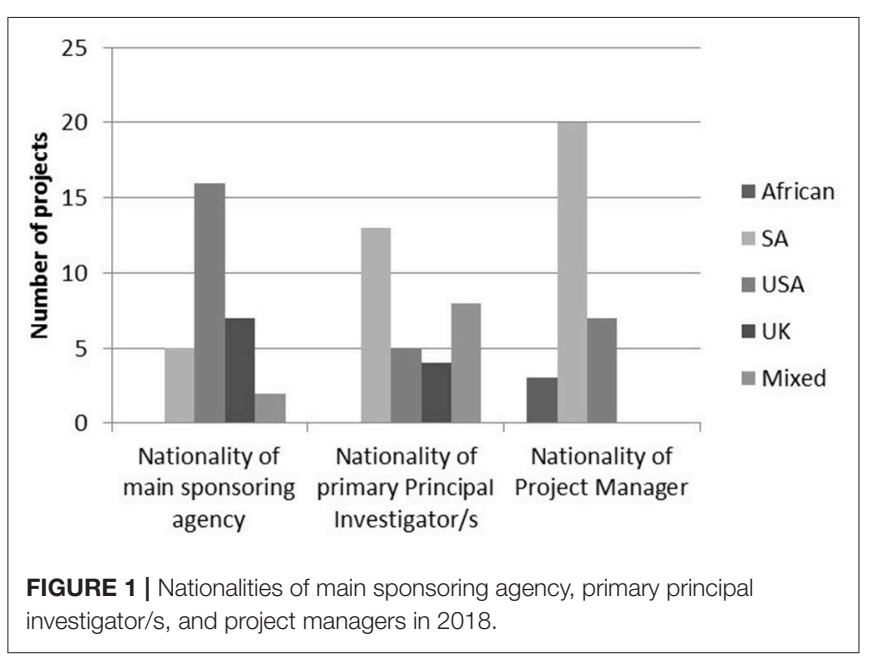




\section{Study Procedures}

This is a case study using multiple qualitative methods that included semi-structured individual, focus group and natural group interviews, ethnographic field notes, and critical incident scenarios (Crisp et al., 2005). The semi-structured individual, natural group, and focus group interviews were conducted with village residents, local leaders, and service providers all from within the study area. These interviews explored their experiences of being involved in the activities of the longitudinal research site. Interview guides were field-tested with the Community Advisory Group. Natural group interviews are group discussions that occur with people forming an existing group so all the participants know each other. Generally, they are based round a shared interest (Beckerleg et al., 1997; Green and Thorogood, 2009). Group interviews with resident groups were natural group interviews but the group interviews with village leaders and home-based carers were focus group interviews.

To recruit village residents, two villages with diverse characteristics were chosen-one far from and one close to the MRC/Wits-Agincourt Unit offices, one with a large and one a small population, and one with a higher and one a lower average household socio-economic status. A table outlining how many participants were needed from each village, ensuring gender and spread across three age groups (18-24, 25-49, and 50+ years). The fieldworkers recruited door-to-door until there were 24 eligible participants. None of the participants were known to the fieldworkers previously. Eight natural group interviews were also conducted with an average of ten participants in each group. Natural groups were made up of: older men who were assistants to the village chief and a group of cattle herders; younger men in a soccer team and in a traditional dance team; older women attending church or who drank tea together; younger women from a church group or a traditional dance team (Table 1). Interviews were conducted by two local, Shangaan speaking fieldworkers in 2016, at participant's homes or other locations of their choosing, and no one apart from the participants and the fieldworkers were present. To avoid socially desirable responses, the interviewers were trained to encourage critical views by explaining that only through these can practice be improved. The reasons for the research were also outlined in the consent form.

A purposive sample of 56 local leaders and service providers was selected from individuals working within organizations involved in governance or service provision at the village and sub-district level, and who were also resident in the study area. Some of these participants knew RT prior to the interviews. Recruitment and logistical arrangements were telephonic. There were 45 participants in the focus group interviews and 11 in individual interviews. Two representatives from village

TABLE 1 | Research participants living within the study area - "residents."

\begin{tabular}{lcl}
\hline & Individual interviews & Group interviews \\
\hline Local village residents & 24 & $\begin{array}{l}56 \text { participants in } 8 \\
\text { groups } \\
45 \text { participants in } 5\end{array}$ \\
$\begin{array}{lll}\text { Service providers and village } \\
\text { leaders resident in the area }\end{array}$ & 11 & groups
\end{tabular}

leadership from each of the 23 villages that had been involved in the HDSS for over 10 years, participated in four focus group interviews of between eight to eleven participants and the managers of eight home-based care organizations participated in another focus group interview (Table 1). Representatives from the traditional councils and municipalities, clinic, and education managers were all interviewed individually. The participants were aged between 25 and 70 years, and were balanced by gender. RT conducted these interviews and the natural group interviews along with a fieldworker in 2015/16. Interviews were undertaken in a venue in the village chosen by the participants, and no-one was present aside from the researchers and the participants.

Data from residents' interviews were analyzed by RT in 2018 focusing on ethics in practice. The emergent themes were informed consent, collection of body tissue samples, confidentiality, adverse events, referral vs. health care provision, end of study withdrawal and benefits such as the HDSS providing employment.

RT took field notes on ethics in practice incidents in the study area during 2015-2017. The purpose of these field notes was to capture and reflect through "thick description" (Geertz, 1973) on "ethically important moments" (Guillemin and Gillam, 2004: p. 266). In 2018, three critical incident scenarios (Crisp et al., 2005) were selected from the field notes depicting situations illustrating the ethics in practice issues that local residents had raised. They were on informed consent, giving back of individual screening results and adverse events. In this paper two are being used. All three scenarios were sent electronically to 10 purposively selected researchers who had been involved in nested studies in the Agincourt HDSS. The criteria for their selection were that they had worked within the study area on a nested study within the last 3 years and equal representation was given to researchers from South Africa and external to South Africa. The ten individuals included: principal investigators, research managers, project site managers, and project coordinators (Table 2). Any researcher who was employed by the HDSS was excluded; this involved 4 men and 1 woman. The researchers who met the criteria included 8 female and 2 male researchers. Gender was not a consideration in the selection of the sample, rather the focus was on having carried out research in the study area within the time period and not being an employee. All the researchers responded with reflections and comments. The case studies were anonymised so that the

TABLE 2 | Senior researchers and senior field staff responding to critical incidents-"researchers."

\begin{tabular}{lccc}
\hline & $\begin{array}{c}\text { Permanent } \\
\text { resident or } \\
\text { citizen in } \\
\text { South Africa }\end{array}$ & International & Total \\
& 1 & 4 & 5 \\
\hline $\begin{array}{l}\text { Senior researchers-principal } \\
\text { investigators and project managers }\end{array}$ & 4 & 1 & 5 \\
$\begin{array}{l}\text { Senior field staff-project site } \\
\text { managers and project coordinators }\end{array}$ & 5 & 5 & 10 \\
\hline Total & & &
\end{tabular}


study was not identified, and as the researchers were sent the scenarios electronically and replied individually, there was no known sharing of reflections.

Participants were given 2 weeks to reflect on the scenarios and respond to two questions: "Describe how you would have taken action (if any) if you were in the research team involved" and "What issues does this scenario raise regarding ethics in practice (ethical issues that arise during fieldwork)?"

\section{Analysis}

All interviews were digitally recorded with the exception of one interview where the participant refused and field notes were taken. The recordings were translated and transcribed from Shangaan into English by the local fieldworkers. Transcripts were not returned to participants for comment as they had been transcribed directly from Shangaan recordings into English. Selected transcripts and questionnaires were read in full by RT and $\mathrm{GH}$ independently in order to identify emergent themes for the initial coding, which was both deductive following the topic guide and inductive in terms of emergent themes within the topics and in addition to the topics. QSR NVivo software (version 10) was used for the coding of interviews with residents. RT undertook manual thematic analysis for the data from researchers.

\section{Ethics Approval and Consent}

Ethical clearance was obtained from the University of the Witwatersrand's Human Research Ethics Committee (Medical) (Certificate numbers M140361 and M140737) and permission for interviewing service providers obtained from both the Mpumalanga Provincial Departments of Health and Education Research Offices. Written informed consent was gained from all participants prior to data collection.

\section{RESULTS}

\section{Informed Consent}

All interviewed residents had been participants in the annual HDSS census update and in various nested research projects, and reflected on their experiences of informed consent. Some residents mentioned that the process had been clear and that they had known what they were agreeing to, but there were instances where a resident, or a family member who had been approached to be a study participant, had not understood fully what agreeing to participate in the study involved.

\footnotetext{
"If you don't understand, the field workers give you a chance to say that. They say that participating is voluntarily. You are allowed to say no. Even during the interview, they allow you to stop if you are not comfortable with their research." Middle aged man 3, village 1

"The problem is that they don't say what is going to happen at the research laboratory. My grandmother was supposed to know what will happen to her. She needed to have more information." Young woman 2, village 1
}

Although some residents said that they had understood the reasons for the research, others said they had not. Residents also spoke about instances when they had asked the field workers questions about the reasons for the research, and the field workers themselves did not know.

"I don't have a problem with these questions as the one who came explained everything. They were checking whether we are eating modern food only and not cultural food. That's why they are asking all these questions." Older man 8, NGI village 2

"I don't want to be asked questions about food as they won't give me money to buy food afterwards. The problem is that they don't tell us why they are asking these questions. All they say is that they are working." Older man 4, NGI village 2

The majority of the residents described a high level of trust in the field workers employed in the MRC/Wits-Agincourt Unit, referred to as "Wits" locally. They said that the field workers were well trained and respectful.

\footnotetext{
"They introduce themselves and they ask for your time. Though the research questions are not good, the field workers are respectful." Older man 4

"When they approach your gate they are smiling, they greet you and they will introduce themselves, telling you where they come from. They will ask for your permission to work and afterwards they will say thank you." Older man 1, NGI village 2

"If I have problems and I don't have someone to share my problems with, I can share with Wits people, particularly when that study is related to my problems." Middle aged woman I, village 2
}

The signing of consent forms without understanding the implications was raised as an issue for older participants. Owing to a high level of trust and respect for the field workers, residents thought that older people sometimes agreed to answer the questions even if they did not fully understand the reasons for the study.

\begin{abstract}
"Yes we understand most of the information on the informed consent. Some read it and sign with understanding. But with old people I think they don't understand everything it would be better if you read it when there is a relative there who can understand what you are saying. Old people will agree to anything as a sign of respect although they didn't understand. I think your field workers need to take their time in the field." Middle aged woman 1 , village 2
\end{abstract}

Residents did talk about particular instances where they felt uncomfortable divulging confidential information to young field workers on sensitive issues such as the nested research studies on aging which have sexual behavior questionnaires that include topics such as frequency of having sex, multiple sexual partners, and contraception. Disclosing details about intimate sexual behavior with a young person was considered inappropriate and there were some doubts about confidentiality.

\footnotetext{
"In our culture we were taught that you talk about sex in your bedroom with your partner. But with Wits, they send a young girl to an old person to ask those questions. We don't know whether they are going to keep the secrets as we don't know them. We used to lie." Young woman 1, village 1
} 
As informed consent was a key concern to interviewees, the critical incident scenario in Box 1, summarized from RT's field notes was sent to 10 researchers.

Researchers' responses to this situation were that it is a complicated situation that has implications for the participant and the family, the study itself and for future nested studies in the longitudinal study area.

"Firstly, there is need to protect the study from possible withdrawal by the participant and other participants which would affect other studies of the Unit. Secondly there is need to protect the life of the young girl by ensuring that she gets all the necessary clinical and family care. Thirdly there is need to protect the family from possible conflicts and disintegration." Senior Field Staff 2

Researchers talked about field workers, despite being trained, being under pressure and taking shortcuts in order to meet targets.

\begin{abstract}
"This brings up two issues. The first is the field worker violating protocol. Unfortunately, this happens despite careful training and a detailed protocol. Situations arise that are not straightforward (this situation is unlikely something the fieldwork team had discussed or planned for) and field workers do not always make the right choice and often do not ask their supervisors for advice. Field workers need to be trained to ALWAYS ask for advice and direction when in doubt of proper procedure. This kind of scenario requires further discussion and training." Senior Research Staff 3
\end{abstract}

Researchers, like the residents, also mentioned that older participants might have more difficulty understanding research processes.

\footnotetext{
"The field worker was supposed to talk to the father directly and not via the grandmother. The field worker had more information about the study and HIV testing compared to the grandmother. The grandmother did not know the major issues surrounding HIV/AIDS." Senior Field Staff 2
}

Researchers spoke about the importance of field worker training and quality assurance procedures being in place to ensure that proper informed consent practices are followed.

"The training for the field workers needs to revised and reinforced and maybe the research manager should consider whether there are adequate on-going quality checks" Senior Researcher 5

\section{Giving Individual Results From Clinical Screening Conducted as Part of a Study}

Increasing numbers of studies in the site include some form of clinical screening in addition to interviews. For example, this can be measuring blood pressure, taking venous blood for glucose levels, dry blood spots for HIV testing or collecting urine samples. Residents liked having their individual results from these tests immediately.

\begin{abstract}
"Researchers came to my house and checked us, blood was taken by pricking our fingers and results were given at the same time. They also checked our blood pressure.... this helped me ... as I was given the results at the same time. I was happy as they came to our home and checked the whole family including the elders. We were all given the results. I remember my mother's blood pressure was high as she was angry that morning. She was told and given a referral letter to the clinic and she came back home with treatment." Young man 1, NGI village 1
\end{abstract}

However, there were many instances where residents talked about either themselves or people they knew who had had blood taken and did not receive their results.

"But there is a participant who told me........they had taken a lot of blood and this worried him a lot because he didn't get any results after they took his blood." Headman 2

In the past, for tests without immediate results participants were sometimes referred to the clinics to get their results. Residents felt that if the researchers could arrange to collect tissue samples at participants' homes, or transport participants to the research laboratory to collect samples, results should be delivered to them personally at home. The clinic managers also expressed challenges with giving research screening results as there were delays in getting the research results to the clinics, and participants became irritated.

\footnotetext{
"You cannot take blood from one person but not give results. Then you come again and you want to collect more blood for another study. Where is the first blood? Where did you send it? People need their own results and not as a group. My child's [nasal] mucus was taken, but there are no results. I think that is wrong..... Bring back your findings. If you can do so, people will be interested to participate. That's my request." Young woman 2, village 1
}

\section{Box 1 | Scenario on informed consent.}

The recruitment of young women for a study involved consenting for HIV testing. In this case, the young woman was 13 years old and lived with her maternal grandmother. Her father lived elsewhere and her mother died 9 years previously. As per approved procedures, the father was called by cell-phone to obtain consent for the caregiver (grandmother) to provide consent for the young woman's participation in the study. The field worker did not speak directly to the father, but allowed the grandmother to conduct the conversation - and the grandmother did not inform him of the HIV testing component of study enrolment. This constituted a protocol violation as the field worker should have personally had this discussion with the father. The father and grandmother and the young woman consented. The young woman was found to be HIV positive during testing and she told her grandmother the result of the test. The father contacted the study team, angry that his daughter was tested without his permission. It appears that the young woman was infected perinatally and that her father had not informed her, nor her grandmother of her status. 
"A challenge I had was that there are those who are being tested for HIV at their homes and being given stickers to come to the clinic for the results. Someone in the clinic had to check for their results in the computer. The results were not available even though it was after quite a long period. That can lead people to not accept field workers the next time because they have had a bad experience." Clinic operations manager 3

Residents, particularly service providers and local leaders, were clear that more consultation earlier in the research process would be helpful to everyone.

"We need to consult with the community. Then the community will come up with ideas of how exactly we can improve." Participant 7, FGI4 CDF

Given that getting individual screening results was an important concern in almost all the interviews, the following scenario in Box 2, based on field notes about an actual critical incident, was sent to 10 researchers for their views.

All the 10 researchers wrote that it was ethically important to give participants back results from screening tests. Some acknowledged that although research may only have policy impact later on, more immediate benefit to participants is important and a right.

"If you are going to require them to give you their time and physical bodies for your research then you must show respect by letting them know the results of the test you are conducting, particularly if it is a test that is of high burden in their community and could save their life and the lives of other people." Senior Research Staff 3

Researchers also wrote that giving back of results would assist future studies in the longitudinal health research area, by helping to maintain trust.

"We have to do this to prevent refusals and the researchers must not take advantage of people participating in their study.... if they [participants] think that they have been used but didn't get their results, they will refuse when other studies similar to that one come." Senior Field Staff 3

"It also raises an issue of partnership ethics. The US partner is weighing their needs higher than the local implementing partner which is also a violation of respect for persons. Given the local

Box 2 | Scenario on giving back results.

An information sheet and informed consent form was sent to the Public Engagement Office for review. Participants were being asked to give a blood sample for HIV testing, but there was no mention in the informed consent of how the participants were going to be given the HIV test results. Upon follow up with the Principal Investigators, it was confirmed that there was no plan for reporting back individual HIV results to participants, and no budget for this. It emerged that the US partner in the study had previously requested more money from the budget for study costs in the US, and this request had been accommodated by the investigating team. budget is running the project I would emphasize the US partner needs to be more accommodating, as without the local buy in, there is no study." Senior Research Staff 3

Researchers problematized the giving back individual results as part of research activities, but were clear it was sensitive and required planning, consultation and funding. A researcher noted that there is a tension between availability of funds and costs of giving back individual screening results, and that international researchers needed to be mindful of fair benefit and researcher accountability to the experimental public.

".... giving back the results .... must be done carefully. The research participants must consent and suggest where he/she would be comfortable to get the results. Some would not be happy to have their results at the clinic and that needs to be considered." Senior Field Staff 2

"Research should be adequately funded, allowing for treating the participants with consideration and dignity. Maybe, in future, this should be considered earlier in the development process." Senior Research Staff 5

Researchers also mentioned the importance of thinking about giving back of results during the project planning phase, and including local researchers and residents in project planning.

"Why was reporting of individual results not a priority during proposal and budget development? What did the study team plan to do when they got the HIV results?" Senior Field Staff 4

\section{DISCUSSION AND CONCLUSION}

The findings from this study using multiple qualitative methods have implications for widening participation of the experimental public as part of study processes in longitudinal health research sites. Issues that arose relating to informed consent and giving of individual results from screening tests are discussed.

Public health research studies often involve complicated field work processes, with multiple informed consent sheets. It is clear from the results that the resident interviewees felt that sometimes neither participants or field workers fully understood study activities, nor the reasons for the research itself. This was reported as being more of an issue with older people. Age differences between participants and field workers was important when older participants were reported as being reluctant to answer questions on their sexual behavior to young field workers, or those of a different gender to themselves.

Residents also reported that, especially but not only for older people, a high level of trust in and respect for field workers influenced participants to sign consent forms despite not understanding the implications. Researchers said that if information in the consent was misunderstood, or not understood, and unrealistic expectations raised, there would be implications for the participant, his/her family, the study itself as well as for future studies in the study area.

The results in this paper reinforce previous findings that informed consent is often complex and requires careful attention. Molyneux et al. (2005) also highlight that the decision to sign an 
informed consent may be made because of a high level of trust in the field worker and the research institution, or because of real or perceived benefits from the study. Kamuya et al. (2015) and Tekola et al. (2009) discuss the complexities of gaining informed consent in research studies, noting the importance of how and what information is presented, and that cultural issues affect the decision to sign consent. Field worker training and support can mitigate ethical issues that occur in the field (Tekola et al., 2009; Kamuya et al., 2015) and it is clear that training at the onset of a study needs to be followed up with frequent monitoring and supervision of the field workers on the taking of informed consent. Calls for standardized training for field workers have been made at a workshop in 2015 involving nine African longitudinal health research institutions in Kombe (2015).

Cultural considerations regarding older people's lack of trust in younger fieldworkers, or of younger fieldworkers contravening cultural practices through having to ask sensitive questions to their elders have also been discussed in relation to informed consent in other HDSS study areas (Tekola et al., 2009; Kamuya et al., 2015). The older population in this study area understands research to a lesser extent than the fieldworkers owing to disparities in access to education during the apartheid area. In 2010, one study in the HDSS found that of 5,056 people aged 50 years and over, over $55 \%$ had no formal education and $24 \%$ had six or less years of education (Ameh et al., 2014). Owing to cultural changes, younger fieldworkers may respect their elders less than in the past (Stadler, 2003). This may lead to elders being submissive, or untruthful in their responses. A current related dilemma in this research setting, is that younger fieldworkers, owing to greater access to post-secondary education post-apartheid, are more likely to be appointed as fieldworkers than applicants who are older. This is considered a benefit by the population in the area, as youth unemployment is extremely high. These fieldworkers are also more likely to understand research and be able to use technology which is vital as data collection has moved from being paper-based to electronic.

Participants appreciated receiving individual results at the time of doing the screening tests, but were clear that results from samples sent off for testing should be delivered personally, or given at the time of doing the test, whether positive or negative. Researchers agreed that there was an ethical imperative to give participants their results, both immediately from screening tests and for those that were sent away for analysis, were positive and clinically relevant and for which treatment was available locally. This would benefit individuals, and future research studies would also benefit as participants would feel that their dignity and interests was being respected and would be more willing to participate in further studies. Researchers wrote that giving individual results required careful planning and resourcing, needed to be included from the proposal development stage, and that this consideration of fair benefit may require budgetary adjustments.

Supporting the findings from Bledsoe et al. (2012), no adverse events were reported by participants regarding receiving individual screening test results, and giving individual results seemed to create a positive attitude toward research, and was seen as a fair benefit from the research (Shalowitz and Miller, 2005; CIOMS, 2016). Provision of individual screening results as part of public health research in general rather than specifically in longitudinal settings is only mentioned in one guideline ICHGCP (1996) in Lairumbi et al.'s (2011) review of research ethics guidelines. It is clear from this paper that participants view this as a real benefit. In countries such as South Africa, where there is primary health care free for many conditions, there may be less risk of therapeutic misconceptions (Appelbaum et al., 1987; Molyneux et al., 2005) when giving individual test results.

Currently in this HDSS, consultation with the PEO and the CAG often only occurs after proposals have been written, funded and ethical approvals obtained. Widening participation through mechanisms for consultation with residents and researchers regarding activities in a longitudinal health study area could assist in guiding decisions around governance in all these research activities, in order to enhance both accountability of researchers and fair benefit (Bäckstrand, 2003; Emmanuel et al., 2004; Levine, 2011; Kamuya et al., 2013; Molyneux and Bull, 2013;; Simwinga et al., 2018).

\section{Implications for Practice in Longitudinal Health Study Areas}

These issues are not unique to this rural, South African setting and there are implications for other longitudinal health study areas globally. There is a need to identify strategies and mechanisms to ensure increased accountability of researchers and stronger participatory governance through involvement of the experimental public in all aspects of longitudinal public health research as part of ethics in practice. From these findings, two strategies have been identified by researchers and residents: improved field worker training and ongoing supervision during data collection, and increased involvement of residents in protocol development, data collection and dissemination.

Development of accredited training modules on informed consent and other ethics in practice for field workers is one strategy to address some of the informed consent issues. More time needs to be budgeted for training, so that research teams can be certain that fieldworkers understand the reasons for the research and the fieldwork processes. Understanding findings from prior research in the study area will allow fieldworkers to better understand the reasons for the research and possibly allow for more targeted dissemination of findings to participants. In areas where research is conducted in collaboration with external principal investigators and research managers, adequate orientation on public engagement, field operations, and ongoing supervision requirements for fieldwork is needed. In this HDSS, there are frequent meetings between on-site research managers and field teams. One possible way forward could be to have a monthly ethics in practice forum for fieldworkers and research staff to reflect on ethical dilemmas encountered in the field. These are essential to supporting fieldworkers, and allow for team discussion around dilemmas that may arise. Additionally, monthly meetings between research managers of different nested projects to discuss fieldwork issues enhances their ability to manage fieldwork. Clear guidelines for principal investigators 
and research managers outlining requirements for protocols, management of ethical issues, public participation, training, and monitoring of fieldworkers also need to be in place and accessible.

One strategy for widening participation is a CAG (Lairumbi et al., 2011; Simwinga et al., 2018). CAG members need adequate training and a constitution that is upheld, for example regarding length of terms of office. With the growth of nested research studies in this HDSS, monthly CAG monthly meetings cannot engage with the detail and governance of each project so Study Advisory Groups were established to advise on information sheets, review topic guides and advise during data collection and dissemination.

Other strategies to widen participation in longitudinal health research areas could include more considered approaches to recruitment and deployment of fieldworkers, ensuring for example that female fieldworkers interview female participants if there are sensitive issues to be discussed, more focused dissemination of research results to specific audiences, monitoring of reasons for refusal to participate and suggestion boxes in the study area. A number of these strategies have been implemented in the study area already, and more strategies to widen participation are planned, including regular focus groups with individuals and service providers around their experience of living and working in this study area. A key lesson learnt during implementation of strategies to widen participation is that it is not possible to include all residents in the study area, and champions are important, but representation needs careful consideration. Public participation in research is not static, and continued assessment of existing strategies is required, consultation and development of new relationships should be ongoing (Lavery et al., 2010).

This paper builds on and extends previous work on ethics in practice in longitudinal health research areas. It highlights the importance of widening the participation of residents who form the experimental public in research governance mechanisms in these settings in order to ensure the longevity of these institutions. Widening participation is

\section{REFERENCES}

Allotey, P., Reidpath, D. D., Devarajan, N., Rajagobal, K., Yasin, S., Arunachalam, D., et al. (2014). Cohorts and community: a case study of community engagement in the establishment of a health and demographic surveillance site in Malaysia. Glob. Health Action 7:23176. doi: 10.3402/gha.v7. 23176

Ameh, S., Gómez-Olivé, F. X., Kahn, K., Tollman, S. M., and Klipstein-Grobusch, K. (2014). Predictors of health care use by adults 50 years and over in a rural South African setting. Glob. Health Action. 7:24771. doi: 10.3402/gha.v7. 24771

Appelbaum, P. S., Roth, L. H., Lidz, C. W., Benson, P., and Winslad, W. (1987). False hopes and best data: consent to research and the therapeutic misconception. Hastings Cent. Rep. 17, 20-24. doi: 10.2307/3562038

Bäckstrand, K. (2003). Civic science for sustainability: reframing the role of experts, policy-makers and citizens in environmental governance. Glob. Environ. Politics 3, 24-41. doi: 10.1162/152638003322757916 intrinsic to the democratization of science as a public good (Bäckstrand, 2003; Levine, 2011) and can enhance both the lives of research participants and the quality of the research.

\section{ETHICS STATEMENT}

Ethical clearance was obtained from the University of the Witwatersrand's Human Research Ethics Committee (HREC) (Medical) (Certificate numbers M140361 and M140737) and permission for interviewing service providers obtained from both the Mpumalanga Provincial Departments of Health and Education Research Offices. Written informed consent was gained from all participants prior to data collection.

\section{AUTHOR CONTRIBUTIONS}

RT, GL, and KK planned the study. RT implemented the study and RT conducted the analysis and linked the findings to the literature, supported by GL. KK provided critical revision of the manuscript.

\section{FUNDING}

This project was supported by the University of the Witwatersrand, the South African Medical Research Council, the South African National Research Foundation through their Community Engagement Funding Instrument (Grant 93314), the EU Marie Curie Improving Population Health Through Research Exchanges' (IPHTRE) grant and the Wellcome Trust (Grants 058893/Z/99/A; 069683/Z/02/Z; $085477 / \mathrm{Z} / 08 / \mathrm{Z} ; 085477 / \mathrm{B} / 08 / \mathrm{Z})$ that supported the health and socio-demographic surveillance system.

\section{ACKNOWLEDGMENTS}

Without the participation of the people living and working in the Agincourt HDSS study area, none of this work would be possible. We thank Jocelyn Watkins, Violet Ndlovu, and Meriam Maritse who assisted with data collection and transcription.

Beckerleg, S., Lewando Hundt, G., Belmaker, I., Abu Saad, K., and Borkan, J. (1997). Eliciting local voices - the use of natural group interviews. Anthropol. Med. 4, 273-288.

Bledsoe, M. J., Grizzle William, E., Clark Brian J, and Zeps N. (2012). Practical implementation issues and challenges for biobanks in the return of individual research results. Genet. Med. 14, 478-483. doi: 10.1038/gim.2011.67

CIOMS (2016). International Ethical Guidelines for Health-related Research Involving Humans. Geneva: WHO.

Collinson, M. A., White, M. J., Bocquier, P., McGarvey, S. T., Afolabi, S. A., Clark, S. J., et al. (2014). Migration and the epidemiological transition: insights from the Agincourt sub-district of northeast South Africa. Glob. Health Action 7:23514. doi: 10.3402/gha.v7.23514

Crisp, B., Green Lister, P., and Dutton, K. (2005). Integrated Assessment: New Assessment Methods Evaluation of an Innovative Method of Assessment-Critical Incident Analysis. Working paper. Glasgow: Scottish Institute for Excellence in Social Work Education. Available online at: https://strathprints.strath.ac.uk/id/ eprint $/ 38310$ 
Duombo, O. K. (2005). It takes a village: medical research and ethics in Mali. Science 307, 679-681. doi: 10.1126/science.1109773

Emmanuel, E. J., Wendler, D., Killen, J., and Grady, C. (2004). What makes clinical research ethical in developing countries. J. Int. Dev. 189, 930-937. doi: $10.1086 / 381709$

Fortmann, L. (2014). Giving back, moving forward. J. Res. Pract. 10:M10. Available online at: http://jrp.icaap.org/index.php/jrp/article/view/399/353

Gaziano, T. A., Abrahams-Gessel, S., Gomez-Olive, F. X., Wade, A., Crowther, N. J., Alam, S., et al. (2017). Cardiometabolic risk in a population of older adults with multiple co-morbidities in rural South Africa: the HAALSI (Health and Aging in Africa: longitudinal studies of INDEPTH communities) study. BMC Public Health 17:206. doi: 10.1186/s12889-017-4117-y

Geertz, C. (1973). "Thick description: toward an interpretive theory of culture," in The Interpretation of Culture: Selected Essays by Clifford Geertz (New York, NY: Basic Books), 3-20. Available online at: https://chairoflogicphiloscult.files. wordpress.com/2013/02/clifford-geertz-the-interpretation-of-cultures.pdf

Geissler, P. W., and Molyneux, C. (2011). Evidence, Ethos and Ethnography: The Anthropology and History of Medical Research in Africa. Oxford: Berghahn Books.

Gómez-Olivé, F., Angotti, N., Houle, B., Klipstein-Grobusch, K., Kabudula, C., Menken, J., et al. (2013). Prevalence of HIV among those 15 and older in rural South Africa. AIDS Care 25, 1122-1128. doi: 10.1080/09540121.2012.750710

Green, J., and Thorogood, N. (2009). Qualitative Methods for Health Research, 2nd $E d n$. Thousand Oaks, CA: Sage.

Guillemin, M., and Gillam, L. (2004). Ethics, reflexivity, and "ethically important moments in research. Qual. Inq. 10, 261-280. doi: 10.1177/10778004032 62360

Harris, B., Eyles, J., Penn-Kekana, L., Thomas, L., and Goudge, J. (2014). Adverse or acceptable: negotiating access to a post-apartheid health care contract. Glob. Health 10:35. doi: 10.1186/1744-8603-10-35

HPTN (2009). By Rennie, S. and Sugarman, J. and the HPTN Ethics Working Group. Bethesda, MD, NIAID: National Institutes of Health

ICH-GCP (1996). International Conference on Harmonisation of Technical Requirements for Registration of Pharmaceuticals for Human Use. Guideline for Good Clinical Practice E6(R1). Available online at: https://www.ich.org/ fileadmin/Public_Web_Site/ICH_Products/Guidelines/Efficacy/E6/E6_R1_ Guideline.pdf

INDEPTH (2012). INDEPTH Network. Retrieved 10 December 2012. Availabile online at: http://www.indepth-network.org/

Kahn, K., Collinson, M. A., Gómez-Olivé, F. X., Mokoena, O., Twine, R., Mee, P., et al. (2012). Profile: Agincourt health and socio-demographic surveillance system. Int. J. Epidemiol. 41, 988-1001. doi: 10.1093/ije/dys115

Kamuya, D. M., Marsh, V., Kombe, F. K., Geissler, W. P., and Molyneux, S. C. (2013). Engaging communities to strengthen research ethics in low-income settings: selection and perceptions of members of a network of representatives in coastal Kenya. Dev. World Bioeth. 13, 10-20. doi: 10.1111/dewb.12014

Kamuya, D. M., Theobald, S. J., Marsh, V., Parker, M., Geissler, W. P., and Molyneux, S. C. (2015). "The one who chases you away does not tell you go": silent refusals and complex power relations in research consent processes in Coastal Kenya. PLoS ONE 10:e0126671. doi: 10.1371/journal.pone.01 26671

Kelly, A. H., MacGregor, H., and Montgomery, C. M. (2016). The publics of public health in Africa. Crit. Public Health 27, 1-5. doi: 10.1080/09581596.2016.1254178

Kombe, F. (2015). Enhancing quality and integrity in biomedical research in Africa: an international call for greater focus, investment and standardisation in capacity strengthening for frontline staff. BMC Med. Ethics 16:77. doi: 10.1186/s12910-015-0071-3

Lairumbi, G. M., Michael, P., Fitzpatrick, R., and English, M. C. (2011). Ethics in practice: the state of the debate on promoting the social value of global health research in resource poor setting particularly Africa. BMC Public Health 12:22. doi: 10.1186/1472-6939-12-22

Lavery, J. V., Tindana, P. O., Scott, T. W., Harrington, L. C., Ramsey, J. M., Ytuarte-Nuñez, C., et al. (2010). Towards a framework for community engagement in global health research. Trends Parasitol. 26, 279-283. doi: $10.1016 /$ j.pt.2010.02.009

Levine, P. (2011). Seeing like a citizen: the contributions of elinor ostrom to civic studies. Good Soc. 20, 3-14. doi: 10.1353/gso.2011.0010
MacQueen, K. M., Bhan, A., Frohlich, J., Holzer, J., and Sugarman, J. (2015). Evaluating community engagement in global health research: the need for metrics. BMC Med. Ethics 16: 44. doi: 10.1186/s12910-015-0033-9

Molyneux, C., Goudge, J., Russell, S., Chuma, J., and Gumede, T. (2009). Conducting health-related social science research in low income settings: ethical dilemmas faced in Kenya and South Africa. J. Int. Dev. 21, 309-326. doi: $10.1002 /$ jid. 1548

Molyneux, C. S., Peshu, N., and Marsh, K. (2005). Trust and informed consent: insights from community members on the Kenyan coast. Soc. Sci. Med. 61, 1463-1473. doi: 10.1016/j.socscimed.2004.11.073

Molyneux, S., and Bull, S. (2013). Consent and community engagement in diverse research contexts: reviewing and developing research and practice. participants in the community engagement and consent workshop, Kilifi, Kenya, March 2011. J Empir Res Human Res Ethics 8, 1-18. doi: 10.1525/jer.2013.8.4.1

Molyneux, S., Kamuya, D., Madiega, P. A., Chatler, T., Angwenyi, V., and Geissler, P. W. (2013). Fieldworkers at the interface. BMC Med. Ethics 13, ii-iv. doi: 10.1111/dewb.12027

Molyneux, S., Mulupi, S., Mbaabu, L., and Marsh, V. (2012). Benefits and payments for research participants: experiences and views from a research centre on the Kenyan coast. BMC Med. Ethics 13:13. doi: 10.1186/1472-69 39-13-13

Montgomery, C. M., and Pool, R. (2017). From trial community; to "experimental publics": how clinical research shapes public participation. Crit. Public Health 27, 50-62. doi: 10.1080/09581596.2016.1212161

Murphy, J., Scott, J., Kaufman, D., Geller, G., LeRoy, L., and Hudson, K. (2008). Public expectations for return of results from large-cohort genetic research. Am. J. Bioeth. 8, 36-43. doi: 10.1080/15265160802513093

Niehaus, I., Mohlala, E., and Shokane, K. (eds.). (2001). Witchcraft, Power, and Politics: Exploring the Occult in the South African Lowveld. London: Pluto Press.

Nuffield Council on Bioethics (2002). The Ethics of Research Related to Healthcare in Developing Countries, 2002. Available online at: http://nuffieldbioethics.org/ wp-content/uploads/2014/07/Ethics-of-research-related-to-healthcare-indeveloping-countries-I.pdf

Participants in the 2001 Conference on ethical aspects of research in developing countries (2002). Fair benefits for research in developing countries (2001). Science 298:2133. doi: 10.1126/science.1076899

Pettifor, A., MacPhail, C., Hughes, J. P., Selin, A., Wang, J., GómezOlivé, F. X., et al. (2016). The effect of a conditional cash transfers on HIV incidence in young women in rural South Africa (HPTN 068): a phase 3, randomised controlled trial. Lancet Glob. Health 4, e978-e988. doi: 10.1016/S2214-109X(16)30253-4

Shalowitz, D. I., and Miller, F. G. (2005). Disclosing individual results of clinical research implications of respect for participants. JAMA. 294, 737-740. doi: 10.1001/jama.294.6.737

Simwinga, M., Porter, J., and Bond, V. (2018). Who is answerable to whom? Exploring the complex relationship between researchers, community and Community Advisory Board (CAB) members in two research studies in Zambia. Crit. Public Health. 28, 1-11. doi: 10.1080/09581596.2018.14 40072

South African Department of Health (2007). Guidelines for Good Practice in the Conduct of Clinical Trials in Human Participants in South Africa. Pretoria: Government Printers.

South African Government (1996). Constitution of the Republic of South Africa, Act 108 of 1996. Pretoria: Government Printers.

Stadler, J. (2003). Rumor, gossip and blame: implications for HIV/AIDS prevention in the South African Lowveld. AIDS Educ. Prevent. 15, 357-368. doi: 10.1521/aeap.15.5.357.23823

Tekola, F., Bull, S. J., Farsides, B., Newport, M. J., Adeyemo, A., Rotimi, C. N., et al. (2009). Tailoring consent to context: designing an appropriate consent process for a biomedical study in a low income setting. PLoS Negl. Trop. Dis. 3:e482. doi: 10.1371/journal.pntd.0000482

Thorogood, M., Goudge, J., Bertram, M., Chirwa, T., Eldridge, S., Gómez-Olivé, F. X., et al. (2014). The Nkateko health service trial to improve hypertension management in rural South Africa: study protocol for a randomised controlled trial. Trials 2014:435. doi: 10.1186/1745-6215-15-435

Tindana, P. O., Singh, J. A., Shawn, T. C., Upshur, R. E., Daar, A. S. Singer, P. A., et al. (2007). Grand challenges in global health; community 
engagement in research in developing countries. PLoS Med. 4, 1-5. doi: 10.1371/journal.pmed.0040273

Tollman, S. (2008). Closing the Gap: Applying Health and Socio-Demographic Surveillance to Complex Heatlh Transitions in South and Sub-Saharan Africa. Ph.D., Umeå University.

Twine, R., Hundt, G. L., and Kahn, K. (2017). The "experimental public" in longitudinal health research: views of local leaders and service providers in rural South Africa. Glob. Health Res. Policy 2:26. doi: 10.1186/s41256-0170046-7

UK National Institute for Health Research (2014). Patient and Public Involvement in Health and Social Care Research: A Handbook for Researchers.

UNAIDS/WHO (2007). Ethical Considerations in Biomedical HIV Prevention Trials.

United Nations (1948). Universal Declaration of Human Rights. Geneva: UNAIDS/World Health Organization.

Ye, Y., Wamukoya, M., Ezeh, A., Emina, J. B., and Sankoh, O. (2012). Health and demographic surveillance systems: a step towards full civil registration and vital statistics system in sub-Sahara Africa? BMC Public Health 12:741. doi: 10.1186/1471-2458-12-741

Conflict of Interest Statement: RT and KK both work for the MRC/WitsAgincourt Unit in which this study was undertaken.

The remaining author declares that the research was conducted in the absence of any commercial or financial relationships that could be construed as a potential conflict of interest.

Copyright (C) 2019 Twine, Lewando Hundt and Kahn. This is an open-access article distributed under the terms of the Creative Commons Attribution License (CC BY). The use, distribution or reproduction in other forums is permitted, provided the original author(s) and the copyright owner(s) are credited and that the original publication in this journal is cited, in accordance with accepted academic practice. No use, distribution or reproduction is permitted which does not comply with these terms. 


\title{
Plain English Summary \\ Rights-based Training Enhancing Engagement of Health Providers with Communities, Cape Metropole, South Africa
}

\author{
Gimenne Zwama, Maria C. Stuttaford, Hanne J. Haricharan, Leslie London
}

Primary health care services are the first point of contact for most people seeking care. According to the World Health Organisation, these services can meet $80-90 \%$ of a person's health needs throughout their life. Yet, there is often a mismatch between the services and the needs of the community. This is mostly found in countries where access to quality care is not taken for granted. Health committees are a way to ensure that primary health care services respond to the needs of the community.

In South Africa, the make-up of health committees is defined by national law. They should consist of community members, a local government councillor and a clinic manager. In this way, the community can hold health providers responsible for their services. These committees can also help communities to take part in the planning and decision-making around local health services. This promotes people's right to take part in their health care. In these ways, health committees can improve access to quality health care services.

The way health committees work varies widely across and within South African provinces. This is partly due to a lack of clear policies on their roles and tasks. Clinic managers and other local health providers play a key role in the success of health committees as well. In some cases, health providers may not understand or support health committee members' roles. The community's ability to engage with health providers is then limited. This raises the question whether health provider training on community engagement could improve the role of health committees.

The Learning Network for Health and Human Rights ran a rights-based training course for health providers in the Cape Metropole of South Africa. We evaluated this training through observations, questionnaires and interviews with those taking part. As a result of the training, health providers thought health committees play a valuable role in creating a dialogue between the community and health providers. Health providers also understood that health committees can promote trust, health education as well as the use and quality of care.

Furthermore, health providers planned to improve work relations and to tackle other challenges to the ways health committees work. Some health providers already made an effort to put into practice what they had learned. Thus, although the length of this study and the training itself was limited, this form of health provider training can help improve the community's part in developing health care services that respond to local needs. Therefore we recommend that the training is tested in other situations and evaluated further. 
OPEN ACCESS

Edited by:

Jenny Douglas,

The Open University, United Kingdom

Reviewed by:

Guido Giarelli,

Università degli Studi Magna Græcia

di Catanzaro, Italy

Rachel Matthews,

National Institute for Health Research

(NIHR), United Kingdom

*Correspondence:

Gimenne Zwama

gimenne@gmail.com

Specialty section:

This article was submitted to

Medical Sociology,

a section of the journal

Frontiers in Sociology

Received: 15 October 2018

Accepted: 04 April 2019

Published: 30 April 2019

Citation:

Zwama G, Stuttaford MC

Haricharan HJ and London L (2019)

Rights-Based Training Enhancing

Engagement of Health Providers With

Communities, Cape Metropole, South

Africa. Front. Sociol. 4:35

doi: $10.3389 /$ fsoc. 2019.00035

\section{Rights-Based Training Enhancing Engagement of Health Providers With Communities, Cape Metropole, South Africa}

\author{
Gimenne Zwama ${ }^{1,2 *}$, Maria Clasina Stuttaford ${ }^{1,3}$, Hanne Jensen Haricharan ${ }^{1}$ and \\ Leslie London $^{1}$ \\ ${ }^{1}$ Health and Human Rights Programme, School of Public Health and Family Medicine, University of Cape Town, Cape Town, \\ South Africa, ${ }^{2}$ Institute for Global Health and Development, School of Health Sciences, Queen Margaret University, \\ Edinburgh, United Kingdom, ${ }^{3}$ Health, Social Care and Education, Kingston and St George's University of London, London, \\ United Kingdom
}

Community participation, the central principle of the primary health care approach, is widely accepted in the governance of health systems. Health Committees (HCs) are community-based structures that can enable communities to participate in the governance of primary health care. Previous research done in the Cape Town Metropole, South Africa, reports that HCs' potential can, however, be limited by a lack of local health providers' (HPs) understanding of HC roles and functions as well as lack of engagement with HCs. This study was the first to evaluate HPs' responsiveness towards HCs following participation in an interactive rights-based training. Thirty-four HPs, from all Cape Metropole health sub-districts, participated in this qualitative training evaluation. Two training groups were observed and participants completed pre- and post-training questionnaires. Semi-structured interviews were held with 10 participants 3-4 months after training. Following training, HPs understood HCs to play an important role in the communication between the local community and HPs. HPs also perceived HCs as able to assist with and improve the quality and accessibility of PHC, as well as the answerability of services to local community needs. HPs expressed intentions to actively engage with the facility's $\mathrm{HC}$ and stressed the importance of setting clear roles and responsibilities for all $\mathrm{HC}$ members. This training evaluation reveals HPs' willingness to engage with HCs and their desire for skills to achieve this. Moreover, it confirms that HPs are crucial players for the effective functioning of HCs. This evaluation indicates that HPs' increased responsiveness to HCs following training can contribute to tackling the disconnect between service delivery and community needs. Therefore, the training of HPs on HCs potentially promotes the development of needs-responsive PHC and a people-centred health system. The training requires ongoing evaluation as it is extended to other contexts.

Keywords: training, health providers, community participation, health committees, governance, PHC, rights, South Africa 


\section{INTRODUCTION}

With global attention for people-centred health systems gathering momentum and the World Health Organisation's (WHO) publication of its global strategy on people-centred services in 2015 , it is widely emphasised that not only service users, but also communities, should play an active and informed role in the maintenance, restoration, and promotion of their own health (Hunt and Backman, 2007; WHO, 2015). The Alma-Ata Declaration stresses that people have the right and duty to participate in the planning, organisation, operation and control of primary health care (PHC), and builds on the right to health, adopting the WHO's definition of health as "the state of complete, physical, mental, and social well-being, and not merely the absence of disease or infirmity" (WHO, 1946, 1978). Community participation in the governance of service delivery can promote people-centeredness and needsresponsiveness of a health system (WHO, 1978, 2015). These are characteristics of a health system in which everyone contributes and benefits and where health care services respond to people's needs and expectations in a holistic manner, rather than focusing solely on disease and the diseased (WHO, 2007, 2015).

For people's participation to be effective and meaningful, communities' active and informed involvement is required in the evaluation of strategies, decision-making, prioritisation, and implementation of the right to health (Potts, 2008). In a systematic review of evidence on Health Committee (HC) effectiveness in low- and middle-income countries (LMICs), HCs have commonly been found to provide a bottom-up platform for community representatives to participate in health care decision-making, monitoring and oversight (McCoy et al., 2012). In Kenya, HCs are official structures with defined roles to close gaps in service delivery and to hold health facilities accountable for the quality and accessibility of the services offered (Goodman et al., 2011). By these means, HCs can facilitate the community's collective ownership of PHC services (Haricharan, 2012) as well as promote the realisation of the right to health (Glattstein-young, 2010; Chikonde, 2017). As HCs serve as community-based governance structures in the delivery of primary health services, they are inherently interdependent on the dynamics of the health system's social, economic, and political contexts (United Nations Committee on Economic Social Cultural Rights UNCESCR, 2000; Gilson and WHO, 2012). This requires us to investigate such contextual factors and cross-cutting issues that can challenge HC functioning. In their reviews, George et al. (2015a) and McCoy et al. (2012) stress the importance of contextual influences in understanding HCs' role and contribution to health systems strengthening.

A cross-case comparative study of 11 HCs in West and Central Africa found that $\mathrm{HCs}$ individualised and non-systematic character can leave marginalised groups excluded (Lodenstein et al., 2017b). Even when HC powers and roles in accountability are partially defined on a national level, full specifications of

Abbreviations: HC, Health Committee; HP, Health Care Provider; LMICs, Lowand Middle-Income Countries; PHC, Primary Health Care; NHA, National Health Act; WHO, World Health Organisation. these powers and tools to execute them are needed (Lodenstein et al., 2017b). The South African National Health Act (NHA) states that a HC must be composed of community members, a local government councillor and a health facility manager (The Republic of South Africa, 2004). The Department of Health, however, delegates the definition of $\mathrm{HC}$ role and mandate to provincial policy legislation and action. All provinces currently have legislation, draft legislation, or guidelines, which differ substantially in the nature and extent to which $\mathrm{HC}$ roles and responsibilities are described (Haricharan, 2013). Accordingly, it was found that Provincial Departments of Health can fall short in their guidance, direction and training of HCs, thereby negatively impacting HCs' effective functioning (Padarath and Friedman, 2008; Meier et al., 2012). This lack of specification on health committees' roles and functions, as well as HCs' lack of power and legal mandate, can limit their uniform functioning and effective integration within the health system (Padarath and Friedman, 2008; Haricharan, 2012; Boulle, 2013).

In addition, there appears to be a general lack of clarity and guidelines on $\mathrm{HC}$ member election procedures and the make-up of the electorate. In South Africa, the Eastern Cape is the only Province that fully specifies the election of $\mathrm{HC}$ members through a representative democratic process in their final draft policy on HCs (Eastern Cape Department of Health, 2009). However, this policy defines HC community members as representatives from organised community initiatives, thereby possibly compromising the $\mathrm{HC}$ member's representativeness of community members. A HC training manual developed for the South African context, encourages and defines the procedure of HC member election by the rules of the Constitution (The Learning Network for Health and Human Rights, 2014).

In comparison to other South African Provinces, the Western Cape had lagged behind in passing HC legislation (Haricharan, 2013). Policy developments lost momentum after the Head of Health for the City of Cape Town, a HC champion, passed away in 2008. The loss of this champion was a critical milestone alongside the broader complexities of the South African health (committee) policy context over time. The long-awaited draft Bill on Health Facility Boards and Committees was published in 2015 (Province of Western Cape, 2016). This Bill became an Act in 2016 and is yet to be implemented. Even though the Act recognises HCs as a community platform, it significantly reduces the scope of their role in decision-making, strategizing, prioritising, and implementing health services according to local needs. Secondly, it allows for the provincial Minister of Health to elect committee members, which can pose a threat to the democratic value of HCs.

The national South African Department of Health committed to the "re-engineering" of PHC in 2010 with the purpose to improve service quality and integration (Barron et al., 2010). This "re-engineering" was to be established by holding the management of the district health system responsible for meeting "key ministerial priorities," implying a top-down, nondemocratic process. In June 2018, the cabinet approved the National Health Insurance Bill with the goal to provide all South Africans "access to quality and affordable health care services based on their health needs irrespective of their socio-economic 
status" (The Republic of South Africa, 2018). Strikingly, considering its purpose, the National Health Insurance Bill does not acknowledge the potential of HCs as a platform for community participation, nor community participation as a continuous mechanism to identify these health needs.

Discrepancies between policy and practice can compromise HCs main role as an intermediary between the community and health services (McCoy et al., 2012; George et al., 2015a). As evaluations across East and Southern Africa and from Brazil suggest, such discrepancies can influence nurses and facility managers' capacity to work with $\mathrm{HCs}$ and require their education on $\mathrm{HCs}$ ' roles and functions (Zambon and Ogata, 2011; Loewenson et al., 2014; George et al., 2015a). George et al. (2015b) reported that poor interpersonal skills, lack of training, perceived lack of skill and lack of trust of providers were challenges for community participatory platforms to improve the quality of services.

For HCs to effectively integrate into and contribute to a people-centred health system, HPs play an important role in creating a responsive environment in which communities meaningfully participate. McCoy et al. (2012) and George et al. (2016) illustrate that there has been a predominant focus on the capacity building of communities. While there are a few studies highlighting both sides of the coin (Mosquera et al., 2001; Sohani, 2005), there is an evident gap in research on the impact of HP training on HCs' effective and meaningful participation. Research in South Africa has shown that while some facility managers are aware of $\mathrm{HC}$ roles and functions and attend their meetings, others are completely unaware (Padarath and Friedman, 2008; Haricharan, 2012; Boulle, 2013). As a result, HPs can be reluctant to involve communities and find it challenging to be held accountable by the community, or perceive HCs solely as an extension of service delivery (Padarath and Friedman, 2008; Glattstein-young, 2010; Haricharan, 2012; Boulle, 2013).

The Learning Network for Health and Human Rights, a collaboration of civil society organisations and two universities in the Western Cape, aims to promote the right to health through community participation. In the Cape Metropole, HCHP engagement was found to be challenged by untrained community members, power imbalances, lack of mutual trust as well as HPs' lack of understanding of the relationship between the right to health and participation (Haricharan, 2012). As part of their activities to fulfil this purpose, the Learning Network trained nearly $300 \mathrm{HC}$ community members across the Cape Metropole (Haricharan, 2017). An evaluation of this HC training indicated that although HC training can improve levels of participation, this is influenced by HP authority as well as power imbalances between HC members (Chikonde, 2017). As HPs had not been trained, a HP training manual was informed by HC members, developed and piloted with the aim to (re-)establish and strengthen HPs' working relationships with HCs.

Building on everyone's right to health and participation, this study evaluated a rights-based, interactive training of HPs on HCs. This paper reports the extent and nature to which HPs' immediate and short-term responsiveness changed as a result of the training. It sheds light on contextual factors that can be of influence on HPs' ability to implement their responsiveness.
Findings are discussed and their potential contribution to the promotion of community participation in the strengthening of people-centred health systems is described.

\section{METHODS}

\section{Socio-Economic Profile}

In 2018, the Cape Metropole population was estimated to reach 4.06 million (Western Cape Government, 2018). The Cape Metropole is the least unequal Metropoles of South Africa with a Gini coefficient of 0.58 . For the next 5 years, the City of Cape Town estimates that the aged population over 65 will increase at 3.4 percentage per year. This, while the child cohort (age 0-14 years) will grow by $1.2 \%$ and the working age population by $0.8 \%$ per year. With an additional unemployment rate of 11.9 percentage, this can be expected to pose a greater burden on social systems and basic service delivery. In line with the disease burden, PHC facilities currently offer testing and treatment of HIV, STIs, tuberculosis, diabetes, and hypertension as well as immunisation and child health services. To varying extents, facilities also offer maternal and mental health services.

\section{Training Purpose and Approach}

The training manual, compiled for the purposes of the rightsbased training evaluated in this research, titled "Community Engagement for Quality Care" consists of two main chapters called "Relationship Building" and "Health Committees and Governance" (Marshall and Mayers, 2015). In line with the NHA (The Republic of South Africa, 2004), this training aimed to promote health services that are responsive to community participation. It facilitated reflection on the dual obligation and responsibilities of health care providers towards the State by referring to the national vision to achieve a society committed to democratic values, social justice, and fundamental human rights as well as the rights of the patient as set out in the Batho Pele or "People First" service principles (The Republic of South Africa, 1996, 1997).

The training adopted an experiential learning approach (Kolb, 1984), whereby the facilitators guided participants through a reflective learning process that shed light on previous and current practices of engaging with, and involving the community. The importance of mutual understanding, collaboration, and respect was illustrated through rights-based case discussions, role plays and reflections on the values of compassion, and professionalism. In these ways, tailored directions could be given and environments promotive of the right to health and participation could be illustrated.

\section{Training Implementation and Participant Recruitment}

Thirty-four health care providers from all City of Cape Town health sub-districts $(n=8)$ were recruited for the training, contributing to the diversity of the study sample (see Table 1). These included (senior) professional nurses and clinic managers working in City of Cape Town clinics, as well as environmental health practitioners, health promotion officers, and programme 
TABLE 1 | Number of participants and sub-districts.

\begin{tabular}{|c|c|c|c|c|c|}
\hline & $\begin{array}{c}\text { Training } \\
\text { observations, } \\
\text { in } \%(n)\end{array}$ & $\begin{array}{l}\text { Pre- } \\
\text { questionnaire } \\
\text { responses, } \\
\text { in \% }(n)\end{array}$ & $\begin{array}{l}\text { Post- } \\
\text { questionnaire } \\
\text { responses, } \\
\text { in } \%(n)\end{array}$ & $\begin{array}{l}\text { Interviews, } \\
\text { in } \%(n)\end{array}$ & $\begin{array}{l}\text { Sub- } \\
\text { districts }\end{array}$ \\
\hline $\begin{array}{l}\text { Training } \\
\text { group } 1\end{array}$ & $58.8(20)$ & 85.0 (17) & $85.0(17)$ & $25.0(5)$ & $A, B, C, D$ \\
\hline $\begin{array}{l}\text { Training } \\
\text { group 2 }\end{array}$ & $41.2(14)$ & $100(14)$ & $85.7(12)$ & 35.7 (5) & $\begin{array}{l}D, E, F \\
G, H\end{array}$ \\
\hline Total & $100(34)$ & $91.2(31)$ & 85.3 (29) & 29.4 (10) & 100 (8) \\
\hline
\end{tabular}

TABLE 2 | Number of participants by professional position and sub-district of origin.

\begin{tabular}{|c|c|c|c|}
\hline Position & & $\begin{array}{l}\text { Questionnaire } \\
\text { responses, in \% (n) } \\
\text { sub-district }\end{array}$ & $\begin{array}{l}\text { Interviews, in \% (n) } \\
\text { sub-district }\end{array}$ \\
\hline \multirow[t]{3}{*}{ Clinic level } & Clinic manager & $\begin{array}{l}48.4(15) \\
A, C, D, E, F, G\end{array}$ & $\begin{array}{l}40.0(4) \\
A, C, F, G\end{array}$ \\
\hline & $\begin{array}{l}\text { Senior } \\
\text { professional } \\
\text { nurse }\end{array}$ & $\begin{array}{l}16.1(5) \\
A, C, E, F\end{array}$ & $\begin{array}{l}20.0(2) \\
C, E\end{array}$ \\
\hline & $\begin{array}{l}\text { Professional } \\
\text { nurse }\end{array}$ & $\begin{array}{l}12.9(4)^{\star} \\
A, D, E\end{array}$ & $\begin{array}{l}10.0(1) \\
D\end{array}$ \\
\hline \multirow[t]{3}{*}{$\begin{array}{l}\text { Sub-district } \\
\text { level }\end{array}$} & $\begin{array}{l}\text { Environmental } \\
\text { health } \\
\text { practitioner }\end{array}$ & $\begin{array}{l}9.7(3) \\
A, H\end{array}$ & $\begin{array}{l}10.0(1) \\
H\end{array}$ \\
\hline & $\begin{array}{l}\text { Health } \\
\text { Promotion } \\
\text { Officer }\end{array}$ & $\begin{array}{l}6.5(2) \\
B, D\end{array}$ & $\begin{array}{l}20.0(2) \\
B, D\end{array}$ \\
\hline & $\begin{array}{l}\text { Programme } \\
\text { officer }\end{array}$ & $\begin{array}{l}6.5(2) \\
B, D\end{array}$ & - \\
\hline
\end{tabular}

*Two missing post-questionnaires, both professional nurses from district $E$.

officers working at sub-district level (see Table 2). Six subdistricts had at least four participants attending the training, of which two sub-districts had eight representatives each. However, one of the remaining sub-districts was represented by two participants both positioned at sub-district level and the other by two environmental health practitioners. Each of the two training groups had one male attendee, both environmental health practitioners.

Initially, the training was intended to consist of 2 consecutive days. However, several sub-district managers expressed their concern about the burden it could place on the facilities when some of their employees are away from the services for this amount of time. As a result, it was decided to decrease the training to 1 day followed up by another half a day at least a month later. Training sessions were implemented in May and July 2015 for the first $(n=20)$ and second group $(n=14)$ of participants, respectively. These 1-day training sessions explored the influences on and key elements for relationship building with communities as well as HC composition, roles, and functions. Preliminary analysis of questionnaires and observations was used to feed into the agenda of the follow-up session. Accordingly, this session intended to further develop HP skills for relationship building with HCs, in particular on how to establish a common vision, host a $\mathrm{HC}$ meeting, and manage conflict. In addition, it would provide an opportunity to further explore and discuss power imbalances and other practical issues raised by participants.

Follow-up sessions were scheduled for $\sim 6$ weeks after the first training sessions. Only two out of 10 enrolled participants attended the follow up training session, both holding a position at sub-district level. The first groups' participants cancelled or did not attend the follow up for various reasons such as conflicting meetings or courses, deadlines for end of financial year reports, and staff shortages due to seasonal illness. A rescheduled, combined follow up session was cancelled due to a low confirmed number of attending participants. The majority of participants expressed interest and enthusiasm for the follow-up session and indicated to be disappointed that it did not take place.

With South Africa recognising 11 official languages, participants' native languages differed. Most study participants' first language was isiXhosa $(n=12)$, followed by Afrikaans $(n=9)$, English $(n=7)$, and Sesotho $(n=2)$. The central sessions of the training were conducted in English, as this was the commonly spoken language amongst the participants. The first training group's session was facilitated by two expert educators from the University of Cape Town (UCT), one experienced in training, and consulting HCs (also proficient in isiXhosa), the other with experience as an academic teacher and professional nurse (also proficient in Afrikaans). Due to unavailability of the former, the latter facilitator acted as the sole facilitator for the training of the second group.

\section{Study Design and Data Collection}

The design was based on a realist evaluation (Pawson and Tilley, 1997). The evaluation purpose was to explore the possible variations in nature and extent of the immediate and shortterm impact of training of HPs on their responsiveness to HCs. In this paper, responsiveness is defined as the collection of understandings, intentions to practices, and practices in support of HC roles and functions. Thereby, we acknowledge that responsiveness is inherently influenced by experiences and contextual factors. The exploration of such factors was facilitated by the training participants' diversity in health care professions, experiences, local contexts, and relationships with HCs. The adoption of a realist approach provided a deeper insight into the facilitating and impeding contextual factors, as well as the dynamic interactions between societal and health systems processes that influence HPs' relationships with HCs and their ability to implement an enhanced responsiveness (Pawson and Tilley, 1997). All data was collected between May and November 2015, and the study adopted a flexible research design making use of pre- and post-training questionnaires, direct observations, semi-structured interviews, and field note journaling.

Field notes were diarised from the moment preparations for training implementation started. Pre- and post-training qualitative questionnaires and a topic guide for semi-structured interviews were developed in consultation and concordance with the facilitators' vision for the training. Due to insufficient time before training implementation, questionnaires were not piloted 
or cognitively tested. Before distribution, they were evaluated by the second and third author of this paper as well as by the training facilitators. Two attribute-inquiring questions were improved regarding phrasing or ambiguity before distribution to the second group. Before its use, the interview topic guide was adjusted and probes related to questions arisen from analysis of questionnaire responses were added.

Written notes of the training observations were taken. These observations also provided $17.5 \mathrm{~h}$ of audio recordings, of which parts were transcribed where relevant to the research questions and where written notes lacked context or clarity. The observations gave insight into the development of changes in HPs' responsiveness and contributed to the triangulation of data.

A total of thirty-one pre-training questionnaires consisting of twenty-one, mostly open-ended, questions were completed by fifteen clinic managers, five senior professional nurses, four professional nurses, three environmental health practitioners, two health promotion officers and two programme officers (Table 2). Four multiple choice questions inquired about the current HC status and relationship at the facility or subdistrict level. Furthermore, participants were asked about their understandings of $\mathrm{HC}$ roles and benefits, their challenges in engaging and working with HCs as well as the ways in which the health facility can promote $\mathrm{HC}$ functioning.

The post-training questionnaires included sixteen questions, of which four open-ended questions to specifically evaluate the training format and content, one multiple-choice question and eleven open-ended questions of which six were similar to the pre-questionnaires. This questionnaire additionally inquired about HPs' views of the role of the training in changing their understandings and practices towards HCs. Post-training questionnaires were completed by 29 participants.

Pre-training and post-training questionnaires were perceived as lengthy and, at times, contained short or missing responses. The second group's responses were overall richer in information, as they were given more time to answer the pre-training questionnaires, and completed the post-training questionnaires in their own time. These participants submitted their responses via email $(n=12)$, resulting in missing data from two professional nurses. This also resulted in completion up to 2 weeks after the training, which for a few participants measured retained rather than immediate responsiveness.

Three to 4 months after the training, interviews were held with 10 purposively selected participants (four clinic managers, two senior professional nurses, one professional nurse, one environmental health practitioner and two health promotion officers). The criteria for selecting participants were based on their differences in sub-district and HC functioning. Besides contributing to the triangulation of earlier collected data, interviews further explored the role of the training on shortterm HP responsiveness and their capacity to translate intentions to practices.

\section{Ethical Approval}

The protocol was carried out in accordance with the recommendations of the Faculty of Health Sciences Human Research Ethics Committee of the University of Cape Town.
The Faculty of Health Sciences Human Research Ethics Committee and the Health Department of the City of Cape Town approved this study (FHS HREC REF 2015/062 and ID no.: 10492, respectively). City of Cape Town sub-district managers permitted the recruitment of training participants for the evaluation. All subjects gave written informed consent in accordance with the Declaration of Helsinki. All training participants consented for the training to be observed $(n=34)$. Thirty-one participants agreed to complete the questionnaires and to be contacted for an interview. All 10 interviewees verbally consented to be contacted for follow up questions.

\section{Data Analysis}

$\{$ NVivo 10$\}$ was used as a tool to manage all data. Questionnaire data was cleaned and anonymised in \{Microsoft Excel\} before being imported in $\{$ NVivo $\}$. This also marked the start of the researcher's immersion in the data. Interviews were transcribed in $\{$ NVivo $\}$ and any text that could lead to the identification of the interviewee was removed. The first author was responsible for all data analysis and adopted a thematic approach as further detailed below.

Structural coding started with the mind mapping of questionnaire responses during preliminary analysis. These mind maps guided the inductive coding of topics and categories into an initial codebook. This codebook subsequently informed the initial codebook for the observations. Having mind-mapped the relationships between categories, and becoming familiar with the breadth of the investigated matter, the researcher examined the codes according to their ability to merge into categories and sub-codes. The data type-specific codebooks were refined and collapsed accordingly, which created small and simple codebooks with clear distinctions between the codes. Data was re-coded into meaningful units and the same was done for the remaining data, which slightly expanded the codebook again, after which the meaningful units were collapsed into themes. The first author discussed the emerging themes the second and third author of this paper. Similarly, as interviews were held 3-4 months after training these were coded sometime after the complete coding of the questionnaires and observations. This reflective pause allowed for emotional and intellectual distance, after which the sub-coded data were reorganised under more refined themes.

Ultimately, this resulted in a common codebook of three categorising codes that guided the answering of research questions, which were: understandings, practices, and intentions to change practice. Six main defining codes provided specifics to the categorising codes, which were; personal engagement with $\mathrm{HC}, \mathrm{HC}$ roles and responsibilities, challenges and issues, stakeholders, role of training in changing responsiveness, and strategies to promote $\mathrm{HC}$ functioning. Thirdly, thematic codes and their descriptive sub-codes described the dimensions of the main and categorising codes. Moreover, data were grouped for analysis of pre- and post-training understandings, intentions and practices as well as classified for participant attributes such as reported HC functioning and professional position. A similar codebook was used for every data type, with differences in sub-codes, thematic codes and with, in some cases, additional main codes. Generally, themes and sub-codes, as well as their 
descriptions, maintained close similarity to the way in which participants phrased them.

Data triangulation and integrative analysis of themes arising from the different types of data guided the interpretations of the deeper meaning of codes, segments, and themes, respectively. After the entire analysis, thematic decisions were reflected upon as the first author's personal views of the themes could have changed. The diverse data revealing participants' changing reflections, understandings and intentions, as well as their ideas on the role of training, were compared to the first author's observations and rich, reflexive field notes.

A programme theory was used to frame the interpretive analysis of themes. This facilitated the assessment of the extent and nature to which HPs' post-training responsiveness outcomes, as defined by Lodenstein et al. (2017a), can contribute to the three interconnected principles of community participation, $\mathrm{PHC}$ and people-centred health systems as described in the introduction.

\section{FINDINGS}

\section{Current HC Presence and Engagement Practices}

Of the 24 participants at clinic level, 17 indicated that the health facility is connected to a HC. All of these HCs consisted of community members and a facility manager, of which eight were said to be functioning well (by six clinic managers, one senior professional nurse, and one professional nurse). In two of these well-functioning HCs, environmental health practitioners were also included as members. A local government councillor was part of five HCs of which four were reported to be wellfunctioning. A little more than half of participants indicated that the facility regularly engages with the HC. Four clinic managers and two environmental health practitioners reported to never engage with the HC. All clinic managers had attended a $\mathrm{HC}$ meeting at least once before. Seven clinic managers, one senior professional nurse, two health promotion officers (a third of total participants) attend HC meetings each month. Ten participants (including all four professional nurses and two senior professional nurses) had never attended a HC meeting.

\section{HC Stakeholders}

Following training, respondents' understandings of $\mathrm{HC}$ composition as defined by the NHA considerably increased ( $n$ $=29$ ). Almost all respondents included community members (27 vs. 15, post-training and pre-training, respectively), local government councillors (27 vs. 10) and facility managers (25 vs. 7) in their description of composition. According to almost half of respondents, the $\mathrm{HC}$ composition, as stated by the NHA, should be complemented to include clinic workers other than the clinic manager. Some participants added that this would enhance communication and progress, this response was not related to the participant being positioned at the clinic. Environmental health practitioners were also viewed as important members by a third of respondents for their ability to address environmental problems that influence community health, such as illegal dumping.
When participants were explaining personal views on $\mathrm{HC}$ composition, a clinic manager expressed her concern:

\begin{abstract}
"My biggest challenge in the foreseeable future is to get a ward [local government] councillor, a proper ward councillor. Because this guy that's been the ward councillor for many years now for this area is very dedicated, is very well informed, has been a lawyer himself for many years so he's got a lot of background. And I think that's going to be very big shoes to fill."
\end{abstract}

Participants recurrently recommended that the HC engages with community stakeholders. For instance, schools, security guards, and social workers were seen to play a role in addressing major social problems, drug abuse and violence in the community. Additionally, non-profit and non-governmental organisations as well as churches in the area were perceived to promote awareness of the HC and avoid unnecessary duplication of health services. For the latter reason, a clinic manager without a $\mathrm{HC}$ expressed the intention to advise the sub-district's health promotion officer and programme coordinator, as well as nongovernmental organisations to link with the HC.

\section{HC Roles and Responsibilities}

To a greater extent than before the training, all participants made specific reference to the importance of HCs as liaison bodies between the wider community and the facility. It was underlined by nurses, clinic managers and a health promotion officer that HCs should inform the community of the challenges experienced by the facility and about the services that are offered to avoid unnecessary referral. In turn, the community was understood to benefit from the $\mathrm{HC}$ as a platform for advocacy. According to one of the clinic managers, the $\mathrm{HC}$ empowers the community to address and clarify their fears. It was also stated that HCs provide a true background of what needs to be done, and insight into how a community feels and thinks: "They are able to reach where we can't". Several participants explained that HCs could identify the source of outbreaks (e.g., diarrhoea), mobilise the community to assist with campaigns, educate the community to prevent further spread and assist the health facility where needed. A clinic manager mentioned that the $\mathrm{HC}$ can facilitate a fast response of the services. Another clinic manager stated:

"They are the people that are your ears and your eyes, but we tend to
forget about them. [...] They can make the decision or help us make
the correct decision pertaining the community in which we serve."

Twenty-nine participants pointed out the health promotional and educational benefit that HCs could provide for the health facility. It was recurrently stated that HCs could assist with outreaches, inform the content of health talks at the clinic and help facilitate these. HC members could do home visits for the purposes of explaining home remedies, or for recalling patients. HC participation in promotional activities was repeatedly perceived to benefit clinic targets. One of the health promotion officers said: "there are programmes that are not functional in the facility without the presence of the health committees, for instance the Health and Safety Committee". 
Most participants understood that HCs can build and promote trust, facilitated by their interaction with both communities and facilities, their insight into the challenges at both levels as well as their ability to explain problems to the community and their closer relationship to them. Other reasons for $\mathrm{HCs}^{\prime}$ role in trust building were transparency on what is being done at the facility and a sense of belonging for the community. A senior professional nurse said: "This [HCs] is a great idea. The government has been spoon feeding the community for a very long time. It is now the time that the society takes the responsibility, or ownership of their health and this change [implementing HCs] would bring a tremendous improvement in our society because they do not feel left out."

HCs were also identified by half of participants as being able to assist with a smoother operation of the health care facility in easing tensions with the community, e.g., by helping with patient flow. Additionally, a couple of participants said the HC can set up a helpdesk at the facility, guide and fast track patients, as well as help management with the planning of health service transitioning, e.g., in the case where a clinic is transformed to a Community Health Centre. Moreover, HCs were commonly seen as beneficial to the facility as they can receive complaints, advise the facility on how to deal with these and lobby or help motivate for (the expansion of) resources. A clinic manager was convinced that services will improve and be used more as people are taking ownership of the health facility's decision-making.

Overall, the HCs' participation by means of these roles and responsibilities was commonly linked to contribute to the quality improvement, accessibility or responsiveness of service delivery to local needs.

\section{Perceived Role of Training}

Most participants were surprised by the interactive nature of the training and reported a change in their perceptions as the training clarified $\mathrm{HC}$ roles and responsibilities. A clinic manager said: "I feel the training was an eye-opener and empowering." As a result of the training, participants indicated they learned about the HC members and stakeholders, as well as the importance of all members' active involvement to be able to effectively implement their roles and responsibilities. Many participants specifically referred to not having known the local government councillor should be part of the HC as stated in the NHA. It also provided participants with insight into a HC's importance, other facilities' HP-HC working relationships, the need to appreciate HCs, their ability to address community problems through one platform and the accompanying opportunity for partnership in working towards a common goal. A senior professional nurse stated that "the puzzle cannot be completed" without HCs, as they play a key role in communicating between different community stakeholders. The majority of participants perceived HCs as an essential component in every community and facility, and confirmed a renewed insight into their importance, or perceived them as more valuable, post-training. The training was also said to facilitate a better understanding of what HCs should do and how to support HC functioning. According to a senior professional nurse, the training gave her a different perspective of the responsibilities of $\mathrm{HCs}$, now making it easier to set boundaries. An environmental health practitioner no longer viewed the $\mathrm{HC}$ as a threat to HPs, as the training clarified that the facility managers' roles are not taken away from them. A clinic manager noted that the training teaches staff that HCs are not there to fight with HPs. Almost half of clinic managers found that their perceptions about HCs' roles and functions had not changed as a result of the training. Reasons being that $\mathrm{HC}$ already clearly outlined their roles or that they have always seen HCs as vital or valuable to the health facility's functioning. One of them added, "... it is just that some of the health committee members did not have a clue of what their roles and responsibilities were when they were still functioning."

\section{Translating Understandings and Intentions to Practice}

Clinic managers indicated that current barriers to their engagement with $\mathrm{HCs}$ are related to their own availability as well as their HC members' level of commitment. HPs' unavailability was, particularly among clinic managers and nurses, commonly explained by workload, having too many meetings already and $\mathrm{HC}$ meetings being held after hours. HC members' lack of commitment was repeatedly attributed to $\mathrm{HC}$ members having hidden agendas, being unavailable due to employment and not keeping to meeting times. A lack of funding was commonly identified as a challenge to retain $\mathrm{HC}$ volunteers, and for both HPs as well as community members to attend $\mathrm{HC}$ meetings. A clinic manager's view was that health committees should be funded regardless of whether they focus solely on HIV and tuberculosis care. Based on her observations, this explained different levels of HC functioning across sub-districts. Alternatives to monetary compensation were also considered, as a clinic manager illustrated:

\footnotetext{
“... what came out for me also is how to motivate your community to take part. Not to just think of the money, but to think of something that is a stepping stone for them to maybe get a job. It is information that can go on their CVs at the end of the day. They gain experience, they gain knowledge, they meet new people. [...] However, the negative of that is that people then sometimes expect to be placed in a position... Because of the high unemployment rate at the moment, people don't want to work for free. So there, we also need to then get people to become creative with how they can raise funds."
}

Other key challenges in working together with HCs were indicated to be a misunderstanding of and lack of mutual respect for one another's roles and responsibilities, leading to crossing boundaries and, consequently, mistrust. A clinic manager illustrated:

\footnotetext{
"One of the negative things could be that HC members feel that they can work with clients and they have the authority to go through, to handle clients' folders, because they are the health committee." She advised: "People [everyone at the clinic] should know their role and function, they [HCs] should be aware of their role and function, then we won't step on the other's toes."
} 
Trust building was more generally perceived to be promoted by training and clear guidelines on roles and functions, providing the $\mathrm{HC}$ with an opportunity to present on their roles and responsibilities, maintaining honesty as well as establishing a common vision at the start. Furthermore, HPs identified HCs' attitudes and judgment as challenging to their relationships. As expressed by a clinic manager: "I think if both of us [HPs and community members] have a positive attitude towards one another, we can move mountains." Moreover, power differences were recurrently understood to be resolved by understanding and setting clear cut roles and responsibilities, ensuring transparency and sharing power equally. As formulated by a clinic manager: "Do not run, do not make me your subordinate, but make me somebody that you work with, then I think we could function."

Five participants stated that they would not engage differently as they were already dealing with community related issues, the HC was already functioning well, or they had established a relationship in which there was an awareness of boundaries. Other reasons for not being completely convinced of different personal engagement were the HCs' lack of visibility in the participants' current position and the need for time off work to engage with them. In contrast, a programme officer indicated that she would assist the facility managers in the $\mathrm{HC}$ role, even though she was not working with HCs herself. Nurses said they would consult the $\mathrm{HC}$ about ways to improve health talks, to provide more guidelines regarding $\mathrm{HC}$ functions, and to involve them in decision-making pertaining to the community. Clinic managers intended to actively participate in meetings more regularly, request help in various work areas, and to invite the local government councillor to assist in establishing a new committee. Another clinic manager said that the training, because it provided self-development and stimulated an awareness of what is happening at other facilities, made her willing to improve her relationship with other $\mathrm{HC}$ stakeholders. Other participants intend to encourage the $\mathrm{HC}$ to run a helpdesk and facilitate active co-operation between all HC members and HPs.

Two clinic managers contacted the local government councillor regarding the $\mathrm{HC}$ as a result of the training. In one instance, it had not yet been possible to reach the councillor, and in the other, the councillor would connect the clinic manager to an active community member who could become involved. Aside from these two cases, most intentions to change practices remained intentions for the duration of this evaluation, with some participants feeling constrained by their superiors. A clinic manager pointed out that her manager questioned her training attendance because of her workload. Some participants therefore perceived it relevant to train other health care providers, such as the sub-district managers and the second in charge. An environmental health practitioner said: "At the beginning I was told not to make myself clever. [...]I don't think I can take initiative on this, because it's not part of my work."

\section{DISCUSSION}

This section discusses the above reported post-training responsiveness of HPs to HCs as community-based governance structures. Further, we shed light on the potential contribution of HPs' enhanced responsiveness to the people-centeredness of health systems. Moreover, study and training limitations as well as recommendations are described.

The evaluated HP training cross-cuts the six key mechanisms to HP responsiveness identified in Lodenstein et al. (2017a) realist review of social accountability initiatives in LMICs. In their proposed programme theory, the authors suggest that HP responsiveness outcomes are influenced by (i) HPs' perceptions on the legitimacy of the social accountability initiative, (ii) their feelings of support, safety, appreciation, and (iii) of moral responsibilities and obligations, (iv) their fear for public or professional reprisal, (v) their self-identification with the initiative's claims or ideals and perceived self-capacity to act, and (vi) their perceptions on health care users. The authors categorise HP responsiveness outcomes as "receptivity," "relations," and "responsiveness." In Table 3, the earlier described themes and findings on HP reported post-training understandings, intentions and practices towards HC functioning are organised by these HP responsiveness outcomes (Lodenstein et al., 2017a). The contextual factors of potential influence as identified by HPs and, to a lesser extent, in the discussion below are also summarised in this table.

\section{Receptivity}

"Receptivity" is the collection of attitudes, awareness and acceptance around the social accountability initiative. Following training, $\mathrm{HCs}$ were increasingly perceived as beneficial to the facility, besides their benefit to the community. HPs increased responsiveness towards HCs' roles and responsibilities consisted of improved understandings of what these roles and responsibilities are and how to support them. Furthermore, HPs increasingly welcomed the active involvement of the local government councillor and the environmental health practitioner as HC members, as well as engagement with other community stakeholders. This receptivity can form a foundation for enhancing relations and health services responsiveness outcomes, thereby facilitating the availability of health services, mobilisation or reallocation of resources and targeting the environmental and socio-economic determinants of health. This would contribute toward the holistic approach of people-centred health care and systems and the right of everyone to a complete state of social, mental and physical well-being (Backman et al., 2008; WHO, 2015). However, HP receptivity to HCs is subject to $\mathrm{HP}$ identified contextual influences such as mutual respect, trust and (feeling subjected to) HC community members' judgment.

\section{Health Service Responsiveness}

To avoid confusion with our own definition of HP responsiveness, we refer to responsiveness as the outcome of HP responsiveness as "health service responsiveness." It is defined by the concrete actions towards improving service provision in line with citizen concerns (Lodenstein et al., 2017a). HPs contribute to people-centred, needs-responsive healthcare when they provide an enabling environment in which the community is truly represented and participating, can take control of their own health and provided a platform to engage with the health system as a whole (WHO, 2015). HPs showed enhanced understandings and intentions towards the participation and representation of the community in the 
TABLE 3 | Summary of themes and findings on HP post-training responsiveness to HCs and contextual influences.

\begin{tabular}{|c|c|c|c|c|}
\hline $\begin{array}{l}\text { HP reported } \\
\text { post-training } \\
\text { responsiveness }\end{array}$ & $\begin{array}{l}\text { Understandings of } \mathrm{HC} \text { roles and } \\
\text { functions }\end{array}$ & $\begin{array}{l}\text { Intentions to engage } \\
\text { with HCs }\end{array}$ & $\begin{array}{l}\text { Practices } \\
\text { towards } \mathrm{HC} \\
\text { functioning }\end{array}$ & Identified contextual influences \\
\hline Receptivity & $\begin{array}{l}\text { - Local government councillor as part of the } \\
\text { HC } \\
\text { - Importance of engagement with other } \\
\text { community stakeholders } \\
\text { - Mutual importance and benefit of HC as a } \\
\text { liaison body for HPs and community } \\
\text { - HC roles and responsibilities } \\
\text { - How to support the HC }\end{array}$ & $\begin{array}{l}\text { - Invite local government } \\
\text { councillor to assist with } \\
\text { new HC establishment } \\
\text { - Assist clinic manager } \\
\text { with HC roles }\end{array}$ & $\begin{array}{l}\text { - Contacted } \\
\text { local } \\
\text { government } \\
\text { councillor }\end{array}$ & $\begin{array}{l}\text { - Mutual respect } \\
\text { - Understandings of roles and responsibilities } \\
\text { - Crossing of boundaries } \\
\text { - Trust } \\
\text { - HC attitude and judgment }\end{array}$ \\
\hline $\begin{array}{l}\text { Health service } \\
\text { responsiveness }\end{array}$ & $\begin{array}{l}\text { - Avoid duplication of health services and } \\
\text { inform patients on services offered } \\
\text { - Identify outbreak sources - prevent spread } \\
\text { - Fast response of services } \\
\text { - Community mobilisation for campaigns } \\
\text { - Assist with health promotion and patient } \\
\text { recall } \\
\text { - Management of patient flow } \\
\text { - Help with: decision-making regarding } \\
\text { community, planning health service } \\
\text { transitions, complaint management, } \\
\text { resource motivation }\end{array}$ & $\begin{array}{l}\text { - Consult } \mathrm{HC} \text { to improve } \\
\text { health talks } \\
\text { - Involve } \mathrm{HC} \text { in } \\
\text { decision-making } \\
\text { regarding community } \\
\text { - Encourage HC to } \\
\text { run helpdesk }\end{array}$ & Not evaluated & $\begin{array}{l}\text { - Broader community awareness of } \mathrm{HC} \\
\text { presence and roles } \\
\text { - Representativeness of members }\end{array}$ \\
\hline Relations & $\begin{array}{l}\text { - Importance of all members' active } \\
\text { involvement } \\
\text { - Have a common vision from the beginning } \\
\text { and partnership working towards it } \\
\text { - Clear cut roles and responsibilities } \\
\text { - Need for appreciation of HCs } \\
\text { - Trust-building, transparency, honesty } \\
\text { - Community ownership } \\
\text { - Easing tensions } \\
\text { - Community and facility awareness of HC } \\
\text { presence and roles } \\
\text { - Role of training } \\
\text { - Sharing power equally }\end{array}$ & $\begin{array}{l}\text { - Regular, active meeting } \\
\text { participation } \\
\text { - Facilitate active } \\
\text { cooperation between } \\
\text { HC members and HPs } \\
\text { - Provide more guidelines } \\
\text { regarding HC roles }\end{array}$ & Not evaluated & $\begin{array}{l}\text { - HC member commitment and availability } \\
\text { - HC member retention } \\
\text { - Repeated training of HCs* } \\
\text { - Individual agendas } \\
\text { - Governmental priorities }{ }^{\star} \\
\text { - Hierarchy } \\
\text { - Current position held } \\
\text { - Guidelines } \\
\text { - Policy and legal framework } \\
\text { - Workload } \\
\text { - Transport money } \\
\text { - Fund raising initiatives } \\
\text { - System funding priorities } \\
\text { - Clinic manager availability (workload, after } \\
\text { hour-HC meetings, other meetings) }\end{array}$ \\
\hline
\end{tabular}

*Identified in the discussion.

setting of goals, decision making and problem solving regarding their identified needs, concerns, and expectations. The extent to which the needs-responsiveness of local health services can be improved will be influenced by the level of awareness of $\mathrm{HC}$ presence and roles amongst the broader community as well as the extent to which $\mathrm{HC}$ members are representative of the community that the facility serves. The exact extent to which HCs would be promoted to actively participate in the monitoring, strategizing, and planning of service delivery, and the weight of their participation in the decision-making remains unclear and is dependent of HP-HC relations.

\section{Relations}

The "relations" outcome is described by the changes in interactions and accountability between communities and HPs. This outcome appears to be the most dynamic in nature. Similarly to the other HP responsiveness outcomes, the relations outcome influences and is influenced by the other two outcomes. Following training, HPs expressed understandings and intentions towards the active involvement of all HC members, their own regular active participation in meetings, and strategies for the building and strengthening of relationships. Such understandings of strategies promotive of HCs' role in building trust included the setting of clear roles and responsibilities, appreciating HCs and working towards a common vision in equal partnership. These HP understandings and intentions can facilitate an enabling environment and opportunities for community members to meaningfully participate in the strengthening of governance and accountability within the health system. Hence, HP enhanced responsiveness following training can play a role in decreasing the "participatory deficit" in the way health services are planned and delivered, contributing to the people-centeredness of service delivery (WHO, 2015). The HP-community relations shape the environment in which HP receptivity to HCs can be influenced and determine the extent to which the community participates, subsequently influencing health care responsiveness outcomes. Moreover, HP-community relations are in itself influenced by e.g., the feasibility of $\mathrm{HC}$ meeting times for HPs and priorities of a variety of actors across the system, including HC community members and supervisors. 


\section{Potential Role of Contextual Influences}

When provincial priorities in the Eastern Cape changed, health promotion managers' and health advisors' role to develop, establish and support HCs were only maintained in a few cases after reviving these roles (Boulle et al., 2008). As identified in this evaluation, unresponsive superiors can impede HPs' ability to engage with the HC. In Kenya, sustainability and replication of HC success required more than once-off training of both community members and health staff, continuous follow-up, as well as commitment from district level authorities (Sohani, 2005). A legal framework recognising and specifying HCs' full capacity as well as some funding to facilitate transport costs for meetings may also be required to build sustainable working relationships between HPs and HCs. However, the opposite can be true. In Guinea, a HC's functioning was attributed to the intrinsic motivation of its members and a HC in the DRC developed their own operational guidelines and received voluntary community contributions (Lodenstein et al., 2017b). This evaluation has shed light on the current presence of HPs who are already responsive to $\mathrm{HCs}$, have promoted $\mathrm{HC}$ functioning or have good relationships with HCs irrespective of political agendas. Furthermore, evidence from Sub-Sahara Africa and Bangladesh (Knox, 2009; Tembo, 2013) shows that although policy and legal frameworks are important in formalising $\mathrm{HC}$ power and mandate, their utility can be limited in the absence of a basic level of trust. This suggests that HPs increased responsiveness to community engagement can positively influence opportunities for the community to participate and facilitate $\mathrm{HC}$ functioning despite crosscutting issues and contextual factors affecting their functioning.

Even though there are presumed plans for a national roll out of $\mathrm{HC}$ training through the training of trainers, provincial and national policies appear to only move further away from meaningful community participation in the delivery of PHC (Province of Western Cape, 2016; The Republic of South Africa, 2018). The current nature of implementation of health reforms, the lack of defined allocated power to HCs and the limitations to $\mathrm{HC}$ member selection points at the technocratic nature of participation in the South African health system. If South Africa is to achieve "universal health coverage" with its National Health Insurance Bill approaching finalisation, it is important to underline and advocate for the role HP-HC relationships and HP capacity building can play in the decision-making, planning, and implementation as well as strengthening of needs-responsive and people-centred PHC. However, we acknowledge that despite HP training, HCs will be subject to other contextual influences while navigating the system. Hence, HP training should be part of a concerted effort to improve HC functioning.

\section{Role of Training}

In short, HP training that adopts a rights-based, interactive approach, and cuts across the six mechanisms for change of $\mathrm{HP}$ responsiveness to social accountability initiatives, can promote HP responsiveness outcomes. This study contributes to the conceptualisation of the programme theory proposed by Lodenstein et al. (2017a). The training facilitated HPs', receptivity to HCs and it also provided HPs with the understandings and skills to develop appropriate intentions and, in some cases, implement practices towards building $\mathrm{HC}$ relations and health care responsiveness.

This evaluation confirmed HPs' key role in the functioning of HCs and provides momentum for the wider investigation of the role of such rights-based, interactive training in promoting social accountability initiatives. In light of our findings, we recommend that HP long-term responsiveness to HCs following training is also evaluated and the training is tested in other contexts. Considering the ever-changing relationship dynamics and contextual influences, both HPs and community members could benefit from iterated interactive training over time. For this purpose, the value and feasibility of jointly organised follow up-sessions is worth exploring further.

\section{Limitations}

This study may have been subjected to an inclusion bias. HPs' ability to attend the training could have been influenced by the priorities and workload of their respective clinic or subdistrict at the date of training. Besides, only HPs linked to "City of Cape Town clinics" were included in this study. City of Cape Town clinics differ from other clinics in the Cape Metropole as they are managed by the municipality instead of the provincial government. Historically, these clinics were more health promotional, preventative and community-oriented. The provincially managed health facilities originally delivered curative services only. Some HPs could therefore have already been more responsive to the concept of community participation. Another current difference is that City of Cape Town clinics are managed and run by nurses only.

The changes to training implementation had consequences on the comprehensiveness of the evaluation and may have impacted rigour. Despite willingness from the participants, the lack of opportunity to follow-up on the first training session could illustrate that competing priorities are a challenge in committing to the full, intended training programme. It would therefore be worth exploring the socio-political and economic influences on cross-health system level stakeholders' responsiveness to community participation, HCs and HP training on community participation through HCs.

The study was constrained by time. Ideally, a longer evaluation period could have allowed for time to translate, pilot and validate the questionnaires. The absence of the translation of our methods into most participants' first language limited the cultural acceptability of our methods, potentially losing out on local meaning and cultural connotations. Nonetheless, the questionnaire responses were consistent with the training observations and there was room for the exchange of crosscultural and -lingual understandings during training sessions and semi-structured interviews. A longer study period could have facilitated a push for the rescheduling of follow-up sessions. Participants raised issues for discussion in these sessions which could have further developed HPs' practical skills to establish a common vision, host a $\mathrm{HC}$ meeting and manage conflict. This can be a limitation to the implementation of participants intended strategies. It would also be recommended to further investigate the role of training on the long term responsiveness of HPs in 
building working relationships with $\mathrm{HCs}$ and on $\mathrm{HC}$ functioning. For instance, a documentary review of the HC meeting minutes was initially proposed in order to assess HPs' pre and posttraining interactions with HCs.

\section{CONCLUSION}

Interactive, rights-based training of HPs on community engagement can enhance HP responsiveness to HCs. As a result of this training, HPs were receptive of HCs as community-based accountability structures. Furthermore, they demonstrated understandings of and intentions towards the strengthening of $\mathrm{HP}-\mathrm{HC}$ relationships and the promotion of $\mathrm{HC}$ roles and responsibilities in the delivery of $\mathrm{PHC}$. HPs' responsiveness following training can facilitate $\mathrm{HC}$ potential to improve the needs-responsiveness of PHC and the people-centeredness of health systems. Considering the contextual influences that HP responsiveness can be subjected to, this training should be tested and evaluated further.

\section{AUTHOR CONTRIBUTIONS}

GZ designed the study, collected, and analysed the data. MS and $\mathrm{HH}$ provided feedback and input throughout these

\section{REFERENCES}

Backman, G., Hunt, P., Khosla, R., Jaramillo-Strouss, C., Fikre, B. M., Rumble, C., et al. (2008). Health systems and the right to health: an assessment of 194 countries. Lancet 372, 2047-2085. doi: 10.1016/S0140-6736(08)61781-X

Barron, P., Shasha, W., and Schneider, H. (2010). Re-Engineering Primary Health Care in South Africa. Discussion Document. Pretoria: South African Department of Health.

Boulle, T. (2013). A Review of the Functioning of Health Committees in Nelson Mandela Bay Health District - With Particular Emphasis on Identifying Key Challenges. The Learning Network on Health and Human Rights. Available online at: http://www.salearningnetwork.uct.ac.za/sln/publications/ other-reports (accessed October 15, 2018).

Boulle, T., Makhamandela, N., Goremucheche, R., and Loewenson, R. (2008). Promoting Partnership Between Communities and Frontline Health Workers : Strengthening Community Health Committees in South Africa. Community Development Unit, Nelson Mandela University South Africa. Harare: EQUINET.

Chikonde, N. (2017). Training Clinic Health Committees: a Vehicle for Improving Community Participation in Health. Dissertation/master's thesis. Cape Town: University of Cape Town. Available online at: https://open.uct.ac.za/handle/ $11427 / 27060$

Eastern Cape Department of Health (2009). Policy on the Establishment and Functioning of Clinic and Community Health Centre Committees: Final Draft.

George, A., Mehra, V., Scott, K., and Sriram, V. (2015b). Community participation in health systems research: a systematic review assessing the state of research, the nature of interventions involved and the features of engagement with communities. PLoS ONE 10:e0141091. doi: 10.1371/journal.pone.01 41091

George, A., Scott, K., Garimella, S., Mondal, S., Ved, R., and Sheikh, K. (2015a). Anchoring contextual analysis in health policy and systems research: a narrative review of contextual factors influencing health committees in low and middle income countries. Soc. Sci. Med. 133, 159-167. doi: 10.1016/j.socscimed.2015.03.049 stages. GZ wrote the manuscript on which $\mathrm{MS}, \mathrm{HH}$, and LL provided feedback.

\section{FUNDING}

This research was financially supported by the European Union (EU Grant Number: DCI-AFS/2012/302-996), the Canadian International Development Research Centre (IDRC Project Number: 106972-002), and the South African National Research Foundation (Grant Number: 116270).

\section{ACKNOWLEDGMENTS}

This study would not have been possible without the City of Cape Town Health Department and their respective subdistrict managers granting permission for health care providers to be recruited for the training and evaluation thereof. Finally, we would like to express our gratitude to the health care providers for their voluntary participation in this study as well as Prof. Pat Mayers and Ms. Fundiswa Kibido for facilitating and kindly accommodating the evaluation of the training. The dissertation by GZ, submitted in partial fulfilment of the Master of Public Health at the University of Cape Town, formed the foundation of the work presented in this paper (Zwama, 2016).

George, A., Scott, K., Mehra, V., and Sriram, V. (2016). Synergies, strengths and challenges: findings on community capability from a systematic health systems research literature review. BMC Health Serv. Res. 16:623. doi: 10.1186/s12913-016-1860-1

Gilson, L., and WHO. (2012). Health Policy and Systems Research: a Methodology Reader. Geneva: WHO.

Glattstein-young, G. (2010). Community Health Committees as a Vehicle for Participation in Advancing the Right to Health. Dissertation/master's thesis. Cape Town: University of Cape Town.

Goodman, C., Opwora, A., Kabare, M., and Molyneux, S. (2011). Health facility committees and facility management-exploring the nature and depth of their roles in Coast Province, Kenya. BMC Health Serv. Res. 11:229. doi: 10.1186/1472-6963-11-229

Haricharan, H. (2012). Extending Participation: Challenges of Health Committees as Meaningful Structures for Community Participation: a Study of Health Committees in the Cape Town Metropole. The Learning Network on Health and Human Rights. Available online at: http://www.salearningnetwork.uct.ac. $\mathrm{za} / \mathrm{sln} /$ publications/other-reports (accessed October 15, 2018).

Haricharan, H. (2013). Rapid Appraisal of Health Committee Policies in South Africa. The Learning Network on Health and Human Rights. Available online at: http://www.salearningnetwork.uct.ac.za/sln/publications/ other-reports (accessed October 15, 2018).

Haricharan, H. (2017). Presentation: Evaluation of the LN EU Project With Health Committees. Available online at: http://www.salearningnetwork.uct.ac.za/sln/ publications/presentations (accessed October 15, 2018).

Hunt, P., and Backman, G. (2007). Health Systems and the Right to the Highest Attainable Standard of Health. Colchester: Human Rights Centre, University of Essex.

Knox, C. (2009). Building trust amidst corruption in Bangladesh. Round Table 98, 449-459. doi: 10.1080/00358530903017972

Kolb, D. A. (1984). Experiential Learning: Turning Experience into Learning. New Jersey, NJ: Prentice Hall.

Lodenstein, E., Dieleman, M., Gerretsen, B., and Broerse, J. E. W. (2017a). Health provider responsiveness to social accountability initiatives in low- and 
middle-income countries: a realist review. Health Policy Plan. 32, 125-140. doi: 10.1093/heapol/czw089

Lodenstein, E., Mafuta, E., Kpatchavi, A. C., Servais, J., Dieleman, M., Broerse, J. E. W., et al. (2017b). Social accountability in primary health care in West and Central Africa: exploring the role of health facility committees. BMC Health Serv. Res. 17:403. doi: 10.1186/s12913-0172344-7

Loewenson, R., Machingura, F., Kaim, B., and Rusike, I. (2014). Health Centre Committees as a Vehicle for Social Participation in Health Systems in East and Southern Africa. Training and Research Support Centre with CWGH and Medico. Harare: EQUINET.

Marshall, A., and Mayers, P. (2015). Community Engagement for Quality Care : a Health Workers Training Manual. University of Cape Town. Available online at: http://hdl.handle.net/10625/55377 (accessed October 15, 2018).

McCoy, D., Hall, J., and Ridge, M. (2012). A systematic review of the literature for evidence on health facility committees in low- and middleincome countries. Health Policy Plan. 27, 449-466. doi: 10.1093/heapol/ czr077

Meier, B., Pardue, C., and London, L. (2012). Implementing community participation through legislative reform: a study of the policy framework for community participation in the Western Cape province of South Africa. BMC Int. Health Hum. Rights 12:15. doi: 10.1186/1472698X-12-15

Mosquera, M., Zapata, Y., Lee, K., Arango, C., and Varela, A. (2001). Strengthening user participation through health sector reform in Colombia: a study of institutional change and social representation. Health Policy Plan. 16(Suppl. 2), 52-60. doi: 10.1093/heapol/16. suppl_2.52

Padarath, A., and Friedman, I. (2008). The Status of Clinic Committees in Primary Level Public Health Sector Facilities in South Africa. Durban: Health Systems Trust.

Pawson, R., and Tilley, N. (1997). Realistic Evaluation. London: SAGE Publications.

Potts, H. (2008). Participation and the Right to the Highest Attainable Standard of Health. Colchester: Human Rights Centre; University of Essex.

Province of Western Cape (2016). Western Cape Health Facility Boards and Committees Act.

Sohani, S. (2005). Health Care Access of the Very Poor in Kenya. Workshop Paper 11: Meeting the Health Related Needs of the Very Poor. Kenya: DFID.

Tembo, F. (2013). Rethinking Social Accountability in Africa: Lessons from the Mwananchi Programme. UKAID: Mwananchi Programme.
The Learning Network for Health and Human Rights (2014). Health Committee Training Participant Manuals. Available online at : http:// www.salearningnetwork.uct.ac.za/sln/resources/training-materials/manuals

The Republic of South Africa (1996). Constitution of the Republic of South Africa, Act 108.

The Republic of South Africa (1997). Government Gazette, General Notice 1459 of 1997, Department of Public Service and Administration.

The Republic of South Africa (2004). National Health Act No.61 of 2003.

The Republic of South Africa (2018). National Health Insurance Bill.

United Nations Committee on Economic Social and Cultural Rights UNCESCR (2000). General Comment No. 14: The Right to the Highest Attainable Standard of Health (Art. 12 of the Covenant). Available at: http://www.refworld.org/ docid/4538838d0.html (accessed October 15, 2018).

Western Cape Government (2018). Socio-Economic Profile City of Cape Town 2017. WHO (1946). Constitution. Basic Documents. New York, NY: WHO.

WHO (1978). Declaration of Alma-Ata. The International Conference on Primary Health Care (Alma-Ata, USSR). Geneva: WHO.

WHO (2007). People at the Centre of Health Care. Harmonizing Mind and Body, People and Systems. Geneva: WHO Western Pacific Region.

WHO (2015). WHO Global Strategy on People-Centred and Integrated Health Services: Interim Report. Geneva: WHO.

Zambon, V. D., and Ogata, M. N. (2011). Municipal Health Council Compositions in the State of São Paulo. Rev. da Esc. Enferm. da USP 45, 890-897. doi: $10.1590 /$ S0080-62342011000400014

Zwama, G. (2016). Improving Health Care Provider-Health Committee Working Relationships for Responsive, People-Centred Health Systems. Dissertation/master's thesis. Cape Town: University of Cape Town. Available online at: https://open.uct.ac.za/handle/11427/23422

Conflict of Interest Statement: The authors declare that the research was conducted in the absence of any commercial or financial relationships that could be construed as a potential conflict of interest.

Copyright $\odot 2019$ Zwama, Stuttaford, Haricharan and London. This is an openaccess article distributed under the terms of the Creative Commons Attribution License (CC BY). The use, distribution or reproduction in other forums is permitted, provided the original author(s) and the copyright owner(s) are credited and that the original publication in this journal is cited, in accordance with accepted academic practice. No use, distribution or reproduction is permitted which does not comply with these terms. 


\section{Plain English Summary}

\section{Towards co-productive learning? The Exchange Network as experimental space}

\section{Rachel Matthews, Constantina (Stan) Papoulias}

Healthcare policy provides Patient and Public Involvement guidance and toolkits are available to shape and influence practice. Despite this, practice can fall short of expectations. An overlooked factor is the limited attention paid to the way interpersonal relationships can generate new ideas, insight and knowledge. In this paper, we share our experience of taking part in the Exchange Network (EXN), which is a new learning space for patients, carers, researchers, clinicians and managers. We highlight the co-designed methods that were tested over time as an original way of bringing people together. We suggest this can change practice and is a necessary step towards co-production.

The EXN operates in an inclusive open way that respects all voices. Members are supported to let go of habits linked with their professional roles - for example giving instructions and advice. They ask open questions to understand beliefs and values, while the facilitators actively listen, respect all contributions and note differences. Any discomfort and unease that arises helps to generate understanding and insight. The EXN is founded on the principles of patient leadership: that is, on an understanding that patient and carer experience is a valuable form of knowledge which can be used to encourage change in organisations. We suggest that the EXN represents an experimental approach to learning and joint working. It operates in a space which changes the traditional rules and rigidity about how patients and professionals interact. The growth in membership and the bonds that have formed between members show how much it is valued. These have led to invitations to collaborate beyond the EXN meetings (in teaching and as co-applicants in research bids).

We realise that such work on its own may not be sufficient to overturn inequalities in established organisational cultures in which patient leadership is not the norm. Nevertheless, we argue that having a space in which to focus on relationships and on challenging professional assumptions is key if we wish to work co-productively within healthcare. 


\section{OPEN ACCESS}

Edited by:

Gill Green,

University of Essex, United Kingdom

Reviewed by:

Tricia Wilson

University of Kent, United Kingdom

Gary Hickey,

National Institute for Health Research

(NIHR), United Kingdom

*Correspondence:

Rachel Matthews

r.matthews@imperial.ac.uk

†These authors have contributed equally to this work

Specialty section:

This article was submitted to Medical Sociology

a section of the journal

Frontiers in Sociology

Received: 31 October 2018

Accepted: 04 April 2019

Published: 24 April 2019

Citation:

Matthews $R$ and Papoulias C (2019) Toward Co-productive Learning? The Exchange Network as Experimental

Space. Front. Sociol. 4:36. doi: $10.3389 /$ fsoc. 2019.00036

\section{Toward Co-productive Learning? The Exchange Network as Experimental Space}

\author{
Rachel Matthews ${ }^{1 * \dagger}$ and Constantina (Stan) Papoulias ${ }^{2 \dagger}$ \\ ${ }^{1}$ National Institute for Health Research (NIHR), Collaboration for Leadership and Applied Health Research and Care \\ (CLAHRC) for Northwest London, Imperial College London, London, United Kingdom, ${ }^{2}$ Health Service and Population \\ Research, King's College London, London, United Kingdom
}

Policy around patient and public involvement (PPI) in the production, design and delivery of health services, and research remains difficult to implement. Consequently, in the UK and elsewhere, recent years have seen a proliferation of toolkits, training, and guidelines for supporting good practice in PPI. However, such instruments rarely engage with the power asymmetries shaping the terrain of collaboration in research and healthcare provision. Toolkits and standards may tell us little about how different actors can be enabled to reflect on and negotiate such asymmetries, nor on how they may effectively challenge what count as legitimate forms of knowledge and expertise. To understand this, we need to turn our attention to the relational dynamic of collaboration itself. In this paper we present the development of the Exchange Network, an experimental learning space deliberately designed to foreground, and work on this relational dynamic in healthcare research and quality improvement. The Network brings together diverse actors (researchers, clinicians, patients, carers, and managers) for structured "events" which are not internal to particular research or improvement projects but subsist at a distance from these. Such events thus temporarily suspend the role allocation, structure, targets, and other pragmatic constraints of such projects. We discuss how Exchange Network participants make use of action learning techniques to reflect critically on such constraints; how they generate a "knowledge space" in which they can rehearse and test a capacity for dialogue: an encounter between potentially conflictual forms of knowledge. We suggest that Exchange Network events, by explicitly attending to the dynamics and tensions of collaboration, may enable participants to collectively challenge organizational norms and expectations and to seed capacities for learning, as well as generate new forms of mutuality and care.

Keywords: co-production, collaboration, action learning, reflexivity, patient and public involvement, quality improvement

\section{INTRODUCTION}

This article aims to contribute to a literature that examines the complex, uneven, and often contradictory dynamics underpinning participatory approaches to health research and service development. The involvement of patients, carers, and the public in healthcare research and quality improvement is an established policy imperative in the UK and internationally, for 
example in Canada, Australia, and Scandinavia (Ministry of Health and Care Services, 1999; Boivin et al., 2010; Farmer et al., 2018). In the UK, the National institute for Health Research as well as other major health research bodies expect plans for such involvement (known as Patient and Public InvolvementPPI) to be detailed in all applications for research funding ${ }^{1}$. This imperative rests on a claim that when people are involved in the development of treatments and healthcare practices and in decisions around their provision, outcomes, and treatment relevance can be improved while care failures and research waste can be minimized (Carter et al., 2013; Chalmers et al., 2014). However, policy around PPI in the production, design, and delivery of health services remains difficult to implement, in part because the demand for involvement is underpinned by different and potentially conflicting rationales conceptualizing its nature, aims, and values (Knaapen and Lehoux, 2016). For example, the claim that patient involvement will increase the relevance of treatments and services points to both a potential democratization of health services in accordance with citizen needs and values, and a managerialist requirement for efficient services. The latter requirement can come into conflict with the former when it is employed to facilitate decommissioning in the guise of consumer choice (Beresford, 2003). It is also the case that a substantive incorporation of "lay" perspectives and insights into research and service redesign may necessitate too radical a transformation of what counts as legitimate forms of knowledge and expertise and may put into question the power relations which sustain such expertise (Rose, 2017). As a result, many initiatives are limited to an ad hoc or tokenistic level, where service users may, at best, have some input in refining minor aspects of the project (typically information sheets and promotion literature), but carry little weight in the overall shaping of healthcare interventions as well as in decisions about commissioning and healthcare provision more generally (Ocloo and Matthews, 2016; O'Shea et al., 2017). Furthermore, there is considerable evidence that those most affected by health inequalities (such as black and minority ethnic populations, older and younger people) remain "seldom heard" in PPI initiatives (Beresford, 2013; Dawson et al., 2018). In this context a growing body of literature seeks to improve practice by identifying barriers and facilitators of PPI; generating evidence of the impact of PPI in research and quality improvement and producing roadmaps for its successful implementation (The PiiAF Study Group, 2014; Staley, 2015; Stocks et al., 2015; Wilson et al., 2015; Staniszewska et al., 2017).

While the emergence and proliferation of this literature points to a desire to stabilize and clarify what might constitute "good PPI," some see this proliferation as contributing to form of "busywork" which fails to challenge the power asymmetries through which broader socio-cultural inequalities enter and

\footnotetext{
${ }^{1}$ In this paper we are broadly following a distinction between involvement (patients actively involved in design and decision making in clinical research and quality improvement), and participation (patients taking part in research as participants). This distinction is laid out by INVOLVE, the UK national advisory group on public involvement in research (see https://www.invo.org.uk/find-out-more/ what-is-public-involvement-in-research-2/).
}

shape the terrain of collaboration in research and healthcare provision (Madden and Speed, 2017). Others have argued that clinicians' and managers expectation that patients' unique perspective can provide solutions to particular problems in research or healthcare provision, may perpetuate an extractive logic of passive patients as resources to be mined (Gilbert, 2018). Furthermore, while the emotional force of patient narratives is frequently noted, there is little evidence that such narratives alone can have a lasting transformative effect on clinicians' and researchers' practice (Adams et al., 2015). In this context, guidelines, toolkits, and standards, although helpful for the planning and budgeting of involvement activities, may tell us little about how different actors can be enabled to reflect on, negotiate and, where necessary, challenge such power asymmetries within a process of knowledge generation. A mechanistic focus on barriers and facilitators does not necessarily advance our understanding of the relational dynamic of collaboration in which different and potentially conflictual forms of knowledge are brought into play (Tritter and McCallum, 2006). To address this, a growing number of studies of PPI make use of ethnography and observation to explore how organizational cultures may constrain collaboration. For example the rigidity and episodic nature of steering group meetings as well as their formal apparatus (agendas, reports, and minutes) may disallow the development of trust and shared habits of work (Martin and Finn, 2011). Furthermore, existing disciplinary and institutional frameworks may work to constrain, neutralize, and appropriate patient voices (El Enany et al., 2013; Renedo et al., 2018).

Yet, while ethnographic methods have provided powerful analyses of what fails to happen in many PPI initiatives, there have been fewer attempts to analyse how alternative forms of collaboration between healthcare professionals and patients can adjust the relational choreography of PPI encounters and open up their transformative potential (Aveling and Jovchelovitch, 2014). Such attention would require a shift away both from listing barriers and facilitators, and from anatomizing ever more precisely all the reasons why PPI initiatives fail to work. Rather, it would demand, we argue, paying more attention to finding ways to enact collaboration differently-and to analyzing how such collaboration might work, unevenly and asymmetrically, in practice. In this paper, then, we turn our attention to the development of the Exchange Network, an innovative endeavor which seeks to foreground and reflect on the dynamics of collaboration themselves and explicitly utilize them as a site of learning.

\section{THE EXCHANGE NETWORK: AN EXPERIMENTAL SPACE}

The Exchange Network (henceforth abbreviated as EXN) is an experimental space which brings together diverse actors (researchers, clinicians, patients, carers, and managers) with the aim of attending to and transforming the relational dynamics of collaboration. Crucially, it does so by providing a shared environment which does not arise within a research 
or improvement project or as a mechanism of organizational oversight but subsists independently and at a distance from these. This distance is both geographic (meetings occur outside institutional spaces) and conceptual: the EXN aims to temporarily suspend the role allocation, timeframe, organizational demands, and other pragmatic constraints of research and improvement projects. We argue that in so doing, the EXN functions as a "knowledge space" (Elliott and Williams, 2008; Gibson et al., 2012): a site which potentiates a dialogic encounter between participants by negotiating the power relations which underpin this encounter.

In this paper, we provide a schematic account of the form, setting, iterative emergence, and key features of the EXN as it is currently organized, to give due attention to how a focus on its choreography might open up some of the-often obscured-aspects that help us understand what is at stake in PPI initiatives. We then proceed to analyse this choreographyand consider how and to what extent the EXN can negotiate the conflicting rationales animating PPI work and interrogate the power relations that underpin it.

Our account of the EXN is not a presentation of research findings. We have not conducted formal research on the workings of the network: rather, this paper seeks to critically elaborate the position of intimacy from which we both write: one of us (RM) is a healthcare professional who has been involved in the co-design of the EXN from its inception and is currently the custodian of the space; the other (CP) is a service user academic who joined the EXN as a critical friend over a period of 2 years. We write from within the choreography rather than analyse it from the outside-and this undoubtedly allows us to describe certain features and dynamics of the EXN at the same time as it makes us less aware of others. This article is offered as a token of our collaboration and as an invitation to engage with the generative logic of the EXN.

\section{SETTING}

The EXN emerged during the tenure of the NIHR Collaboration for Leadership in Applied Health Research and Care (CLAHRC) NorthWestLondon. The CLAHRCs are infrastructure grants specific to English regions and awarded on 5-year cycles by the Department of Health and Social Care since 2009. Their purpose is to expedite improvements in the national health service (NHS) on a local level through translation of research evidence into clinical practice and through establishing sustainable partnerships across a number of stakeholders (universities, health service trusts, commissioners, charities). Since the CLAHRCs are mechanisms set up to improve clinical outcomes in a region, the funder places strong emphasis on demonstrable involvement by service users and/or carers in that region. There are currently 13 CLAHRCs covering most regions in England; with each one bringing a distinctive focus to this objective, both in terms of the specific health services they concentrate on and in terms of the kinds of partnership they favor. CLAHRC North West London focuses on developing emergent quality improvement and evidence translation models capable of acknowledging the complexity of healthcare systems. This means that such models work by eschewing solution based interventions, tolerating uncertainty, and engaging multiple actors in improvement efforts (Reed et al., 2014, 2018). In adopting these models, this CLAHRC could be said to foster a collectivist culture privileging the relational and contingent aspects of knowledge production and improvement (Renedo and Marston, 2015). This orientation provided a hospitable setting for experimentation with innovative forms of patient and carer involvement.

\section{RATIONALE AND PHASED EMERGENCE}

The EXN developed through a collaboration between service users and carers with PPI leads and managers working together through CLAHRC North West London funding. An initial team of 13 people came together through a series of externally facilitated meetings to explore possibilities for an alternative working practice. Participants had been involved in earlier CLAHRC improvement projects and "effective patient" training initiatives and shared a professed dissatisfaction with what they perceived as the tokenism and top-down dynamic of customary PPI practice. The group were encouraged to work in an experimental manner, embedding the ethos of CLAHRC North West London quality improvement models and resisting pressure to make assumptions about what shape such a space could take. Broadly, the EXN developed in three phases through exploratory, design and testing work (Table 1). Initial "exploratory" meetings between 2013 and 2014, tried out a plurality of organizing values for the future design of the network. Chief among these was an enduring orientation toward an ethos of co-production, as this was expressed in a set of principles developed by the National Endowment for Science Technology and the Arts (NESTA), a London based foundation which favors participatory approaches to public sector innovation. These principles, themselves an adaptation of the values laid out in Edgar Cahn's democratizing model of co-production, include a recognition of people's different assets; the development of reciprocal relationships between professional and lay members of a team; an emphasis on establishing networks; the development of activities to fit people's skills; an orientation toward personal development (Cahn, 2000; NESTA, 2012). The team recognized that adopting this model in its entirety might be beyond their capacity at present and settled instead on one of the principles: the development of reciprocal relationships in collaborative spaces. The proposed name of the emergent formation-initially "exchange group" later evolving to "exchange network"- signaled a similar attentiveness and, in particular, the ambition of the group to develop a certain practice of reciprocity: "exchange" pointed to a give-and-take which would define the nature of the workshops; "network" testified to the open, fluid and inclusive nature of the space.

In 2014, the initial team, having established potential organizing principles and aspirations for the group, proceeded to a second, "design" phase, in order to determine how to make the network "live.' This meant parsing out of the initial themes a coherent infrastructure and mechanisms capable of forming and sustaining the group (membership, learning methods, payment, evaluation strategy). In 2015, the actualization of 
TABLE 1 | Evolution of the exchange network.

\begin{tabular}{|c|c|c|c|}
\hline & Explore phase & Design phase & Test phase \\
\hline Membership & $n=13$ & $n=13$ & $n=65$ \\
\hline Meetings & $n=3$ & $n=3$ & $n=17$ \\
\hline Meeting design & Chaired or facilitated & Facilitated & Co-facilitated \\
\hline Structure & Agenda & Question based agenda & Semi-structured \\
\hline Content & Imposed & Negotiated & Negotiated, co-designed \\
\hline Sample content & Ground rules & Roles and responsibilities & Involvement as an aspect of mental health recovery \\
\hline \multirow{4}{*}{$\begin{array}{l}\text { Influential features introduced following } \\
\text { reflection }\end{array}$} & \multirow[t]{4}{*}{ Third party facilitator } & \multirow[t]{4}{*}{ Using questions to frame discussions } & Action Learning \\
\hline & & & Dialogic process \\
\hline & & & Explanatory materials \\
\hline & & & Pre-attendance interviews \\
\hline $\begin{array}{l}\text { Integration with NIHR CLAHRC NWL } \\
\text { programme }\end{array}$ & No & No & $\begin{array}{l}\text { Yes, through collaborative learning events and } \\
\text { improvement leader fellowship }\end{array}$ \\
\hline $\begin{array}{l}\text { Connections outside of NIHR CLAHRC } \\
\text { NWL }\end{array}$ & No & Yes (new design group members) & $\begin{array}{l}\text { Yes e.g., (NIHR CLAHRCs South London, North } \\
\text { Thames, West Midlands, CCG representative, PhD } \\
\text { students, NHS clinicians, community contacts) }\end{array}$ \\
\hline
\end{tabular}

TABLE 2 | Test phase plan-do-study-act-cycles-testing form and function.

\begin{tabular}{llll}
\hline No & Date & Title & \\
\hline 1 & $04 / 02 / 2015$ & Complete cycle? \\
2 & $28 / 04 / 2015$ & Acceptability of membership and asset mapping forms & Yes \\
& Can an early planning conversation with Exchange Network Members & Yes & No \\
3 & $06 / 05 / 2015$ & How do we extend the network? & Yes \\
4 & $17 / 09 / 2015$ & Welcoming new members and introducing group tasks & No \\
5 & $19 / 11 / 2015$ & Welcoming new members and introducing group tasks-repeat & \\
6 & $17 / 03 / 2016$ & Welcoming new members and introducing group tasks-repeat & \\
7 & $16 / 06 / 2016$ & Activating new members to contribute & Yes \\
8 & $01 / 09 / 2016$ & Activating new members to contribute-repeat & Yes \\
9 & $24 / 11 / 2016$ & Activating new members to contribute-repeat & No \\
11 & $15 / 06 / 2017$ & Introduce new co-facilitator & Yes \\
\hline
\end{tabular}

the network began through a "testing" phase, which consisted in the delivery of regular planned events-quarterly meetings of $4-5 \mathrm{~h}$ in duration, iteratively adjusted through plan-dostudy-act (PDSA) cycles (Taylor et al., 2013) (Table 2). During this phase, membership expanded from the initial 13 to 65 through engagement of broader audiences in various CLAHRC collaborative events and other networks. To date (February 2019) 17 such meetings have taken place.

In what follows we focus on particular aspects of EXN development in order to indicate how it attempts to re-orient involvement practice toward a horizon of co-production.

\section{CURRENT FORMAT AND ESSENTIAL FEATURES}

Currently EXN meetings follow a two-part format: each event brings together 15-20 people who gather in an accessible community venue with good transport links. The EXN has no lead as such: however the group is currently administered by one of the founding members employed through CLAHRC funds (RM) who acts as its custodian and moderator. Before each meeting, members are invited to contribute topics or bring particular problems to the room. Each workshop starts in a large group before breaking into smaller sets of four to five. In the morning sessions, the group responds to one or more topics presented by a new or existing member (these vary from troubleshooting a research proposal, offering learning points from a completed project, discussing potential methods for involving patients and the public in proposed collaborationssee Table 3). In the afternoon, members in the smaller facilitated groups take it in turns to work on a specific challenge or issue reported by one amongst their number. These can be research or quality improvement related problems, or equally, issues relating to the work environment itself or the organizational cultures experienced by participants (for example experiences of racism or discrimination). At the end of each session the whole group comes together once more to reflect on learning for the day. These reflections are then used to shape and improve on ensuing meetings. 
TABLE 3 | Examples of "air time" use in the Exchange Network.

- How to be more influential with individuals who hold different power to them for example in a meeting or in a relationship

- Seeking knowledge and feedback on past action in order to inform future action for example successfully recruiting community health champions and then struggling to evolve roles in a meaningful way

- How to obtain information and gain insight without making people defensive

- Sharing embryonic plans to capture patient experience in initiatives to improve care

- Reflecting on the challenges of being a carer for children with long term conditions

- Reflecting on the discrimination experienced as a carer from a BME background

- Practicing how to construct questions that enable people to work out "what matters to them" rather than just asking "what's the matter"?

- Seeking feedback on draft ideas to recruit lay advisors

- Sharing information about contacts and events

- Sharing relevant information and intelligence about local, regional, and international initiatives

EXN meetings make use of action learning sets to activate shared problem solving. Developed by Reg Revans between the 1940 s and 1960s in the context of management education, action learning sets are a set of techniques which aim to enable members of an organization to address emergent complex problems by coming together to learn from each other (Revans, 1982). While there are different orientations in action learning, their shared characteristics include foregrounding the learner; privileging experiential learning over established "expertise" (in Revans' terms "insight" over "programme"); and making use of social interaction for the generation of such learning. Ultimately, the aim of action learning techniques is to be generative-while they have a pragmatic, problem solving focus, they mobilize action on problems through the sustained production of open questions, rather than the provision of answers (Pedler et al., 2005). Speakers present a problem as a starting point and discussion seeks to unpack its premises and, where possible, to challenge the speaker's assumptions about its intractability. In this way action learning proposes a move beyond tackling specific problems, to creating and seeding the capacity for "insight," that is, the ability to "learn how to learn."

These action learning techniques are selectively deployed in EXN meetings: groups are fluid and participants are not expected to turn up every time or to report on progress. Rather than focusing on problem solving, meetings focus on the relational space itself and situate action learning within a broader dialogic/reflexive envelope. This means that participants are not directed to specific actions or held to account for performance. Instead participants are encouraged to challenge their habitual ways of positing and engaging with problems while also focusing on the group dynamic in the room as itself a site of learning. They are encouraged to actively listen by observing the impact verbal and non-verbal communication has on them and the effect they have on others. In doing so participants begin to identify how defensive patterns might circulate across the group and how these patterns may themselves produce and perpetuate opposition and conflict. The use of co-facilitation in the workshops embeds this active listening as the facilitators support the group in reflecting on the dynamics of the encounter. Co-facilitation also supports critical reflection on the nature and impact of individual facilitator styles through the interaction between facilitators. The smaller afternoon groups more closely resemble typical action learning sets, with each participant taking it in turns to present an issue which the others will discuss, while resisting the impulse to give advice or propose a solution. Here different members may volunteer to facilitate, although this role is usually taken up by more regular and established members of the group or those who are more experienced in action learning techniques.

A feedback session which concludes each meeting ensures that the group assumes an active role in the ongoing iteration of a learning space by providing continuous evaluation: the feedback process, elicited through a further series of open questions, allows participants' observations and suggestions to adjust the workshop for consecutive meetings. Furthermore, "air time" issues are followed up where necessary with group emails and sharing of resources.

\section{THE EXCHANGE NETWORK AS A SPACE OF TENSION}

The unique properties of the EXN reside in members' professed determination to move away from the structured approaches characterizing much of patient and public involvement (PPI) and engagement initiatives in both health research and health service delivery (for example, steering/advisory groups or committees, where "patient or carer reps" are included in professional teams) and the armature which sustains these (membership process, terms of reference, agendas, and minute taking). The process of moving away from these structured approaches to PPI is fraught however: in its successive stages, the evolution of the EXN testifies to an ongoing engagement and negotiation of the expectations associated with such structured approaches and with organizational expectations of "output" and a trying out of alternative solutions. Materials generated in the different phases of EXN work bear the traces of this negotiation-it is to these materials we now turn.

A tension between an emphasis on process vs. one on outputs became visible in the early phases of planning and is registered in the notes made during discussions in the exploratory workshops organized to guide the development of the group (Table 4). These notes suggest that the group shared an understanding of the importance of PPI in research and quality improvement, but what this shared understanding is, is never specified, except through an insistence that the group's perspective on PPI is different from and opposed to routine PPI practice and through a sense that their vision is embattled ("our vision is opposed"; "organizations... don't share our goals," "[the group will be] a lifeboat for those who do get it"). Furthermore, the notes include several references to "value" and sketch out competing rationales for the purpose of patient and public involvement: value is perceived as economic benefit, as reduction of research waste, as influence on policy and health services commissioning, as patient activation, self- leadership and individual empowerment or as the "unfreezing" of individuals' assets. Here, distinct forms of social, economic, and personal benefit rub against each other and are held together without resolution, thus posing the question of 
TABLE 4 | Exploratory phase.

\section{WHAT PROBLEM ARE WE TRYING TO SOLVE?}

- More of the "good" stuff'-rapid spread the message of engagement and exporting a culture that has developed through CLAHRC NWL

- Create a product that is useful to a range of people

- Create an impact on health and social care-e.g., commissioning

- Realize individual potential-unfreeze assets

- Realize economic benefits, create value, reduce waste-wide benefits

- Desire to influence what happens outside of CLAHRC (Health and Well-being Boards/local politicians/providers \& CCG's/scope of influence

- Increase diversity - be able to sit with a range of views, create a spirit of inquiry. Ask more questions

\section{WHAT MAKES THE EXCHANGE GROUP DIFFERENT?}

- Relationships formed over an extended period

- Trust-N.B. types of trust

- Regular contact and events

- Spaces created-Fellowship, activation, equal partnerships, catalyst

- Time-allocated to work together, positive encouragement to think and reflect

- Diverse opinion and perspectives

- Relationships

- Authenticity

- Self-leadership

- Learning culture

- Community of practice-networking, connectivity

- WITH and BY, not TO, and FOR

\section{WHY ARE WE CREATING THE EXCHANGE GROUP?}

- To take risks

- A lifeboat for people who do get it

- Connection to a range of tools, support from others

- To provide nourishment and energy

- Networking

- Meet emotional and rational needs

- Compassion/courage/challenge

- Say what others want to be can't

\section{WHAT ARE THE RISKS?}

- Feels like too big a task-break it down into manageable goals

- Need to interact with organizations and individuals who don't share our aims/goals

- Our vision is opposed

- Regression to old culture

how these differing and potentially contradictory aspirations can be reconciled.

In the subsequent "design" phase the initial ambitions are narrowed down in an attempt to sketch out potential outputs for the group. Notes from this phase show that the question of measuring success in concrete terms comes to the fore (Table 5). Here, the initial assertion of a shared vision becomes specified as a demand for a membership strategy, "asset mapping" is proposed as a way of facilitating the "unfreezing of assets," while considerations of reward and payment come to the fore and potential criteria for the measurement of success are suggested (for example, members propose delivering satisfaction surveys, tracking increase in membership, recording social media influence, developing training, or fundraising).

In the next, "testing" phase, as regular workshops start running, the structures, and measures drawn out in earlier phases are tried out, discussed and adjusted. For example, the membership forms and an associated "asset mapping" exercise
TABLE 5 | Design phase.

\section{EMERGING QUESTIONS}

1. A membership strategy (who can join, how do they join, what support can be expected, and how do members leave?)

2. How do we identify and share individual skills, knowledge and experience (asset mapping)?

3. Where do we start with principles of recognition, reward, and payment?

4. How will the "exchange mechanism" work? What are the offers or the menu of opportunities?

5. How will we capture learning and share it with others?

6. How will we demonstrate and measure success?

\section{SUGGESTED SUCCESS MEASURES}

1. Increased number of members

2. Increased number of invitations to external

workshops/meetings/seminars/groups

3. Increased funding

4. Increased outreach

5. Increased menu of opportunities

6. Internal and external collaboration between Exchange Network members

7. Completing tasks, goals and objectives - with accurate record-keeping

8. E-bulletins

9. Shared stories, tips, and tricks

10. Publications, articles, and features

11. Social Media Presence-trending hashtags

12. Impact (for individuals and sectors) measured by satisfaction survey and confidence and ability to voice opinions

13. Involvement with local government-Health and Well-being Boards

14. Becoming involved with CCGS and being "quality" control representatives

15. Certificates or other recognition

16. Training courses - co-training

17. Community and public celebration events

proposed in early workshops are initiated, but participants eventually abandon them stating that it was not clear why that information needed to be collected and how it might be useful for the network. In the absence of such documents and role specifications, alternative ways of explaining what the network is and how it operates are sought, so that new members could be attracted, and retained. While induction documents with information about the history and background to the EXN were initially drafted, these were then abandoned, as participants found that such information failed to reduce discomfort. Furthermore, it was felt that such documents were not useful in communicating the flavor and purpose of the meetings and the way in which each encounter foregrounded the quality of relational dynamics. In the place of induction documents, an informal one-on-one induction was introduced starting in 2016. This consists in brief pre and post-meeting conversations between new members and one of the cofacilitators. These conversations, also modeled on action learning set principles, do not focus on providing information on the meetings, but concentrate instead on asking prospective participants to speak of their expectations, anxieties and possible concerns about them. Additionally, in 2017, facilitators produced a brief document to serve as a more formalized induction to the network (see Supplementary File). This document affirms the orientation of the EXN around co-production, introduces the "operating principles" of dialogic learning and presents "the ladder of inference" a tool adapted from action science work on 
organizational change (Argyris, 1990). The ladder surfaces how tacit beliefs, assumptions and values may shape and determine action and invites the viewer to attend to and transform habits of selective listening. The presence of the ladder on the induction sheet thus visualizes the EXN purpose (a move from a defensive to an open practice of listening) as a simple, memorable image. The document, consisting of two sides of an A4 sheet, is currently distributed to all participants at the beginning of each meeting while facilitators reiterate the principles outlined there, so that all participants, whether regular, occasional or new, can start each workshop on the same footing.

While the EXN enacts parity and active listening in its principles, facilitation, and induction materials, it remains uncertain how far these can reach, or to what extent they can challenge institutional priorities and the logic of performance management in which these are embedded. Feedback comments collected during sessions, while necessarily brief, typically reiterate participants' appreciation of the reflexive approach and open-endedness of EXN workshops and of their difference from the culture of performance and scrutiny typical of the organizations they inhabit. However, participants may on occasion report some anxiety or discomfort with the absence of concrete measurable outputs or follow up action on the problems they may bring. Furthermore, this same open-endedness and fluidity of the meetings also means that on occasion clinicians and researchers may tap into the group in a tokenistic or extractive manner and see it as no different than an advisory or PPI group which is there to serve researchers' predetermined outcomes (for example by improving information sheets and consent procedures).

\section{DISCUSSION}

We have suggested that in proposing to concentrate on the relational dynamics of collaboration the EXN is poised between the undoing and reassertion of organizational values and priorities. In this discussion section, we further open out some of the key arenas through which such possibilities, asymmetries, and tensions take form.

\section{Techniques, Tacit Knowledges, and Rituals of Inclusion}

Typically, PPI work in research and quality improvement is constituted through a series of regular patterned meetings set up as advisory or steering groups. These meetings, while exercising oversight for particular projects, also serve to socialize members to organizational cultures: they install and validate institutional codes, priorities, and appropriate behavior via the circulation of communicative objects (agendas, minutes, or reports) (Schwartzman, 1989). Such objects work to bind new actors into an organizational culture, its timelines, conventions, and expectations, thus enacting a professionalization of outsiders. In so doing, they arguably neutralize the potential of service user knowledges and perspectives to disrupt institutional habits (El Enany et al., 2013; Croft et al., 2016). By contrast, EXN workshops make use of a plurality of techniques borrowed from action learning and dialogic pedagogies in order to cleave apart such organizational habits and interrogate the tacit knowledges and values these embody. The decision to host the EXN in an accessible community venue embodies this intention to relax organizational expectations and allow for a proximity to community concerns. The adoption of an open-ended quality improvement model for EXN events ensures that such events are never decided in advance and brings to the fore their constitutive dynamics instead of rendering these invisible in favor of focusing to the "business-at-hand." EXN communicative objects, such as the induction sheet, also work to bind new members to the culture of the group: the document's references to group principles, to dialogue and to the ladder of inference provide anchor points-what the original patient facilitator called a "structure and container" - for the meetings. The circulation of the document, the act of reading aloud and re-asserting its principles at every meeting thus acquire a ritual function: in reaffirming the group purpose, they generate a sense of belonging and sustain relational inclusivity (Clarke et al., 2019). These acts explicitly reiterate this culture at each meeting as the ongoing work of suspending habit and set it up as something contingent, that is, as what is produced anew in the present of each encounter and is therefore dependent on new members' decision to act in a particular way (to produce open questions, to challenge assumptions and so on).

\section{Action Learning: Compliance and Transformation}

The use of action learning sets in the EXN is far from unique in the context of healthcare organizations. Indeed, there is currently a global proliferation of action learning workshops for healthcare professionals and teams (Chivers, 2005; Attwood, 2007; Mathews et al., 2017) and it can be argued that, since the initial development of action learning sets took place in English state hospitals during the 1960s, Revans' work emerged in response to the specific institutional dynamic of the NHS and as a way of harnessing knowledge and resources from staff in order to improve their ability to function within its organizational complexity. Revans and his successors have written extensively about the ability of action learning techniques to increase efficiency by managing and regulating the particular kinds of risk and anxiety experienced by the NHS workforce (Revans, 1982). In this context some have argued that the increased investment in action learning workshops by healthcare organizations, testifies to their effectiveness as a technology of compliance which aims to ensure that staff at all levels willingly internalize and embed organizational priorities. This internalization means that staff may come to see the implementation of policy imperatives as a marker of personal empowerment and efficacy (Brook,

\footnotetext{
${ }^{2}$ The phrase "structure and container" as well as the selective appropriation of action science techniques relate to the work of patient consultant Mark Doughty who developed these techniques in his earlier collaboration with David Gilbert, at the Centre for Patient Leadership. David Gilbert is currently the first patient director in the British NHS at Sussex Musculoskeletal Partnership (Central), while Mark Doughty is senior consultant in the Leardership and Organizational Development Team at the King's Fund, a think tank working on the health system in England.
} 
2010). However, more recently developed critical action learning approaches have broadened their reach from working with the experiential knowledge of participants to reflecting on and calling into question the assumptions and values which underpin such knowledge (O'Neil and Marsick, 1994). Unlike Revans' original model, critical action learning does not primarily focus on problem solving and on actions emerging as a consequence of group meetings. Rather, it concentrates on the meeting itself, and the affective and communicative dynamics through which a group is constituted. Here, the role of the facilitator or coach is central in ensuring that such dynamics are surfaced as an object of learning. The ethos of these reflexive models resonates in the interactions characterizing EXN meetings. EXN workshops draw attention to facilitation, engagement with the relational climate in the room and the quality of interactions among participants. In so doing they focus on the power dynamics and tensions which constitute the process of collaboration. Since EXN meetings do not operate as conventional action learning sets, there is no expectation that participants will produce an action plan and report on progress in subsequent meetings (although any such report is welcomed). Instead, meetings make use of Argyris' ladder of inference and other tools to identify how established institutional habits may define participants' responses to each other and to loosen the grip of such habits so that participants may develop a capacity for open listening. In some forms of critical action learning, an interrogation of institutional habits can extend to an interrogation of organizational priorities and an understanding of how these may be shaped by and contribute to the perpetuation of wider socio-political inequalities (Marsick and O'Neil, 1999; Rigg and Trehan, 2004; Traeger, 2017). This level of criticality is not explicitly spelled out during EXN meetings, yet the insistence on forging relational literacy through an interrogation of institutional habits also entails an interrogation of how healthcare professional habits may marginalize lay or service user knowledge. In their cultivation of relational literacy and open listening, EXN meetings thus orient action learning principles toward an ethos of co-production, understood here as a critical focus on group dynamics and as building capacity for working with others.

\section{Patient Leadership as a Complex Form}

A discussion of the EXN cannot sidestep the foundational role of patient leadership initiatives to its origins, development and facilitation style. Patient leadership work rests on the argument that the "lived experience" of patients can be repurposed to enact a form of leadership from below, and become a key resource for service improvement, in so far as it works in partnership rather than opposition to healthcare professionals. Its proponents privilege dialogic interaction and develop techniques for building leadership skills with patients while shunning the practices of what they call "the engagement industry" (which typically relies on consultation, patient feedback mechanisms and the installation of patient representatives in various steering groups). These practices, they argue, far from empowering patients, function to perpetuate institutional privilege, knowledges, and priorities, by delegitimizing patient voices (Gilbert and Doughty, 2012a,b; Gilbert, 2015). Patient leadership initiatives start by resituating the figure of the patient as an agent of organizational change rather than "a problem to be solved" and make use of experiences of distress as springboards for such change. In so doing, these initiatives can be said to counter organizational orthodoxies concerning the production of leadership qualities and to enable a paradigm shift toward a more "participatory medicine" (deBronkart, 2018). At the same time however, patient leadership initiatives explicitly borrow from self-leadership discourse and the conceptualizations of self-management that underpin it (Neck and Houghton, 2006). They thus rely on an underlying conceptualization of "the patient" as a resilient, self-regulating, self-efficacious agent of change. This conceptualization has been critiqued for its positioning of resilience as an individual psychological resource and minimizing the role of structural factors, such as social and economic inequalities, in conditioning people's sense of well-being and ill health and their sense of worth and agency (Miller and Rose, 2008; Friedli, 2012). In this reading, the figure of the patient leader becomes a social entrepreneur, whose sense of empowerment is atomized and therefore detached from a broader demand for organizational or social transformation (Miraftab, 2004; Carr, 2018). The discursive complexity of patient leadership initiatives raises the question of how far the dialogic ethos of the EXN may be undercut by participants' reliance on such models of atomized empowerment and of an autonomous, self-regulating subject,models which may constrain or even run counter to the principles of interdependence, and collaborative exchange upon which these initiatives are built (Renedo and Marston, 2015).

\section{From Space of Tension to Experimental Space}

While some of the founding principles and action learning techniques of the EXN may testify to a proximity to institutional and managerial rationalities and to atomized models of selfleadership as self-management, the experimental aspects of the workshop events through which the network is enacted may also be poised to unsettle these. By attending to EXN workshops as experimental spaces we borrow from Fitzgerald and Callard's work on such spaces as locations of a certain unanticipated productivity (Fitzgerald and Callard, 2015). The authors' work on what they call "experimental entanglements" stems from their autoethnographic exploration of the dynamics of collaboration in their own interdisciplinary work across the social sciences and the neurosciences. In carrying out this work they resist the temptation of denouncing collaboration as the subjugation of different actors by powerful institutions and their priorities. At the same time they refuse to imagine that reciprocity and mutuality between unequally placed "partners" is possible (Callard and Fitzgerald, 2015). Instead they invite us to acknowledge that all collaborative endeavors are shaped by power asymmetries and institutional priorities which may be intractable. Yet they also suggest that such asymmetries do not completely determine the outcomes of collaborative work. They thus propose that we think of collaborative spaces as experimental spaces, by which they mean encounters which can 
give rise to something new (connections, networks, findings) which is irreducible to their constituent parts and to their intended outcomes. An experiment is a generative space: it may arise within controlled conditions, but its outcomes cannot be anticipated or contained by these conditions. Attending to the logic of the experiment means considering how the workshopevents through which the EXN is actualized cannot be decided in advance or controlled through their institutional constraints. It means acknowledging that the EXN workshops are not about creating a level playing field but a "generative space" in which patients, clinicians, commissioners managers, and carers may invent new relational possibilities (Filipe et al., 2017). The emergent qualities of such a space may broaden our expectations of the forms that citizen participation in healthcare development can take.

\section{CONCLUDING REMARKS}

We have suggested that by focusing on the relational aspects of collaboration and on the way in which knowledge comes to be legitimized in such collaboration, the EXN can generate a learning space which holds a promise of transformative encounters between patients, carers, researchers, and healthcare professionals. However, in so doing, it is also poised between the undoing and the reinforcement of institutional scripts, and its potential to work as a transformational encounter is undecided. Because of this we have suggested that the logic of the experiment might provide a more promising approach to an analysis of the EXN, one which calls attention to the unpredictability of the encounters it puts into play, without losing sight of the unequal distribution of power in which such encounters are inevitably mired.

Furthermore, while EXN workshops rehearse collaborative practice, it is unclear how such practice might ripple outside the bounds of the workshops themselves and what effects such rehearsals might have on practice more generally. If the EXN is less about problem solving than it is about building capacity for an ethical and reflexive collaborative practice, where might an evaluation of this practice begin? How might we begin to track the extent to which experimental spaces such as the EXN generate new relations of care and whether they are able to attenuate institutional dynamics of exclusion? And how could such evaluation enable us to bring to visibility the kinds of emotional and relational labor required to initiate and sustain such a collaborative space?

Providing answers is beyond the scope of the present article as it is indeed beyond the scope of the experiment itself. We hope, instead, that the experiment that is the Exchange Network can continue to invite us to pose new questions.

\section{REFERENCES}

Adams, M., Robert, G., and Maben, J. (2015). Exploring the legacies of filmed patient narratives: the interpretation and appropriation of

\section{AUTHOR CONTRIBUTIONS}

All authors listed have made a substantial, direct and intellectual contribution to the work, and approved it for publication.

\section{FUNDING}

RM is supported by the National Institute for Health Research (NIHR) Collaboration for Leadership in Applied Health Research and Care North West London at Chelsea and Westminster NHS Trust. The views expressed are those of the author and not necessarily those of the NHS, the NIHR or the Department of Health CP is supported by the National Institute for Health Research (NIHR) Collaboration for Leadership in Applied Health Research and Care South London at King's College Hospital NHS Foundation Trust. The views expressed are those of the author and not necessarily those of the NHS, the NIHR or the Department of Health and Social Care.

\section{ACKNOWLEDGMENTS}

We wish to draw attention to the limitations presented by publishing and disciplinary constraints in recognizing the contributions of all parties in this account of collaborative effort. We therefore wish to specially mention Alison Cameron for her initial challenge to involvement practice at NIHR CLAHRC NWL and for enlightening us about the value of co-production. We thank her and other members of the original co-design group; Alison Baker, Cherelle Augustine, Ganesh Sathyamoorthy, Jane McGrath, Jenny Trite, Liz Evans, Meerat Kaur, Nicola Kingston, and Nordia James. We thank Mark Doughty for his facilitation and influence in the co-design and early testing phases, Julie Reed for her expert knowledge in improvement science and quality improvement and Catherine French for helpful discussions about collaborative learning literature. We thank Felicity Callard for her helpful conversations on collaboration and her advice which nudged the final versions of this manuscript. We finally extend our thanks to every single person who has attended the Exchange Network since 2015 for being open to a different way of working together, sharing constructive feedback, and providing valued peer support. Your contributions and influence are more than words on paper.

\section{SUPPLEMENTARY MATERIAL}

The Supplementary Material for this article can be found online at: https://www.frontiersin.org/articles/10.3389/fsoc.2019. 00036/full\#supplementary-material 
Attwood, M. (2007). Challenging from the margins into the mainstreamimproving renal services in a collaborative and entrepreneurial spirit. Action Learn. Res. Pract. 4, 191-198. doi: 10.1080/14767330701592904

Aveling, E.-L., and Jovchelovitch, S. (2014). Partnerships as knowledge encounters: a psychosocial theory of partnerships for health and community development. J. Health Psychol. 19, 34-45. doi: 10.1177/1359105313509733

Beresford, P. (2003). User involvement in research: exploring the challenges. NT Res. 8, 36-46. doi: 10.1177/136140960300800106

Beresford, P. (2013). Beyond the Usual Suspects: Towards Inclusive User Involvement: Findings. London: Shaping Our Lives Publ.

Boivin, A., Currie, K., Fervers, B., Gracia, J., James, M., Marshall, C., et al. (2010). Patient and public involvement in clinical guidelines: international experiences and future perspectives. Qual. Saf. Health Care 19:e22. doi: 10.1136/qshc.2009.034835

Brook, C. (2010). The role of the NHS in the development of Revans' action learning: correspondence and contradiction in action learning development and practice. Action Learn. Res. Pract. 7, 181-192. doi: $10.1080 / 14767333.2010 .488329$

Cahn, E. (2000). No More Throwaway People: The Co-production Imperative. Washington, DC: Essential Books.

Callard, F., and Fitzgerald, D. (2015). Rethinking Interdisciplinarity Across the Social Sciences and the Neurosciences. Basingstoke: Palgrave Macmillan. doi: $10.1057 / 9781137407962$

Carr, S. (2018). "Who owns co-production?" in Social Policy First Hand: An International Introduction to Participatory Social Welfare, eds P. Beresford and S. Carr (Bristol: Policy Press), 74-83.

Carter, P., Beech, R., Coxon, D., Thomas, M. J., and Jinks, C. (2013). Mobilising the experiential knowledge of clinicians, patients and carers for applied health-care research. Contemp. Soc. Sci. 8, 307-320. doi: 10.1080/21582041.2013.767468

Chalmers, I., Bracken, M., Djulbegovic, B., Garattini, S., Grant, J., Gülmezoglu, A. M., et al. (2014). How to increase value and reduce waste when research priorities are set. Lancet 383, 156-165. doi: 10.1016/S0140-6736(13)62229-1

Chivers, M. (2005). Ordinary magic: developing services for children with severe communication difficulties by engaging multiple voices. Action Learn. Res. Pract. 2, 7-26. doi: 10.1080/14767330500041178

Clarke, J., Waring, J., and Timmons, S. (2019). The challenge of inclusive coproduction: the importance of situated rituals and emotional inclusivity in the coproduction of health research projects. Soc. Policy Admin. 53, 233-248. doi: $10.1111 /$ spol.12459

Croft, C., Currie, G., and Staniszewska, S. (2016). Moving from rational to normative ideologies of control over public involvement: a case of continued managerial dominance. Soc. Sci. Med. 162, 124-132. doi: $10.1016 /$ j.socscimed.2016.06.010

Dawson, S., Campbell, S., Giles, S. J., Morris, R. L., and Cheraghi-Sohi, S. (2018). Black and minority ethnic group involvement in health and social care research: a systematic review. Health Expect. 21, 3-22. doi: 10.1111/hex.12597

deBronkart, D. (2018). The patient's voice in the emerging era of participatory medicine. Int. J. Psychiatry Med. 53, 350-360. doi: 10.1177/00912174187 91461

El Enany, N., Currie, G., and Lockett, A. (2013). A paradox in healthcare service development: professionalization of service users. Soc. Sci. Med. 80, 24-30. doi: 10.1016/j.socscimed.2013.01.004

Elliott, E., and Williams, G. (2008). Developing public sociology through health impact assessment. Soc. Health Illn. 30, 1101-1116. doi: 10.1111/j.1467-9566.2008.01103.x

Farmer, J., Bigby, C., Davis, H., Carlisle, K., Kenny, A., and Huysmans, R. (2018). The state of health services partnering with consumers: evidence from an online survey of Australian health services. BMC Health Serv. Res. 18:628. doi: 10.1186/s12913-018-3433-y

Filipe, A., Renedo, A., and Marston, C. (2017). The co-production of what? Knowledge, values, and social relations in health care. PLoS Biol. 15:e2001403. doi: 10.1371/journal.pbio.2001403

Fitzgerald, D., and Callard, F. (2015). Social science and neuroscience beyond interdisciplinarity: experimental entanglements. Theory Cult. Soc. 32, 3-32. doi: $10.1177 / 0263276414537319$

Friedli, L. (2012). CS06-03 - Mental health, resilience and inequalities: a social determinants perspective. Eur. Psychiatry 27:1. doi: $10.1016 /$ S0924-9338(12)74077-4
Gibson, A., Britten, N., and Lynch, J. (2012). Theoretical directions for an emancipatory concept of patient and public involvement. Health 16, 531-547. doi: $10.1177 / 1363459312438563$

Gilbert, D. (2015). The Engagement Industry. In Future Patient Blog. Available online at: https://futurepatientblog.com/2015/01/22/the-engagementindustry/ (accessed October 15, 2018).

Gilbert, D. (2018). Rethinking engagement. BJPsych. Bull. 29, 1-4.

Gilbert, D., and Doughty, M. (2012a). When Patients Become Leaders. HSJ. Available online at: https://www.hsj.co.uk/when-patients-become-leaders/ 5048691.article (accessed October 15, 2018).

Gilbert, D., and Doughty, M. (2012b). Why Patient Leaders are the New Kids on the Block. HSJ. Available online at: https://www.hsj.co.uk/why-patient-leadersare-the-new-kids-on-the-block/5046065.article (accessed October 15, 2018).

Knaapen, L., and Lehoux, P. (2016). Three conceptual models of patient and public involvement in standard-setting: from abstract principles to complex practice. Sci. Cult. 25, 239-263. doi: 10.1080/09505431.2015. 1125875

Madden, M., and Speed, E. (2017). Beware zombies and unicorns: toward critical patient and public involvement in health research in a neoliberal context. Front. Sociol. 2:7. doi: 10.3389/fsoc.2017.00007

Marsick, V., and O'Neil, J. (1999). The many faces of action learning. Manag. Learn. 30, 159-176.

Martin, G. P., and Finn, R. (2011). Patients as team members: opportunities, challenges and paradoxes of including patients in multiprofessional healthcare teams. Sociol. Health Illn. 33, 1050-1065. doi: 10.1111/j.1467-9566.2011.01356.x

Mathews, S., Golden, S., Demski, R., Pronovost, P., and Ishii, L. (2017). Advancing health care quality and safety through action learning. Leader. Health Serv. 30, 148-158. doi: 10.1108/LHS-10-2016-0051

Miller, P., and Rose, N. (2008). Governing the Present: Administering Economic, Social and Personal Life. Malden MA: Polity Press.

Ministry of Health and Care Services (1999). The Patients' and Service Users' Rights Act. Available online at: https://ec.europa.eu/health/sites/health/files/ ehealth/docs/laws_norway_en.pdf (accessed October 3, 2018).

Miraftab, F. (2004). Making neo-liberal governance: the disempowering work of empowerment. Int. Plan. Stud. 9, 239-259. doi: 10.1080/135634705000 50130

Neck, C., and Houghton, J. D. (2006). Two decades of self-leadership theory and research: past developments, present trends, and future possibilities. J. Manage. Psychol. 21, 270-295. doi: 10.1108/0268394061066309

NESTA (2012). People Powered Health: Co-production Catalogue. London. Retrieved from: https://qi.elft.nhs.uk/wp-content/uploads/2018/05/coproduction_catalogue.pdf (accessed February 20, 2019).

Ocloo, J., and Matthews, R. (2016). From tokenism to empowerment: progressing patient and public involvement in healthcare improvement. BMJ Qual. Saf. 25, 626-632. doi: 10.1136/bmjqs-2015-004839

O'Neil, J., and Marsick, V. (1994). Becoming critically reflective through action learning. N. Direct. Adult Contin. Educ. 63, 17-30.

O'Shea, A., Chambers, M., and Boaz, A. (2017). Whose voices? Patient and public involvement in clinical commissioning. Health Expect. 20, 484-494. doi: 10.1111/hex.12475

Pedler, M., Burgoyne, J., and Brooke, C. (2005). What has action learning learned to become? Action Learn. Res. Pract. 2, 49-68. doi: 10.1080/147673305000 41251

Reed, J. E., Howe, C., Doyle, C., and Bell, D. (2018). Simple rules for evidence translation in complex systems: a qualitative study. BMC Med. 16:92. doi: 10.1186/s12916-018-1076-9

Reed, J. E., McNicholas, C., Woodcock, T., Issen, L., and Bell, D. (2014). Designing quality improvement initiatives: the action effect method, a structured approach to identifying and articulating programme theory. BMJ Qual. Saf. 23, 1040-1048. doi: 10.1136/bmjqs-2014003103

Renedo, A., Komporozos-Athanasiou, A., and Marston, C. (2018). Experience as evidence: the dialogic construction of health professional knowledge through patient involvement. Sociology 52, 778-795. doi: 10.1177/00380385166 82457

Renedo, A., and Marston, C. (2015). Developing patient-centred care: an ethnographic study of patient perceptions and influence on quality 
improvement. BMC Health Serv. Res. 15:122. doi: 10.1186/s12913-0150770-y

Revans, R. W. (1982). What is action learning? J. Manag. Dev. 1, 64-75. doi: 10.1108/eb051529

Rigg, C., and Trehan, K. (2004). Reflections on working with critical action learning. Action Learn. Res. Pract. 1, 149-165. doi: 10.1080/1476733042000264128

Rose, D. (2017). Service user/survivor-led research in mental health: epistemological possibilities. Disabil. Soc. 32, 773-789. doi: 10.1080/09687599.2017.1320270

Schwartzman, H. (1989). The Meeting: Gatherings in Organisations and Communities. New York, NY: Springer. doi: 10.1007/978-1-4899-0885-8

Staley, K. (2015). 'Is it worth doing?'Measuring the impact of patient and public involvement in research. Res. Involv. Engage. 1:6. doi: 10.1186/s40900-015-0008-5

Staniszewska, S., Brett, J., Simera, I., Seers, K., Mockford, C., Goodlad, S., et al. (2017). GRIPP2 reporting checklists: tools to improve reporting of patient and public involvement in research. BMJ 358:j3453. doi: 10.1136/bmj. j3453

Stocks, S., Giles, S., Cheraghi-Sohi, S., and Campbell, S. (2015). Application of a tool for the evaluation of public and patient involvement in research. BMJ Open 5. doi: 10.1136/bmjopen-2014-006390

Taylor, M. J., McNicholas, C., Nicolay, C., Darzi, A., Bell, D., and Reed, J. E. (2013). Systematic review of the application of plan-do-study-act method to improve quality in healthcare. BMJ Qual Saf, 23, 290-298. doi: 10.1136/bmjqs-2013-001862

The PiiAF Study Group (2014). The Public Involvement Impact Assessment Framework Guidance. Liverpool; Exeter: Universities of Lancaster.
Traeger, J. (2017). What can action learning offer a beleaguered system? A narrative representing the relationship. Leadersh. Health Serv. 30, 129-137. doi: 10.1108/LHS-09-2016-0042

Tritter, J. Q., and McCallum, A. (2006). The snakes and ladders of user involvement: moving beyond Arnstein. Health Policy 76, 156-168. doi: 10.1016/j.healthpol.2005.05.008

Wilson, P. M., Mathie, E., Keenan, J., McNeilly, E., Goodman, C., Howe, A., et al. (2015). ReseArch with Patient and Public invOlvement: A Realist evaluation: the RAPPORT Study (38), Health Services and Delivery Research. Southampton: NIHR Journals Library.

Conflict of Interest Statement: RM is funded via the CLAHRC North West London, an award from the National Institute of Health Research UK which also provides the funding for the Exchange Network, the series of collaborative workshops described in the article. RM is also the co-facilitator and curator of the workshops.

The remaining author declares that the research was conducted in the absence of any commercial or financial relationships that could be construed as a potential conflict of interest.

Copyright (C) 2019 Matthews and Papoulias. This is an open-access article distributed under the terms of the Creative Commons Attribution License (CC BY). The use, distribution or reproduction in other forums is permitted, provided the original author(s) and the copyright owner(s) are credited and that the original publication in this journal is cited, in accordance with accepted academic practice. No use, distribution or reproduction is permitted which does not comply with these terms. 


\section{Plain English Summary}

\section{"Research usually sits on shelves, through the play it was shared." The Co-Production of Knowledge through post-show discussions between the audience and expert panels following live performances of Research-Based Theatre on Health Care.}

\section{Gillian Lewando Hundt*, Maria Stuttaford, Claudette Bryanston, Christine Harrison}

Theatre has long been used for communicating health messages. This paper explores how theatre based on research findings impacts on audiences' understanding and knowledge. Live performances of two research-based plays were followed by post-show discussions with an expert panel of health professionals, researchers, service users and actors. The plays were developed from interviews with research participants. Passing On explored living and caring towards the end of life. The research was based on interviews with bereaved relatives and hospital staff, and the play used word-for-word text from different interviews to tell a story about a daughter and her frail mother. Cracked focused on different ways young people seek help when experiencing a serious mental crisis in families of different ethnicities. The young people were played by different youth groups from the places where the play was performed. The world was represented by poetry and physical theatre. The family members were two mothers and a brother attending a support group telling each other about their situation.

The paper reports on the immediate, post-performance impact of research-based theatre and post-show discussions as a method to encourage the co-production of knowledge. Co-production of knowledge means the way in which the actors, panelists and members of the audience can learn from each other to create new understanding.

The plays were toured to very different audiences in theatre and non-theatre spaces. Post-show discussions with expert panels were held after each performance to widen participation of the audience members in discussions about the impact of completed research. These discussions were audio-recorded and the members of the audience were asked to complete post-show questionnaires. The audience members were researchers, service providers, service users, and carers.

The findings in this paper are based on the feedback forms and the recordings of the post-show discussions. The results show evidence of learning about types of service provision and the co-production of knowledge through discussions that occurred between the audiences and the panel members on lived experiences. The discussions covered policy and practice in caring for people who are dying or have mental health issues, personal experiences, and theatre making. Research-based theatre with post show discussions and evaluation forms is an approach that can be used for widening participation and engagement with complex health care issues, through the learning co-production of knowledge creating new understanding. 


\section{OPEN ACCESS}

Edited by:

Beth Maina Ahlberg,

Uppsala University, Sweden

Reviewed by:

Rachel Matthews,

National Institute for Health Research

(NIHR), United Kingdom

Caroline Ackley,

London School of Hygiene and Tropical Medicine (LSHTM),

United Kingdom

*Correspondence:

Gillian Lewando Hundt gillian.hundt@warwick.ac.uk

Specialty section:

This article was submitted to

Medical Sociology,

a section of the journal

Frontiers in Sociology

Received: 07 November 2018

Accepted: 20 May 2019

Published: 19 June 2019

Citation:

Lewando Hundt G, Stuttaford MC, Bryanston C and Harrison C (2019) "Research Usually Sits on Shelves,

Through the Play It Was Shared." Co-producing Knowledge Through Post-show Discussions of Research-Based Theatre. Front. Sociol. 4:48.

doi: 10.3389/fsoc.2019.00048

\section{"Research Usually Sits on Shelves, Through the Play It Was Shared." Co-producing Knowledge Through Post-show Discussions of Research-Based Theatre}

\author{
Gillian Lewando Hundt ${ }^{1 *}$, Maria Clasina Stuttaford ${ }^{2}$, Claudette Bryanston ${ }^{1}$ and \\ Christine Harrison ${ }^{1}$
}

${ }^{1}$ Warwick Medical School, University of Warwick, Coventry, United Kingdom, ${ }^{2}$ Centre for Health and Social Care Research, Kingston and St. George's University, London, United Kingdom

This is a critical analysis of the co-production of knowledge on health care with members of the public attending two research-based plays that were followed by post-show discussions with expert panelists. Passing On was developed from the findings of a qualitative research study of family decision making toward the end of life. Cracked explored help seeking pathways for young people experiencing psychosis in families of different ethnicities developed from a research study on this topic. The analysis provides critical reflections on the immediate, post-performance impact of research-based Theatre as a strategy to encourage the co-production of knowledge beyond delivery of the performance itself. The plays were developed through partnership working from interview transcripts and joint workshops engaging academics, users and Theatre practitioners (writers, director, actors). Post-show discussions with expert panels were held after each performance to widen participation of the public in the co-production of knowledge to enhance the impact of completed research and stimulate debate. These discussions were recorded and the audience were asked to complete post-show feedback forms. Audience members were researchers, service providers, service users, and carers. This is an analysis of the co-production of knowledge using the feedback forms and transcripts of the post-show discussions. The analysis showed evidence of impact and co-production of knowledge through dialogues that occurred between the audience members, the members of the panel, and the audience and the panel. The discussions covered policy and practice, personal experiences, and Theatre making. The post-show discussions led the public to critically discuss issues with the panel and other audience members thus widening participation in the co-production of knowledge. The feedback forms gave information on the audience demographics and the immediate impact of the performances. Research-based Theatre with post-show discussions and evaluation forms is a strategy for widening participation and engagement with health research findings, through the co-production of knowledge on complex health issues.

Keywords: research-based Theatre, post-show discussions, co-production of knowledge, widening participation, impact, knowledge translation, public engagement, evaluation 


\section{INTRODUCTION}

This paper explores how post-show panel discussions following research-based Theatre performances are a strategy for the co-production of knowledge during the dissemination phase of health research. The focus of the analysis is the immediate impact of two plays developed from research studies. The play Passing On was developed from qualitative research on the experiences of caring toward the end of life. The other play Cracked was developed from qualitative research with young people and their families' experiences of help seeking for psychosis. Both plays were written by the playwright Mike Kenny and were 80-90 min in length. The paper explores how audience participation in post-show discussions of researchbased Theatre performances furthers the co-production of knowledge about health care. This paper focuses on the immediate impact of the live performances and the post-show discussions. The participatory co-production of knowledge in the development and performance of the plays will be the subject of a subsequent paper.

There has been some debate about the terms knowledge transfer or knowledge translation seeming to imply a straightforward exchange (Greenhalgh and Wierenga, 2011) and recently the co-production of knowledge within health care and research has been used more widely. This term recognizes that the process involves multiple types of knowledge and experience from a plurality of stakeholders and actors (Rycroft-Malone et al., 2016). The term co-production was developed by Hess and Ostrom (2007). She argued for common ownership of public goods and viewed science as a public good. This has been taken up within civic science (Backstrand, 2003), and co-production is viewed within research as providing a space for exploratory interactions between different types of expertise, such as clinical practice, experiential, and authoritative knowledge (Filipe et al., 2017).

A recent study of public involvement in research (National Institute for Health Research, 2015; Staniszewska et al., 2018) recommends fostering co-production which is defined as having six principles (Boyle et al., 2010) of which four apply to the practice of research-based Theatre and post-show discussions. These are: breaking down boundaries, facilitating as well as delivering, promoting mutuality and reciprocity, and recognizing people and their expertise as assets. In developing the plays with clinicians, researchers, service users and Theatre makers, working with service users and having post-show panel discussions with audience members, unexpected dialogues, and interactions occurred that resulted in reciprocal exchanges between lived experience and professional expertise. This paper is an analysis of the post-show panel discussions as a forum for the co-production of knowledge.

\section{Definition of Research-Based Theatre}

Research-based Theatre is situated within the broad area of Applied Theatre, such as that developed by Boal $(1979,2000)$, by Theatre in Education (O'Toole, 1977), Applied Theatre
(Prentki and Preston, 2009), and Ethnodrama (Akroyd and O’Toole, 2010, Davis, 2018). All have a history of stimulating social action. Within health and social care, this is an innovative way to engage stakeholders in the complexities and dilemmas of difficult contested areas. Applied Theatre has also been used to validate research findings (Stuttaford et al., 2006). Research-based Theatre provides a multi-disciplinary platform that enables the impact of original research to extend its reach beyond academic publications and presentations. Experiencing live Theatre performance created from research findings deepens understanding and allows for learning through cognitive and emotional engagement and debate of complex and contested issues during post-show discussions (Lewando Hundt et al., 2010). Research-based Theatre has been found to provide new knowledge and enhance existing knowledge (Colantionio et al., 2008).

Four Theatre genres can be identified from the literature on using Theatre for knowledge transfer/translation in health research: non-theatrical performances, ethnodramas, theatrical research-based performances, and fictional theatrical performances. Non-theatrical performances are conversational or poetic monologs between researchers. Ethnodramas are largely based on the methodology of Augusto Boal and involve data-based vignettes. Theatrical research-based performance "are informed by the research process, but do not strictly adhere to the data as script.... this genre may move away from realism and verisimilitude toward the aesthetic and creative power of Theatre as an interpretive, analytic tool" (Rossiter et al., 2008: 136). Passing On and Cracked fit Rossiter et al.'s (2008) definition. Both productions used some verbatim text from in-depth interviews in primary research studies and engaged with audiences in post-show discussions. The productions also used theatrical devices to stimulate critical engagement of the audience. For example, in Passing On, the audience were given queue numbers as they entered the Theatre, positioning them in an Accident and Emergency waiting area, and a life size puppet represented the frail, ill mother. In Cracked, poetry inspired by the interview themes was the soundscape for a youth ensemble, with actors as the adult carers attending a support group sitting on chairs placed in a circle.

Evaluation of research-based Theatre is challenging. In postperformance evaluations, there is feedback on both the content and aesthetics. Three main methodologies have been used for evaluating knowledge transfer in Theatre: unstructured feedback, such as reflective journals or informal discussions, structured open-ended questionnaires, and structured quantitative surveys (Rossiter et al., 2008). Here, the data for the post-performance evaluation of both productions consisted of semi-structured feedback forms and audio-recorded post-show discussions between the audience and panelists to capture the nature and dynamics of the co-production of knowledge.

\section{Ethics}

There are ethical issues related to using research-based Theatre (Lafrenière et al., 2012), such as protecting the privacy of research participants and audience members especially in postshow discussions. There was ethical approval given for the 
anonymized interviews from the primary research studies to be developed into plays to be performed for educational purposes through Chairs' Action of the National Health Service West Midlands Coventry and Warwickshire Ethics Committee that had approved the primary research studies some years previously. The two plays in this paper were developed from anonymized interview transcripts for which the interviewees had given formal written consent. The verbatim text was a composite text from combining different interviews with demographic details altered-i.e., gender, age, situation. The poetry in Cracked was inspired by the themes in the qualitative data but did not use the actual words from any of the interviews. For Passing On, all interviewees were written to, requesting that they contact us, if they did not wish for their interviews to be included in the development of the play. Two people phoned for further information, but no one requested to be excluded.

For the post-show discussions (two of which were filmed and the remaining 17 audio-recorded or captured with detailed notes) audience members gave their oral consent. Audience members were informed by public announcement prior to the Theatre performances, that post-show discussions would be taking place after a short interval and that they could choose to come back to the auditorium if they wished to take part. They were also informed in the same announcement that a designated health professional was available to answer questions or offer support after the performance. In addition, those that returned were told, that they could request that their comments or contributions be deleted from the recorded material. On average, about 50\% of the audience participated in the post-show activities and noone requested that their contribution be excluded. The size of audiences ranged from 50 to 150 people.

Evaluation forms comprising four questions were on the audience seats together with a summary of the research the play was drawn from. The first two questions were to what extent the play raised awareness and understanding of either decision making toward the end of life (Passing On) or about mental health (Cracked), and if the post-show discussion did the same. The possible responses were very well, well, not very well, or not at all. The third question invited comments about the performance and discussion. The fourth asked people to specify if they were a health professional, social worker, carer, service user, friend of attendee or performer, regular, or occasional Theatregoer. In this way the evaluation was anonymized and voluntary.

\section{METHODS AND APPROACH}

Santé Theatre Warwick (since 2017 Santé Theatre and Media Productions-STAMP) has been a collaboration between academics and Theatre makers seeking innovative ways to enhance the impact of research and encourage public debate (Lewando Hundt et al., 2010) and as a way of validating research findings (Stuttaford et al., 2006). The research-based plays, Passing On and Cracked both focused on complex health care issues-dying and mental health. These are experiences that affect us all, and in recent years have become part of public debate through campaigns, such as Dying Matters and charities like
MIND and Samaritans. The methodology used for developing research-based Theatre provided an opportunity for research participants' voices to be heard in a way that was authentic and that represented them with integrity.

The methodological approach involves several stages. First, published papers and qualitative interviews from a completed research study are read independently and then thematically summarized through discussion with the researchers. The playwright, Mike Kenny (MK) worked dramaturgically with the Theatre director Claudette Bryanston (CB) both in close partnership and in the rehearsal space with the researchers and creative team, to develop drama strategies by subjecting the research data to a performative translation. Students, researchers, and health professionals are involved in developmental drama workshops enabling exploration of knowledge, ideas, issues, and actions.

Rehearsals are interactive with iterative collaboration between the writer, Theatre director, actors, and researchers. To date, live performances have been followed by post-show discussions involving a panel of these co-creators, health, and social care professionals and service providers in debate with the audience. Performances of Passing On and Cracked took place in Theatre and non-Theatre spaces to audiences that included service users, carers, students, researchers, and health, and social care service providers and the wider public.

\section{Passing On}

Verbatim text from a research study on end of life care that included a medical record review and interviews with bereaved relatives and health professionals (Jackson et al., 2010) were used to create Passing On. The Theatre director and co-author (CB) working with the playwright, $(\mathrm{MK})$, and actors with input from the academic researchers and health professionals, developed the play through a series of workshops. In collaboration with Little Angel Theatre a life size puppet representing the dying person was created. The play was developed through a series of workshops with academics and health and social care professionals with the director and writer. A composite verbatim text play was written from the research interviews by the playwright (MK) and revised by the Theatre director (CB) during rehearsals. Passing On was performed nine times in 2013 in London and the Midlands with recorded post-show discussions following each performance and filmed excerpts of the play and a post-show discussion can be viewed on line at http://www. stamproductions.co.uk/past-productions/passing-on.

\section{Cracked}

Cracked was developed with a similar methodology. The research explored lay understandings of psychosis and patterns of help seeking amongst families of different ethnicities (Islam et al., 2015; Singh et al., 2015). The play used verbatim text derived from interviews with carers of young people who had experienced psychosis. Poetry represented the inner world of the young people and was spoken by a youth ensemble of young people. The play was developed through workshops facilitated by the director (CB), involving Theatre makers (stage designer, writer, poet, and actors), clinical scientists (psychiatrists, clinical 
ethicist), social scientists (social work academic, anthropologist), service users, and young adults (youth workers, youth ensemble members). The youth ensembles were drawn from different institutions in each touring venue and in total 68 young people attended the rehearsal workshops and took part in the 11 performances. The young people participating were diverse in terms of region, ethnicity, and education. Filmed material of Cracked (produced by Zebra Digital) including a 10 min film on psychosis, a $30 \mathrm{~min}$ film on the method and process of developing research-based Theatre, and one of a post-show discussion can be viewed on line at www.stamproductions.co.uk/pastproductions/ cracked/.

The expert panel members were academic researchers, health and social care professionals, service users, the Theatre director, and cast members. Semi-structured feedback forms were left on the chairs of audience members. In total only 311 audience members completed the feedback forms from Passing On and Cracked although the two plays were performed to more than 1,000 people. Sixteen post-show discussions were recorded, and transcribed. In three instances, as shown on Table 1 below, there was no audio-recording made but notes were taken. In Theatre settings, there was a short interval at the end of the plays, and roughly $50 \%$ of the audience returned for the 13 post-show discussions. There is a lack of information about why people chose not to stay but reasons could have included logistical travel arrangements, domestic commitments or a preference for private reflection. There was no interval after the six performances in non-Theatre settings, so everyone stayed. Information was provided prior to the event as part of the schedule or timetable. The data set consisted of 311 feedback forms and 19 written accounts (transcripts or notes) of post-show discussions. Authors, GH, and MS undertook analysis of the data identifying emergent themes from the transcripts independently. Table 1 summarizes the performance venues of both plays and the different groups of young people participating in Cracked.

\section{FINDINGS}

The written and oral comments of audience members are reported here as said or written. As there was no follow up with individuals following the post-show discussions, it was not possible to interrogate their views further. They represent their immediate responses to the event rather than a reflective discussion after a filmed presentation (Adams et al., 2015).

The feedback forms from about $20 \%$ of the audience members gave an indication of the audience make-up. They self-identified as students, members of the public who often had personal experiences of the health care situations explored in the play, service users, health care professionals or academics. There were equal numbers of regular and occasional Theatregoers and a third of people identified themselves as never or rarely going to the Theatre. This indicates outreach to non-Theatre goers through using non-Theatre spaces for some performances. For example, Cracked was performed as part of the Scottish Mental Health Arts and Film Festival at the Platform-Bridge Theatre in Easterhouse, Glasgow, in a church at a Conference on African Caribbean Men's
TABLE 1 | Venues of performances of Passing On and Cracked with young people involved in Cracked.

\begin{tabular}{|c|c|c|c|c|}
\hline Venues & Passing On & Cracked & $\begin{array}{l}\text { Youth groups in } \\
\text { Cracked }\end{array}$ & $\begin{array}{l}\text { Numbers and } \\
\text { ages }\end{array}$ \\
\hline $\begin{array}{l}\text { University of } \\
\text { Warwick } \\
\text { Lozells Church } \\
\text { Sandwell charity }\end{array}$ & 2 & $\begin{array}{c}2 \text { (1 not } \\
\text { recorded) } \\
1 \\
\text { (not recorded) }\end{array}$ & $\begin{array}{l}\text { Wolverhampton } \\
\text { Theatre } \\
\text { Group-4 } \\
\text { performances }\end{array}$ & $\begin{array}{l}10 \text { young } \\
\text { people } \\
16-18 \text { years old }\end{array}$ \\
\hline $\begin{array}{l}\text { Nottingham } \\
\text { Lakeside } \\
\text { Theatre }\end{array}$ & 2 & 1 & $\begin{array}{l}\text { B.Tech. } \\
\text { students from } \\
\text { FE college }\end{array}$ & $\begin{array}{l}16 \text { students } \\
16-18 \text { years old }\end{array}$ \\
\hline Derby Theatre & & 2 & $\begin{array}{l}\text { University of } \\
\text { Derby Theatre } \\
\text { interns }\end{array}$ & $\begin{array}{l}6 \text { young people } \\
18-20 \text { years old }\end{array}$ \\
\hline $\begin{array}{l}\text { Birmingham } \\
\text { Repertory } \\
\text { Newman College }\end{array}$ & 2 & 1 & $\begin{array}{l}\text { Drama } \\
\text { students-2 } \\
\text { performances }\end{array}$ & $\begin{array}{l}15 \text { students } \\
18-20 \text { years old }\end{array}$ \\
\hline $\begin{array}{l}\text { London } \\
\text { Little Angel } \\
\text { Theatre, } \\
\text { Pub Theatre }\end{array}$ & 2 & & & \\
\hline $\begin{array}{l}\text { Glasgow } \\
\text { Platform } \\
\text { Theatre }\end{array}$ & & $\begin{array}{l}1 \text { (not } \\
\text { recorded) }\end{array}$ & $\begin{array}{l}\text { Platform Youth } \\
\text { Theatre }\end{array}$ & $\begin{array}{l}9 \text { young people } \\
16-25 \text { years old }\end{array}$ \\
\hline $\begin{array}{l}\text { Blue Coat } \\
\text { School Theatre, } \\
\text { Coventry }\end{array}$ & & 2 & $\begin{array}{l}\text { Sixth form } \\
\text { students }\end{array}$ & $\begin{array}{l}12 \text { young } \\
\text { people } \\
16-18 \text { years old }\end{array}$ \\
\hline Total & $\begin{array}{c}9 \\
\text { performances }\end{array}$ & $\begin{array}{c}11 \\
\text { performances }\end{array}$ & & $\begin{array}{l}68 \text { young } \\
\text { people }\end{array}$ \\
\hline
\end{tabular}

Mental Health in Birmingham, and at a community center in Sandwell. Both plays were performed to 60 social work students at the University of Warwick in studio space where, for Passing On, 22 of whom reported on their forms that they rarely or never went to the Theatre.

The co-production of knowledge was the major emergent theme in the analysis of the post-show discussions and feedback forms and had two sub-themes, (1) the process and impact of Theatre making from research, and (2) participative discussions of issues raised in the plays with a sharing of experiences.

\section{Co-production of Knowledge Through the Process and Impact of Theatre Making From Research}

There were many comments both orally and in writing about the power of Theatre to represent universal experiences that people could respond to cognitively and emotionally knowing that it was developed from the experiences of research participants. Audience members reported how they learnt through the live performance about real life phenomena and were able to generalize from the particular to the more general.

\footnotetext{
"Research usually sits on shelves, through the play it was shared. The acting, for me brought out the thoughts/experiences the individual goes through which I had not experienced before"
} 
(Feedback form, Occupational Therapy Student, Cracked, Derby Theatre, 10.10.2015)

\begin{abstract}
"The play... explores the impact on their carers, the family members, the mums and dads who try to make sense of their child's irrational broken world... We are all a bit cracked, it's part of being human, some more than others."
\end{abstract}

(Feedback form, Charity worker/Regular Theatregoer, Cracked, Blue Coat School Theatre, 15/16.10.2015)

Theatre makers on the panel were able to explain how the process of developing research based Theatre and by doing so revealed how the voices of research participants were respected and heard. As the playwright explained:

"When I started reading the interviews I thought: I can't say that better. I've got to use the true, authentic voices of the people going through these experiences... it's an honest reflection of the experiences that those people went through."

(Playwright Mike Kenny, Cracked, Derby Theatre, 10.1.2015, afternoon, post-show discussion).

The use of theatrical devices, such as the life-size puppet in Passing On were discussed and commented on. Here an actor reflected on the use of the life size puppet to represent her mother.

"I'm not a very experienced puppeteer... I never at any point think she isn't my real mother, and that's really odd. Because the audiences project onto her, but I think we do as well, and quite often during the show I just sort of think... 'But she does look like my mother!' Or when she's dying I really believe that she is. And it's a very odd thing when you start to love a puppet."

(Actor Ali Belbin, Passing On, Birmingham Repertory Theatre, 7.3.2013 post-show discussion)

Actors in both productions when taking part both in rehearsals and the post-show discussions, expressed how the plays and performances impacted on them and related to their own experiences of bereavement and mental health issues in their own lives. An actor in Passing On explained how important it was to respect research participants voices by delivering verbatim text accurately in terms of content and tone. Another actor explained how creating Cracked was a dialogue and how everyone contributed their own personal experiences, while keeping the characters being portrayed "real." By combining personal creativity with the verbatim text, the actor described the process as being "therapeutic." One member of the cast of Passing On, wrote later that the play had sparked more discussion and interest in his family than any production he had taken previously taken part in.

The Theatre student actors responded positively about participating in Cracked, both in terms of the opportunity to perform and learn about research-based Theatre, but also in terms of learning about mental health issues:

"Well obviously for me I did not know a lot about [mental health] because I only know about acting -that is my world. So, getting in contact with this world through what I love is absolutely amazing.
Especially for young people, it is really hard to look into something if you're not directly related to it."

(Theatre student actor, Cracked, Derby, 10.10.2015, afternoon post-show discussion)

Another had learnt about early signs of psychosis from the play:

"Normally I do role play for medical exams. So it was really interesting to see the early onset and to see all the flags being missed, as it were,... how easy it is to miss, to brush it off... Because obviously you hear a lot in the media about when it's full blown... but you don't often hear what about the initial symptoms and how terrifying that must be"

(Theatre student actor, Cracked, Derby 10.10.2015, afternoon post-show discussion)

The co-production of knowledge through the process and impact of research-based Theatre was experienced by both actors and audience members. This was further demonstrated in the way that audience members shared experiences during the participative post-show discussions.

\section{CO-PRODUCTION OF KNOWLEDGE THROUGH PARTICIPATIVE DISCUSSION AND SHARING OF EXPERIENCES}

Audience members expressed that the plays resonated realistically with their own professional or personal experiences. Some health professionals expressed how realistic Passing On was concerning caring for someone toward the end of life:

"Thinking about the work I've done with people with dementia when people lose their sense of speech-the non-verbal becomes much more important. That hand stroking is really significant. Also, when people die that sort of guttural sound of the breath, that is what it sounds like, and it was very realistic."

(Audience member, Passing On, 22.1.2013, Lakeside Matinee, post-show discussion)

"I'm a health professional myself and throughout the whole play my friend was saying, I was nodding and shaking. I recognized there the situations that I've come across myself."

(Audience member, Passing On, 7.2.2013, Little Angel Theatre, London, post-show discussion)

The written feedback of audience members who had experienced mental health issues as service users, showed that they recognized aspects of the play Cracked as an "accurate representation" (Feedback form User, Lakeside, 30.9.2015), and another expressed that

"Some of the script, lines and feelings expressed, struck resonance with me and reminded me of times in my life"

(Feedback form, Service User Cracked, Derby Theatre, 10.10.2015) 
Some audience members gave written feedback which showed how they related to the situations portrayed in Cracked to situations they encountered in their working lives.

"I work for a Housing Association and deal with complaints from people about their neighbors. I recognized many of the scenarios/issues in the play as issues that are often part of complaints like. My neighbor is keeping me awake by running up and down the stairs all night or My neighbor is staring at me and shouts through the walls at me."

(Feedback form, Regular Theatre goer/Friend, Cracked, Derby Theatre 10.10.2015)

"I work within an early intervention service and I felt this was a very powerful portrayal of the experience of psychosis from both the individual and family perspective"

(Feedback form, Health professional, Cracked, Blue Coat School 15/16.10.2015)

Like the actors, some audience members felt that there was a therapeutic element to the plays. One service user felt that seeing Cracked felt "very peaceful and it helped" (Feedback form, Service user, Cracked, Blue Coat School, 15/16.10.2015)

Another service user shared with the audience that:

"Nobody could fix me because I couldn't fix myself. I was drinking to die at the end of my drinking. Five years on, I'm in a much better place. I work with others and I share my experience honestly and openly because I have no fear today. I'm grateful for this evening because it always helps me to remember to look at me today. So, thank you all."

(Audience participant, Derby Theatre, 10.10.2015, post-show discussion)

Another audience member reflected on learning about on help seeking more generally:

"The play had a deep emotional impact on myself. I could identify with the fact that health authorities don't always understand until a person has reached breaking point. It has also helped to identify certain patterns in mental health."

(Feedback form, Experience of mental health issues Cracked, Blue Coat School Theatre 15/16.10.2015)

Another sub-theme was how the local as presented in the plays was also global. Audience members from elsewhere wrote on the feedback forms that the narratives as performed in the researchbased plays was transferable globally. One student wrote that the situations portrayed in Passing On were "very similar when I compare it with my hometown, Hong Kong" (Feedback form, 7.2.2013, Little Angel Theatre, London) and another person in the audience at the same performance wrote "Thoughts between doctors and relatives are the same in my country. It's quite familiar to me." (Feedback form, Regular Theatregoer, Passing On, 7.2.2013, Little Angel Theatre, London).

Written feedback is not shared with other audience members and so the co-production of knowledge is an individual reflection on the impact of the research-based plays. However, similar comments were expressed and shared in the post-show discussions like this one below.

"I lost my grandmother a few years ago and I have a medical background so I can relate to the different perspectives as well... I'm coming from different country and I think the perspectives you saw, the family and also the medical ones, are quite international... Even if it's a different system, things happen more or less in similar way."

(Audience participant, Passing On, Post-show discussion 30.1.2013, Warwick,)

The research-based Theatre performances stimulated discussion about change for example through requests for information and the sharing of experiences and knowledge between service users and service providers. On one occasion an audience member asked "Why do nurses delay responding when a bedpan is needed so that accidents happen after?" Whereupon, a student nurse in the audience, responded that sometimes, she was so busy and fatigued in an understaffed situation toward the end of a shift that it would happen. This is an example of the co-production of knowledge between audience members triggered by the play.

Several audience members described the use of research-based Theatre as thought provoking and authentic and then went on to explain about how the performance and post-show discussion extended their knowledge and understanding. The following three examples of the co-production of knowledge are from student audience members who all felt the performances had extended their understandings of end of life care or help-seeking for psychosis.

\footnotetext{
"An excellent production portraying an incredibly realistic story. Beautiful incorporation of puppetry to create a sense of powerlessness and fragility. Learnt a lot about issues surrounding end of life care that I wasn't previously aware of."
}

(Feedback form, Theatre design student, Passing On, 22.1.2013, Lakeside, Nottingham)

"The aim of raising understanding on mental health was definitely achieved - through the research to performance aspect. I think the verbatim and portrayal of psychosis/stories was true."

(Feedback form, Drama Theatre Student, Cracked, Derby Theatre, 10.10.2015)

"Amazing, very informative. I am a young person of 15 years old and I think more young people should see this."

(Feedback form, feedback form Cracked, Blue Coat School Theatre, 15/16.10.2015)

Health and student health professionals expressed how it reminded them about the needs of patients and carers and their skills: 
"The story was very moving - good to have a reminder about thoughts and feelings of relatives and how healthcare professionals' actions have an impact."

(Feedback form, Registered nurse (palliative care)/regular Theatre goer, Passing On, 22.1.2013, Lakeside, Nottingham)

\begin{abstract}
"A powerful piece of Theatre, presented in a sensitive manner. Very thought provoking and as a trainee health professional I found it to be a great insight into end of life care and the way in which patient-centered care is essential."
\end{abstract}

(Feedback form, Student physiotherapist, Passing On, 7.2.2012, Little Angel Theatre, London)

While the evaluation is limited to immediate impact, there were comments from health professionals who were in the audience showing that the co-production of knowledge was occurring though reflective learning relating to professional practice or behavior:

"The issues raised in the play and by the post-show discussion were very thought provoking and will make me consider these issues where necessary and ensure that the difficult questions and conversations which are necessary are had in good time before death."

(Feedback form, NHS Manager, Passing On, 22.1.2013, Lakeside Nottingham)

"Thought provoking play... made me think about my hospital ward and what we do well or could improve on."

(Feedback form, NHS Manager, Passing On, 22.1.2013, Lakeside Nottingham)

"It did make me consider some questions/problems I had not thought about before. It has also encouraged me to want to talk about death more in my personal life and work."

(Feedback form, Regular Theatregoer, Passing On, 7.2.2013, Little Angel Theatre, London)

The co-production of knowledge was evident in comments from both plays also in relation to the situation of carers as well as the isolation and stigma in these situations.

"Thank you for the reassurance that mental health is being taken seriously, that the stigma is being taken away and for promoting awareness which will provide support for both sufferers and family that they are NOT alone"

(Feedback form, Occasional Theatregoer/Carer, Cracked, Blue Coat School Theatre, 15/16.10.2015)

It provided insights to people about the experiences of carers:

"Excellent performance, it really brought home the situation of the position of carers and family and reminded me of when my father died."
(Feedback form, Passing On, 22.1.2013, Lakeside, Nottingham)

"The show allowed me to see the good and bad side of caring for people at the last stages of their life. It provided a good glimpse into how people feel and the experiences they go through."

(Feedback form, Regular Theatregoer, Passing On, 22.1.2013, Lakeside Nottingham)

The research-based Theatre performances stimulated requests for more information during the post-show discussions.

"What work is actually being done with care homes to change the outcome of, you know, what happened there?"

(Audience member, Passing On, Midlands Art Center, matinee 7.3.2013, Post-show discussion)

"I'd have welcomed more depth of knowledge on the mental health/psychological side of things i.e., why do people get to the situations in which they find themselves"

(Feedback form, Occasional Theatregoer/friend/trainee psychotherapist, Cracked, Derby, 10.10.2015)

The above two quotes illustrate the importance of the postshow discussion in the engagement process. A member of the panel answered the first question above immediately. The second was written on an anonymous post-show evaluation form with no mechanism for responding.

The combination of performance and post-show discussion was identified by audiences as being important for extending knowledge and understanding.

"I was more moved by the play's representation of end of life, but together with the post-show discussion issues on end of life care were better understood. They work together to achieve this aim very well."

(Feedback form, Passing On, 7.2.2013 Little Angel Theatre, London)

We would argue, that the co-production of knowledge on end of life care and psychosis was enhanced by the combination of research-based Theatre performances followed by post-show discussions. The diversity of the panel provided a depth and breadth to the post-performance discussion. The play stimulated people to ask questions and seek information. The discussion was not only a dialogue between different audience members and the panelists but sometimes became a more inclusive discussion including other members of the audience widening both participation and deepening the co-production of knowledge. For example, at performances of Cracked, audience members were often keen to ask questions about cannabis use and mental health which then prompted a more general discussion with audience members sharing views and experiences in addition to the responses of the panelists.

Other questions raised by audience members after performances of Cracked were about psychosis in relation to gender, UK experiences compared to Europe, links to suicide, and self-harming, trigger points and the influence of social 
factors. An audience member at the evening performance of Cracked in Derby asked about the negative and positive implications of seeking help from religious figures for mental health issues. In responding to this question, academics provided information from the empirical research underpinning the play on this issue, as well as ongoing training interventions with religious leaders, service providers talked about the need for further training of health professionals and another audience member talked about her experiences with religion.

The post-show discussions provided an opportunity to provide information about local services. For example, in the performance of Passing On in Sandwell, audience members spoke about the need to prepare emotionally and mentally, not only financially and logistically, for the death of a relative and they also spoke about the need for improved communication between families and health professionals, especially in relation to older people and children. A local resident who also worked as an advocate took the opportunity to signpost people to relevant local services:

There's information on your chair about compassionate communities and we always advocate it. We hope that bringing the play is part of pushing this with members of the public.... It's opening that discussion with your family and friends.

(Post-show discussion, Charity Worker, Passing On, Sandwell, 19.2.2013)

Audience members also shared information. For example, a youth worker attending Cracked explained how young people feel that social media is sometimes distressing. A panel member at the Cracked evening performance in Derby working with young people with mental health issues explained the triggers for psychosis, how it is for young people, carers and health professionals and another responded with the need to continue the conversation started in the post-show discussion after leaving the Theatre. People often stayed on in the Theatre café or bar discussing the play.

The questions in the post-show discussions led to answers from panelists that were an opportunity to signpost audience members to services, publicize where to get further information and communicate evidence and research as well as good practice. In a post-show discussion of Passing On (Sandwell 19th February 2013), an audience member observed how the daughter in the play told the doctors she did not want her mother to know she was dying. A panelist responded explaining why health professionals feel they do have a duty to tell patients. At another performance of Passing On, local good practice was highlighted during the postshow discussion:

"I think recently in Nottinghamshire we've seen a really good uptake of training from care home settings and domiciliary care settings as well. Working jointly with the county council we're able to provide a lot of training that we might not be able to do on our own.

"Recently we managed to secure funding through the county council toward the Gold Standards Framework for Care Homes training programme, and we've just found out that one of our homes has got Beacon Status, which is the highest. So things are changing in the care home setting."

(Trainer, Passing On, 22.12.2012, Lakeside evening, Nottingham, post-show discussion)

The shared experiences were practical as well as more general. During the post-show discussions of Passing On, people talked a great deal about palliative care options and advance medical directives and two frail elderly members of the audience produced and showed to others, the Do Not Resuscitate cards that they were carrying in their wallets. During the discussions the panelists reported on the impact of the play on others at previous performances:

"I have a friend who came when, her sister was dying. She said after seeing the play she was able to go and visit her sister and have a conversation about topics that she'd been frightened to talk about, like 'What do you want the funeral to be like? How do you want to be buried? How can I help you?' She found the play facilitating."

(Academic panelist, Passing On, University of Warwick, 27.2.2013, post-show discussion)

"It can be a trigger can't it? Because the power of Theatre is that you respond to it both intellectually and emotionally so that you can start a different sort of conversation. Definitely a different conversation to reading an academic paper... So for example people who have seen the play have said to me: I'm going to write a 'do not resuscitate order', that is properly dated and is in my home."

(Academic panelist, Passing On, Little Angel Theatre, London, 7.2.2013).

\section{DISCUSSION AND CONCLUSIONS}

The emergence of Death and Dying and Mental Health as topics for public debate has been evident in this century. These post-show discussions following the performances of two plays developed from research on death and dying and mental health, respectively, continued the process of public engagement with dialogue and co-production of knowledge on these topics.

The six principles of the co-production of knowledge identified by Boyle et al. (2010) and incorporated into the recent NIHR report (National Institute for Health Research, 2015) are summarized in Box $\mathbf{1}$.

We would argue that post-show discussions following research-based Theatre performances promote the coproduction of knowledge in terms of four of these principles (2, 4,5 , and 6 ). The post-show discussion promoted mutuality and reciprocity between the audiences and the actors and panelists. In this case, there was evidence of boundaries becoming more porous and fluid through the sharing of experiences and expertise and the research being shared beyond academic papers. The post-show discussions facilitated this sharing and the lived experiences of the research respondents and members of the audience were recognized as well as the authoritative knowledge 
Box 1 | Six principles of co-production of knowledge.

1. Building on people's existing capabilities

2. Promoting mutuality and reciprocity

3. Developing peer support networks

4. Breaking down boundaries

5. Facilitating as well as delivering

6. Recognizing people and their experiences as assets.

Adapted from Boyle et al. (2010) and NIHR (2016, p.17).

of the panel members. The post-show discussions created an exploratory space and new interactions (Filipe et al., 2017) and were underpinned by the Ostrom's commitment to science as a public good (Hess and Ostrom, 2007).

The panels always included Theatre makers, service users, academics, and health, and social care professionals. They were seated in front of the audience and responded to questions relating to their expertise that the facilitator directed to them. They often elaborated on each other's responses so that there were interactions between both members of the audience and panel members as well as between the panel members. In terms of power dynamics, the tone was informal rather than didactic and the audience led the direction and scope of the discussions. Each one was different in content and reach but all included requests for information, questions on the process of transforming research into Theatre as well as generous sharing of lived experiences.

The audience oral and written responses demonstrated public engagement with research findings and the co-production of knowledge through requests for information, comparing, and contrasting experiences and establishing dialogue with the multi-disciplinary panels (Jones, 2002). The panelists and audiences became collaborators in engaging with the findings of the research and the diversity of the panels was important for connecting with truths from the research and the authenticity of audience experiences (Mitchell et al., 2011). Audience members, Theatre practitioners and panelists connected in new ways and shifted understanding and meaning (Mitchell et al., 2011).

Audience members expressed that they would be more able to talk about sensitive issues, and would be more committed to destigmatizing talking about subjects seldom spoken about freely. The feedback forms showed that audience members felt that the plays conveyed authentic experiences and truths, that through the performances, and the post-show discussions, they had increased their understanding of health care at the end of life and mental health of young people. The postshow discussions had recurring questions and concerns raised by the audience members. These were: How to get help? How to recognize when to seek help? and How to further understandings of the topic? The audience members appreciated that the plays included the perspectives of the service users, carers, and health professionals, and with the use of verbatim text was sensitive and respectful of the participants. Health professionals felt that the plays were authentic representations, true to case histories and life experiences they encountered in their work.

Similarly, carers and users expressed that the portrayal of families' experiences reflected their own. The use of researchbased Theatre performances with post-show discussions is a strategy for encouraging extending the co-production of knowledge beyond the performances through enhanced public engagement. The audience members were engaged with the health research and dilemmas in health care represented in the plays and in the post-show discussions with the panelists-academics, Theatre practitioners, health professionals, and users.

There are methodological challenges to capturing the coproduction of knowledge and impact of research-based Theatre. The data show the immediate impact of research-based Theatre performances and participative post-show discussions, but as yet there is little evidence of longer-term engagement. Another limitation is that discussions were primarily between the members of the audience and members of the expert panels and to a lesser extent between audience members. Further informal talk continued after the performance and post show discussion that was not captured. In Theatre settings, only about $50 \%$ of the audience returned after an interval for the post-show discussion, however, in non-Theatre spaces all the audience remained. In both settings, only a minority actively participated with questions or view but silent participants had chosen to be present. These challenges are a priority to address in future productions as a way of developing methods to capture the multiple layered dimensions of the co-production of knowledge.

Live performances followed by participative discussions reach a limited number of people but has impact, whereas digital versions on line reach far more people. However, we know little about the impact of the on-line material other than the number of likes and dislikes and do not know if it was used by individuals or shown to groups, such as students as part of active learning with facilitated discussion. One of the limitations of this analysis is that it only captures the immediate impact of research-based Theatre. Medium term impact could be measured by contacting audience members 3-6 months after the performance. A more in-depth exploration of the co-production of knowledge could use a preand post-evaluation of audience members' understandings before and after performances. Using research-based Theatre with postshow discussions as a strategy for increasing the co-production of knowledge has powerful and immediate impact. To what extent this remains with those participating is still open to question and debate.

\section{ETHICS STATEMENT}

This study was carried out in accordance with the recommendations of name of guidelines, name of committee with written informed consent from all subjects. All subjects gave written informed consent in accordance with the Declaration of Helsinki. The protocols were approved by the Birmingham Research Ethics Committee and Coventry and Warwickshire Research Ethics Committee. 


\section{AUTHOR CONTRIBUTIONS}

MS and GL independently identified key themes from the data and jointly drafted the paper. $\mathrm{CB}$ and $\mathrm{CH}$ reviewed drafts of the paper. All authors were involved in the development of the plays and post show-discussions.

\section{FUNDING}

We acknowledge funding from the University of Warwick (CAPITAL Center, the Institute for Advanced Teaching and Learning, the Institute for Advanced Studies,

\section{REFERENCES}

Adams, M., Robert, G., and Maben, J. (2015). Exploring the legacies of filmed patient narratives: the interpretation and appropriation of patient films by health care staff. Qual. Health Res. 25, 1241-1250. doi: $10.1177 / 1049732314566329$

Akroyd, J., and O'Toole, J. (2010). Performing Research: Tensions, Triumphs and Trade-offs of Ethnodrama. London: Institute of Education Press.

Backstrand, K. (2003). Civic science for sustainability: reframing the role of experts, policy-makers and citizens in environmental governance. Glob. Environ. Polit. 3, 24-41 doi: 10.1162/152638003322757916

Boal, A. (1979). Theatre of the Oppressed. London: Pluto Press.

Boal, A. (2000). Theatre of the Oppressed. London: Pluto Press.

Boyle, D., Slay, J., and Stephens, L. (2010). Public Services Inside Out: Putting Co-Production into Practice. London: NESTA.

Colantionio, A., Kontos, P. C., Gilbert, J. E., Rossiter, K., Gray, J., and Keightley, M. L. (2008). After the crash: research-based theatre for knowledge transfer. J. Contin. Educ. Health Profes. 28, 180-185. doi: 10.1002/chp.177

Davis, S. (2018). Beyond ethnodrama: exploring nursing history and identity through scriptwriting as research. Drama Austr. J. 42, 37-50. doi: $10.1080 / 14452294.2018 .1443753$

Filipe, A., Renedo, A., and Marston, C. (2017). The Co-production of what? Knowledge, values and social relations in health care. PLoS Biol. 15: e2001403. doi: 10.1371/journal.pbio.2001403

Greenhalgh, T., and Wierenga, S. (2011). Is it time to drop the knowledge transfer metaphor? A critical literature review. J. Royal Soc. Med. 104, 501-509. doi: $10.1258 /$ jrsm.2011.110285

Hess, C., and Ostrom, E. (2007). Understanding Knowledge as a Commons: From Theory to Practice. Cambridge, MA; London: MIT Press.

Islam, Z., Rabiee, F., and Singh, S. P. (2015). Black and minority ethnic groups' perception and experience of early intervention in psychosis services in the United Kingdom. J. Cross Cult. Psychol. 46, 737-753. doi: 10.1177/0022022115575737

Jackson, A., Purkis, J., Burnham, E., Lewando Hundt, G., and Blaxter, L. (2010). Views of relatives, carers and staff on end of life care pathways. Emerg. Nurs. 17, 22-26. doi: 10.7748/en2010.03.17.10.22.c761626.

Jones, J. L. (2002). Performance ethnography: the role of embodiment in cultural authenticity. Theatre Topics. 12, 1-14. doi: 10.1353/tt.20 02.0004

Lafrenière, D., Hurlimann, T., Menuz, V., and Godard, B. (2012). Health research: ethics and the use of arts-based methods in knowledge translation processes. Int. J. Creat. Arts Interdiscipl. Pract. 11, 1-26. Available online at: http://www. ijcaip.com/archives/IJCAIP-11-paper3.html

Lewando Hundt, G., Bryanston, C., Lowe, P., Cross, S., Sandall, J., and Spencer, K. (2010). Inside "Inside View": reflections on stimulating debate and engagement through a multimedia live theatre production on the dilemmas the Warwick Higher Education Infrastructure Fund, the Social Sciences ESRC Impact Acceleration Account). We also acknowledge funding from the Wellcome Trust for People Award 105106/Z/14/Z.

\section{ACKNOWLEDGMENTS}

We would like to thank the playwright Mike Kenny, poet Julie Boden, Little Angel Theatre, Zebra Digital and collaborating researchers, Theatre practitioners, health professionals, young people in the youth ensembles, and audience members for their creative participation. and issues of pre-natal screeing policy and practice. Health Expect. 14, 1-19. doi: 10.1111/j.1369-7625.2010.00597.x

Mitchell, G. J., Dupuis, S., Jonas-Simpson, C., Whyte, C., Carson, J., and Gillis, J. (2011). The experience of engaging with research-based drama: evaluation and explication of synergy and transformation. Qual. Inquiry 17, 379-392. doi: $10.1177 / 1077800411401200$

National Institute for Health Research (2015). Going the Extra Mile: Improving the Nation's Health and Wellbeing Through Public Involvement in Research. The final report and recommendations to the Director General Research and Development/Chief Medical Officer Department of Health of the 'Breaking Boundaries' strategic review of public involvement in the National Institute for Health Research

O'Toole, P. (1977). Theatre in Education. London: Hodder Arnold H\&S.

Prentki, T., and Preston, S. (2009). The Applied Theatre Reader, Abingdon: Routledge.

Rossiter, K., Kontos, P., Colantonio, A., Gilbert, J., Gray, J., and Keightley, M. (2008). Staging data: theatre as a tool for analysis and knowledge transfer in health research. Soc. Sci. Med. 66, 130-146. doi: 10.1016/j.socscimed.2007.07.021

Rycroft-Malone, J., Burton, C. R., Bucknall, T., Graham, I. D., Hutchinson, A. M., and Stacey, D. (2016). Collaboration and co-production of knowledge in healthcare: opportunities and challenges. Int. J. Health Policy Manag. 5, 221-223. doi: 10.15171/ijhpm.2016.08

Singh, S. P., Brown, L., Winsper, C., Gajwani, R., Islam, Z., Jasani, R., Parsons, H., Rabbie-Khan, F., and Birchwood, M. J. (2015). Ethnicity and pathways to care during first episode psychosis: the role of cultural illness attributions. BMC Psychiatry 15:287. doi: 10.1186/s12888-015-0665-9

Staniszewska, S., Denegri, S., Matthews, R., and Minogue, V. (2018). Reviewing progress in public involvement in NIHR research: developing and implementing a new vision for the future. BMJ Open 8:e017124. doi: 10.1136/bmjopen-2017-017124

Stuttaford, M., Lewando Hundt, G., and Byranston, C. (2006). The use of applied theatre in data validation and dissemination. Health 10, 31-45. doi: $10.1177 / 1363459306058985$

Conflict of Interest Statement: The authors declare that the research was conducted in the absence of any commercial or financial relationships that could be construed as a potential conflict of interest.

Copyright (c) 2019 Lewando Hundt, Stuttaford, Bryanston and Harrison. This is an open-access article distributed under the terms of the Creative Commons Attribution License (CC BY). The use, distribution or reproduction in other forums is permitted, provided the original author(s) and the copyright owner(s) are credited and that the original publication in this journal is cited, in accordance with accepted academic practice. No use, distribution or reproduction is permitted which does not comply with these terms. 


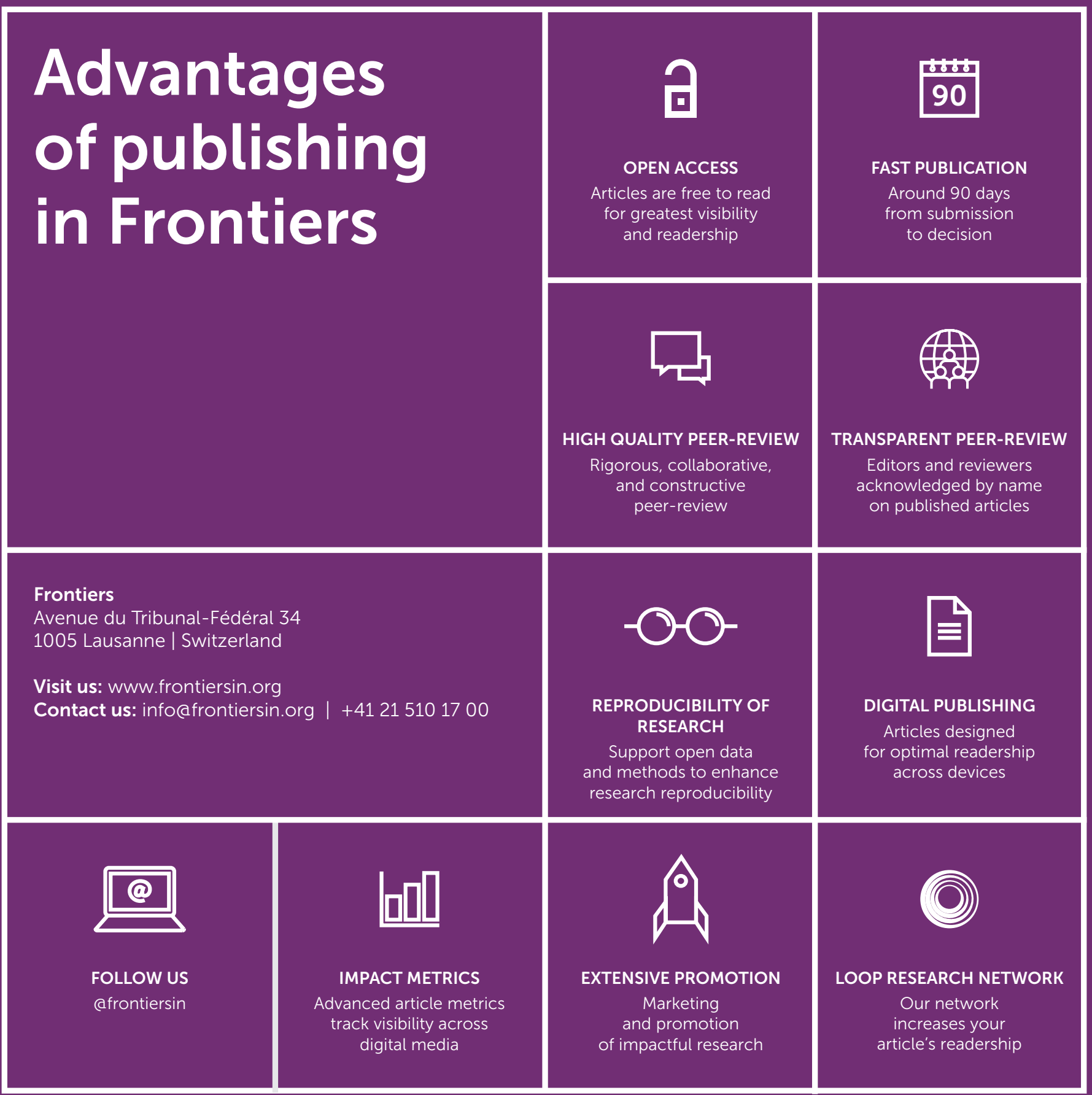

